$$
\text { A LINE OF BEST FIT }
$$

Re-stitching earthquake prone buildings and re-connecting pedestrian networks in Wellington City 
Acknowledgements

recoogoniotion

Mass Noun. The action or process of recognising or being recognised, in particular.

Dedicated to my grandma Ali.

Firstly I would like to thank Mum and Dad - you have been an incredible support over the course of my study. I want to thank you for all the time, interest and encouragement you have given me. I also want to acknowledge my three brothers and extended family for always being there to talk to.

A special thank you to my supervisor Sam Kebbell. Your enthusiasm, guidance and fresh perspective on architecture has challenged and inspired me throughout this year. I want to express my gratitude to the other lecturers and tutors who have taught and influenced me over the past five years. A particular mention to Andrew Charleson for sharing his knowledge and enthusiam for earthquake strengthening.

Thank you to everyone in studio. Your friendship, along with Scopa Tuesdays and Bristol Fridays, has made the insanely long hours spent at architecture school unforgettable.

Finally thank you to my 'non-architecture' friends - for the laughs and fun times over the last five years and for showing me that, in fact, there is life outside of architecture.
$+1$

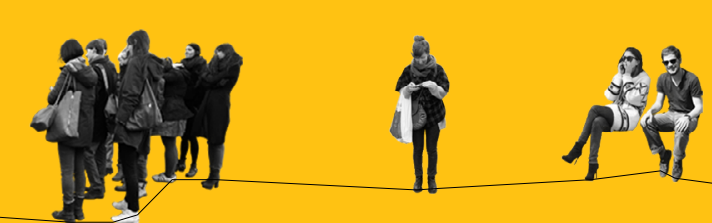
t)

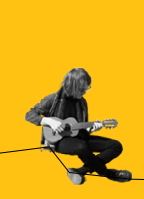
i 
Weakness: There are over 600 earthquake prone buildings in Wellington. The urgency to strengthen buildings risks compromising the aesthetic integrity of the city through abrasive strengthening techniques, or losing a large portion of our built environment to demolition. The need for extensive earthquake strengthening in Wellington, Christchurch and other New Zealand cities provides an exciting opportunity for architecture.

Disconnection: In Wellington pedestrian activity is focused around three main routes: Cuba Street, Lambton Quay and Courtney Place. The adjacent areas are often disconnected and lack vibrancy due to large building footprints, no-exit laneways and lack of public spaces.

The Design proposes a strategy for earthquake strengthening, preserving and upgrading the built environment, and expanding and connecting the pedestrian realm. The site is two earthquake prone buildings on the block between Marion Street and Taranaki Street in central Wellington. A cut through the centre of the Aspro and Cathie Buildings ties the buildings together to strengthen and create a new arcade as public space. The cut aligns with existing pedestrian routes connecting the block with the city.

The Design is divided into three components: Void, Curve, and Pattern and Structure Void investigates the implications of cutting a portion out the existing buildings and the opportunities this provides for connection, urban interaction, and light. Curve discusses the unusual form of The Design in terms of scale, the human response and the surrounding spaces. Pattern and Structure considers the structural requirements of the project and how a void enveloped in perforated screens can strengthen the earthquake prone buildings.

The importance of connection, providing strength in the city, a dialogue between old and new, and engagement with the unexpected are evaluated. Opportunities for further development and research are discussed, with particular reference to how the principles of The Design could be implemented on a larger scale throughout our cities.

A Line of Best Fit is an architectural proposal that creates strength and connection. 


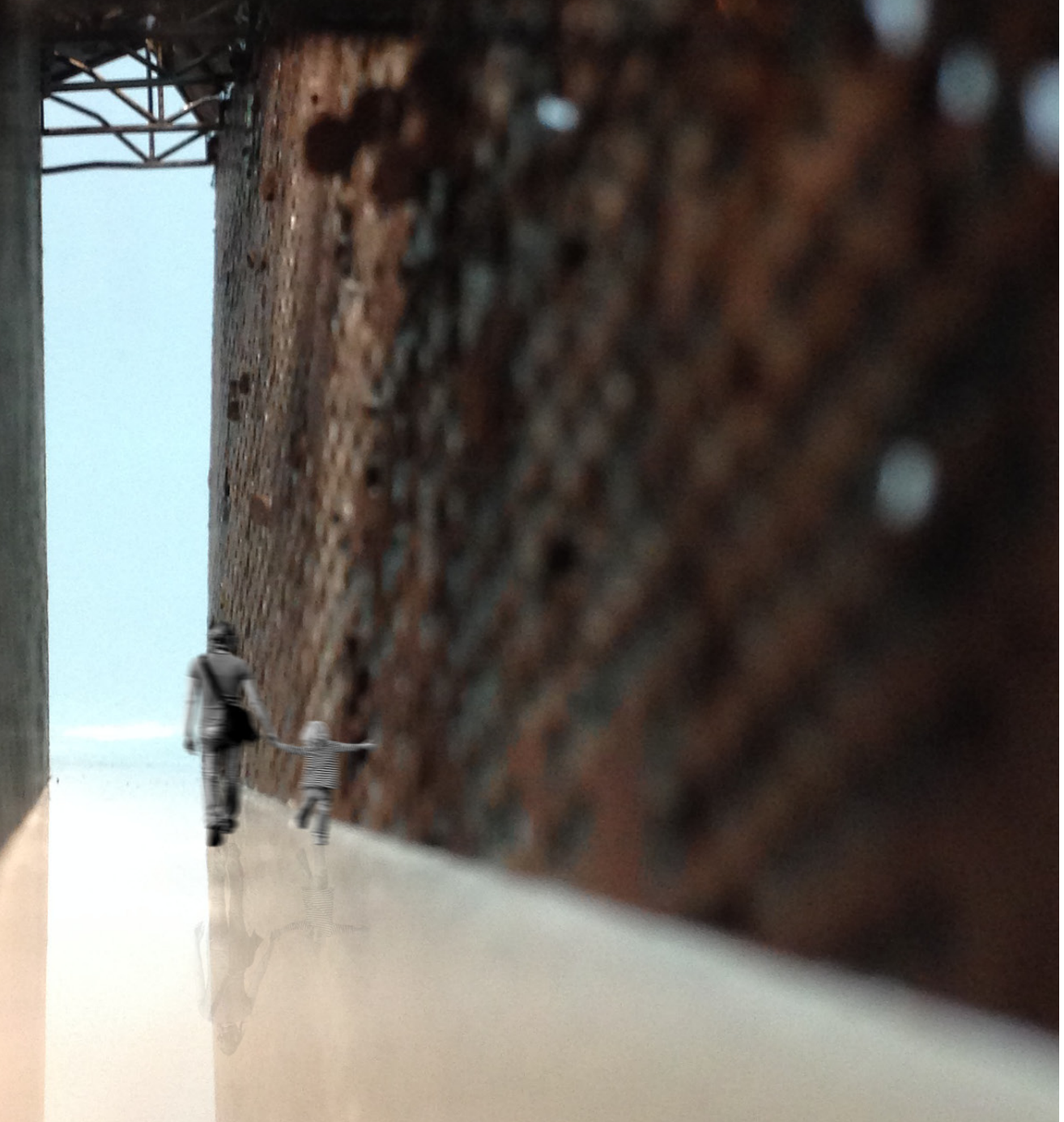

Introduction

An Annotated Thesi

The Design Structure

Research Diagram

The Design Images

Research Question

The Problem

A Weak City

Disconnected Pedestrian Routes 
Lighten Up

A Link

Bizarre Bazaar

Curve

The Swoop

Exhilaration \& Awe

Alice in Wonderland

Commercial Cathedral

Structure and Pattern

A Standard Approach

Skin Deep

Prosthetic Spine

The Grid

Carbon Copy

Screening

\section{The End}

Design Exegesis

Opportunities and Limitation

A Future City

Summary of Case Studies

Works Cited

Figure List
132

141

144

148 
Annotated thesis

an॰no:tate

Verb. Adding notes to (an image or diagram) giving explanation or comment

An 'annotated thesis' pursues a design oriented approach to research. It investigates the problem of earthquake strengthening and disconnection in the pedestrian realm through The Design. The emphasis is on photographs, diagrams, drawings and other images with the written componen giving explanation and disciplinary elaboration where required. All diagrams and drawings have been carried out by the author, unless otherwise specified in the legend.

THE BEGINNING

The first section gives an overview of the design outcome, describes the research question and summarises the problem. This is followed by an in-depth analysis of the site.

THE MIDDLE

The body of this thesis is in three sections based on the core elements of The Design: Void, Curve and Pattern + Structure. Each section has been divided into sub-sections that elaborate on the design features in greater detail.

In each sub-section The Design is discussed, followed by; what others have written about the issue, my analysis of case studies, and my previous design experiments. To assist the reader, symbols have been inserted for each of these components (The Design, selected literature, case studies and process). THE END

An exegesis summarises how The Design responds to the initial problem, and what the implication

and opportunities are for seismic architecture in New Zealand.

\section{II}

Each section starts with discussion about different aspects of the final design outcome The final design outcome will be referred to as The Design throughout this thesis. Images of The Design may be repeated when different aspects of The Design are discussed.

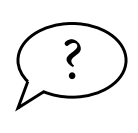

A selective review of the literature focuses on how The Design relates to wider discussions on architectural and cultural context. The literature review is therefore also spread through the subsections, in relation to different aspects of The Design.

\section{C}

"What's done?

Case studies are analysed throughout the thesis to demonstrate different influences and perspectives. Case studies may be considered several times in relation to different aspects of design. A summary of the case studies can be found at the end of this thesis.

\section{무뭄}

'Along the line'

Design experiments and conceptual work that led to the final design outcome are described where relevant. These give insight into the development of specific aspects of The Design. 
This thesis investigates the opportunity to reconnect the city's pedestrian network when undertaking seismic strengthening of earthquake prone buildings. The consequences of The Design, other than the strengthening of seismically weak buildings, were the adaptive re-use of character buildings and the provision of new public space in the city. The site is a block between Marion Street and Taranaki Street in central Wellington, New Zealand. The Design cuts through two of the earthquake prone buildings on this block, tying them together and strengthening them from the interior. The Design generates a concave void that swoops from three storeys on Taranaki Street to one storey on Marion Street. This form is enveloped by a steel perforated skin and steel cross-braced frames, tied back to the existing floor diaphragms of the Aspro and Cathie Buildings. The main body of this thesis is divided into three sections: Void, Curve, and Pattern \& Structure. Each section is further divided into sub-sections that provide analysis of different aspects of The Design (refer to figure 1.6).

VOID

The first section investigates cutting longitudinally through the centre of the existing buildings in order to create a link through the city, allowing light into the large building footprints and activating the block. It discusses proportion and intimacy of urban space, an approach working with existing building fabric to integrate a mixed use development into the block.

\section{CURVE}

This section describes the curved form of the void, a feature that differentiates the project from usual urban interventions. It analyses this from four perspectives: the actual form of the curve, the emotional impact this could have on pedestrians, the relationship between form and scale, and the retail letting opportunities that the curve provides.

\section{PATTERN AND STRUCTURE}

In this final section earthquake strengthening is critically evaluated. The section discusses a standard approach to strengthening and then introduces The Design as a point of difference. Analysis of the existing structural grid is discussed in terms of programme and circulation. The generation of pattern for the perforated screens is explored with reference to relevant examples in the discipline.

Assumptions + Limitations

I have assumed that the Wellington City Council (WCC) and the New Zealand Historic Places Trus (NZHPT) would be interested in supporting this approach to earthquake strengthening.

The design assumes the building owners are willing to lease their buildings as a collective, and thus reduce the cost of strengthening. It also proposes an approach to adaptive re-use, inserting a four metre wide public, unlettable space based on benefits of higher pedestrian flow through the block. Building owners and the Wellington City Council would need to commit to the on going management of the public and semi-public spaces generated by The Design.

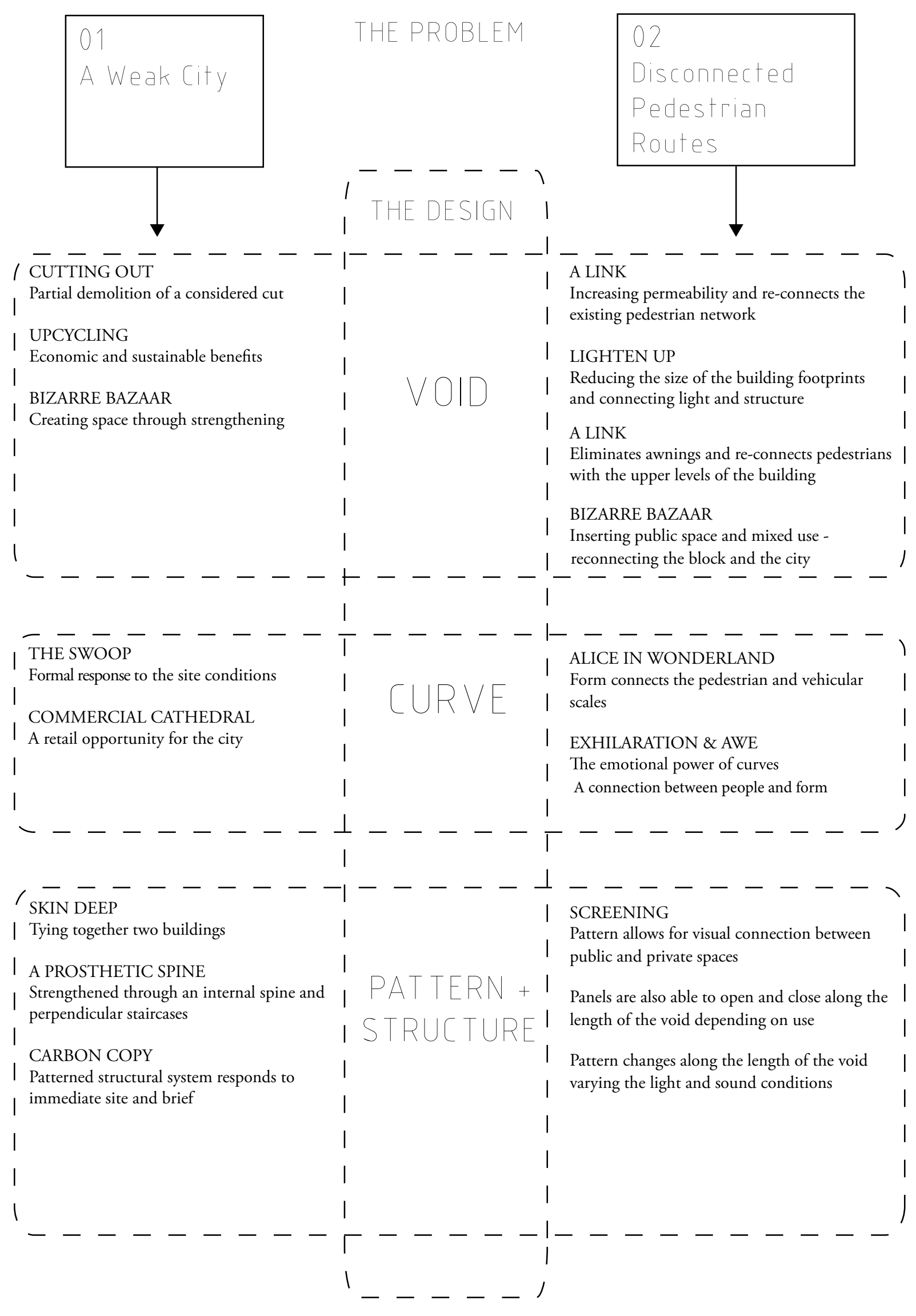

Figure 1.6 (Above) Research diagram showing how The Design responds to the problems: outline of thesis structure. 

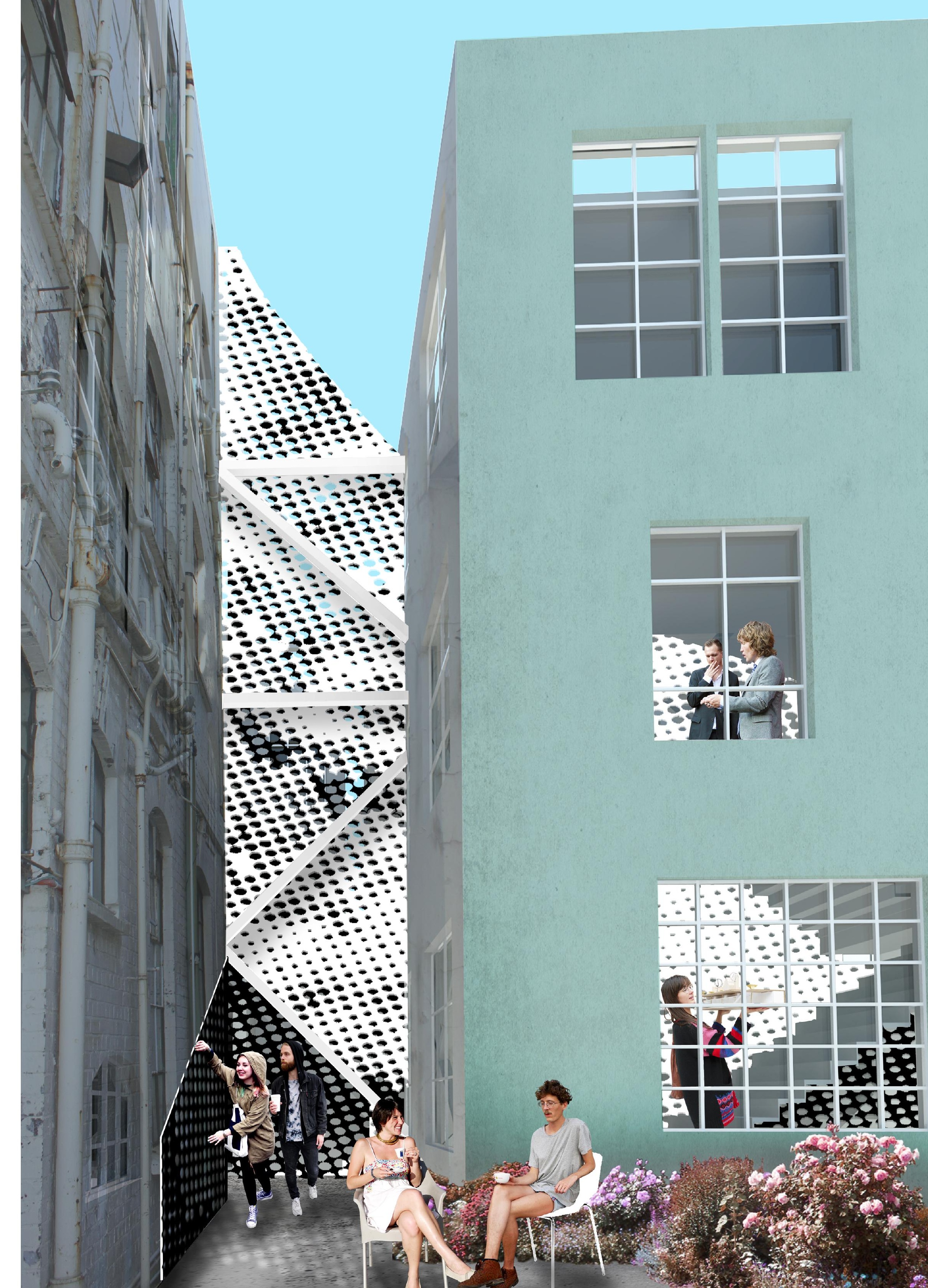


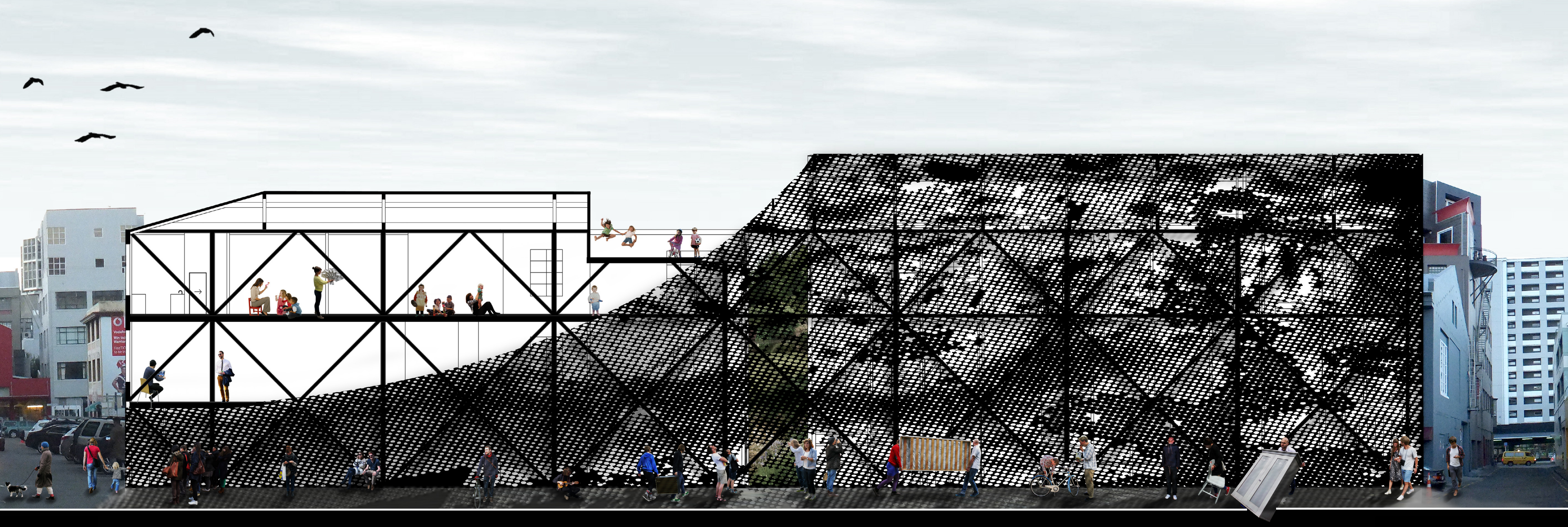




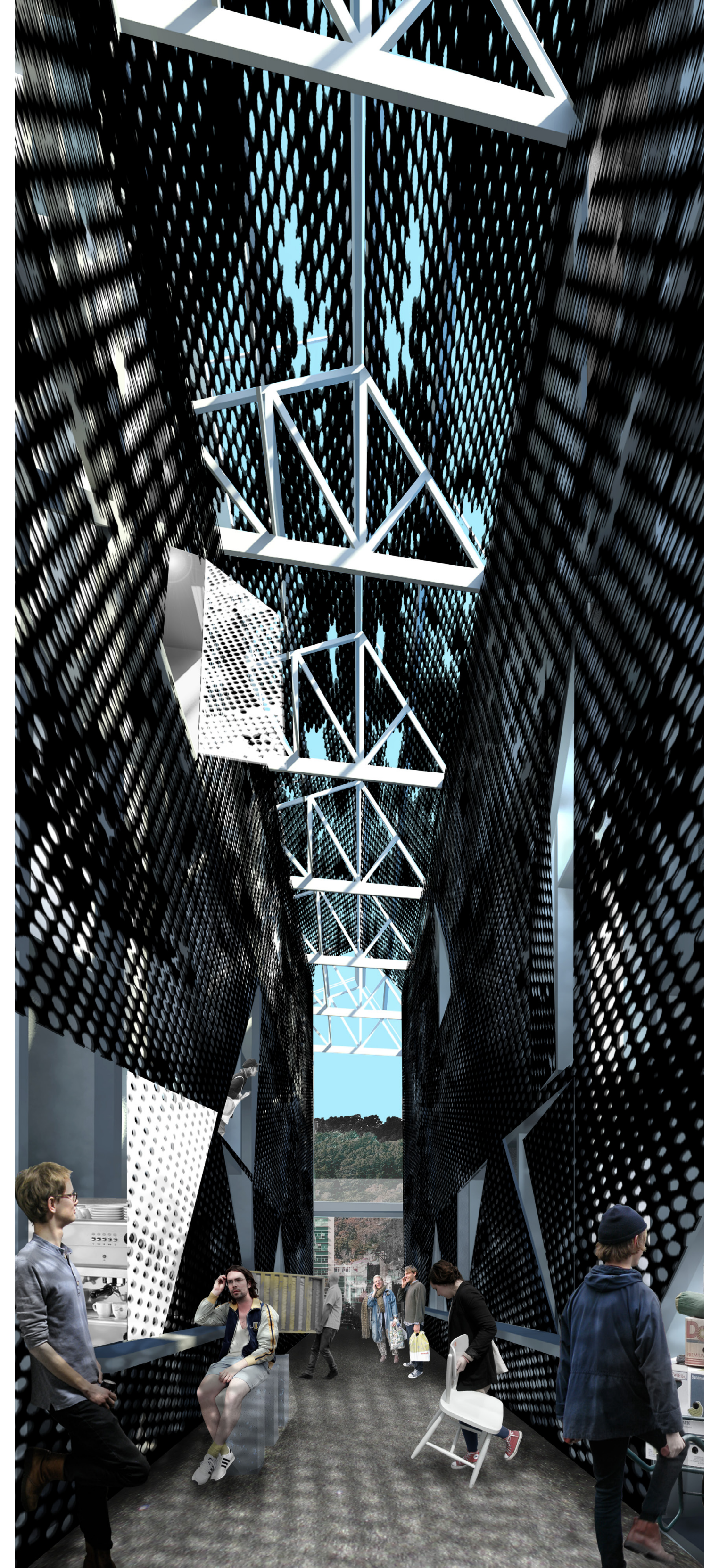




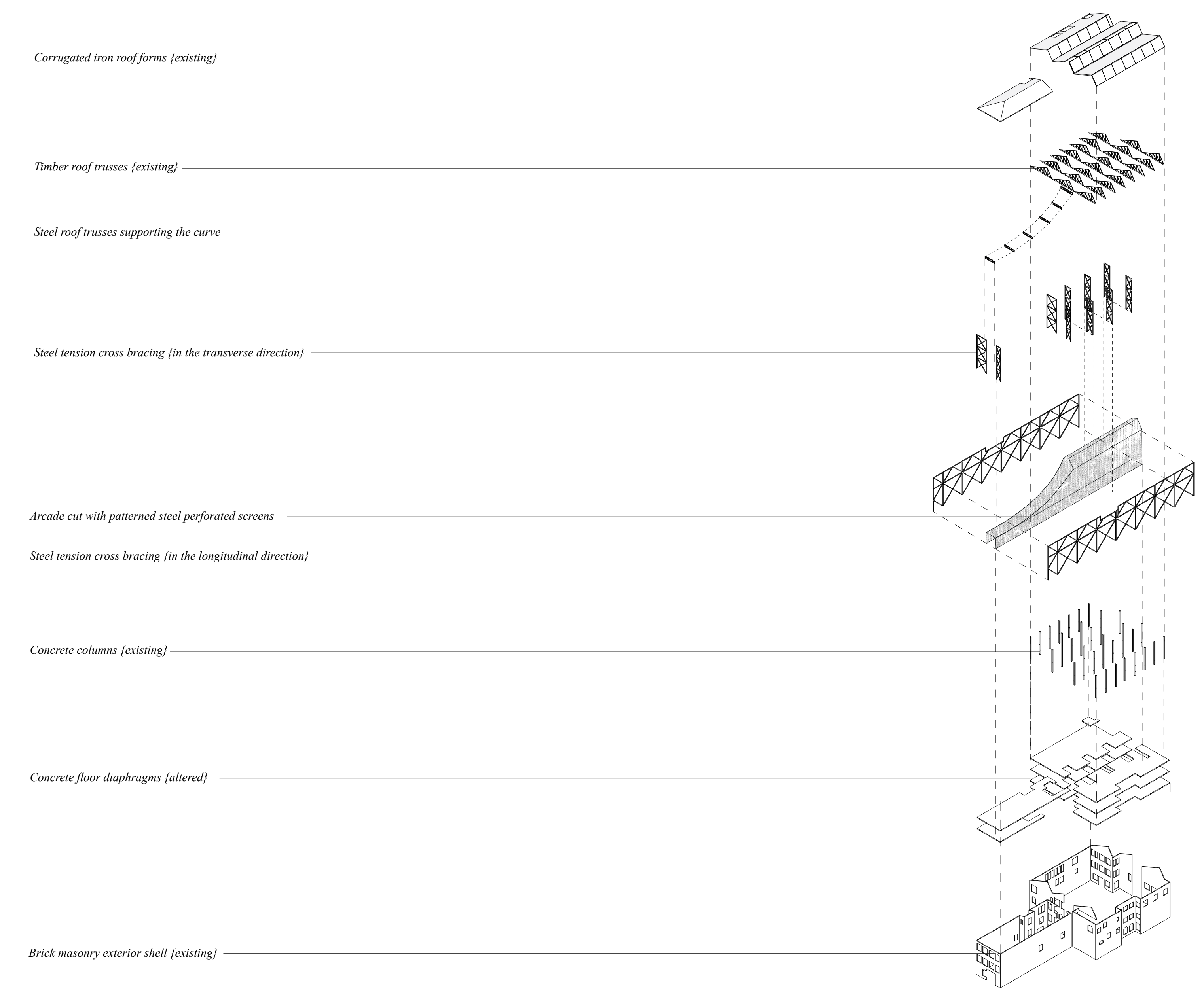




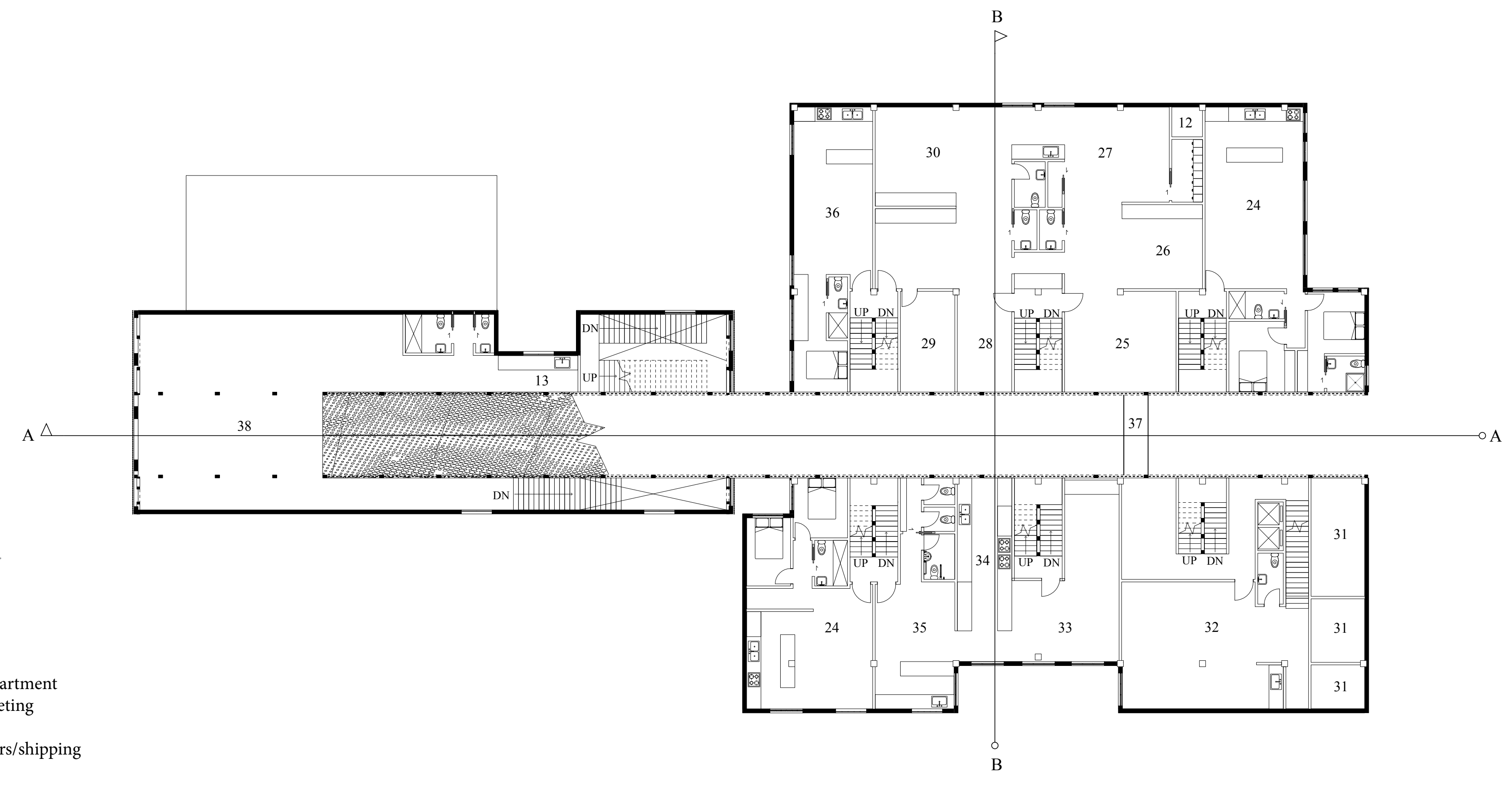

28 Office - staff area

29 Office - conference room

30 Office - resources

31 Office - private offices

32 Office - furniture design

33 Restaurant dining area

34 Restaurant kitchen

35 Restaurant bar

36 Residential - one bedroom apartment

37 Pedestrian bridge over arcade

38 Office

Scale 1:200 


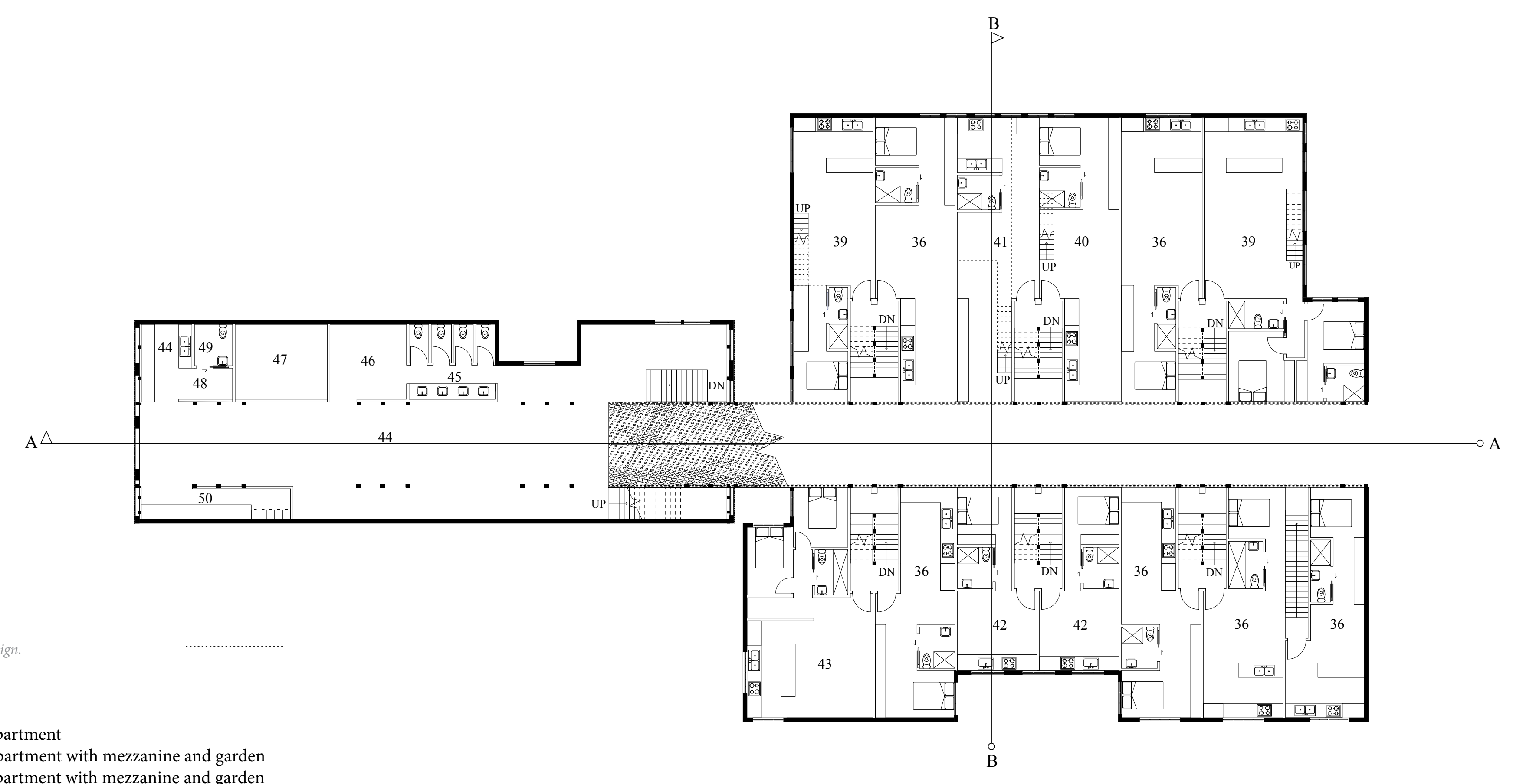

Key:
36 Residential - one bedroom apartment

39 Residential - two bedroom apartment with mezzanine and garden

40 Residential - one bedroom apartment with mezzanine and garden

41 Residential - large one bedroom apartment $\mathrm{w}$
42 Residential - one bedroom studio apartment

43 Residential - large two bedroom apartment

44 Kindergarten - childrens play space

45 Kindergarten - childrens bathrooms/wash up space

46 Kindergarten - childrens cloakroom

47 Kindergarten - sleeping/quiet space

48 Kindergarten - staff cloakroom

49 Kindergarten - staff bathroom

50 Kindergarten - admin/office space

Scale 1:200 


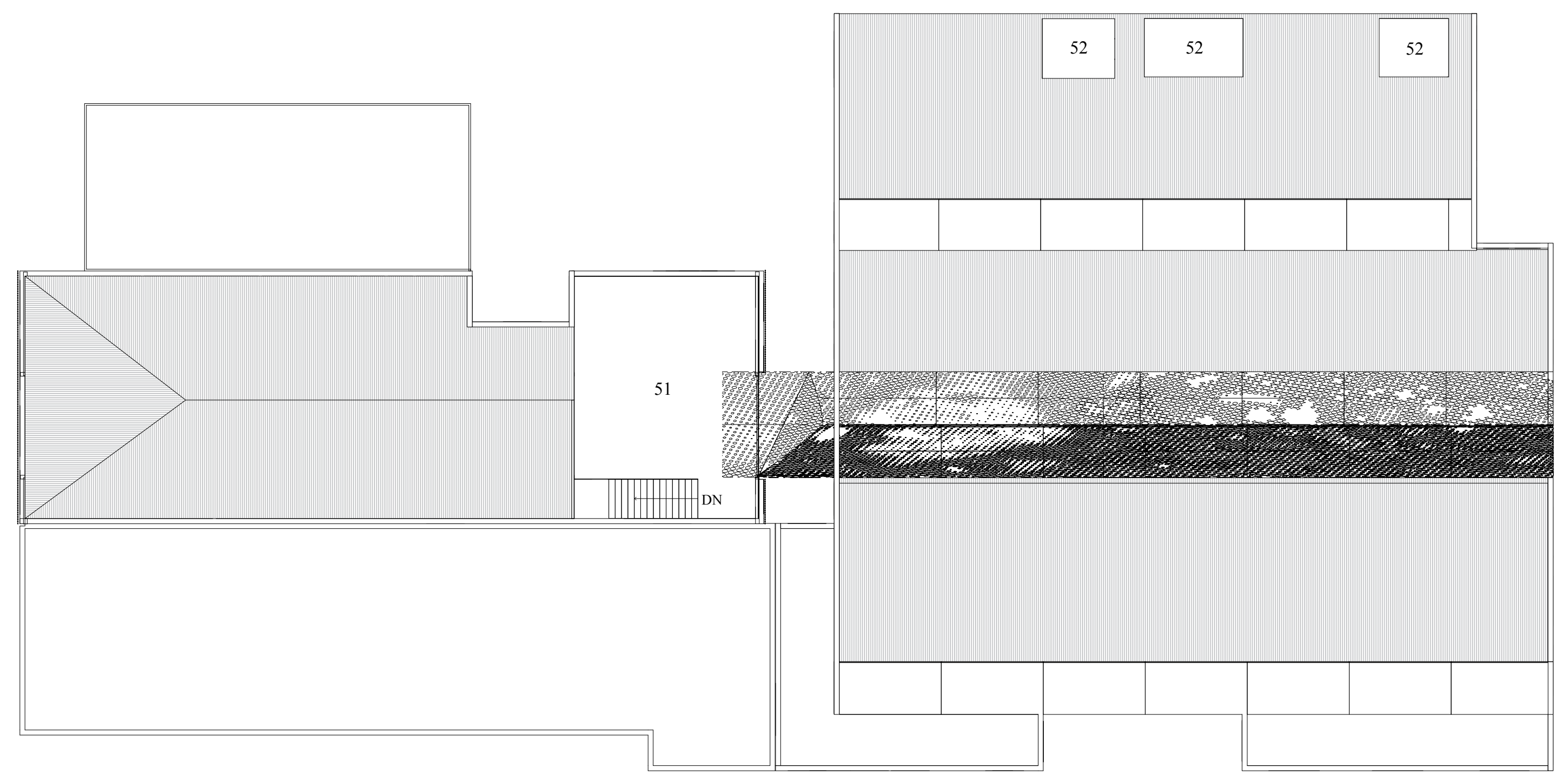

Figure 1.15 Roof plan of The Design.

Key:

51 Kindergarten - roof courtyard cut into Aspro roo 52 Residential - roof garden cut into saw tooth roof

Scale 1:200 

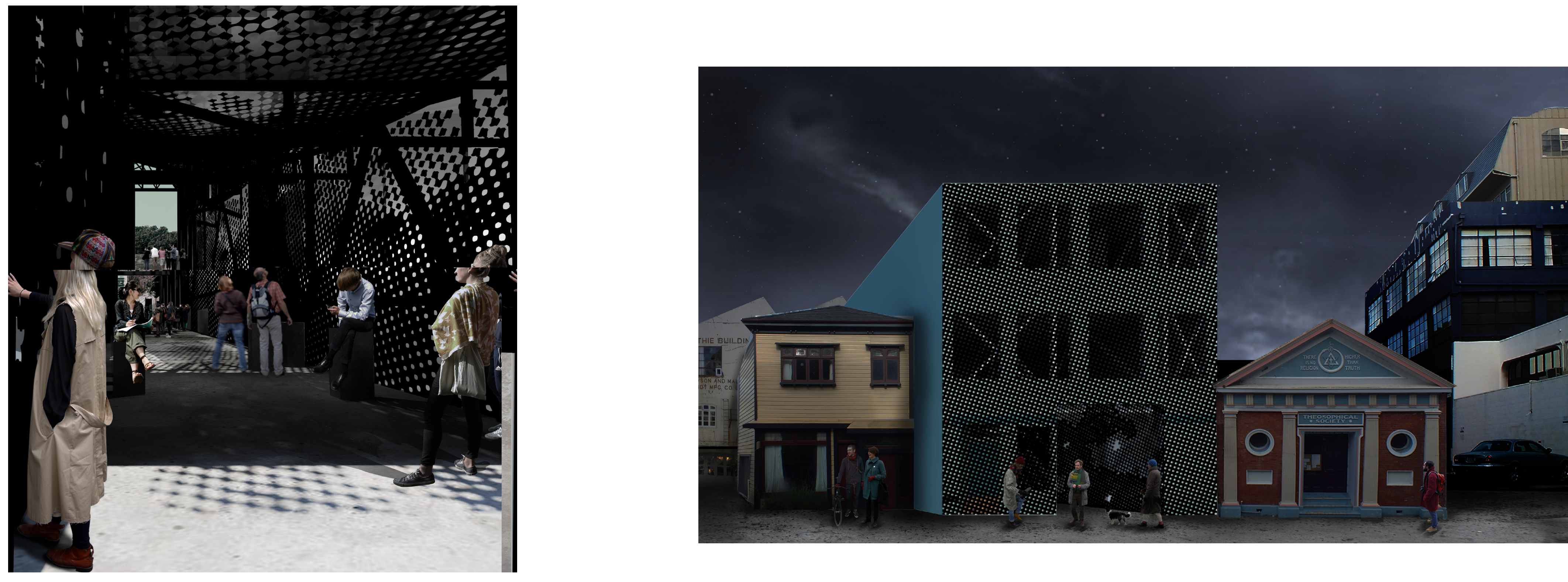

Figure 1.16 (Above) Interior render looking into the low part of the curve from Marion Street.

Figure 1.17 (Opposite) Night render approaching Marion Street from the post office areade off Swe Lane 


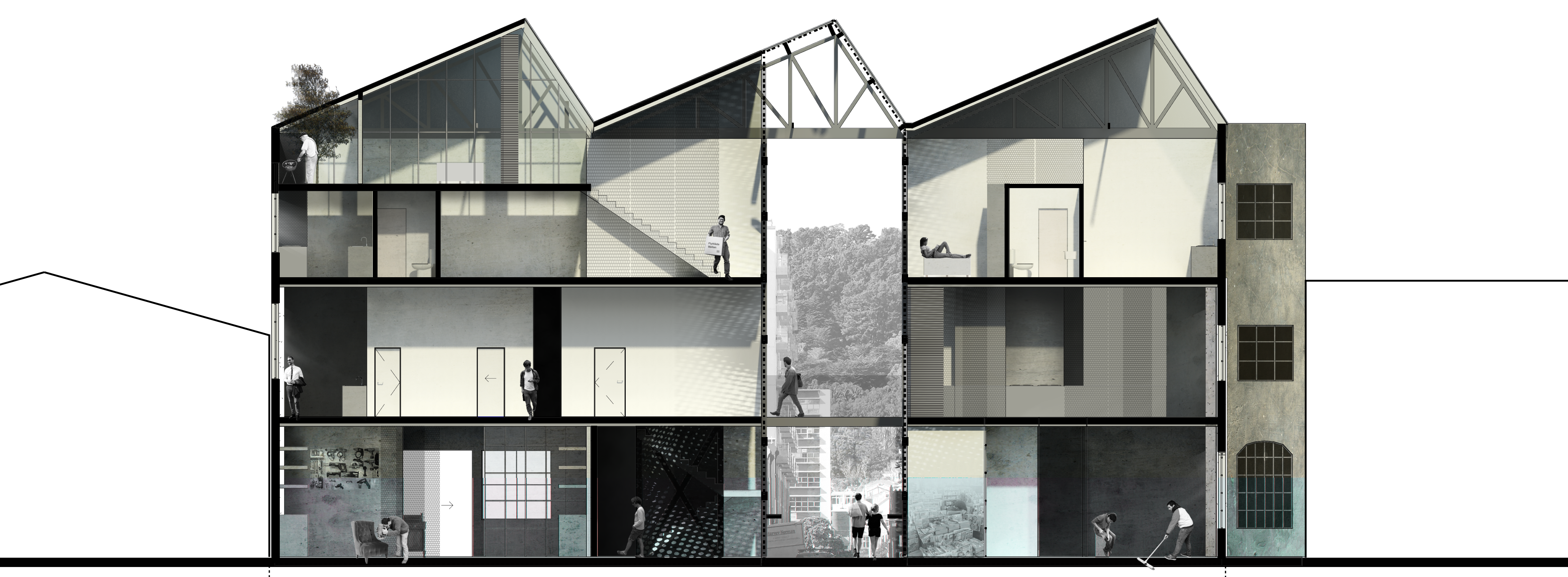

Figure 1.18 Transverse section BB through the Cathie Building showing the relationship between the 
How can we strengthen earthquake prone buildings in a way that reconnects the pedestrian realm? 


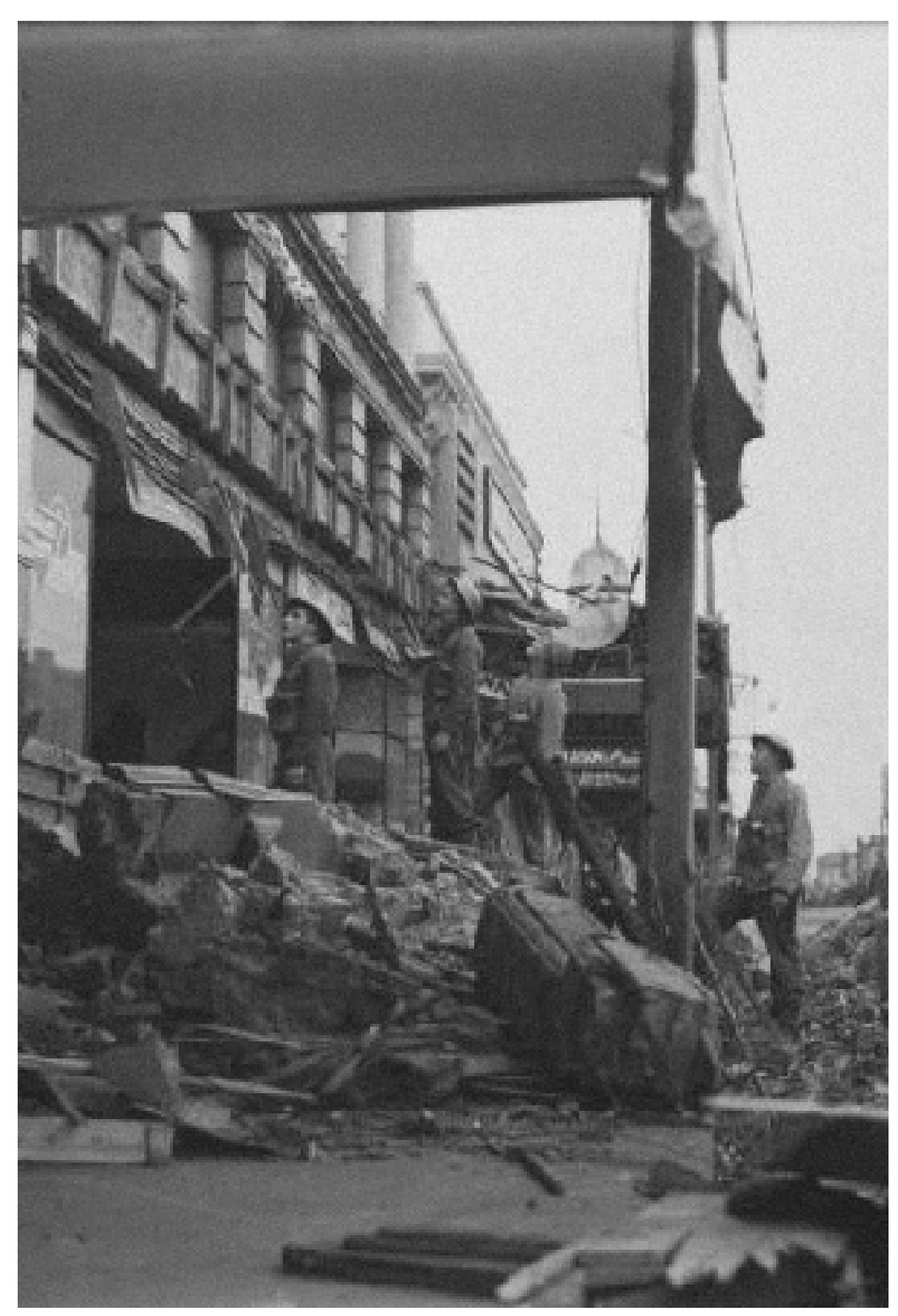

PROBLEM 


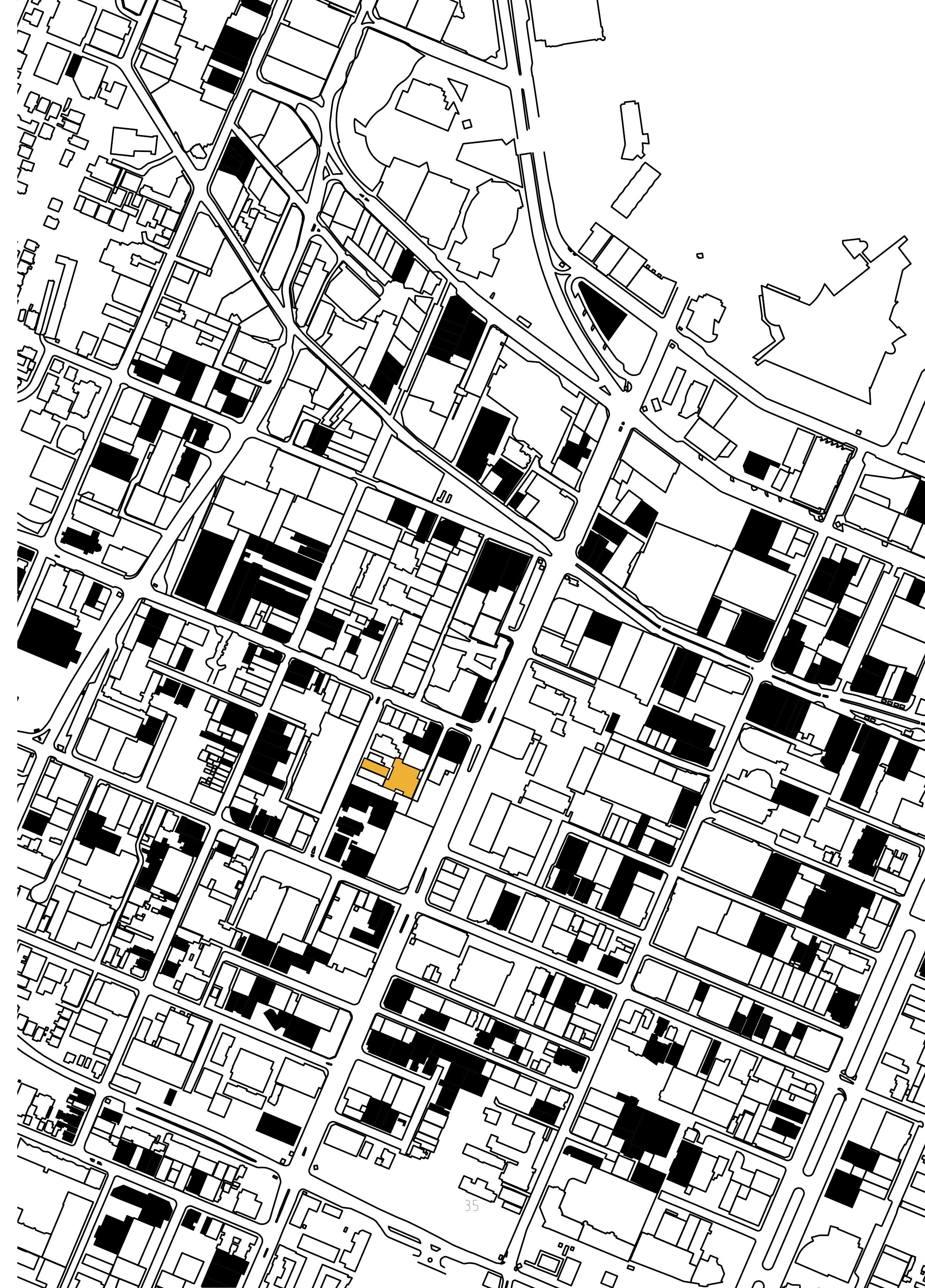




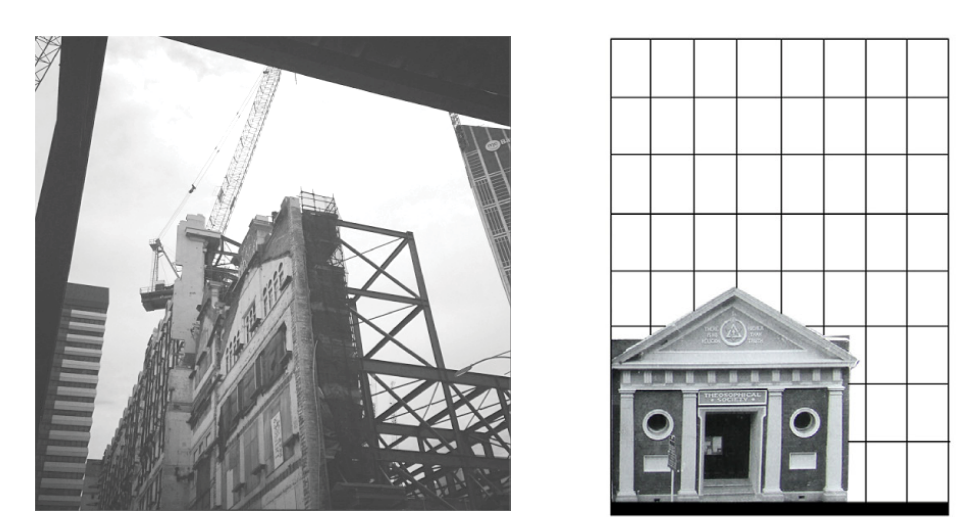

Figure 1.27 Standard outcome 2: Retaining facade/parts of the building and rebuil his.

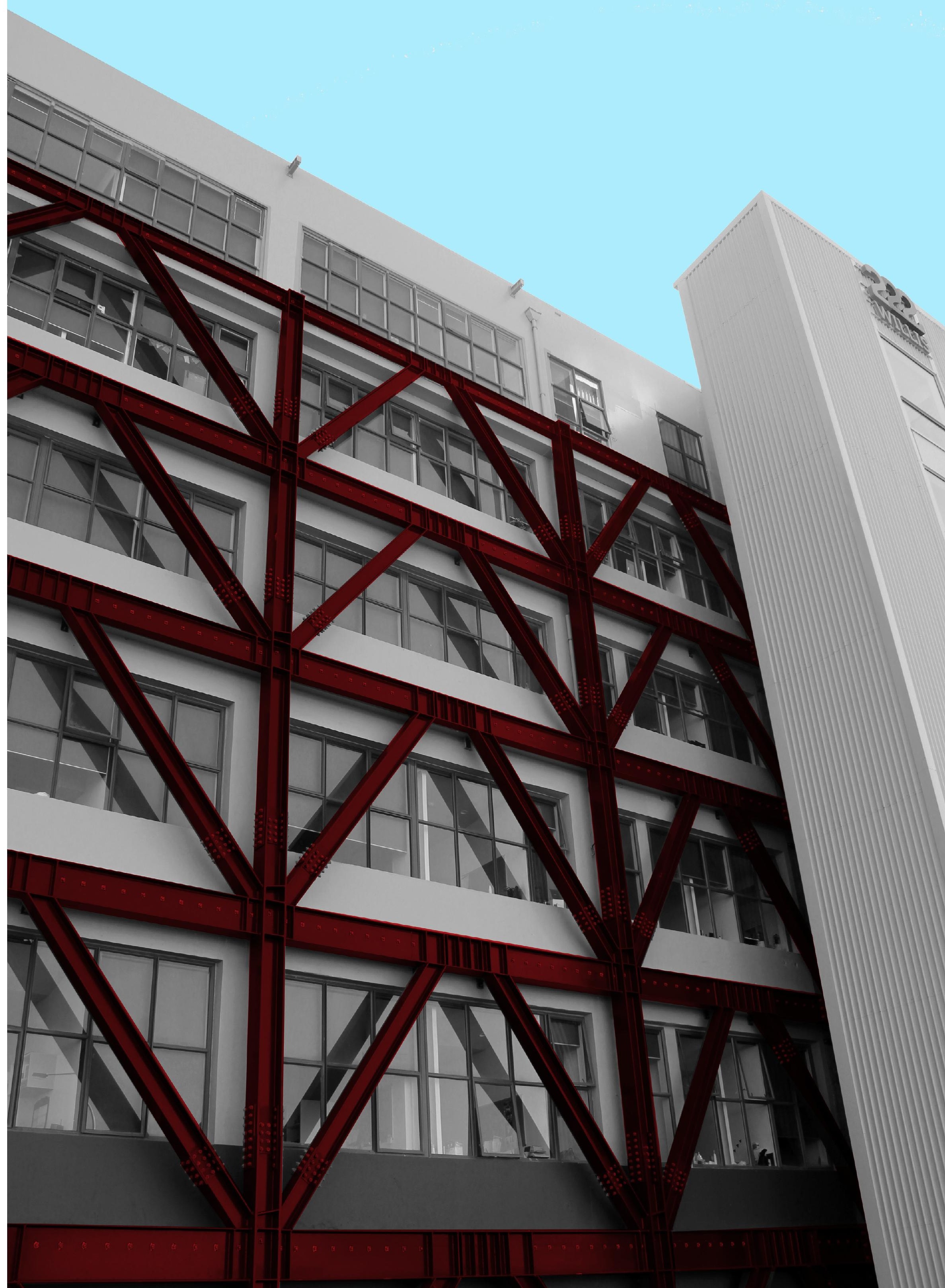

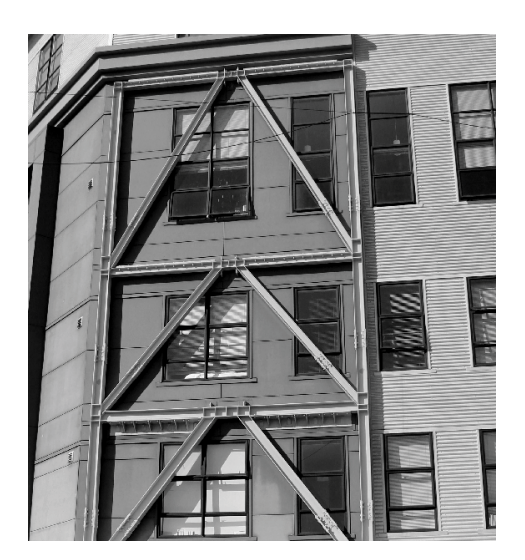




\section{Disconnected Pedestrian Routes}

Wellington is a pedestrian city. Small walking distances and a large number of bars and cafes make it a desirable city to explore on foot (figure 1.34). This thesis investigates three aspects of the pedestrian realm: connectivity, shelter and activation.

\section{Horizontal disconnection}

Large building footprints and no-exit laneways inhibit permeability through the city. This scheme aims to break down large building footprints and reconnect the existing pedestrian network (figure $131)$

Vertical disconnection

Wellington's pedestrian experience can often be unpleasant due to exposure to wind and rain. As a result, Wellington's pavements are sheltered by overhangs and awnings. These obstruct the connection between the street and the upper levels of buildings, encouraging pedestrians to only have an immediate connection with the ground floor, and segregating public and private use within the city (figure 1.32).

Activation

Activation of a space is directly related to the programmatic use of the surrounding spaces. Providing mixed use within a certain length of street allows for an interesting route for a pedestrian (Jacobs, 155). An integration of public and private, night and day, and various scales of use, provides a diverse, safe and appealing pedestrian realm. Cuba Street has a vibrant street culture, one which has been activated through its attractions for all types of people and uses. The site for this design, although only a block from Cuba Street, is used as a means of convenience for pedestrians and vehicles rather than an appealing public attraction in its own right (figure 1.33). Large building footprints and lack of diverse uses has created inactive pedestrian pockets and unused spaces throughout Wellington city.

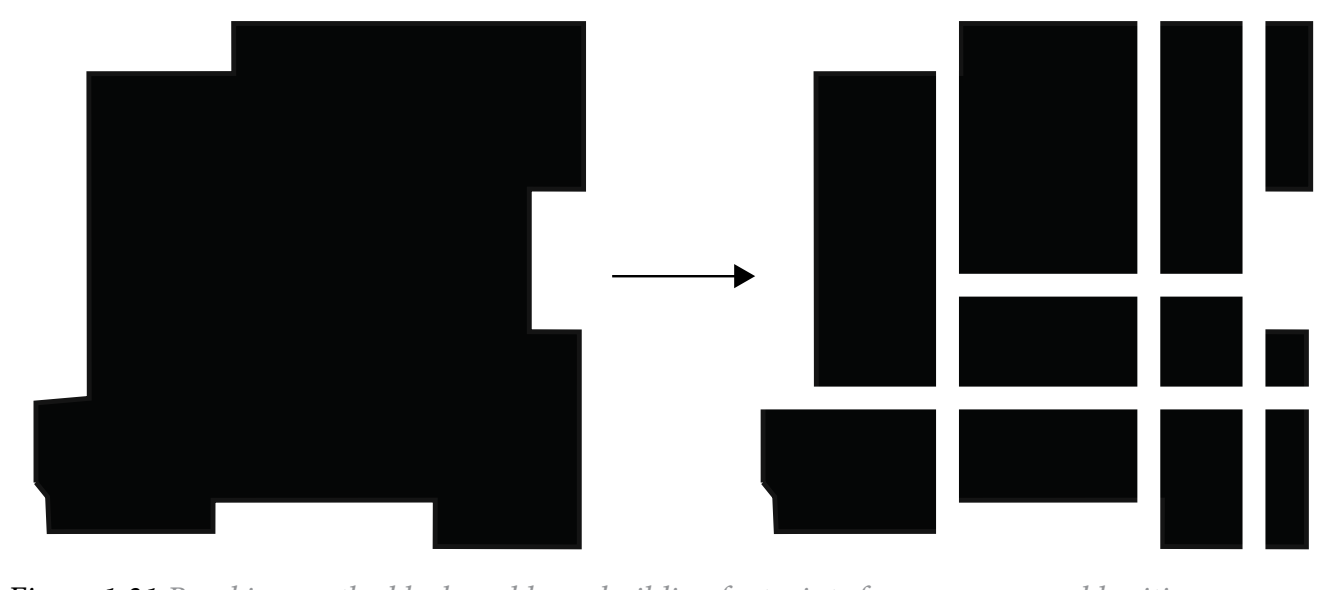

Figure 1.31 Breaking up the block and large building footprints for more permeable cities

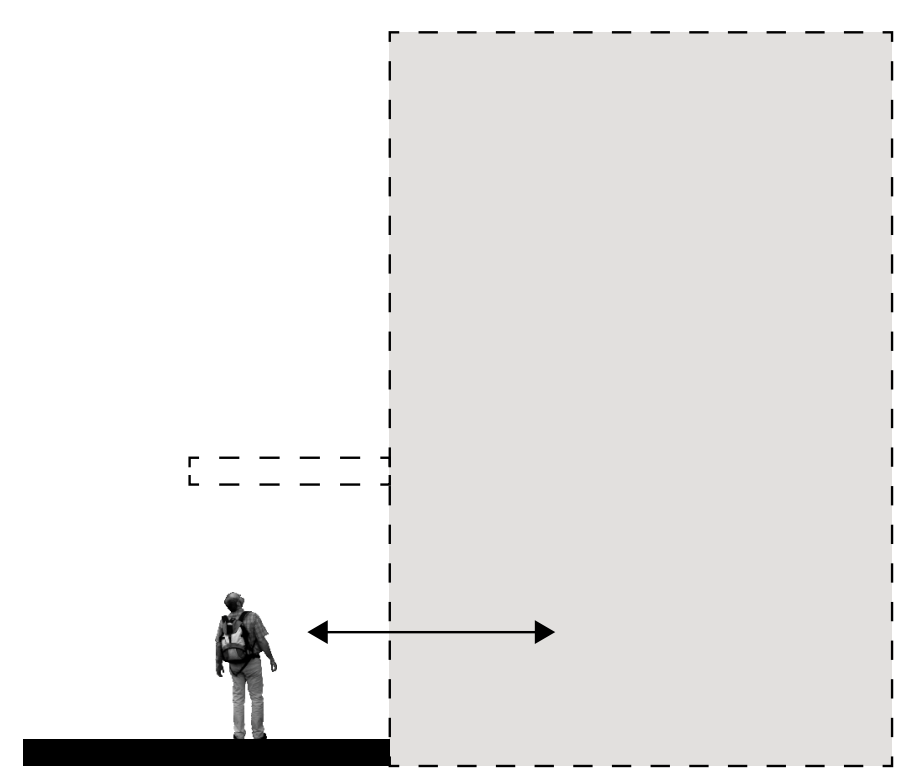

Figure 1.32 Pedestrian experience in Wellington. A strong connection to the ground floor, lack of connection to the upper floors due to weather awnings.

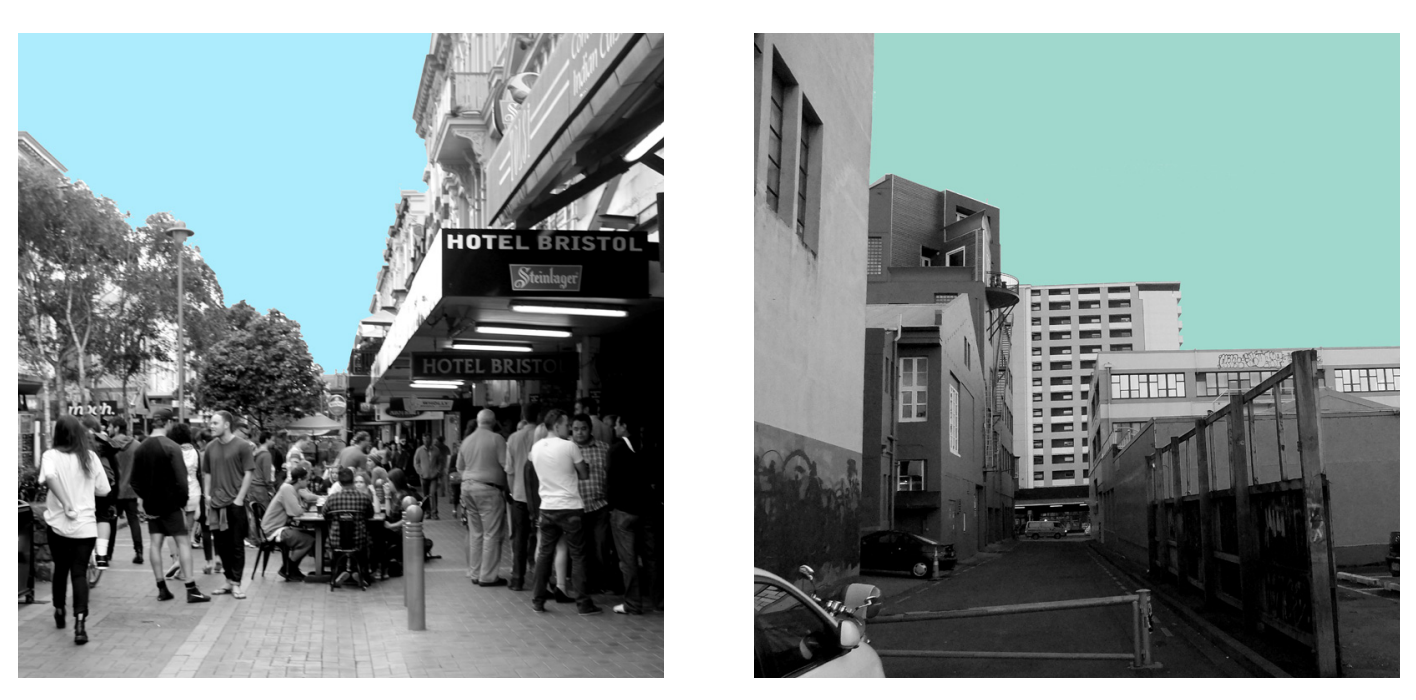

Figure 1.33 Photos of Cuba Street and Furness Lane showing the difference in pedestrian activit 
-1 触 

A Line of Connection

The block is situated at the intersection of two pedestrian routes across Wellington. Marion Street is an underused continuation of Leed Street and Eva Street, a route that passes through Opera House Lane to the waterfront Following the west east axis Swan Lane and the covered arcade that extends from this are met with a confronting end at Marion Street. There is potential to connect this route to the smaller pedestrian scale streets (such as Jessie Street) on the other side of Taranaki Street (figures 1.36 and 1.37$)$.

Surrounding Streets

The block is framed by three heavily used vehicular routes. Taranaki Street consists of four lanes of two-way traffic and is the primary link across the city from Mount Cook. Vivian Street is a two-lane one-way street that is an extension of the Northern motorway exit. Ghuznee Street is one of the few two-way streets that crosses east-west through the city, and is therefore heavily used to gain access to between Ghuznee and Vivian Street and as a convenient place for parking. Furness Lane off Ghuznee Street is the only street which penetrates the block. However, because it has no exit and is narrow in width, it is primarily used for servicing and deliveries to the surrounding buildings (figure 1.36).

Figure 1.35 (Previous) Aerial view of Wellington City highlighting the location of the block and

Figure 1.36 (Opposite) Closer aerial view of the block and the surrounding streets. The yellow line illustrates the existing pedestrian routes across the cit

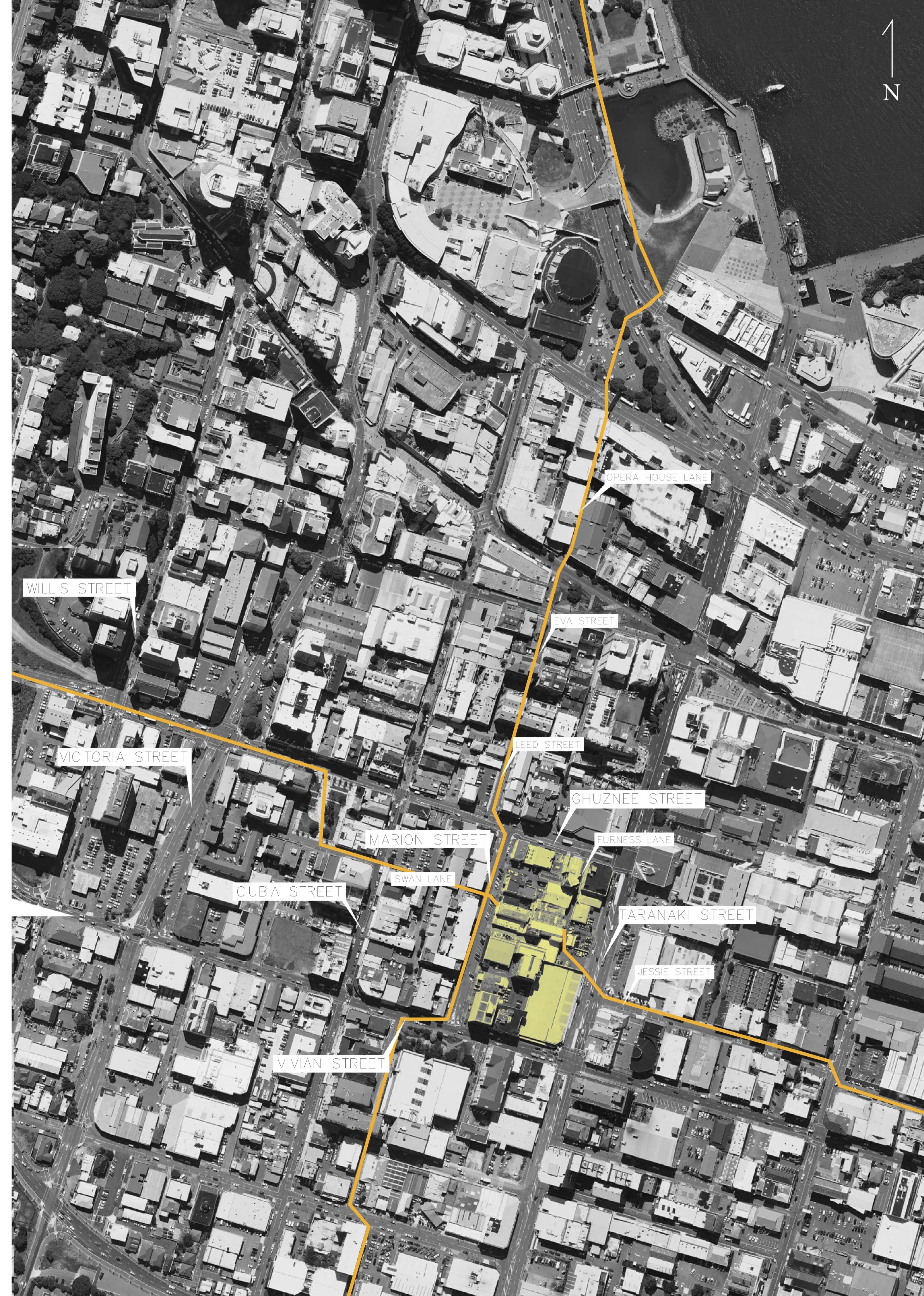




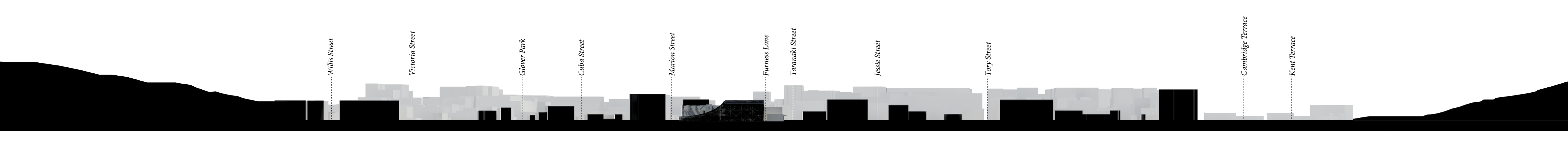




\section{Buildings on the Block}

Of the twenty-two buildings on the block, eleven have been listed as earthquake prone. This equates to the highest proportion of prone buildings on any block in Wellington. One hundred and twenty one prone buildings appear of the Wellington City Council Heritage Building List. There is a wide spectrum of construction dates and consequently architectural styles on the block (figures 1.38 and 1.39). This eclectic mix of buildings is a distinctive characteristic of Wellington's built environment.

\section{Use and Age}

The diverse range of building styles on the block has unfortunately not been translated into the use and activity. The building uses are limited to residential, industrial factories and suppliers, and a few offices. This has resulted in a lack of public facilities on the block, creating a place where only a pedestrian with particular interests would reside. Compared to the mixed use and resultant vibrancy of nearby Cuba Street, the Marion Street block appears underutilized and lifeless. The strong vehicular presence in the surrounding streets also contributes to thi.

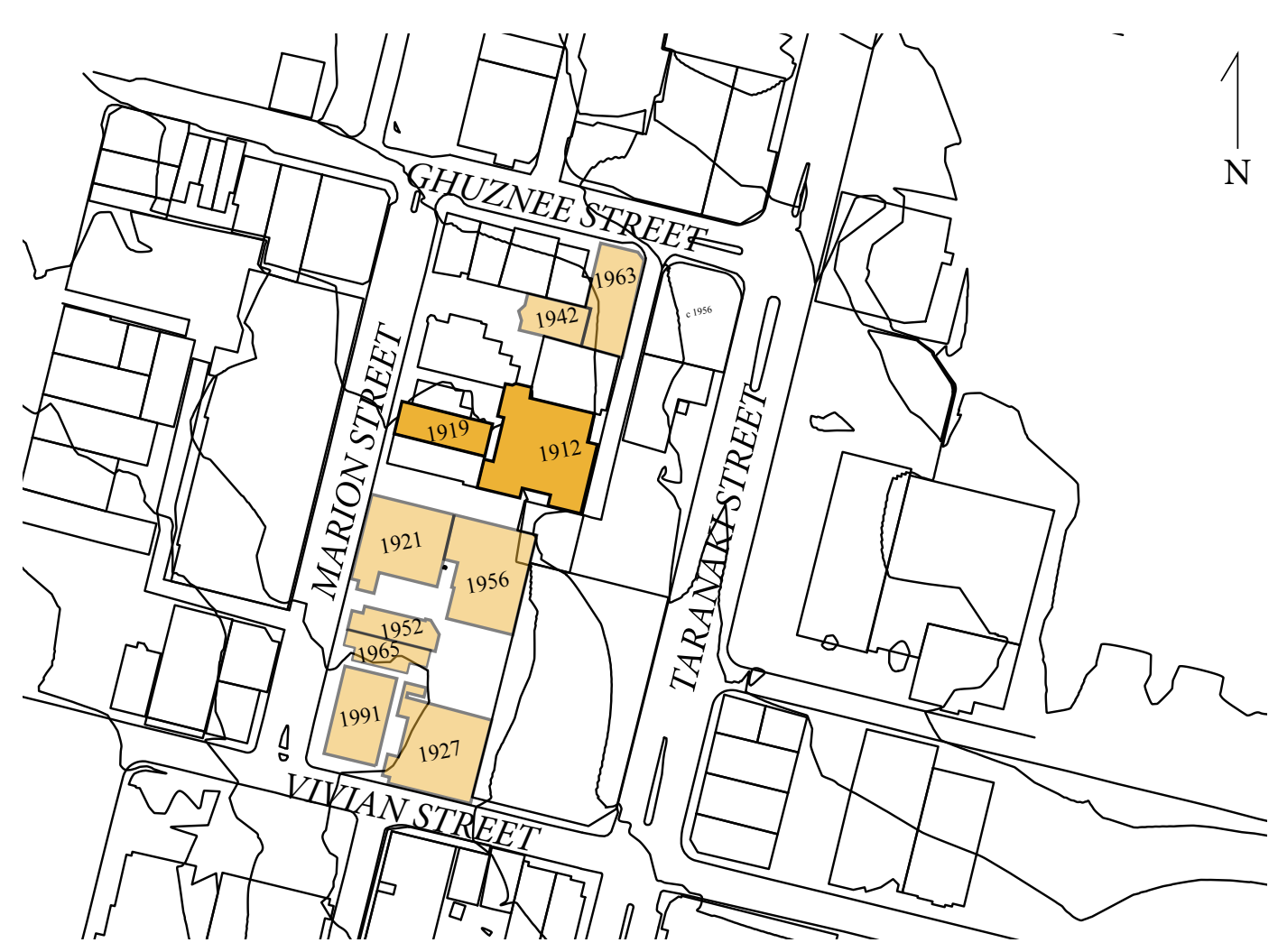

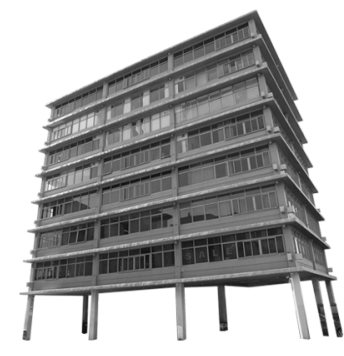
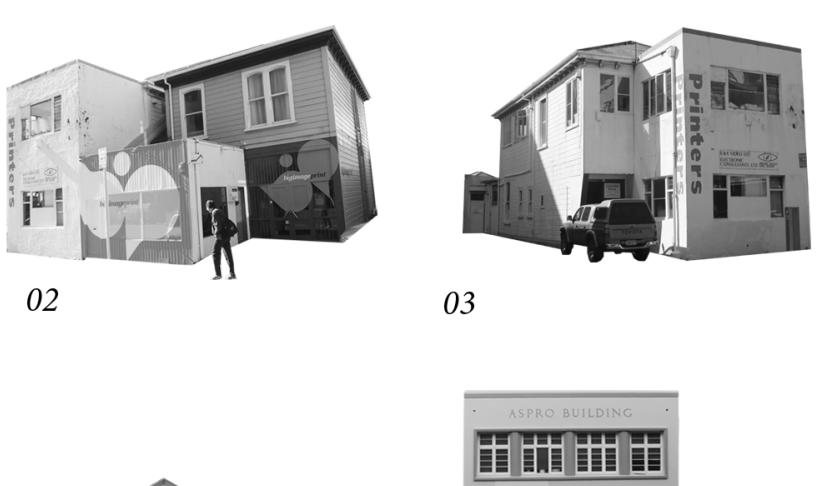

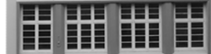
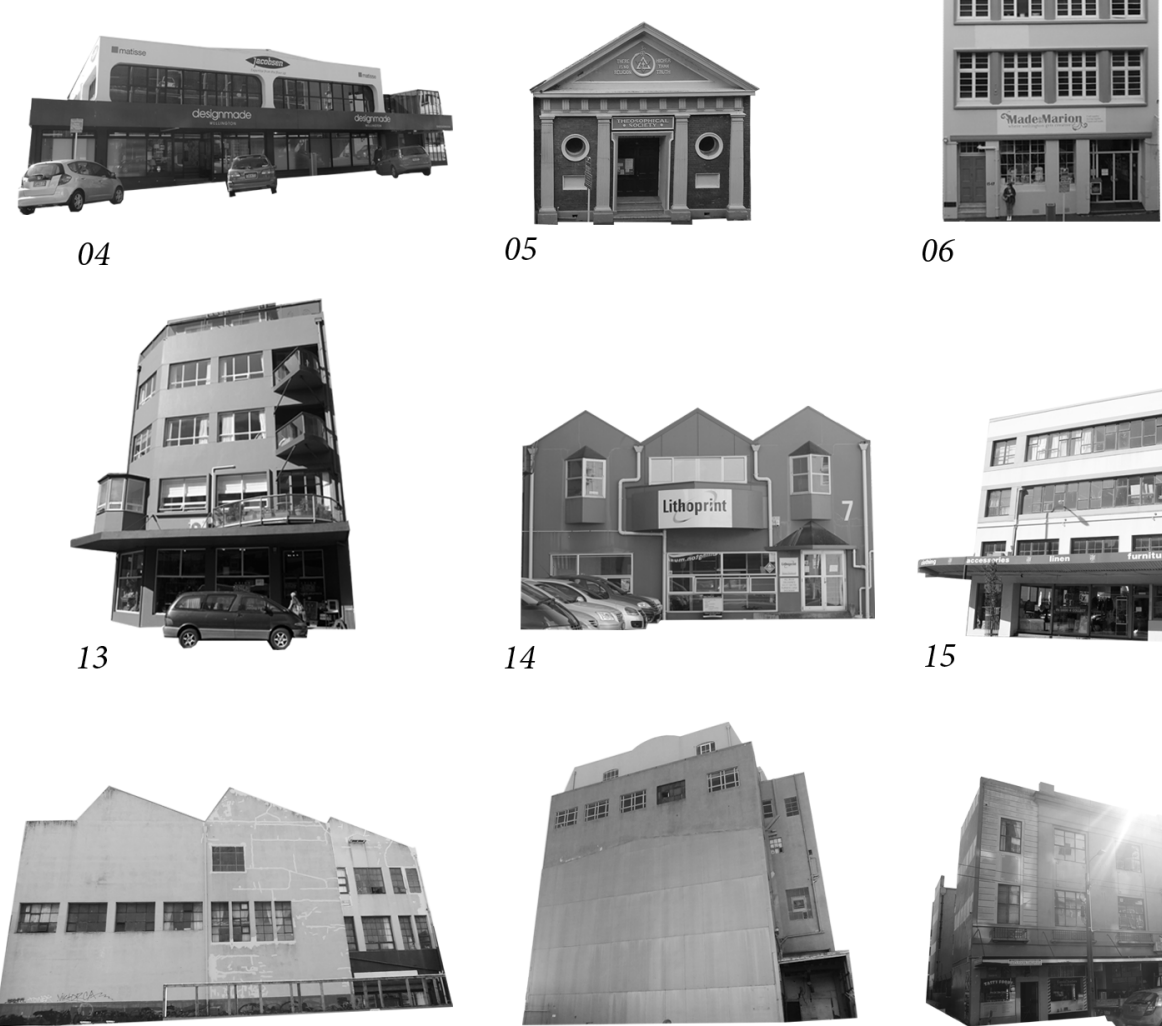
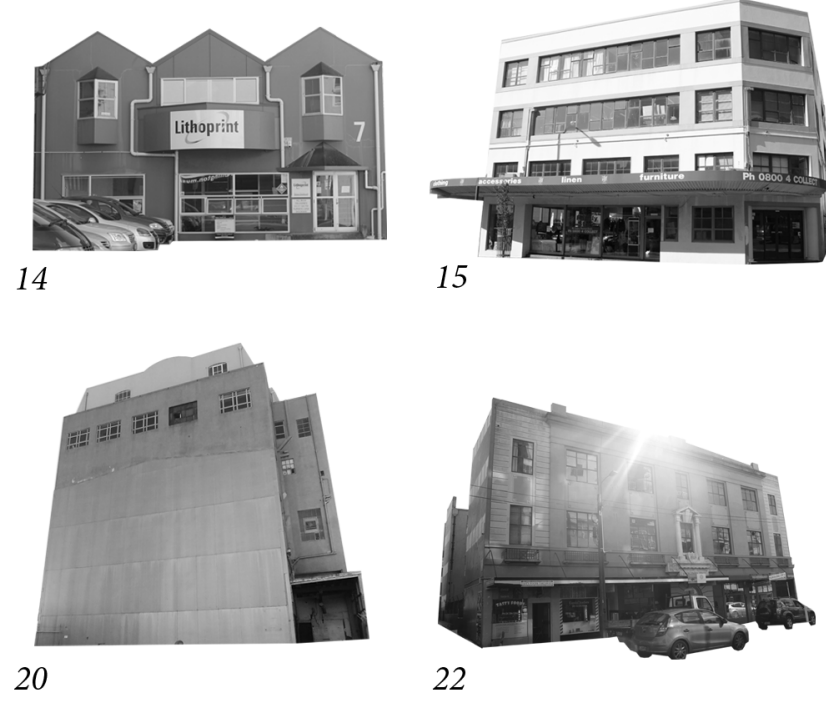

Figure 1.38 (Opposite) Diagram of the block highlighting the earthquake prone building and their onstruction dates.

Figure 1.39 (Above) Cut out elevation of the eleven earthauake prone buildings on the block. The specific buildings in The Design are 18 \& 06 . Refer to Figure 1.41 to view the above buildings in plan 


\section{The Site}

Two of the earthquake prone buildings on the block have been selected as the site for this project. The Aspro Building on Marion Street, and the Cathie Factory Building is off Taranaki Street on Furness Lane (figure 1.40).

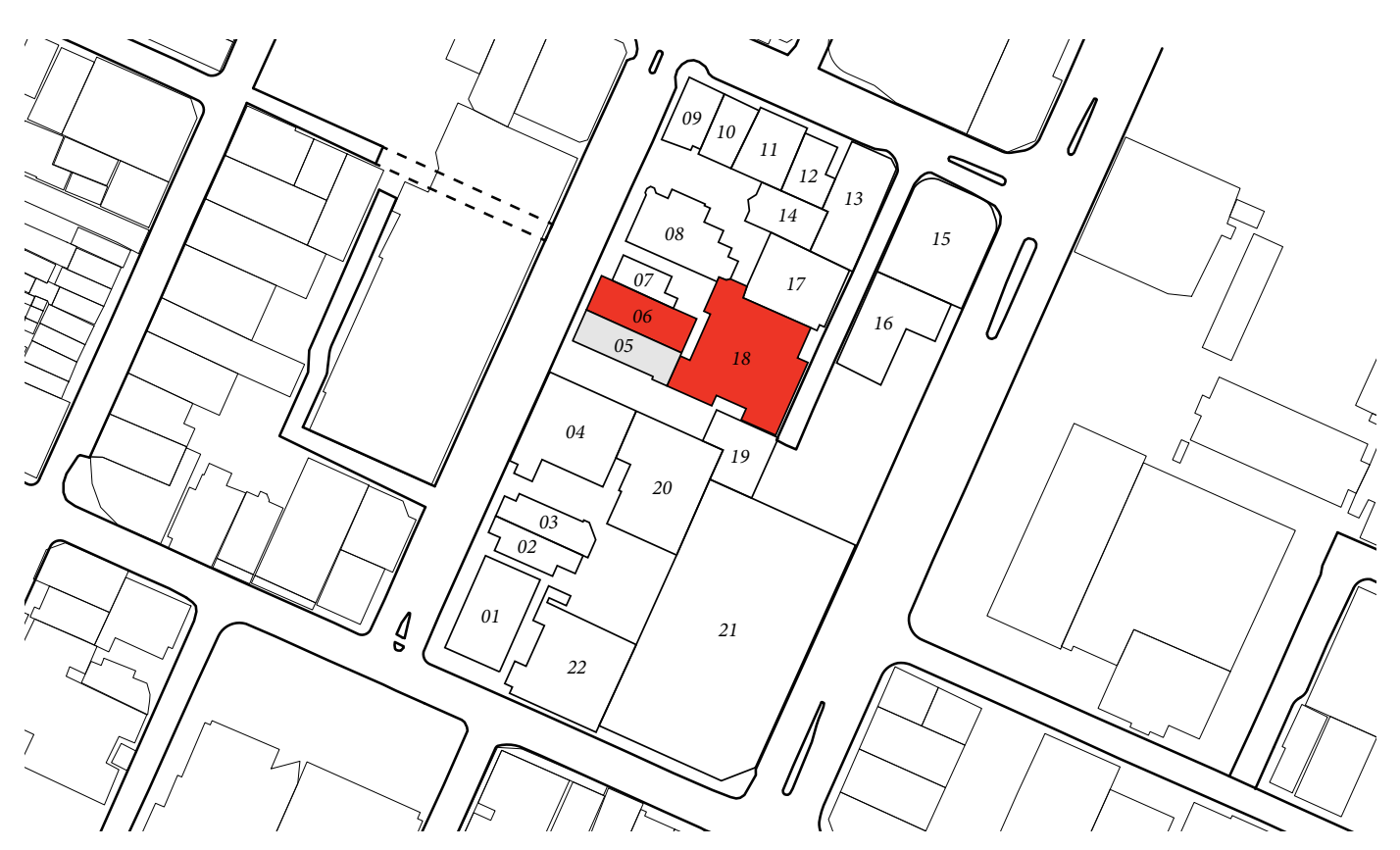

Figure 1.40 Diagram of the block highlighting the site in red and the neighbouring Theosophical society in grey. The Theosophical Society, although not on the site itself, is relevant due to its significant heritage status and the proximity to the earthquake prone Aspro Building

Figure 1.41 (Opposite) Site plan

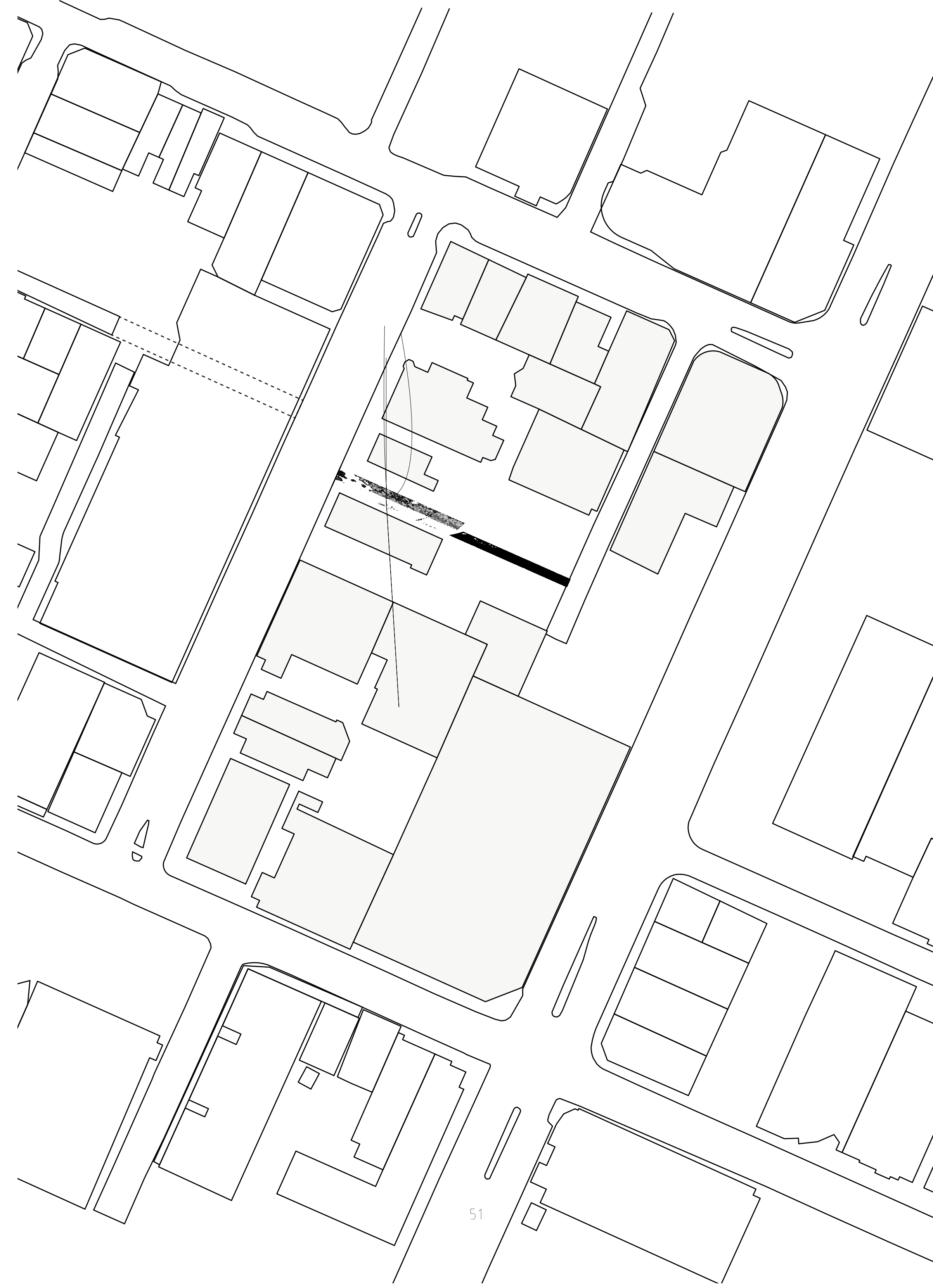



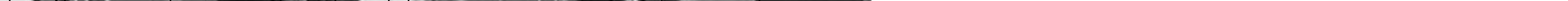

Figure 1.42 (Opposite) Aerial photo of the block with the building footprints overlaid and the two buildings in red. Numbers that refer to Figure 1.43 are noted on this plan. 


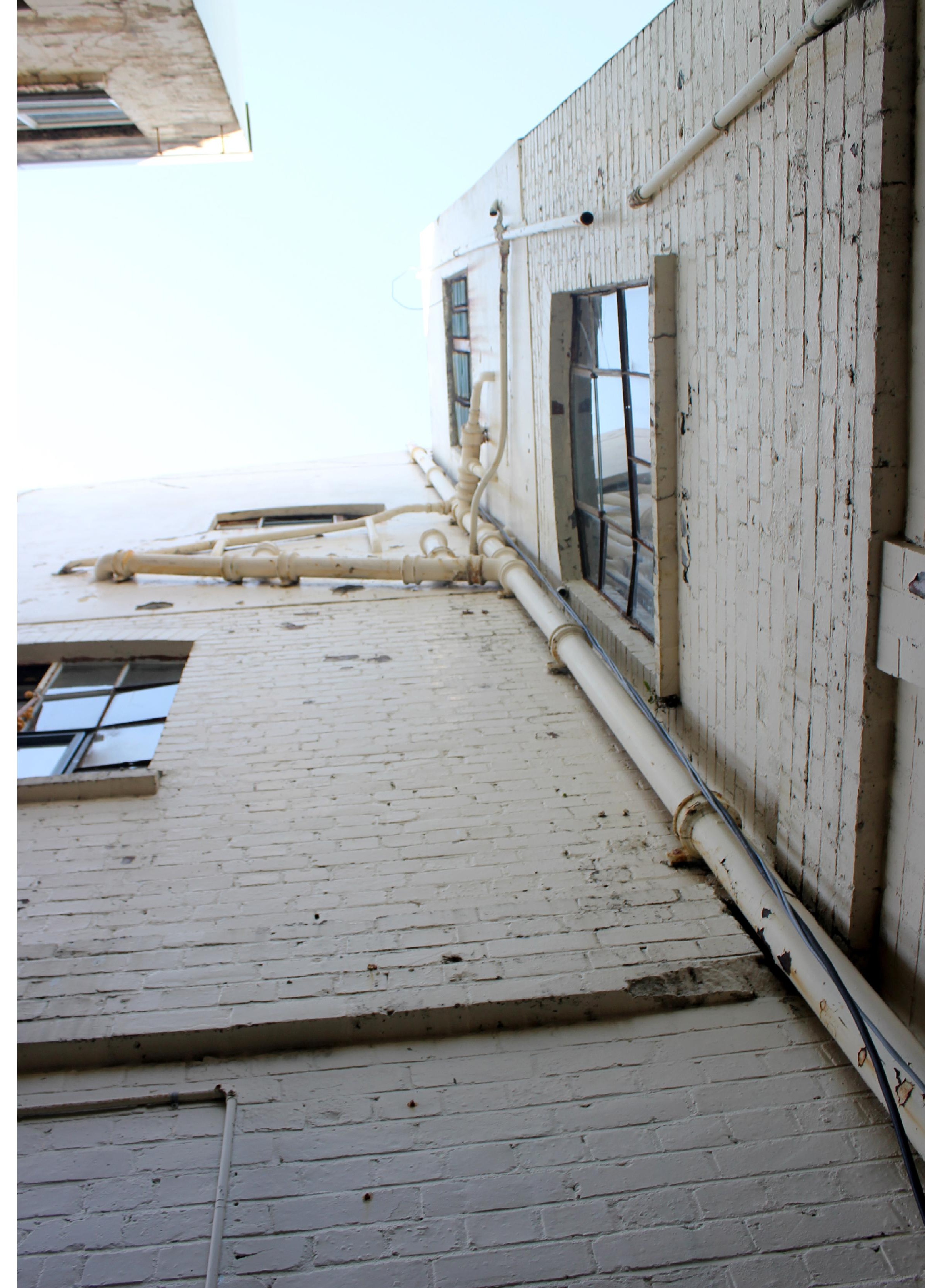


Existing structure
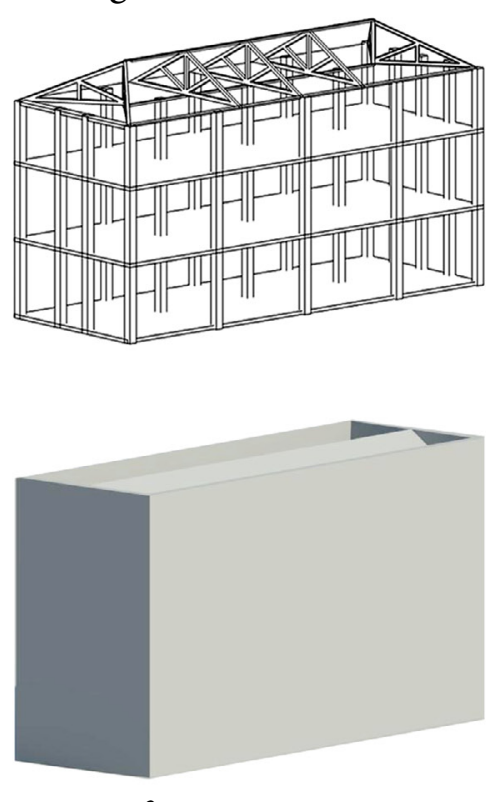

Existing form

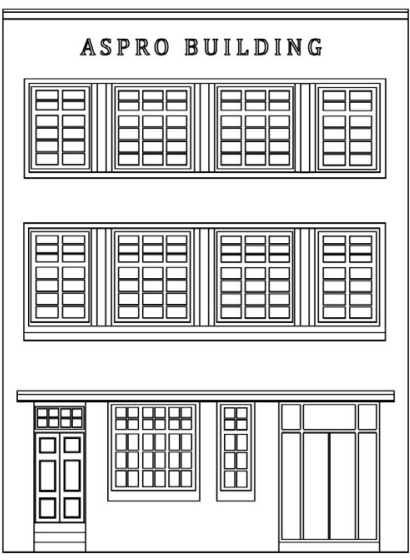

Existing west elevation

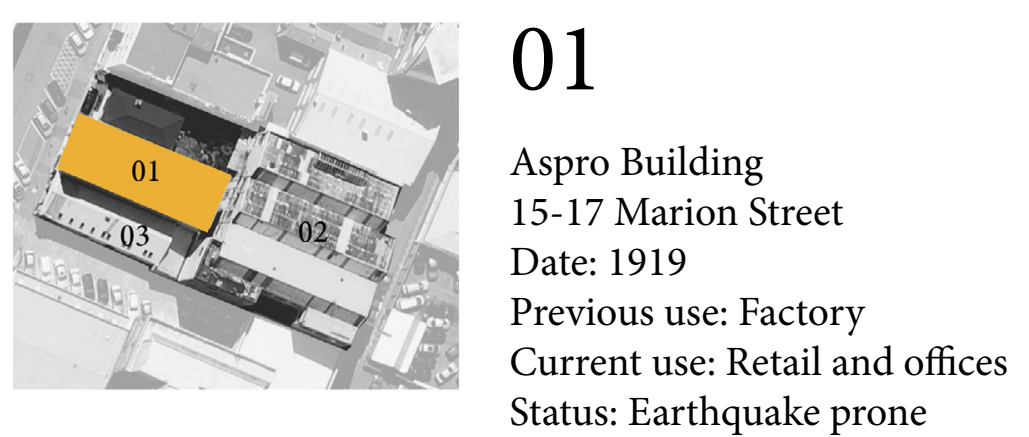

Existing structure
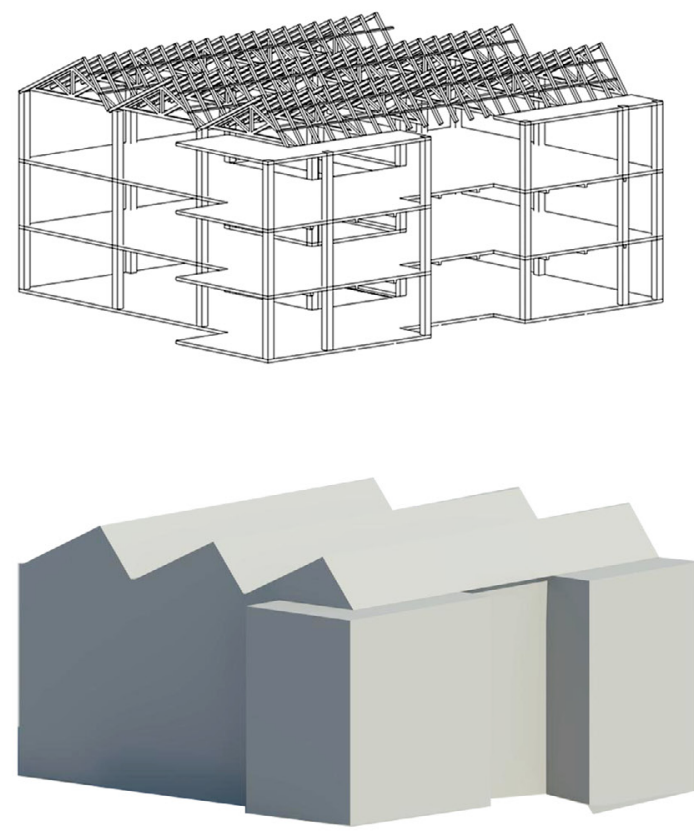

Existing form

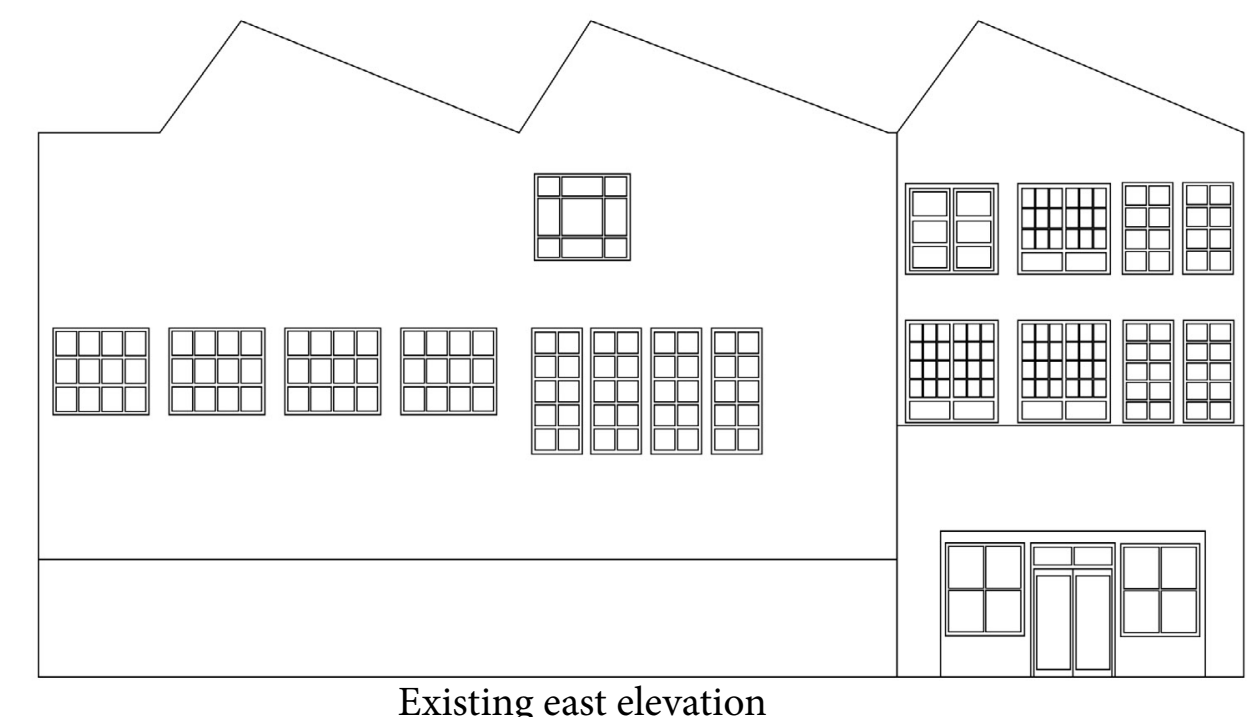

Existing east elevation

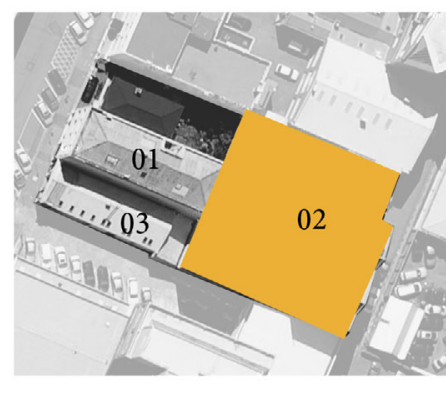

02

Messr Cathie Building Ltd (Cathie Building)

21/11a marion street

Date: 1906

Previous use: WW2 uniform factor

Current use: Residential

Status: $\quad$ Earthquake prone

WCC heritage building 


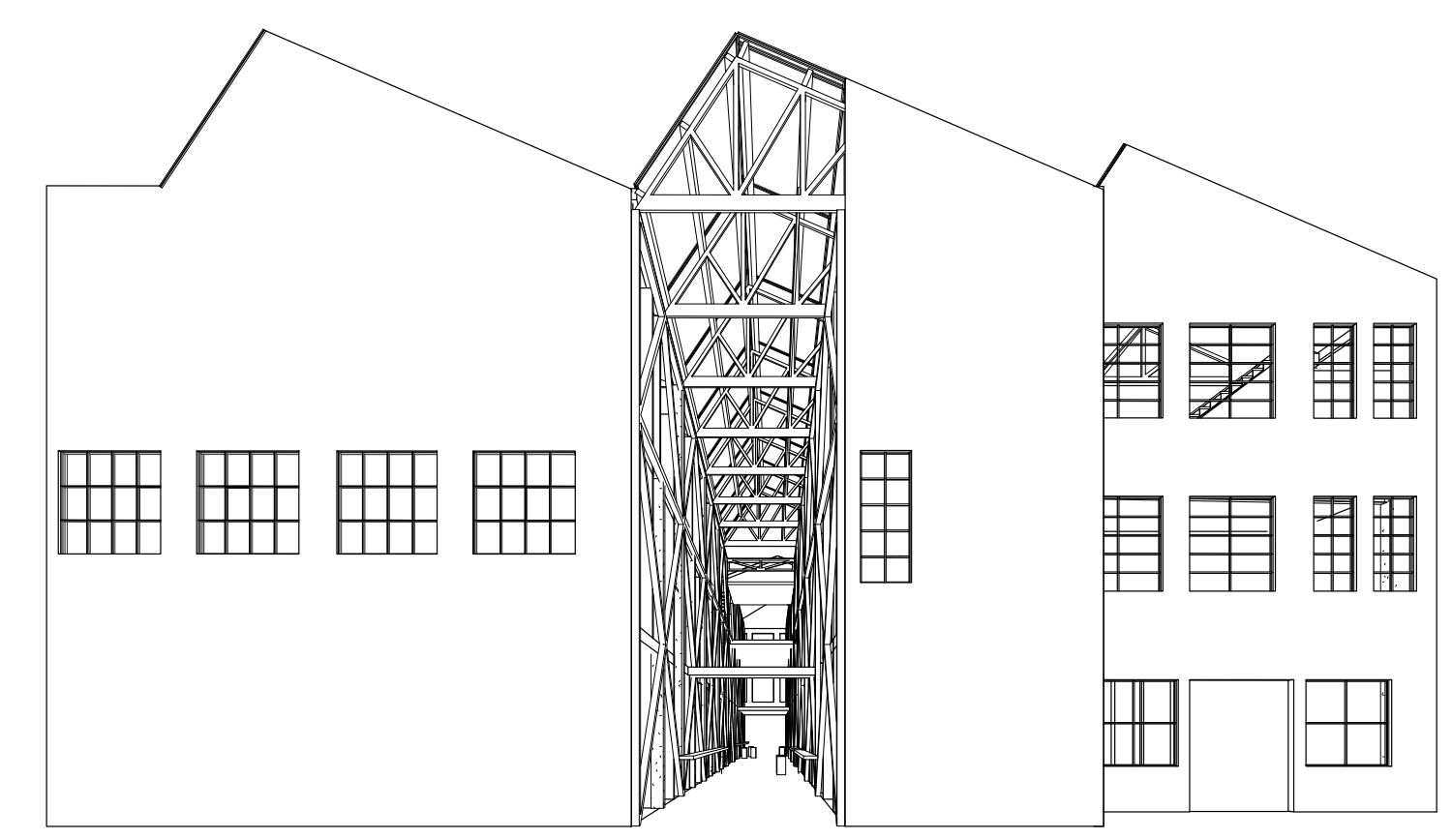

\section{VOID}

A void four metres wide was inserted straight through the centre of the Aspro and Cathie Buildings. This penetration into the existing buildings allows light to enter and activation to occur within the block. It also increases permeability and connectivity across the city. 


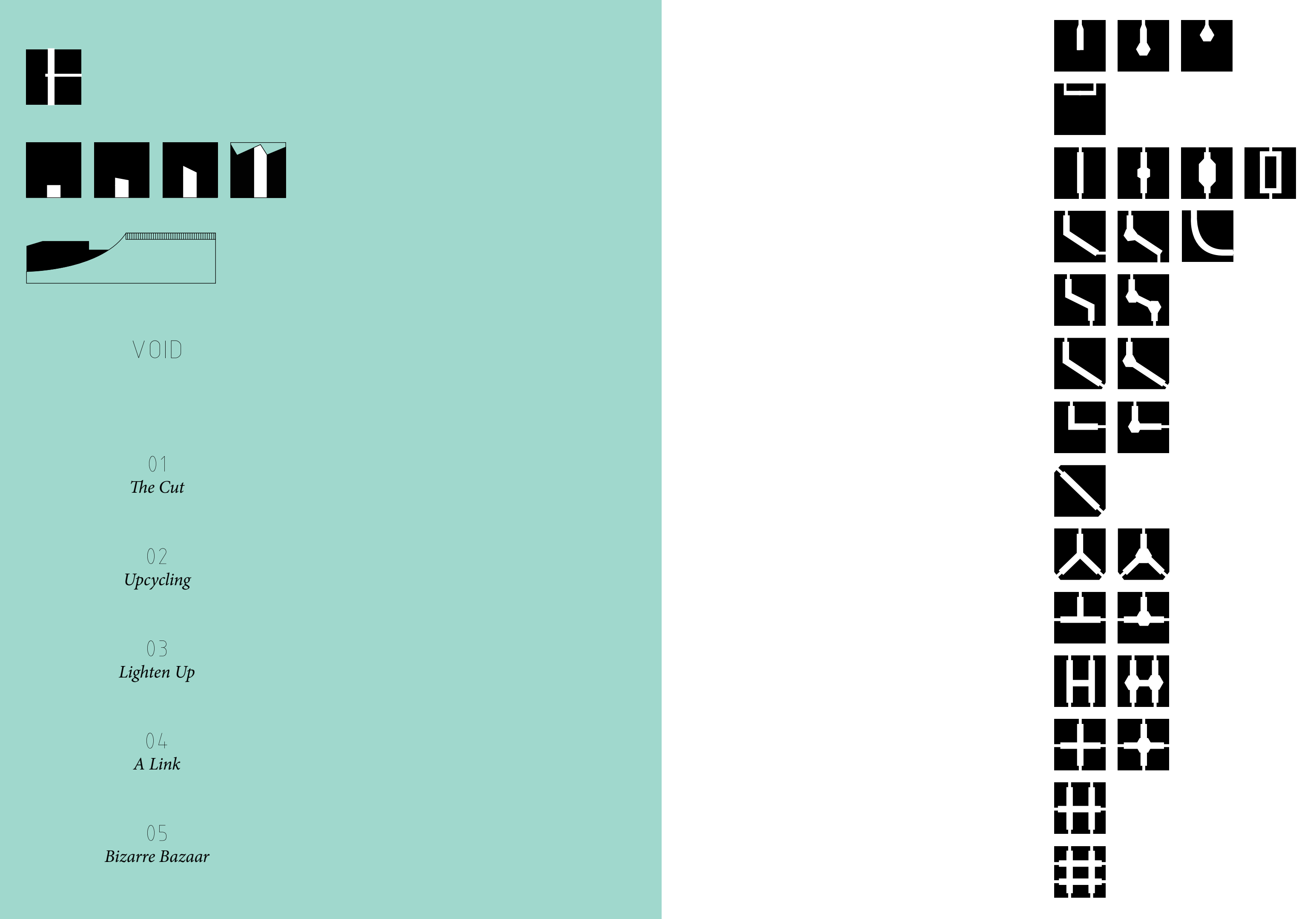



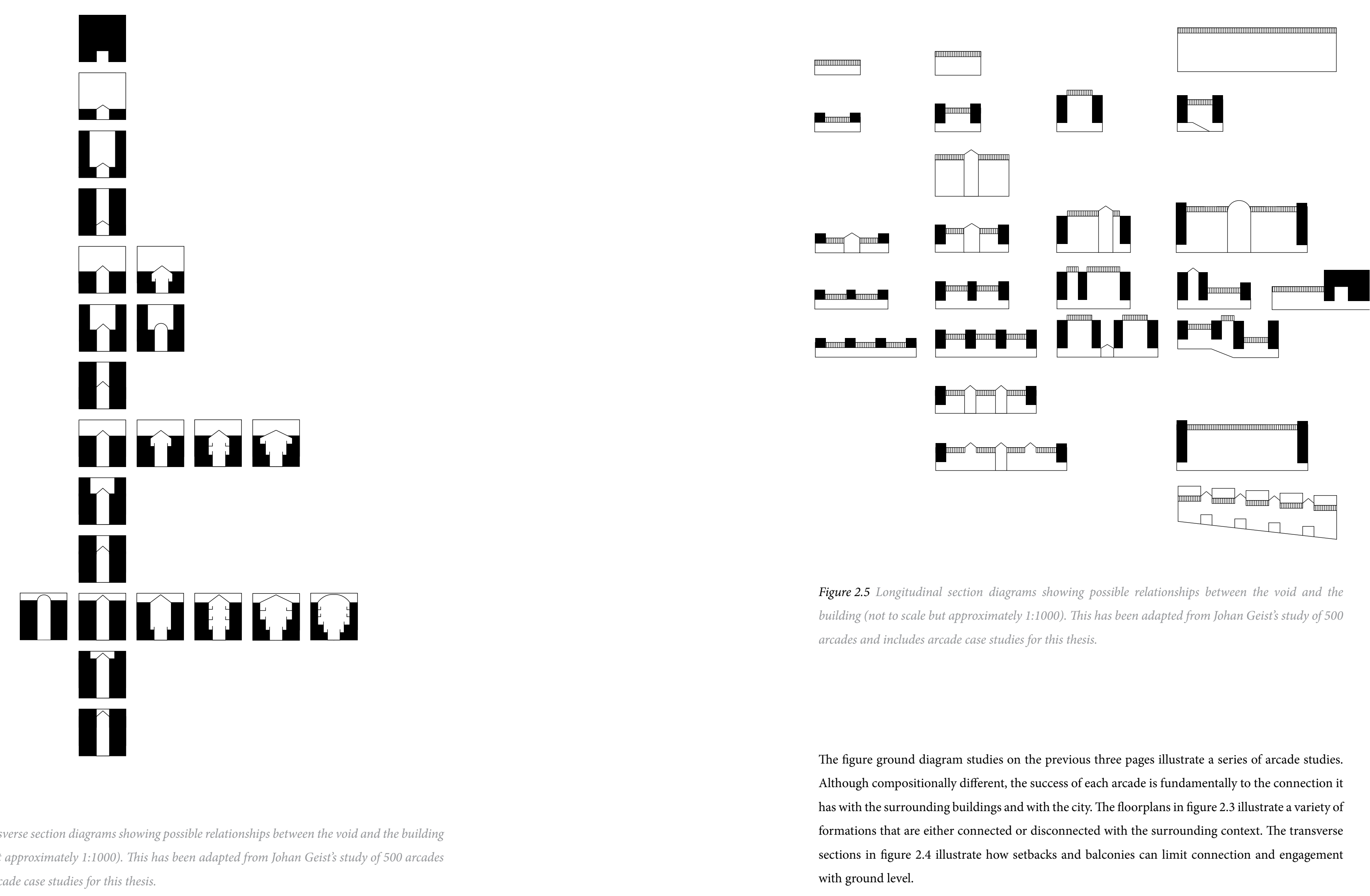


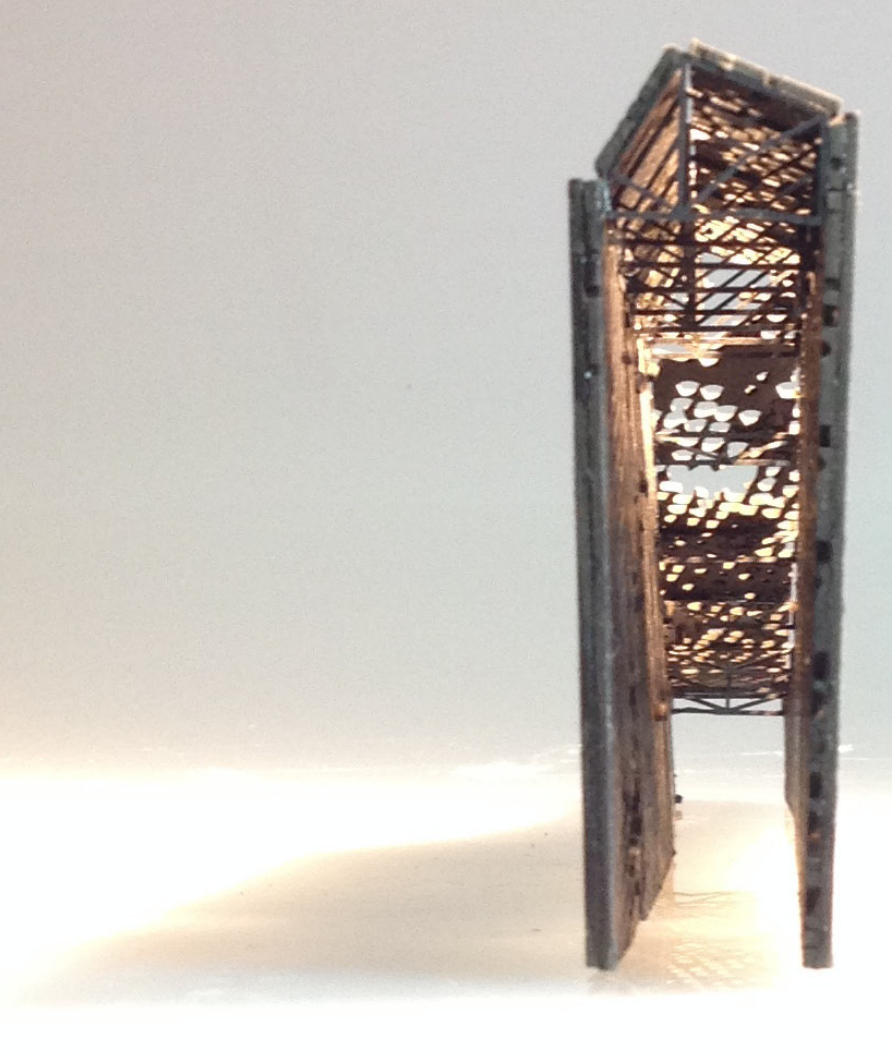

Figure 2.6 (Opposite) Brown cardboard model of the Cathie Building with the black void cut out from the centre The surrounding context is modeled in black cardboard. Photograph taken from Taranah Street perspective.

Figure 2.7 (Above) The form of the void standing alone. Although this is not an accurate representation of the project, it emphasises the space itself rather than the context. 
in

$0=5$
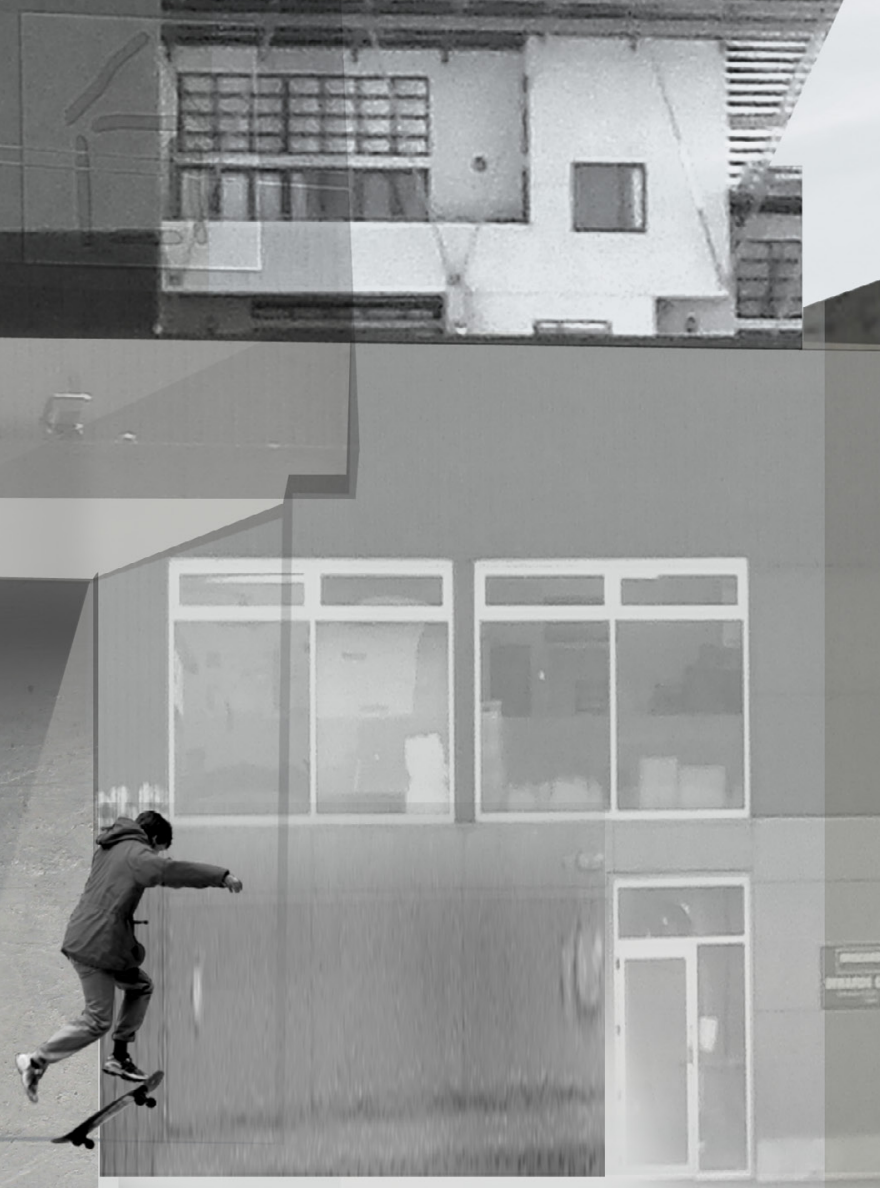

>in
Biscosis L

\begin{tabular}{|l|l|l|l|}
\hline & & \\
\hline & & & \\
\hline & & \\
\hline
\end{tabular}

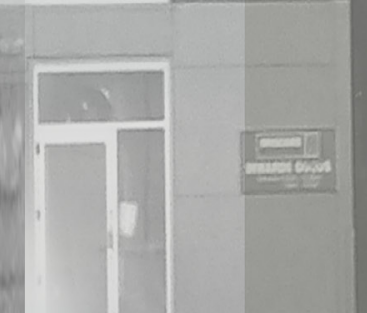

$\ln 2$

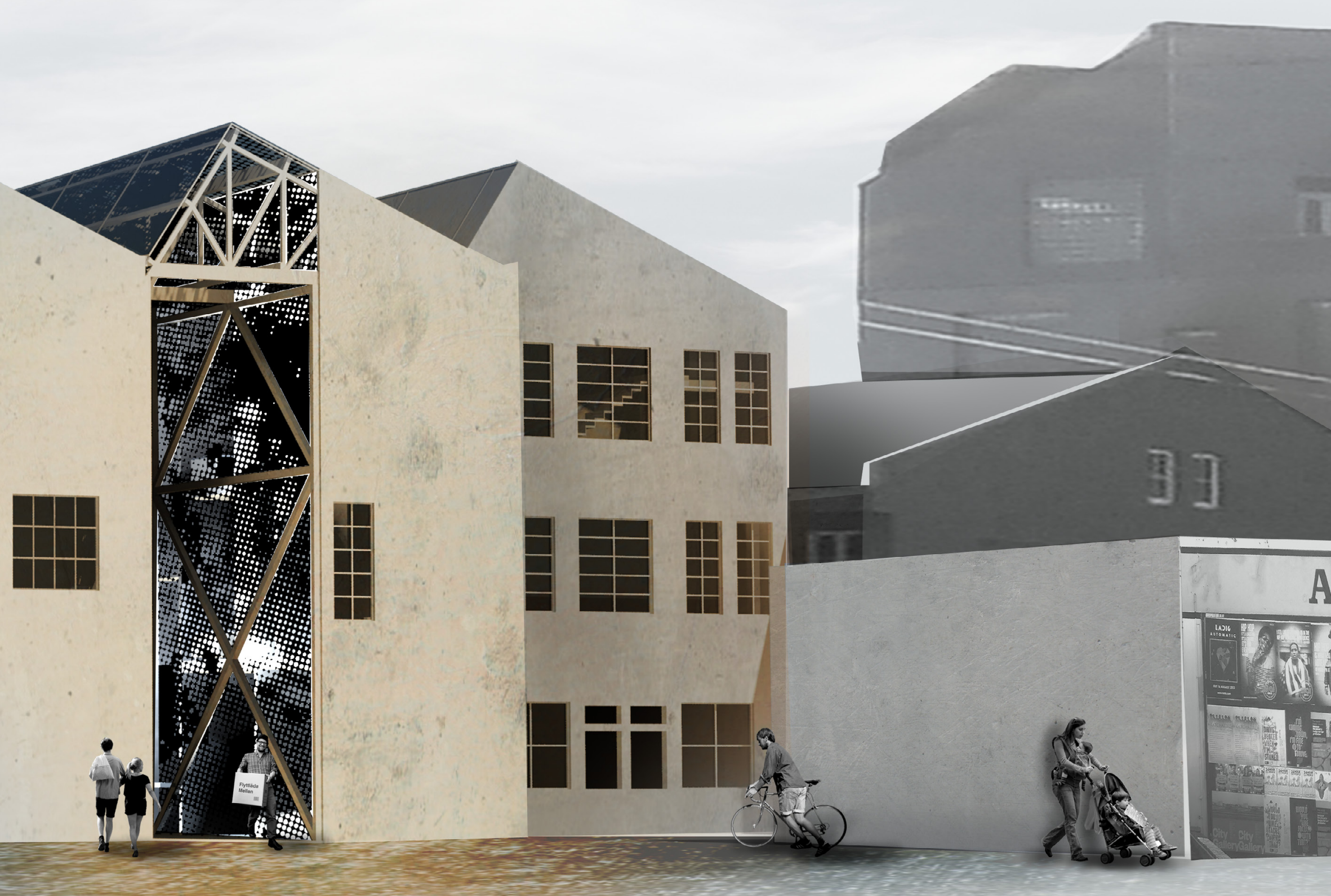




\begin{abstract}
01
CUT OUT

Verb Making an opening incision, or wound in (something). or to remove (something) from something Larre
\end{abstract}

II How wide?

The four metre width of the void allows for pedestrian movement and edge activity to co-exist (figures 2.10 and 2.11). This width is likely to support intimate, personal and social distances between pedestrians (Gehl, 69). Greater width would reduce the intimacy of the experience in the void.

The dimensions of public spaces can contribute to social interactions and atmosphere within them (Gehl, 68). Gehl comments that 'the relationship between distance and intensity, closeness and warmth, in various contact situations has an important parallel in the prevalent perception of architectural dimensions' (Gehl, 69).

Edward T. Hall defines four social distances: intimate distance where intense feelings are expressed personal distance for close conversation, social distance for ordinary conversation, and public distance for more formal situations (Gehl, 69).

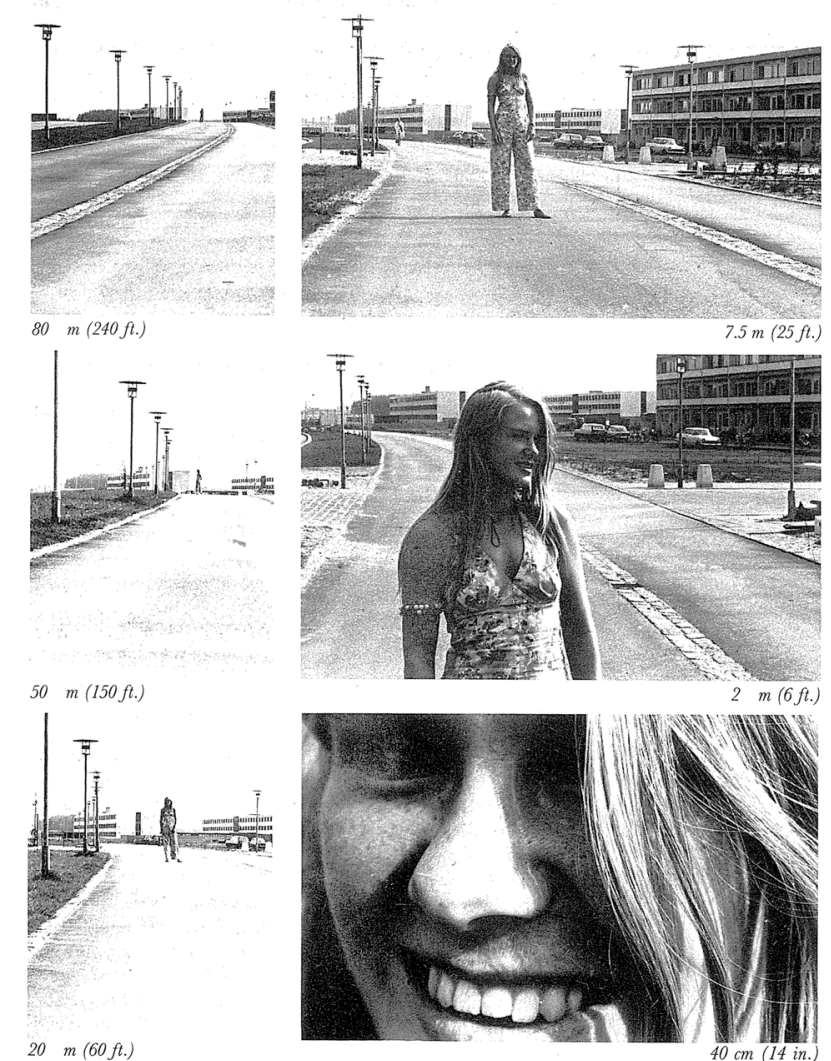

Figure 2.9 Photographs illustrating the relationship hetween distance and intensity of contact (Gehl, 68)

The sociological dimension of distance was explored by George Simmel who analysed the visual relationship between people through a series of caricatures (figure 2.9). He found that the average urban dweller was at ease when in close contact with strangers. "This ease was like that experienced within an interior' (Di Palma, 79). More specifically:

the arcade has been portrayed as a human collective, a unique sociological formation in which spatial proximity makes the human inhabitants not only dependent on each other, but also permanently at each other's mercy. The natural distance and the anonymity of the street is reduced to inescapable opposition, to necessary eavesdropping. It becomes a form of collective behaviour which is disturbed only by the shopper, the passerby' (Geist, 516).

Urban theorist, Jan Gehl, states the distance between people in public space is linked to the programm and size of the space. 'A very conscious use of distances is involved in nearly all contacts. The distance between participants is reduced if mutual interest and intensity are increased' (Gehl, 67). The ease of being at close proximity to others adjusts accordingly with the size and use of the public space. 


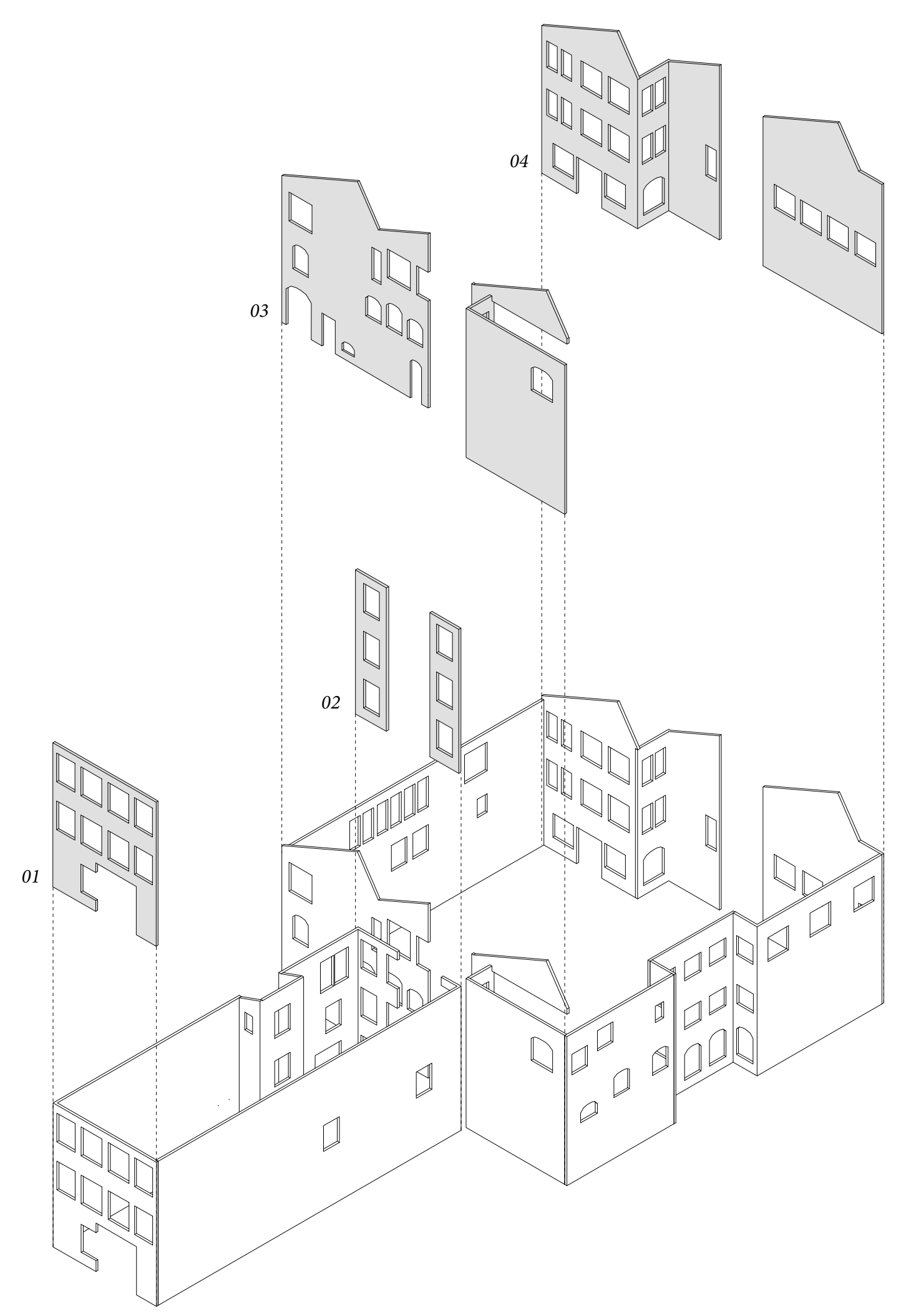

Figure 2.10 (Above) Exploded axonometric diagram of the Cathie Building and the Aspro Building

Figure 2.11 (Opposite) Drawings of the east and west elevations of the two buildings, with the void emphasised in red. This figure is referential to Figure 2.10
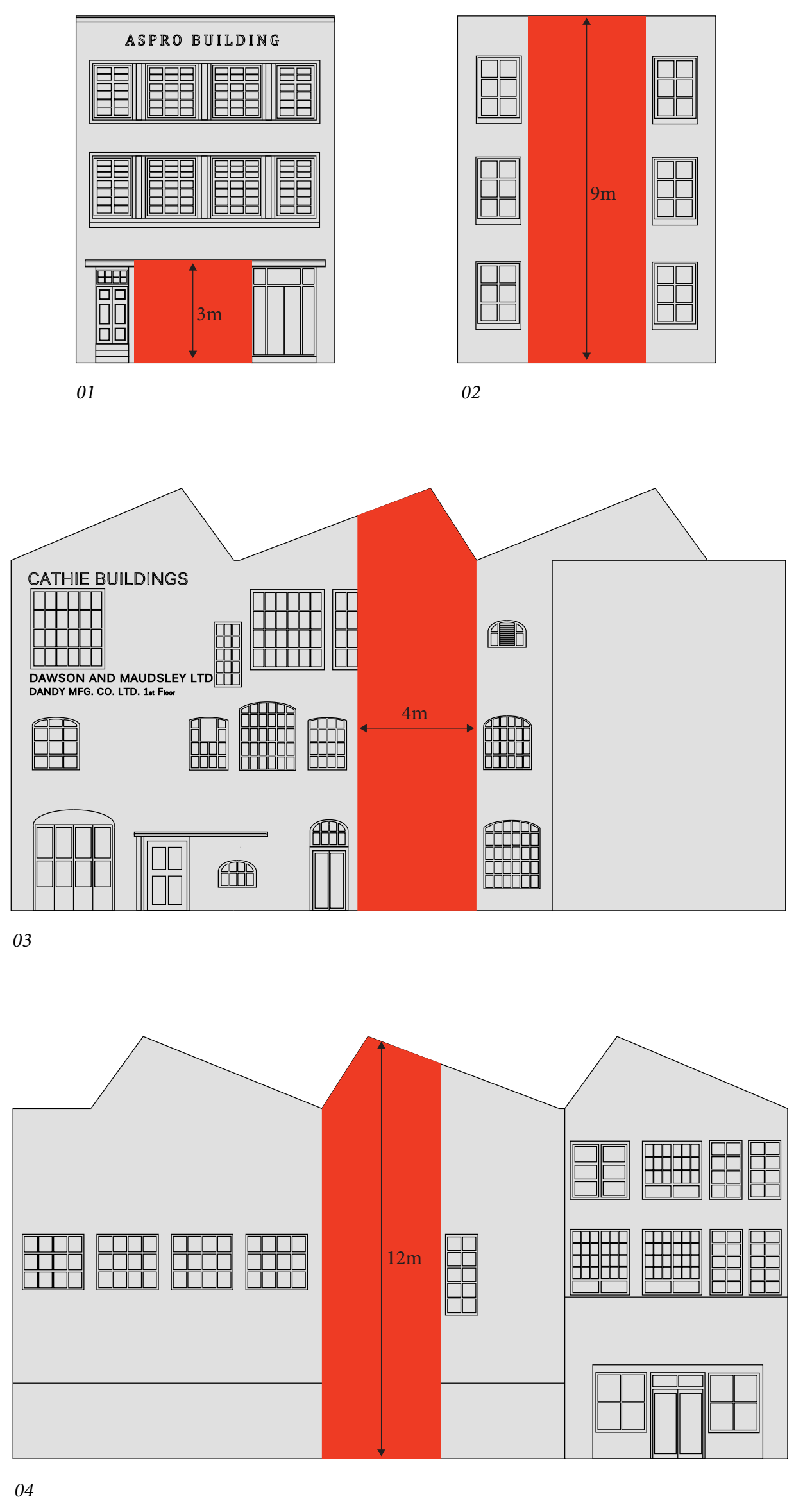
CASE STUDY

C

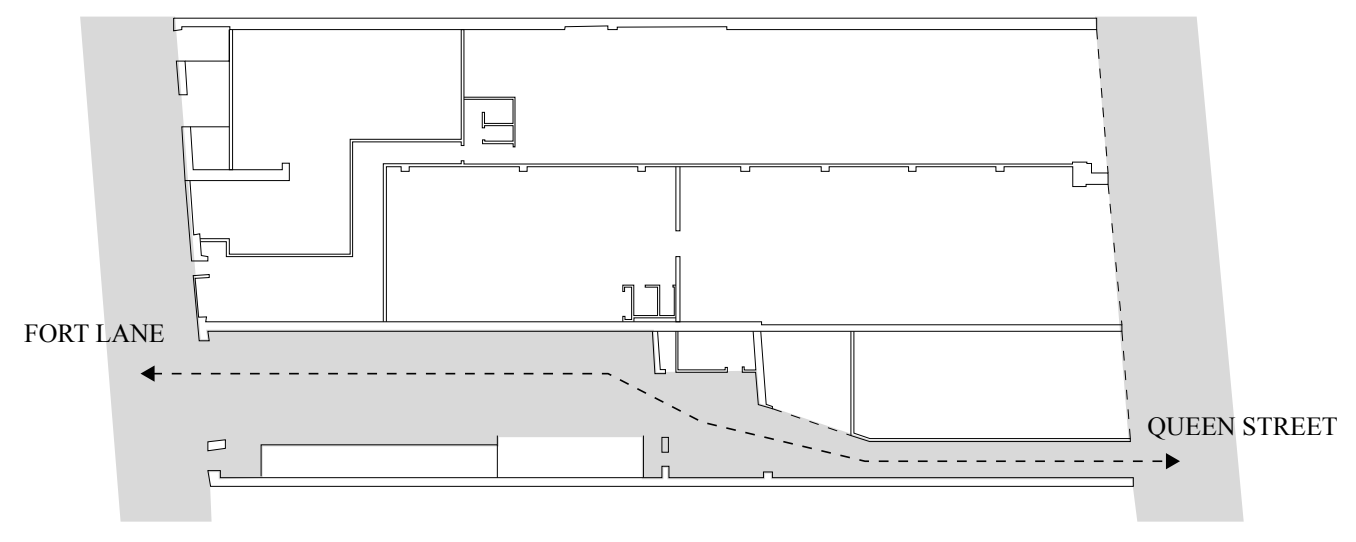

Ground floor plan of Imperial Lane showing varying width along the length

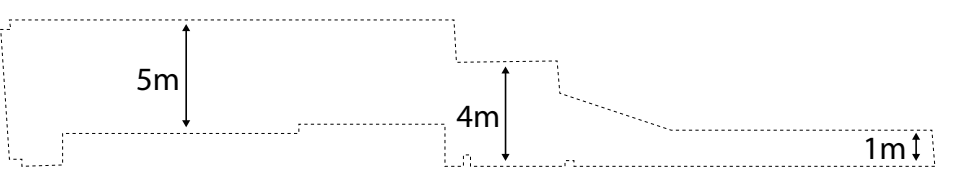

Varying width of the laneway encourages varying use along the length, with the narrow Queen Street entrance feeling private and unused

II

MARION STREET
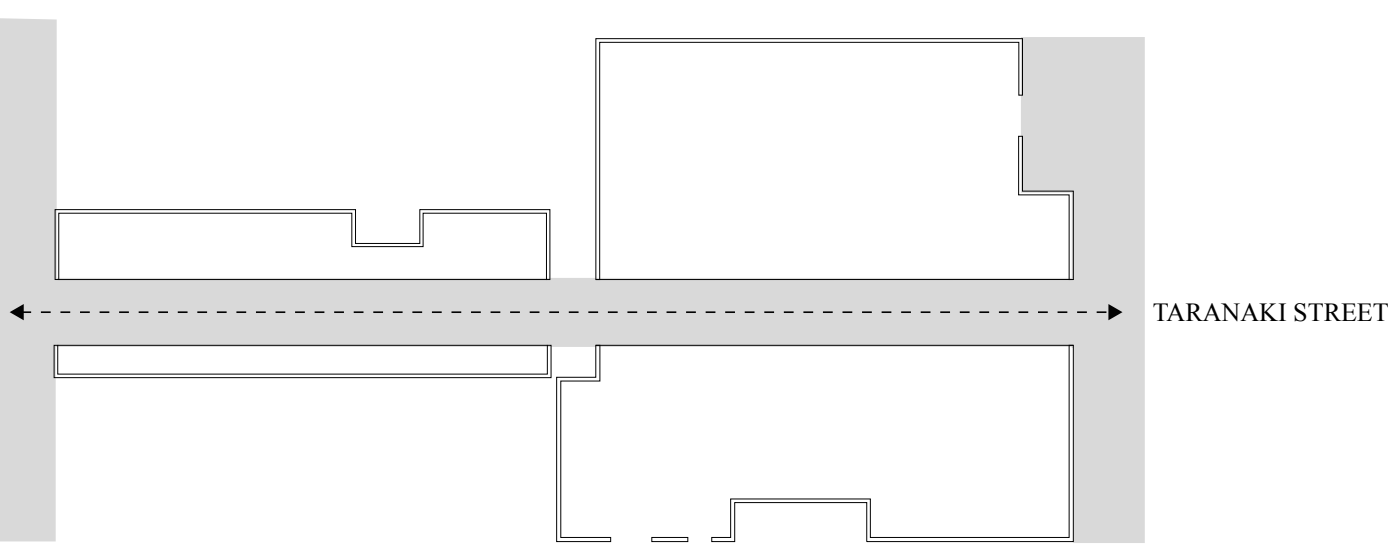

Ground floor plan of The Design showing constant width of $4 \mathrm{~m}$ along the length

$$
4 \mathrm{~m}\left[\begin{array}{ll}
4 \mathrm{~m}] & 4 \mathrm{~m} !
\end{array}\right.
$$

Constant width of the design scheme assists with orientation and enables public activity and use along the entire length of the arcade
C

CASE STUDY

The James Cook Arcade, 1979. Wellington, New Zealand. Architect: Roger Walker and Gus Watt

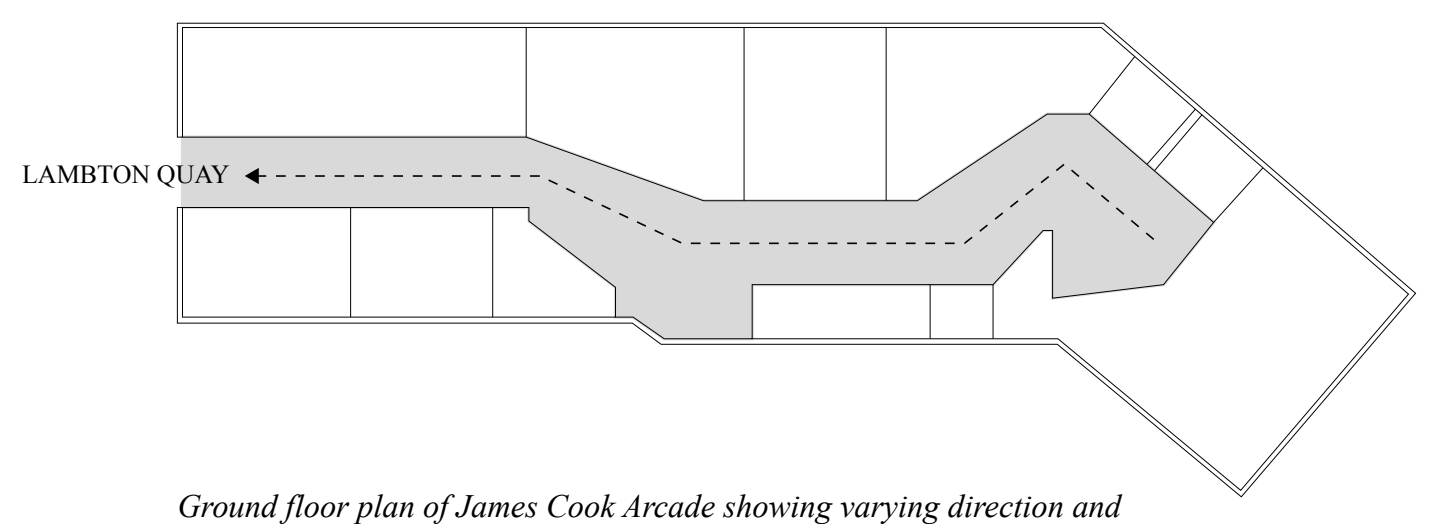

Ground floor plan of James Cook Arcade showing varying direction and width along its length

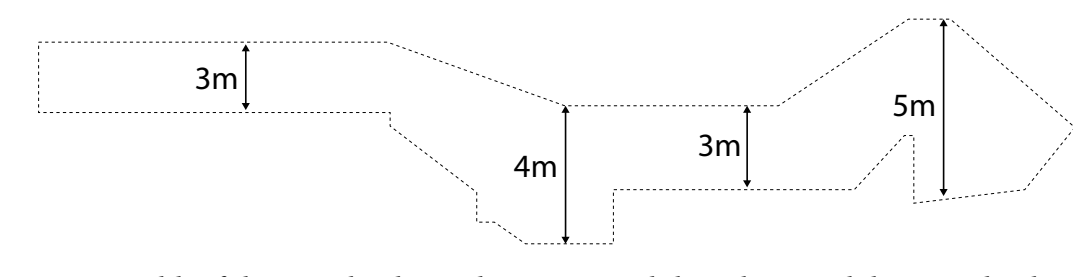

Varying width of the arcade along, distorting visibility along with being a dead end discourages pedestrian activity along the length

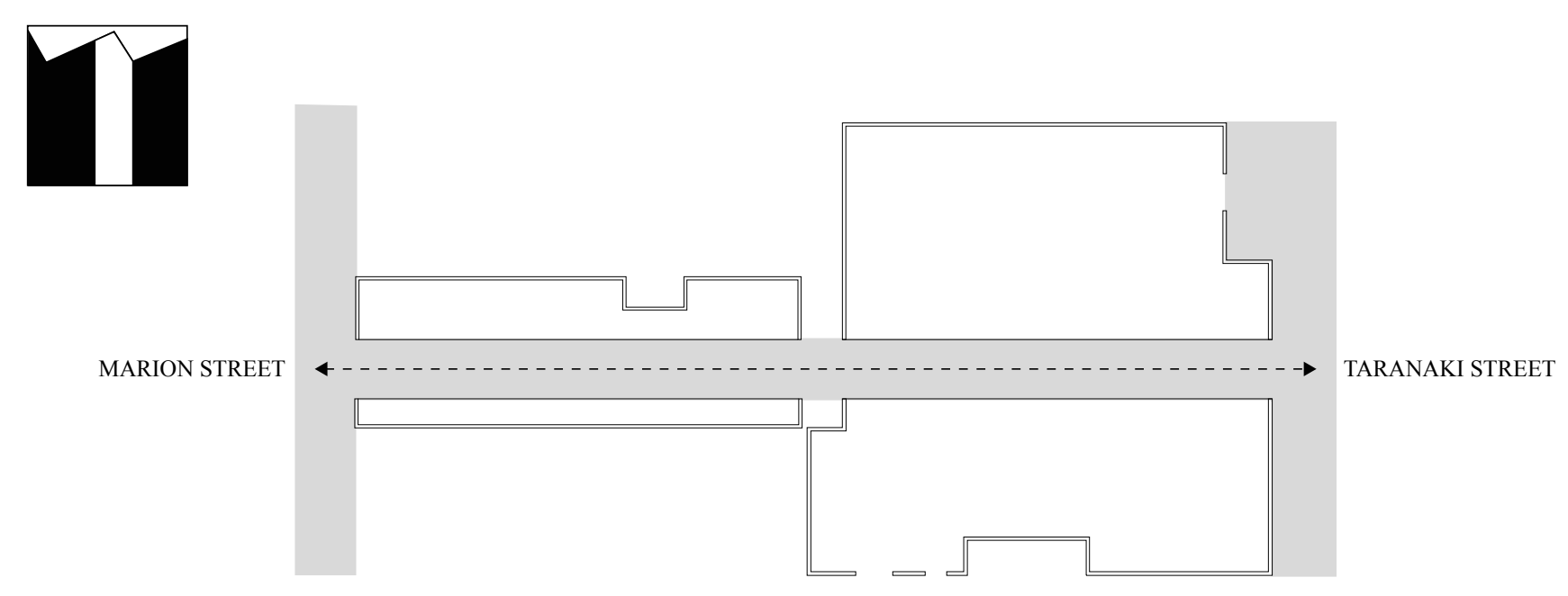

Ground floor plan of The Design scheme showing constant width and singular direction along the length

$$
4 \mathrm{~m}[\quad 4 \mathrm{~m}] \quad 4 \mathrm{~m}]
$$

Constant width of the design scheme assists with orientation visibility and consequently pedestrian safety. Being a thoroughfare rather than a dead end space ensures pedestrian use. 


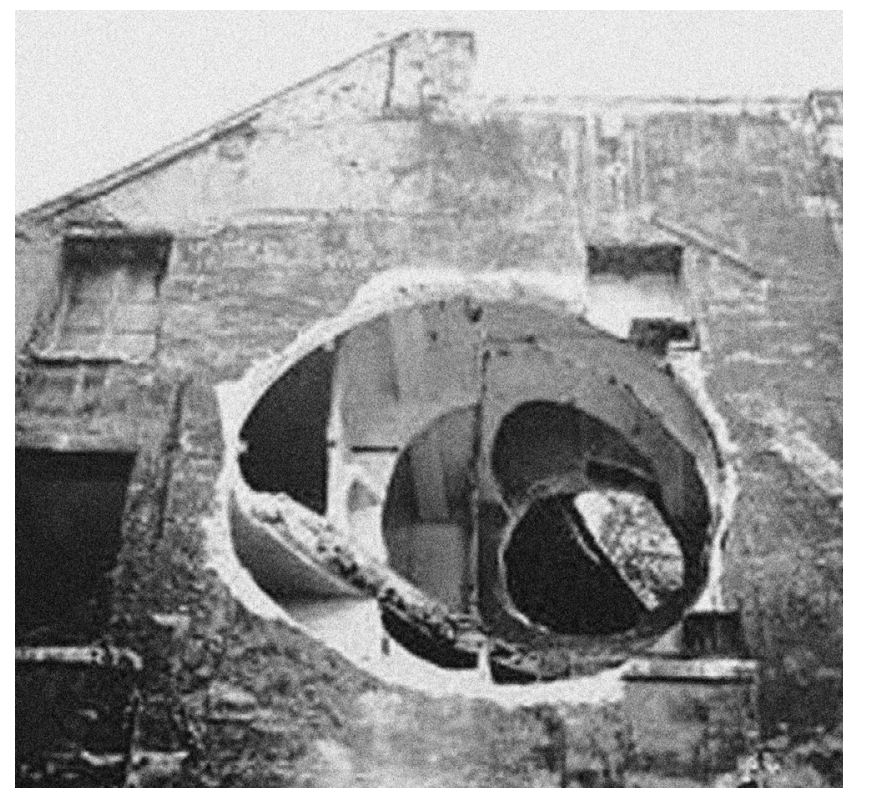

CASE STUDY

Splitting, 1974. New Jersey, United States Artist: Gordon Matta-Clark.
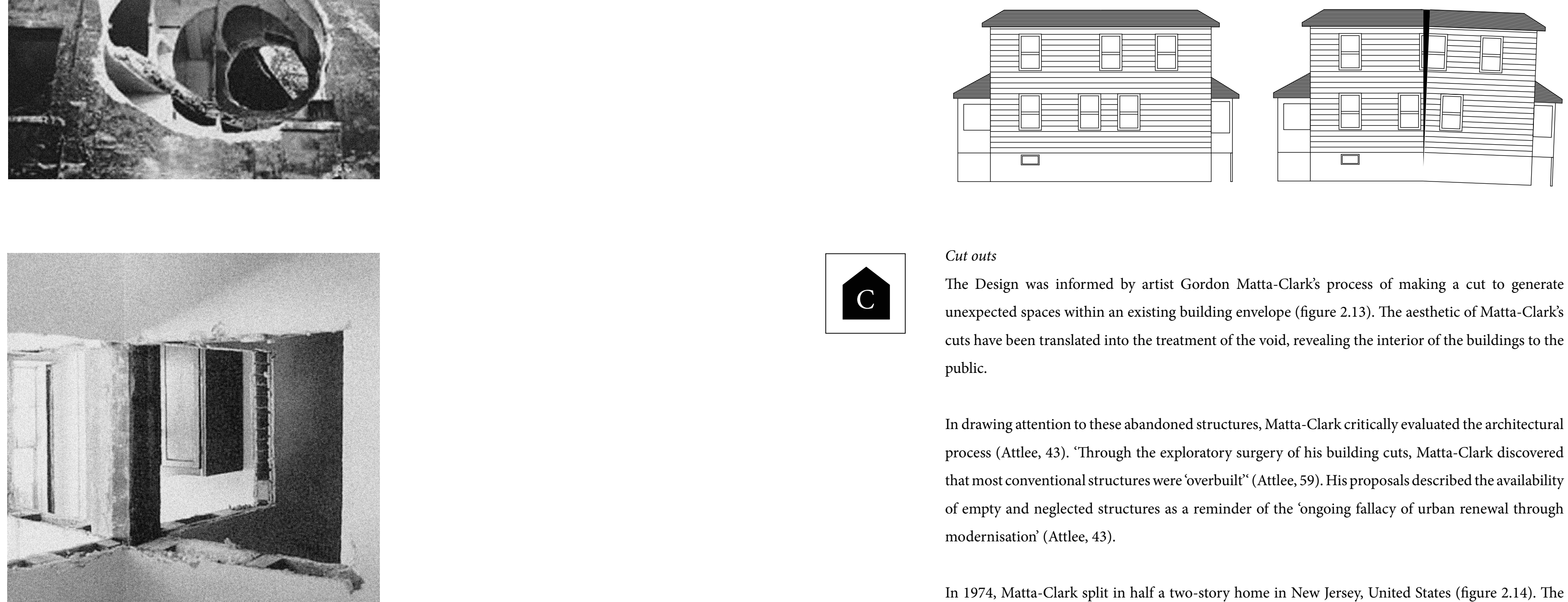

Cut outs

C The Design was informed by artist Gordon Matta-Clark's process of making a cut to generate unexpected spaces within an existing building envelope (figure 2.13). The aesthetic of Matta-Clark's cuts have been translated into the treatment of the void, revealing the interior of the buildings to the public

In drawing attention to these abandoned structures, Matta-Clark critically evaluated the architectural process (Attlee, 43). ‘Through the exploratory surgery of his building cuts, Matta-Clark discovered that most conventional structures were 'overbuilte" (Attlee, 59). His proposals described the availability of empty and neglected structures as a reminder of the ongoing fallacy of urban renewal through modernisation' (Attlee, 43).

In 1974, Matta-Clark split in half a two-story home in New Jersey, United States (figure 2.14). The light from the incision entered the interior and revealed the raw cut. The artist photographed his work and created a collage of prints, the unconventional composition of which re-creates the disorienting experience of the project (figure 2.15) (Splitting: Gordon Matta-Clark).

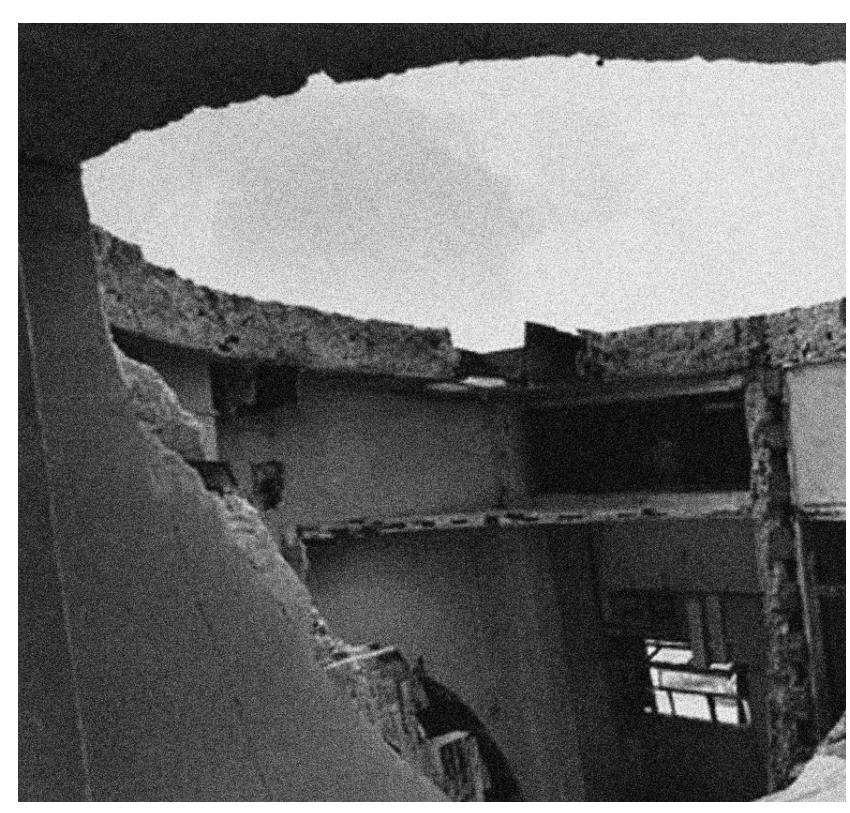

Unlike Matta-Clarks work, The Design uses the void to increase liveability of buildings in the city. Earthquake prone buildings in Wellington, although deemed uninhabitable for structural reasons, could be revitalised through cutting out the building fabric. 
2.8 metres between the buildings. There is no standardised length of an arcade because the length tends to relate to the sités block size.

Why straight?

The void follows a straight line through the block, with a secondary perpendicular route intersecting

the main route at its mid-point. The straight line allows the void to act as an east-west axis for

pedestrians, framing views of Mount Victoria from Marion Street (figure 2.18). The straight line is the most efficient formal move to cut across the block, redefining the surrounding buildings in a manner

that is consistent with the existing structural grid. The straight line results in visual permeability

through the space, reducing blind spots and increasing safety.
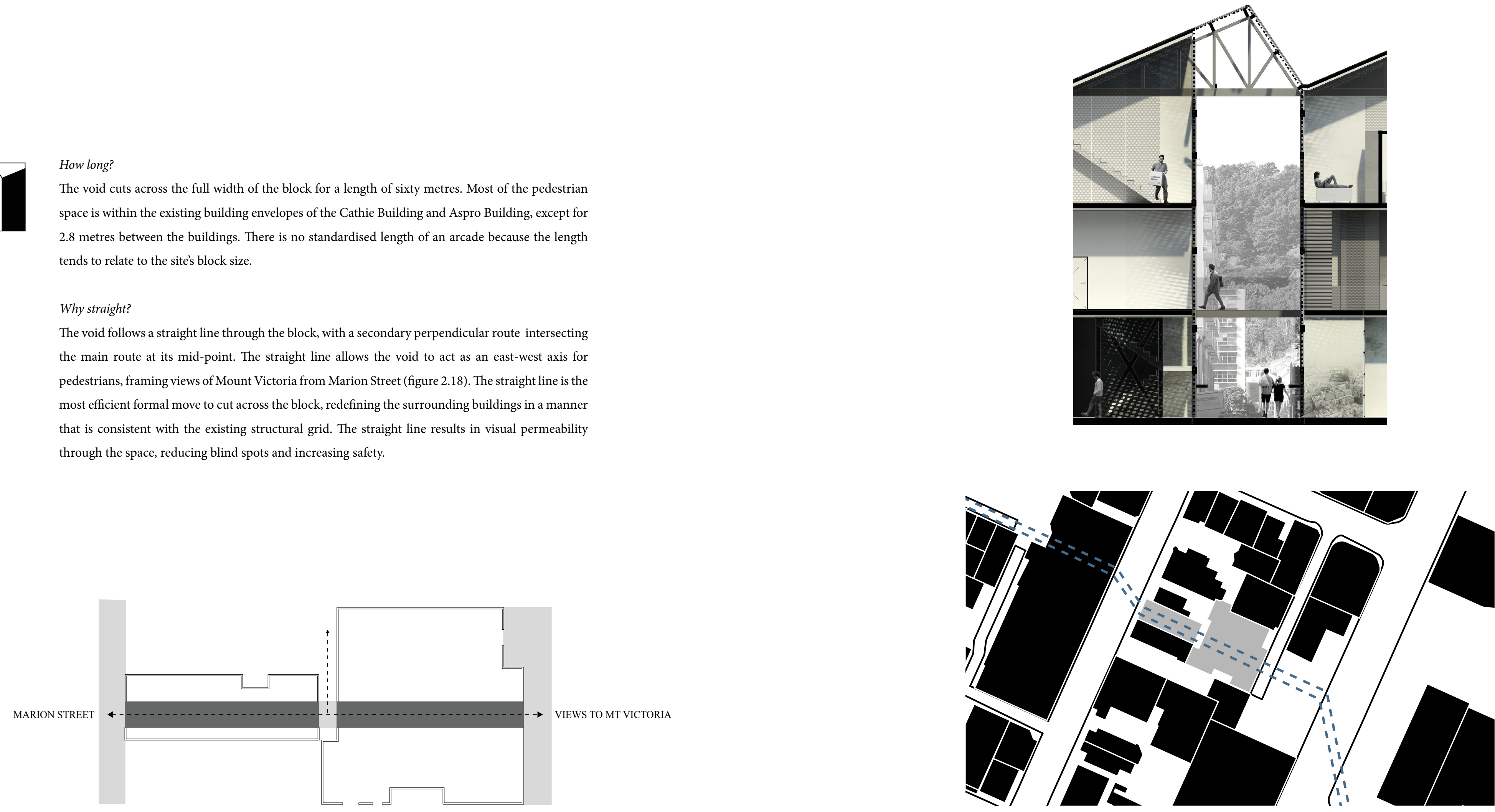

Figure 2.18 (Top) The straight cut allows for visual permeability along the void and frames views of

Figure 2.19 (Bottom) A cut through the buildings connects the void with existing pedestrian routes. 


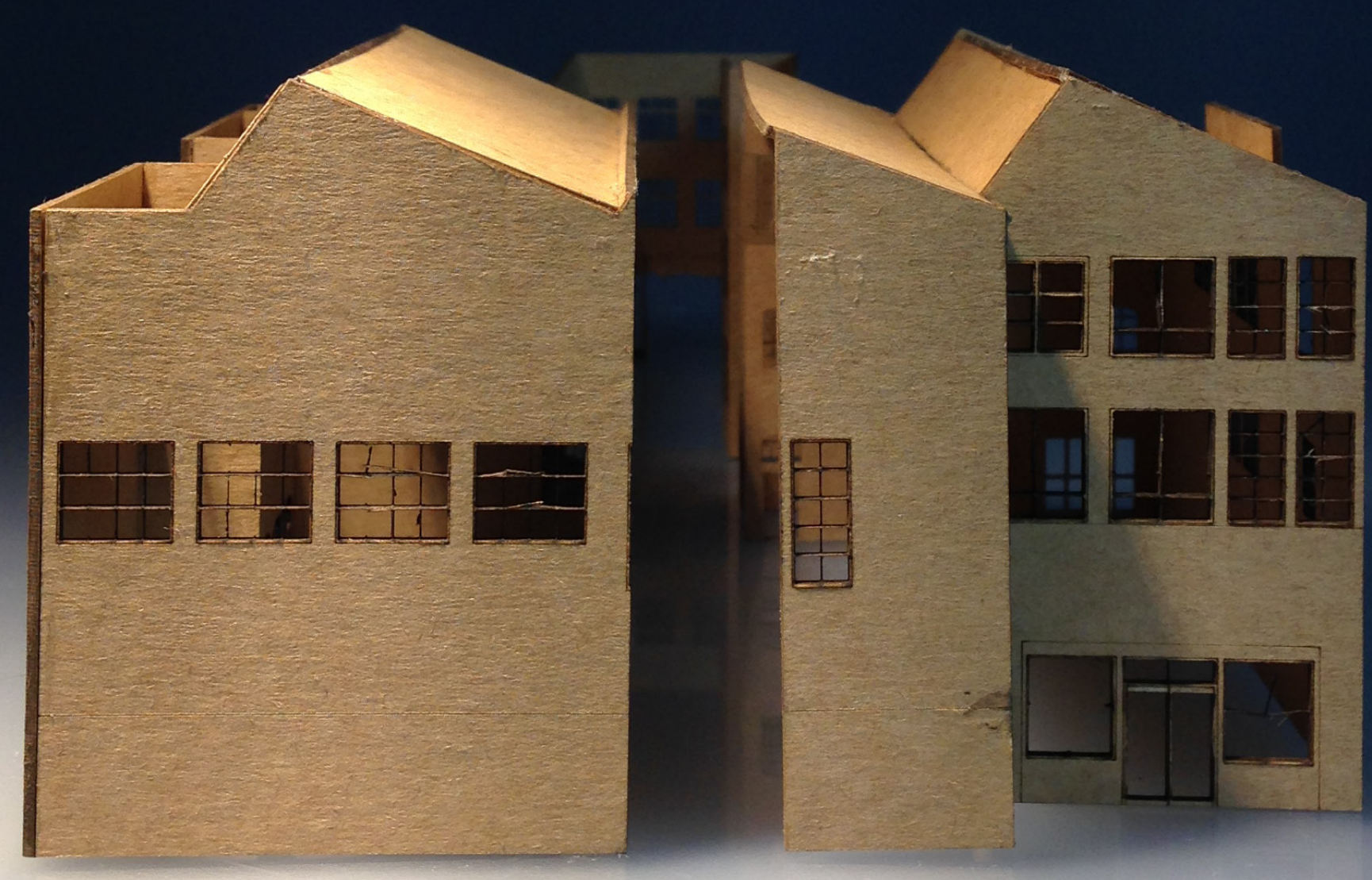

\begin{tabular}{|c|c|}
\hline 明㖆 & 田田 \\
\hline 湡曲典 & 田田 \\
\hline 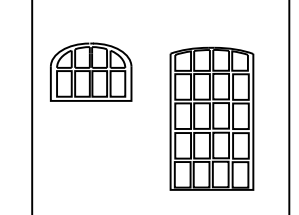 & 田四 \\
\hline
\end{tabular}





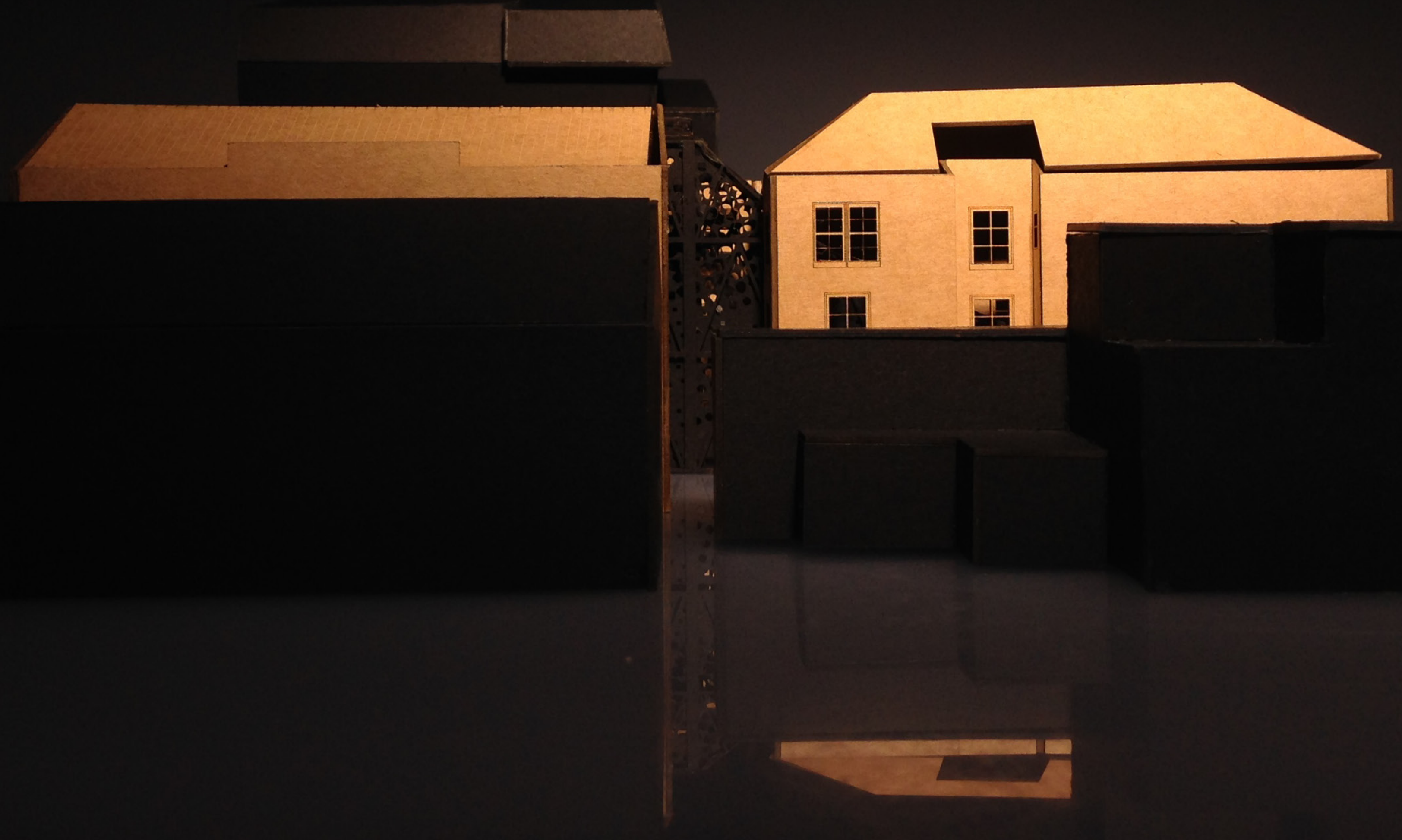




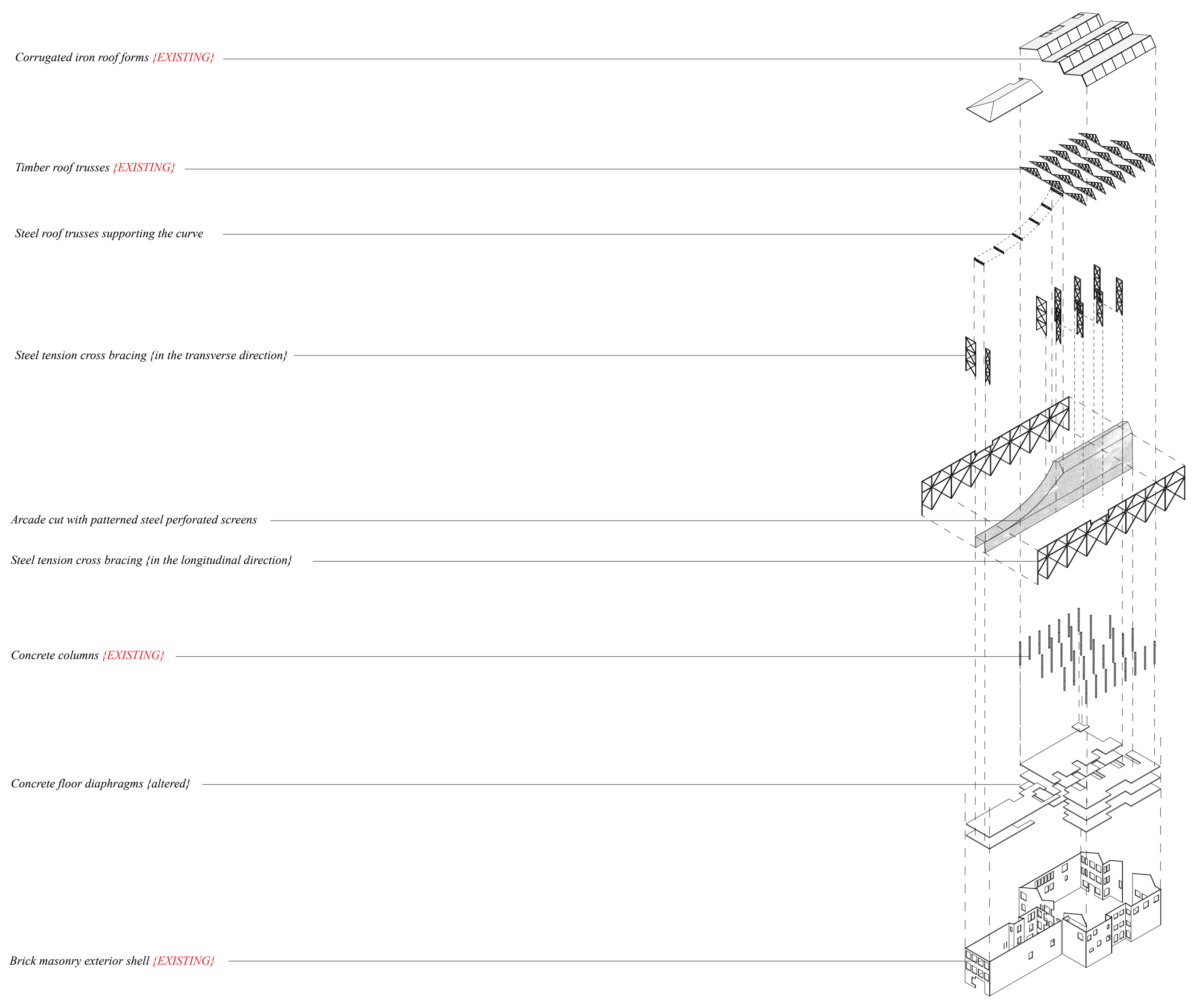



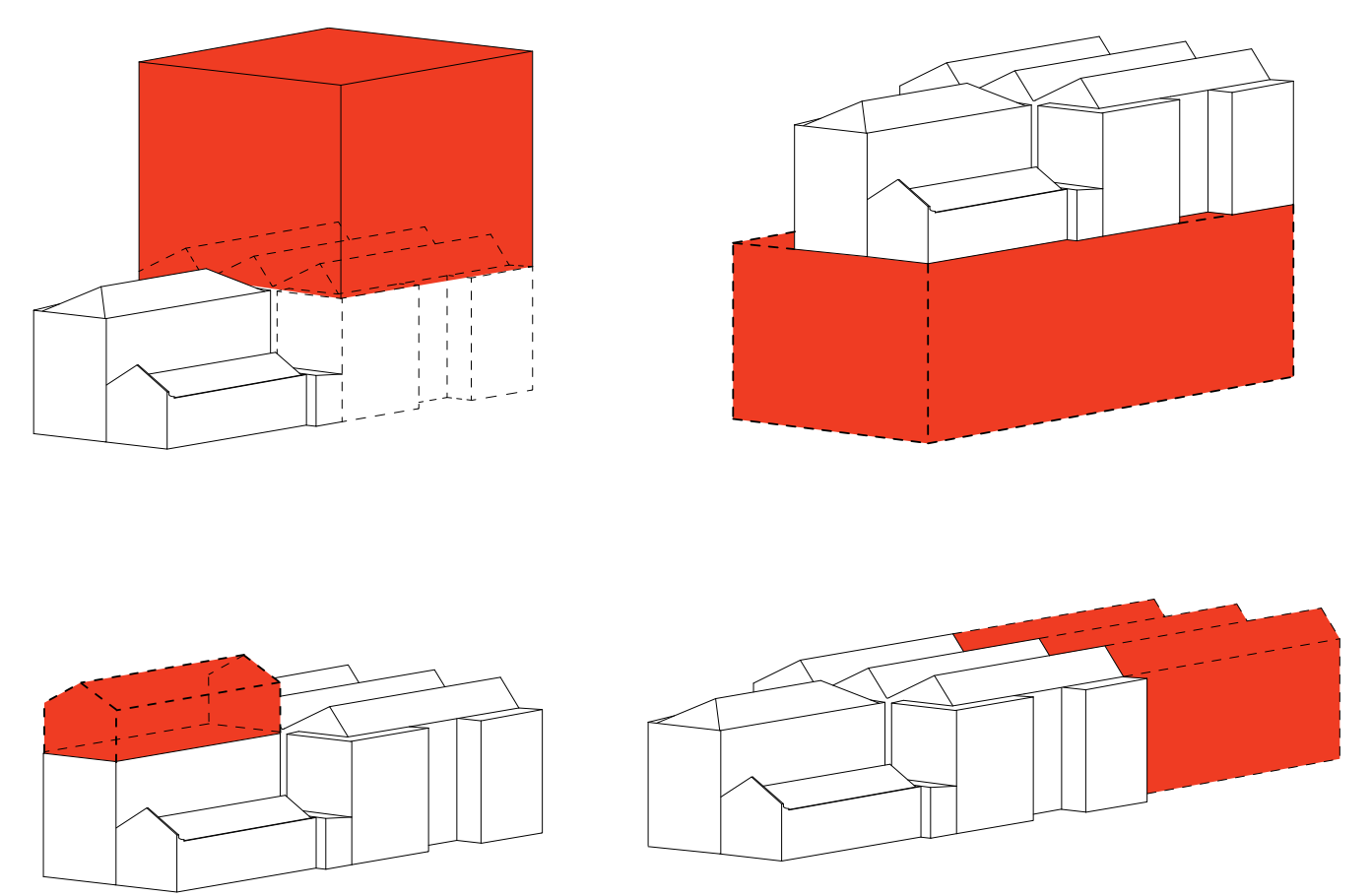

Figure 2.25 Massing experiments of forms that increase the lettable floor area of the existing building. A and $B$ are bold contrasting forms, whereas $C$ and $D$ are more subtle, coherent forms. 묘묘 were tested before the decision to make a vertical cut through the buildings. The horizontal cut was unable to incorporate sufficient strengthening as the structure had to run through the entire height of the buildings. It also inhibited connection around the city and between the pedestrian and the upper levels of the buildings.

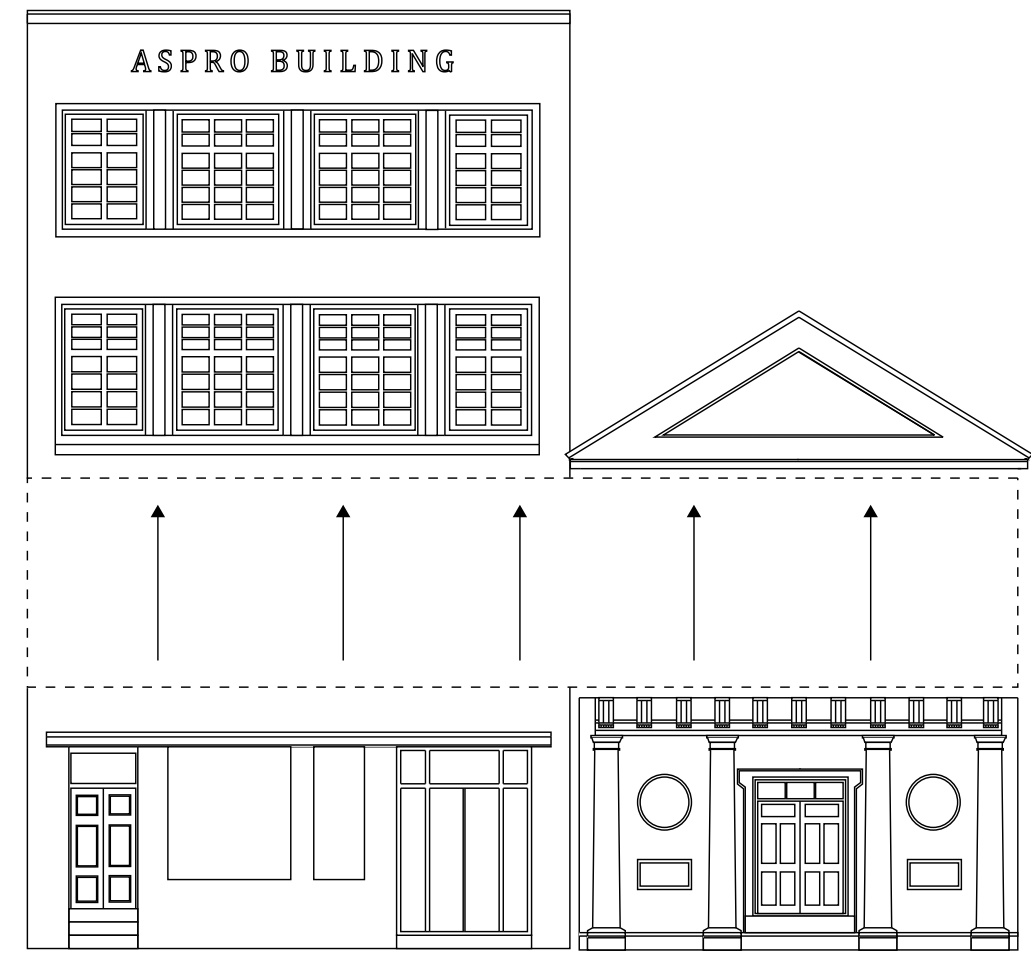

Along the line

A number of massing experiments were carried out to evaluate how the overall intervention relates

$\square \square$ to the existing building forms. 
CASE STUDY
San Telmo Museum extension, 2006-2011. San Sebastián, Spain. Architect: Nieto Sobejano Arquitectos.

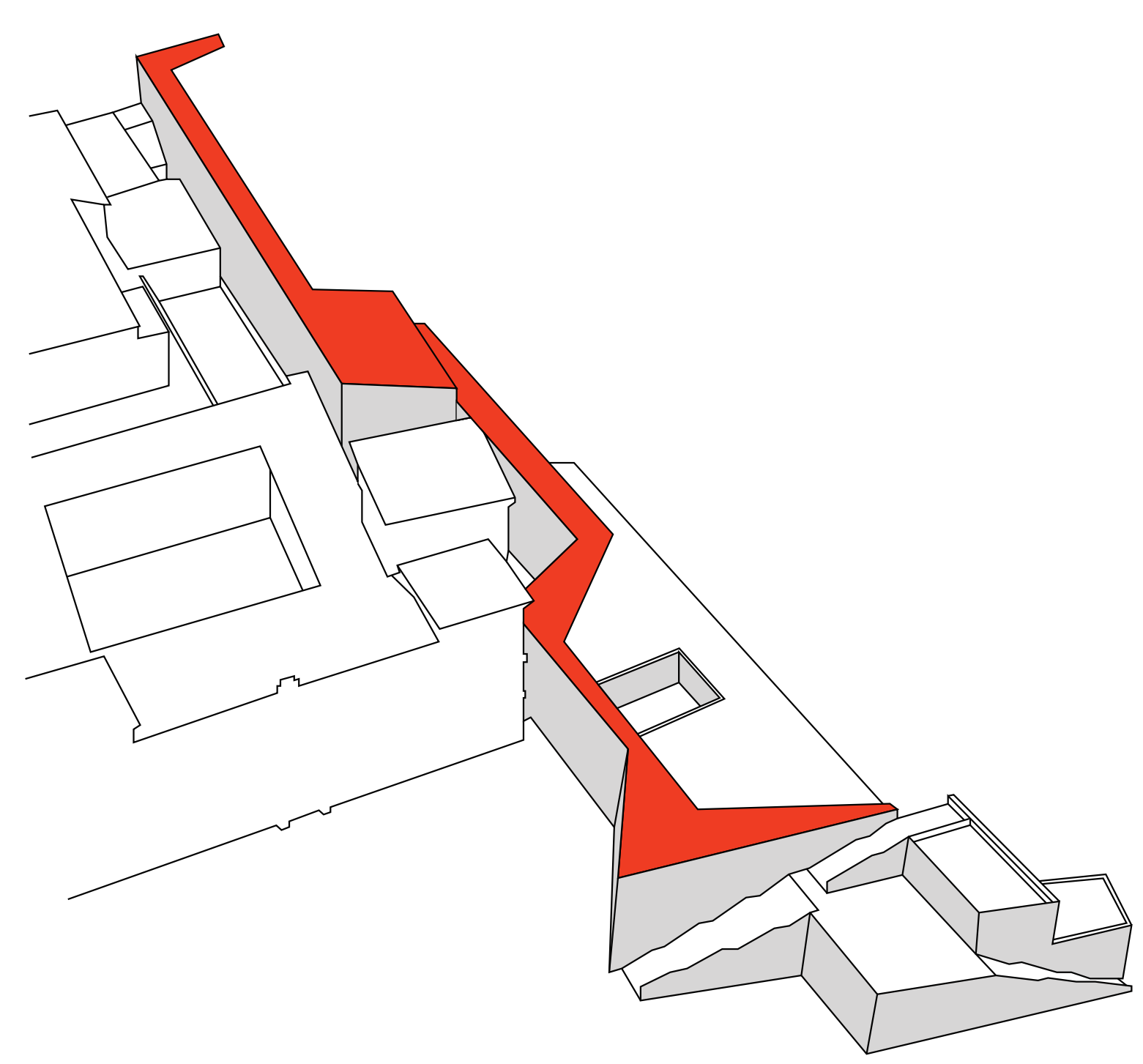

Figure 2.27 The linear form of the San Telmo Museum extension weaves between the existing museun buildings.

What's done?

C The following case studies analyse different ways of working with existing built form, balancing coherence and contrast.

The San Telmo Museum extension weaves through the site, utilising the interstitial space between buildings and the landscape (figure 2.27). The angles of the intervention contrast with classical geometry of the old museum. It introduces a new axis that does not relate to any exisiting routes. The concrete panelled façade relates to the existing building's plastered masonry. It has been strippped of all ornamentation and perforated for light and vegetation to penetrate and change the facade over time. Introducing a strong alternative axis that connects to the existing context was the main aspect of the San Telmo Museum that influenced The Design.
CASE STUDY

The Dovecote Studio, 2009. Snape, Suffolk. Architect: Haworth Tompkins.
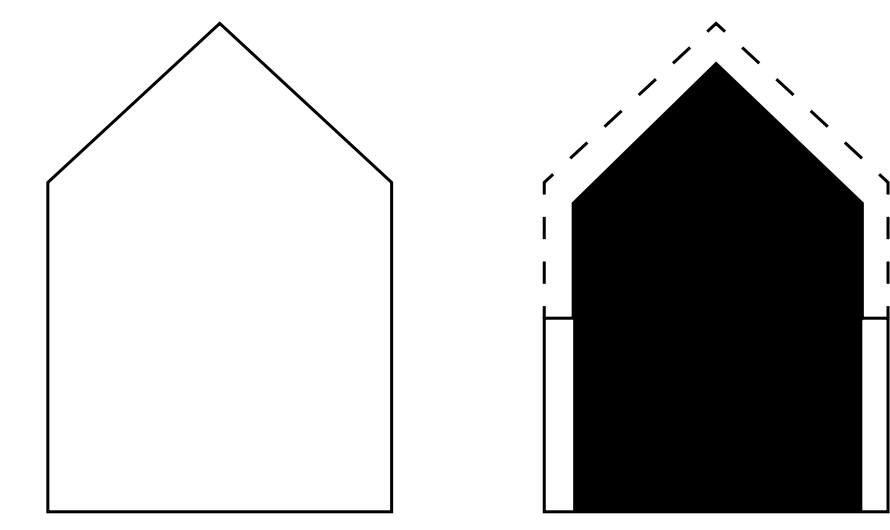

Figure 2.28 Diagram of the previous profile and the new building profile show the mimickry

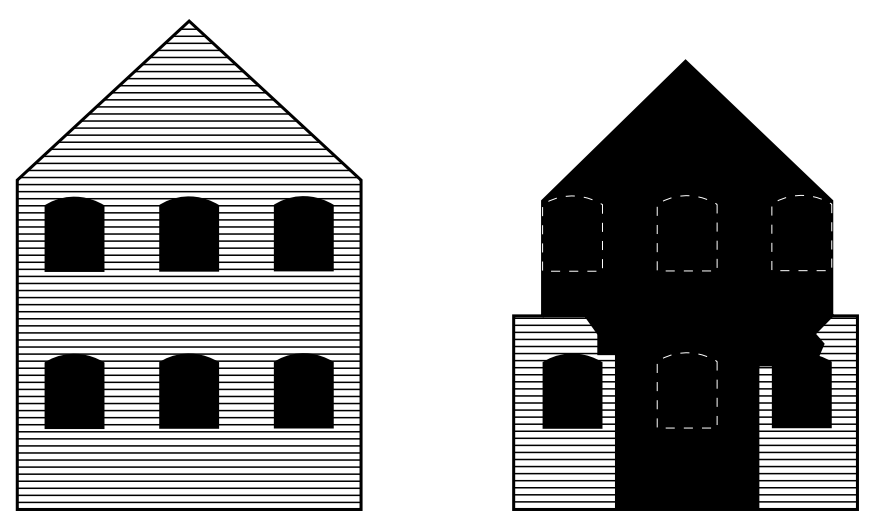

Figure 2.29 Diagram of the relationship between the existing ruins and the new intervention.

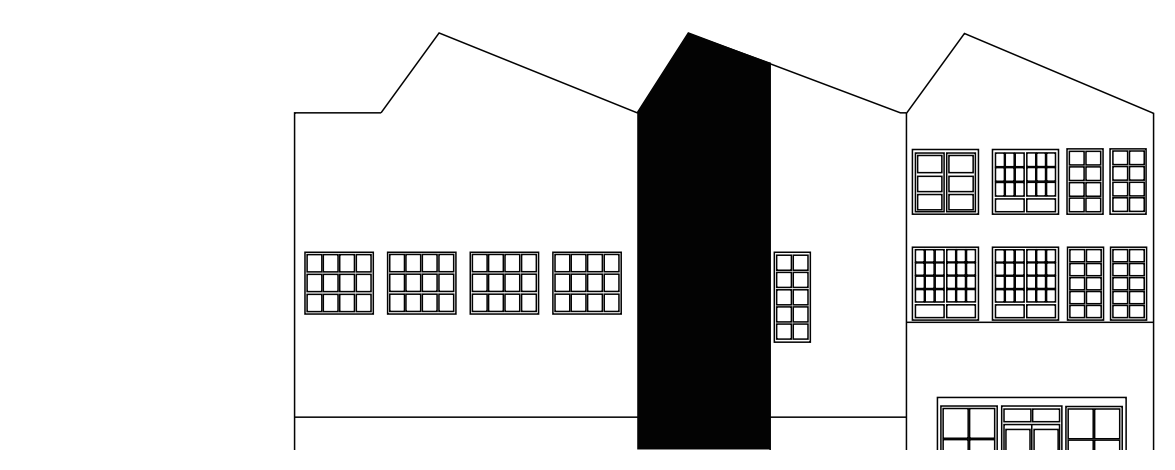

Figure 2.30 Diagram of the Cathie Building east facade with the void remored but sill maintnining the existing saw tooth roof profile

The Dovecote Studio inserts a simplified form that references the building that was previously on the site (figure 2.28). While the form is coherent with the profile of the previous buildings, the sheets of corten steel contrast with the variegated brickwork of the ruins (figure 2.29). Referencing of existing forms and contrasting materiality were aspects of this case study that influenced The Design (figure 2.30). 
CASE STUDY
Kolumba Museum, 2008. Cologne, Germany. Architect: Peter Zumthor.

c
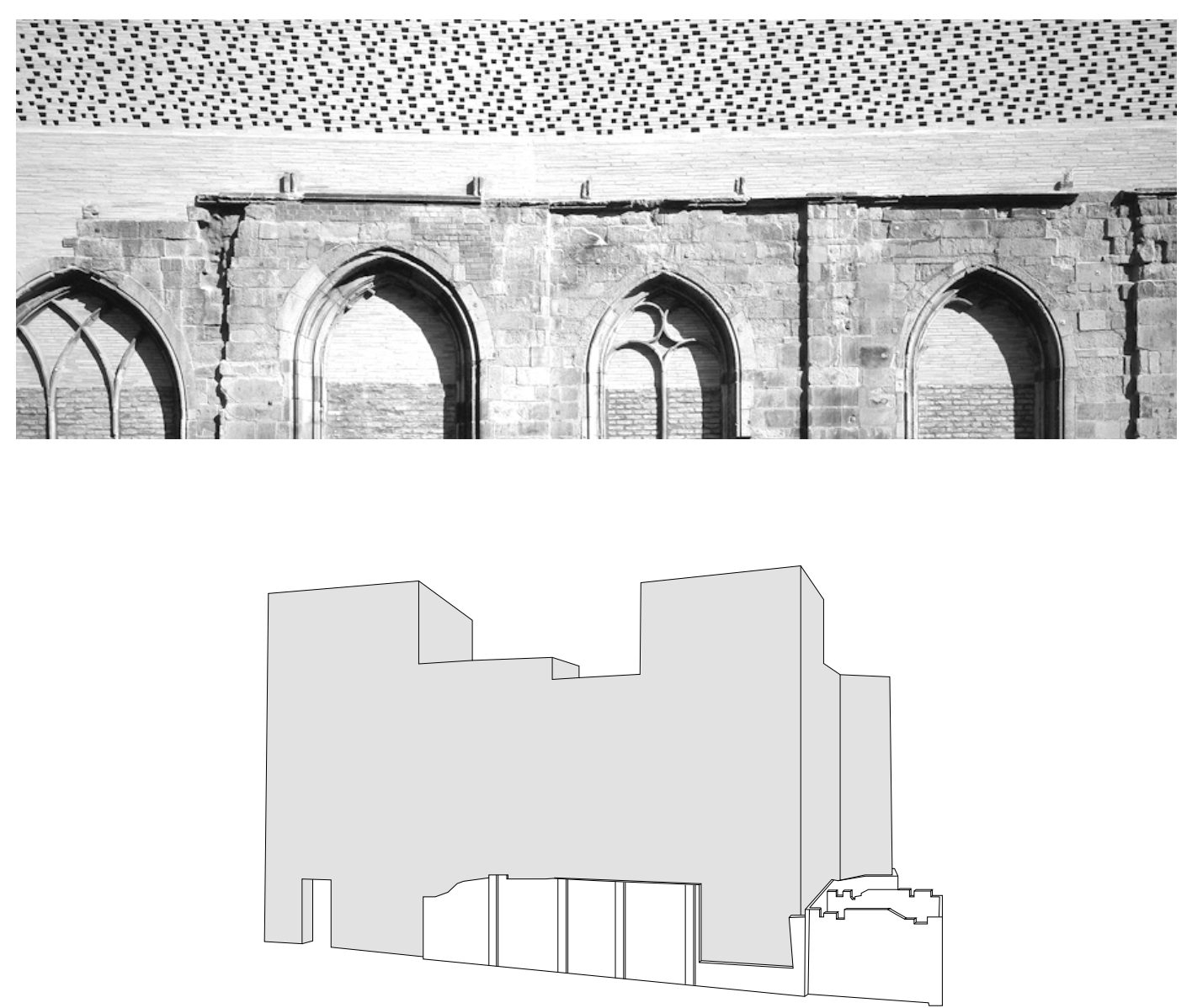

The Caixa Forum and Kolumba Museum both place bold forms on top of existing buildings or ruins (figures 2.32 and 2.33). The striking contrast between old and new in the Caixa Forum relates to its form, materiality, colour and surface perforations. The Kolumba Museum extension is similar, except for the coherent materiality between the solid brickwork of the ruins and the brick fretwork of the new form (figure 2.31). The junction between old and new is seamless with the base of the new form fitting the roof profile of the older building. These case studies informed the earlier massing experiments but not the final outcome (figures 2.34 and 2.25).

Figure 2.31 (Top) Photograph showing the join between the new mass and the existing ruins. The bricks in the new intervention were made from the existing ruins on site, allowing the colour and material palatte to be cohesive.

Figure 2.32 (Bottom) Diagram of the Kolumba Museum showing the weight of the new mass wrapping around the ruins.
0

CASE STUDY
Caixa Forum, 2001-2008. Madrid, Spain. Architect: Herzog e De Meuron.

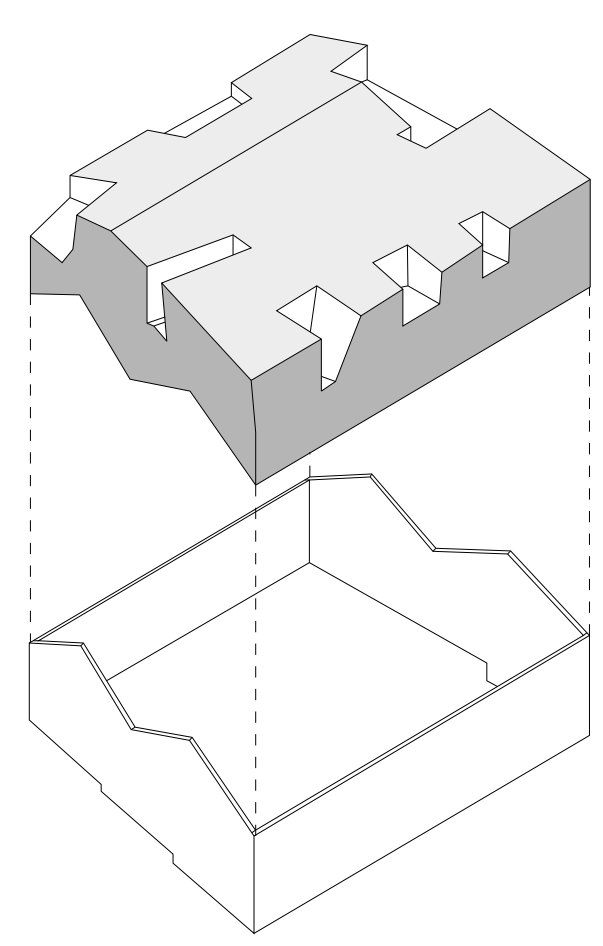

뭄믐
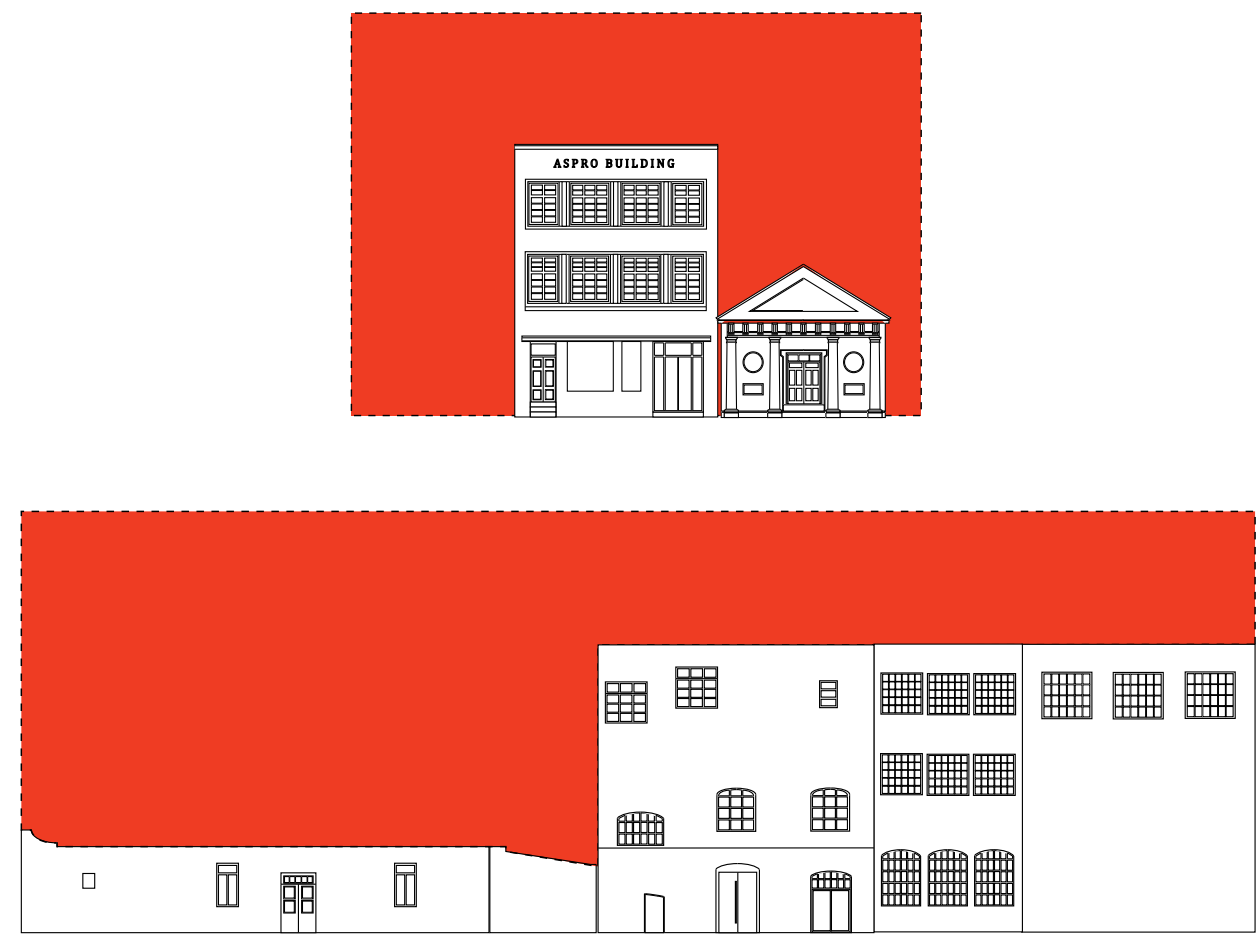

Figure 2.33 (Top) Exploded axonometric diagram of the Caixa Forum showing how the new mass sit. on top of the existing building.

Figure 2.34 (Bottom) Process diagram showing experimentation of mass on top of the existing site. 

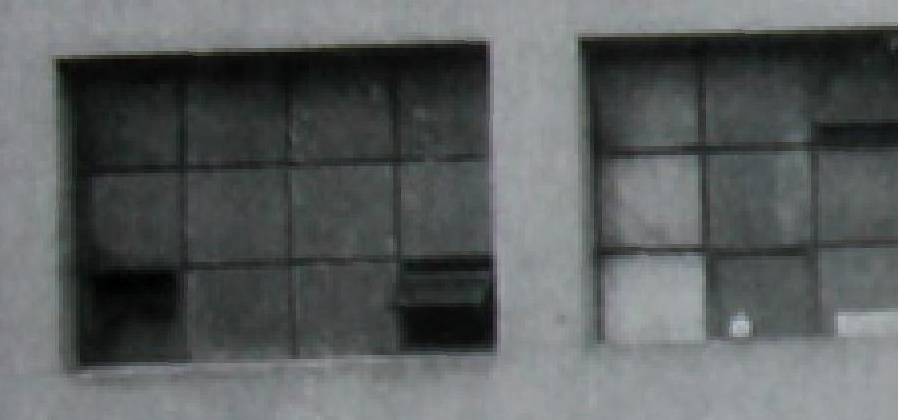


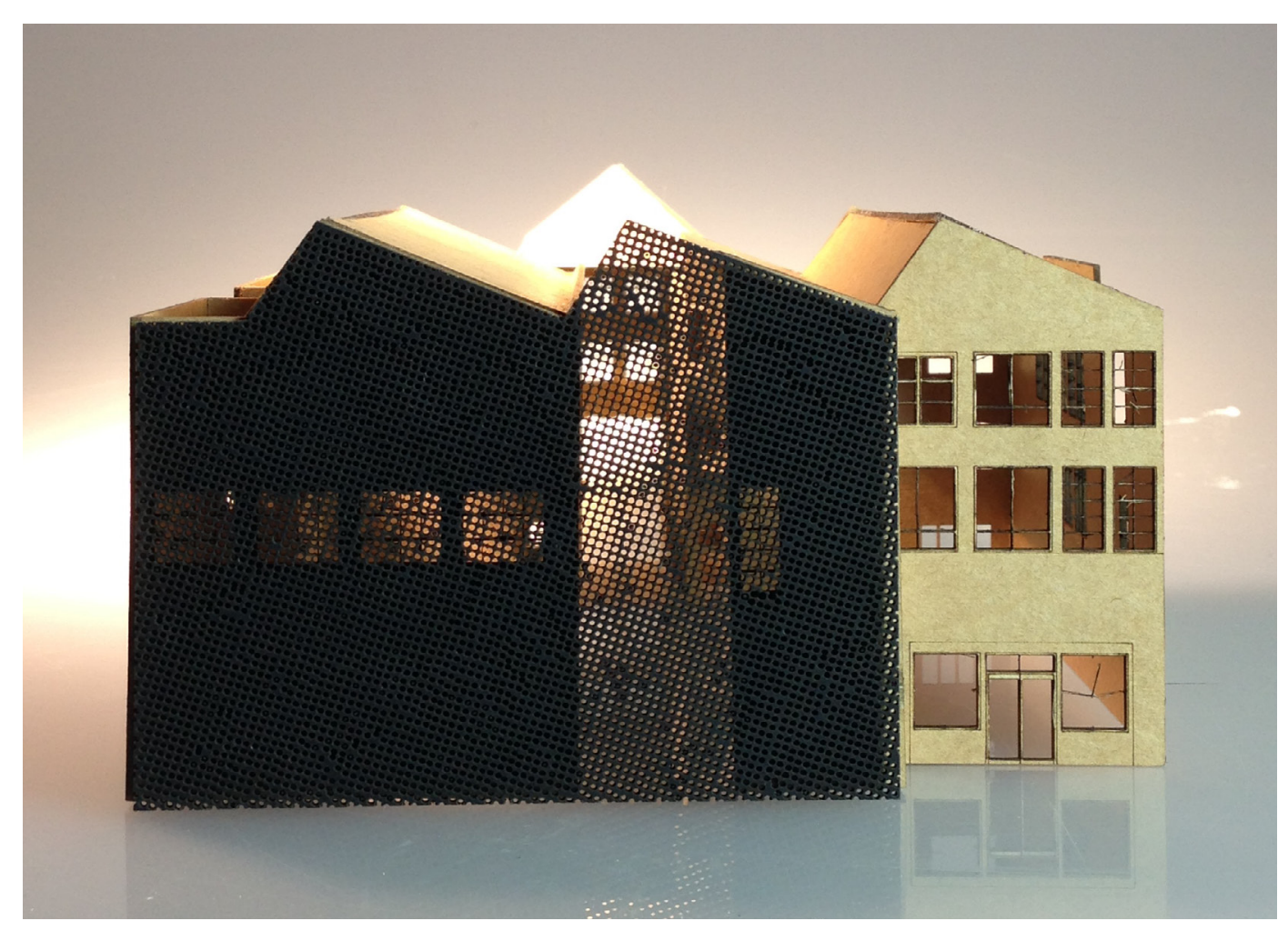

Figure 2.36 Process model experimenting with black cardboard laser cut screens. These were cut to ghos the existing Cathie Building facades, allowing the previous life of the building to still be acknowledged after the void had been inserted.

What about the facade?

The façade can indicate that a building has been upcycled. In The Design after cutting the void, perforated screens were inserted that ghost the original window compositions on the facades. These were experimented with on all facades in the early design phase. The screens only remain on the east and west facades of the Aspro Building, due to weak masonry needing support.

CASE STUDY
The Imperial Buildings, 2011. Auckland, New Zealand. Architect: Fearon Hay Architects.

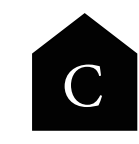

Hotel Fouquet Barrière, 2003-2006 STUDY

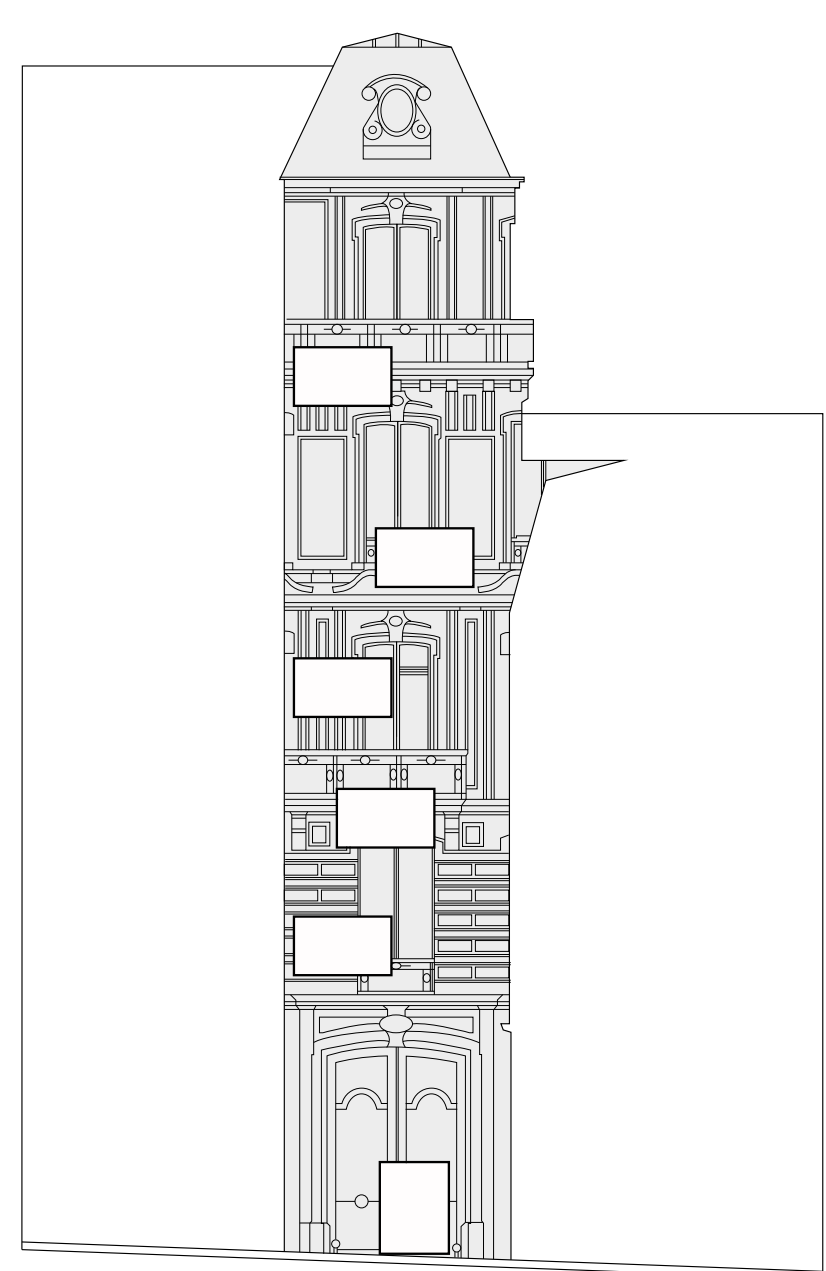

Figure 2.38 (Opposite bottom) Hotel Fouquet Barriere is an interesting interpretation of old and new. While being entirely new, it molds the ornamentation of an existing building facade. This is overlaid with modern, glazed incisions, which similarly to Imperial Lane appear to be randomly inserted within the classical composition. This case study introduced the importance of layering and potential to reference older buildings.

Figure 2.37 (Opposite top) The entrance to Imperial Lane is cut to echo the profile of the old service entrance. Other openings on the facades of the Imperial Buildings were closed in by masonry with new glazing being randomly inserted. In The Design the Marion Street entrance is cut to fit with the existing window openings at ground level. The perforated exterior screen partially covers the existimg widt 



\section{3}

LIGHTEN UP

lighteen

Verb. To make more cheerful.

II

The void introduces light into the centre of the large footprints of the existing buildings. Contained within a steel perforated screen, the public space is filled with dappled light that changes through the day. The apartments and offices opening into the void also benefit from this natural light. At night the light in the void is reversed and artificial light from the apartments shines through the perforations.

At the eastern end the void cuts through the entire height of the Cathie Building, with external glazing to provide a naturally lit space. At the western end the void curves down through the Aspro Building, contained within the existing envelope. This prevents natural light entering the void from above, allowing it to only pass through the Marion Street entrance. Pedestrians from the street are compelled to walk to the centre of the void where light spills in from the gap between the two buildings. This central light well is also a centre of activity, with a café opening out into an exterior courtyard (figures 2.45 and 2.46).

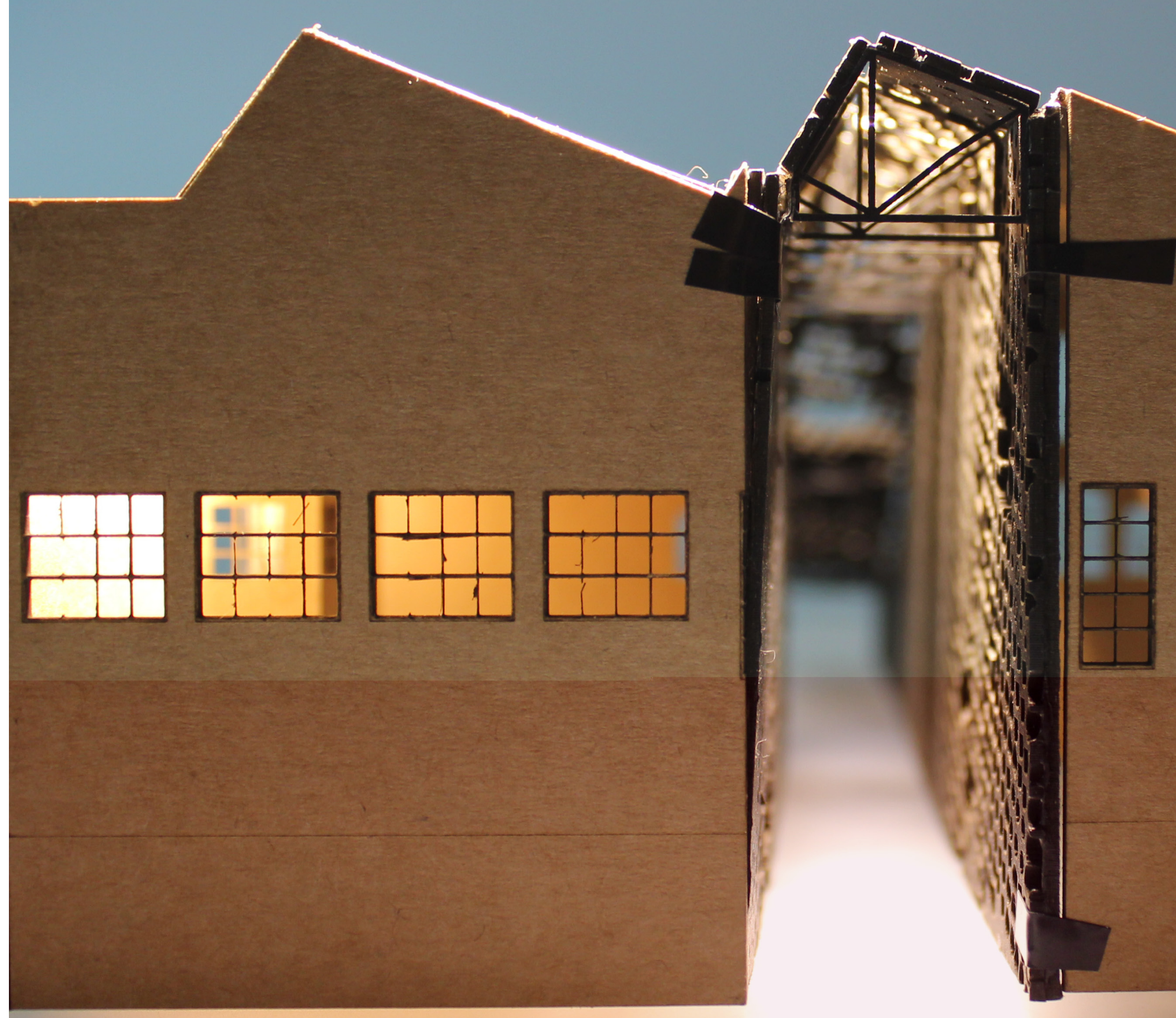

Figure 239 (Previous) Photograph of brown cardboard model of the Cathie Building from the west

므믐 elevation, with perforated laser cut screen on the east facade.

Figure 2.40 (Opposite) Photograph of brown cardboard model showing the void within the Cathie Building and the lighting effects in the surrounding spaces. 


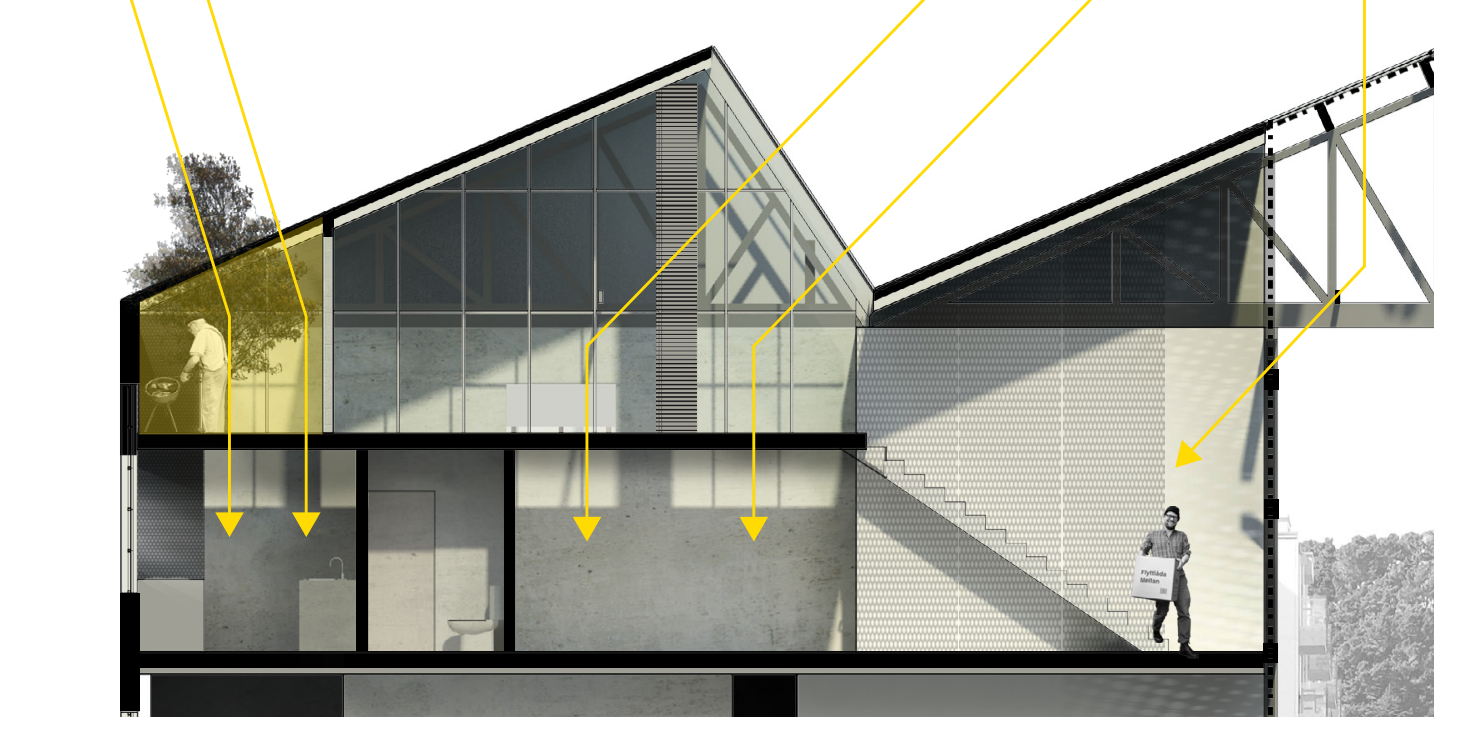

Figure 2.41 The roof cut outs and the void along with the glazed sawtooth roof allowings light into the surrounding apartments

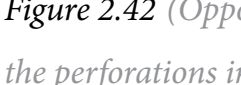

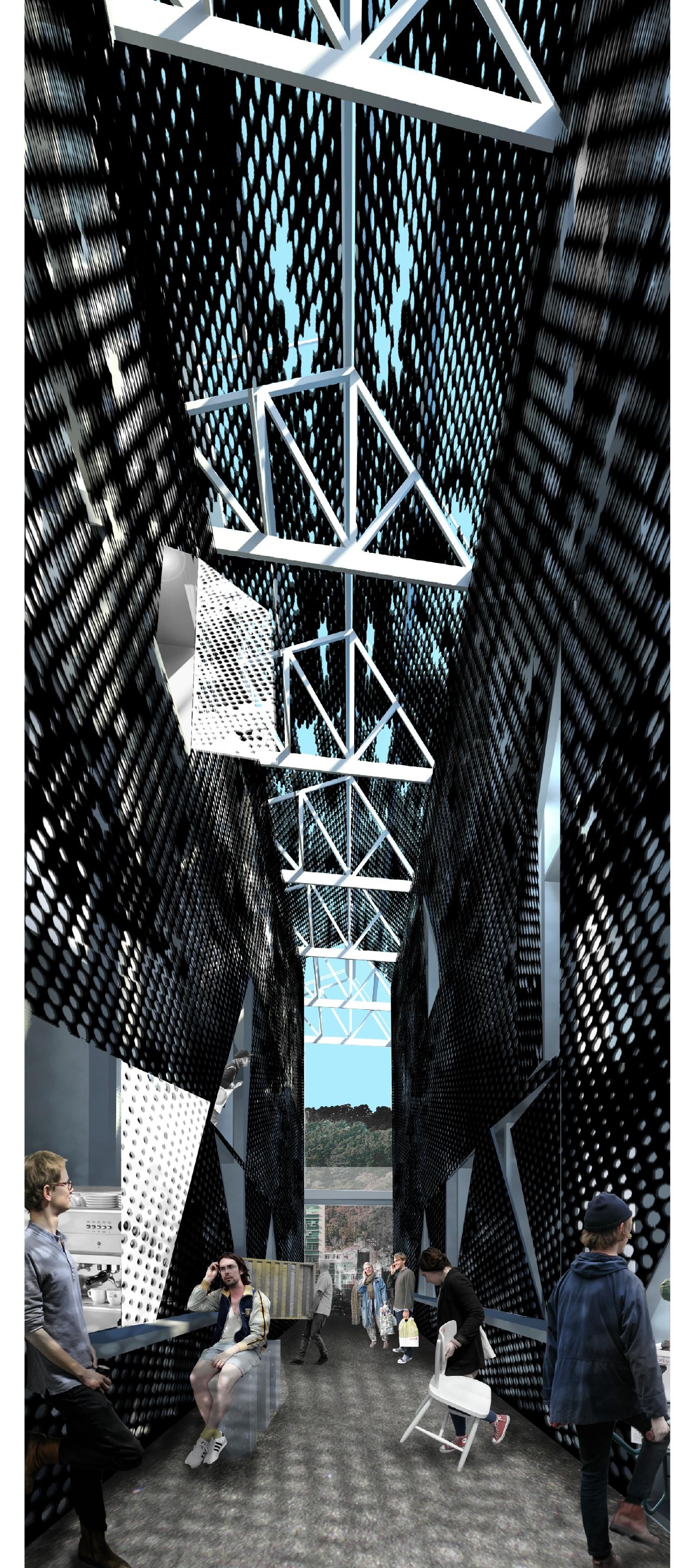


In the words of Walter Benjamin

"These arcades, a recent invention of industrial luxury", states an illustrated guide to Paris of 1852, "are glass-roofed, marble-paneled corridors extending through whole blocks of buildings, whose owners have joined together for such enterprises. Lining both sides of these corridors, which get their light from above, are the most elegant shops, so that the passage is a city, a world in miniature'

(Benjamin, 19).

Geist analysed arcades and observed that a successful arcade must be sky lit through the roof (20). Similarly. Conroy (15) notes that a glazed roof is the most essential element of the arcade as it provides a space for an undisturbed promenade (Pound, 10).

$\mathbf{I}$

After a number of design experiments of different forms it was found a continuous arcade of single height and roof lighting failed to engage with the context. Lowering the void at the Marion Street end changed the light and spatial conditions, acknowledging the transition between two buildings. The void functioning as a connection through the block ensures pedestrian movement through the space even in the section which is not naturally lit.

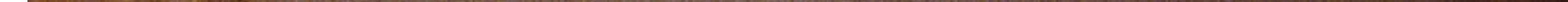



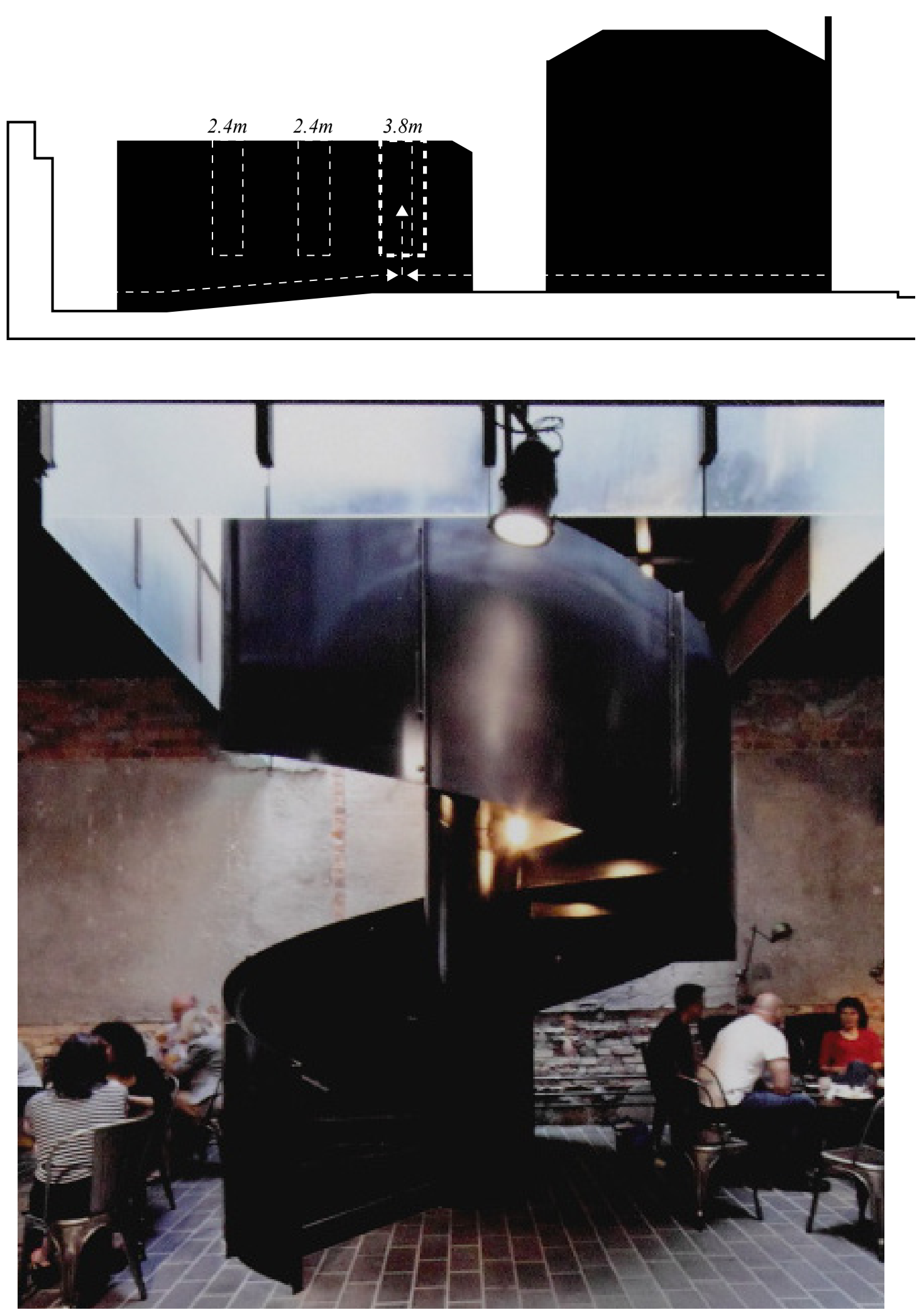

c

In the Imperial Buildings by Fearon and Hay Architects, there are three light wells that penetrate to the ground floor. The central light well has been widened, to allow to a spiral staircase accessing the upper levels. This allows more light into the centre of the laneway, drawing people into the centre of the project.

Figure 2.44 (Top) Diagram showing the widening of the central light well to allow for vertical circulation. Figure 2.45 (Bottom) Photograph of the central arcade space, showing people gathering where there is more natural light.
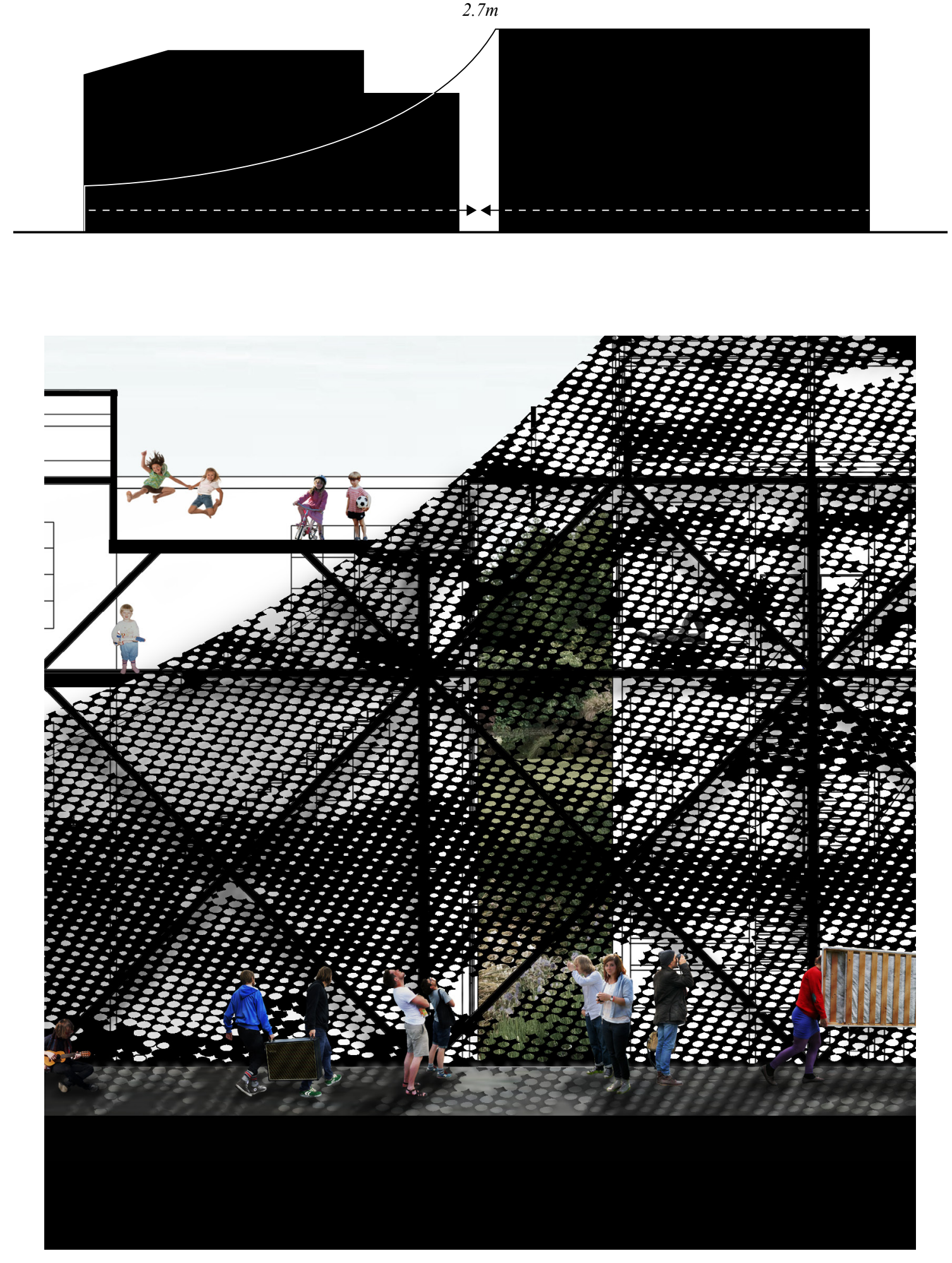

In the design scheme there is a 2.7 metre gap between the two buildings where the laneway is not
enclosed within the existing building envelopes. Similarly to Fearon and Hay's Imperial Lane, this
central light well draws people into the centre of the void.

Figure 2.46 (Top) Diagram showing the gap between the Aspro Building and the Cathie Building and how this lets natural light into the central space, drawing pedestrians to this poin. Figure 2.47 (Bottom) Perspective render of the courtyard that is located in this central light point. 
CASE STUDY

The James Cook Arcade, 1979. Wellington, New Zealand. Architect: Roger Walker and Gus Watt

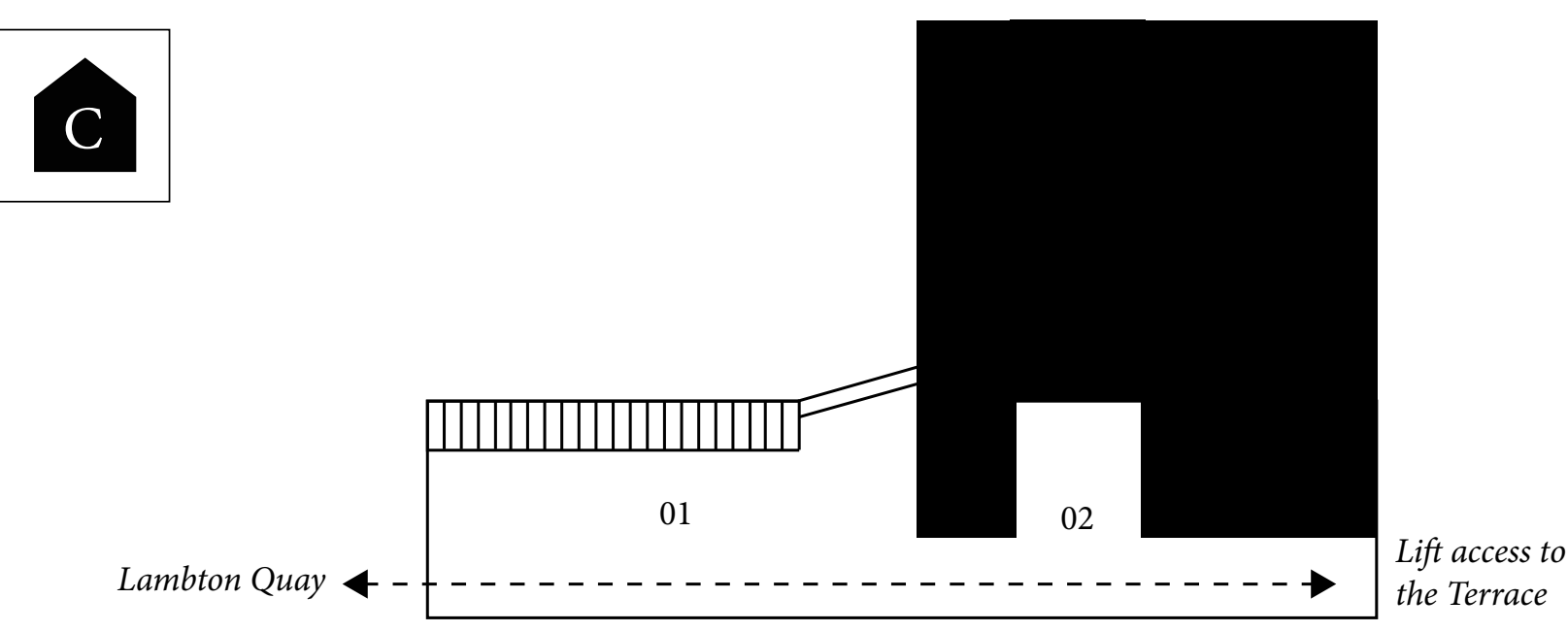

\section{$\mathbf{I}$}

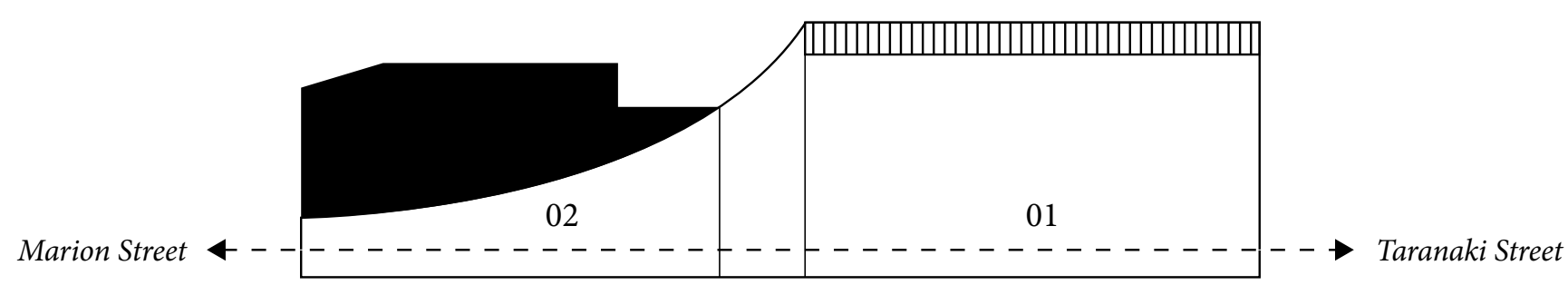

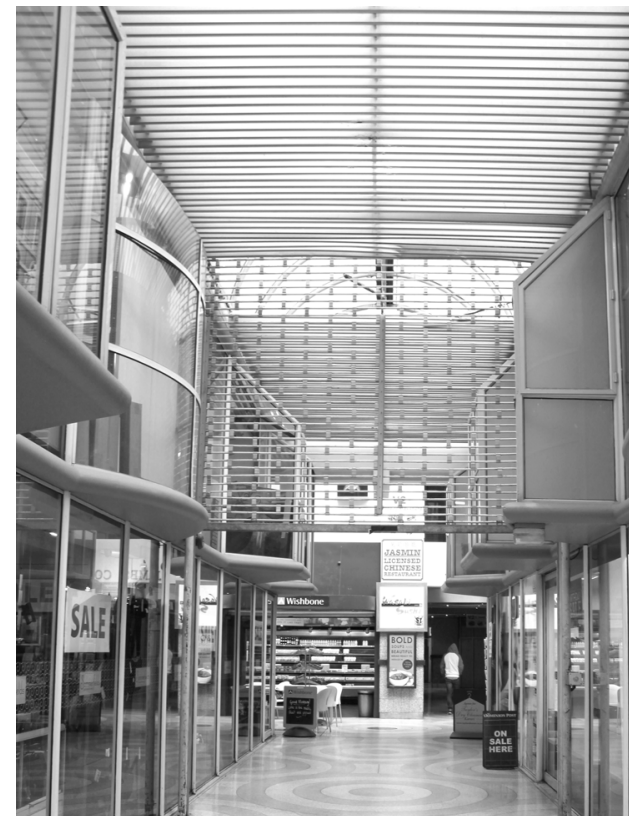

01 The glazed entrance off Lambton Quay.

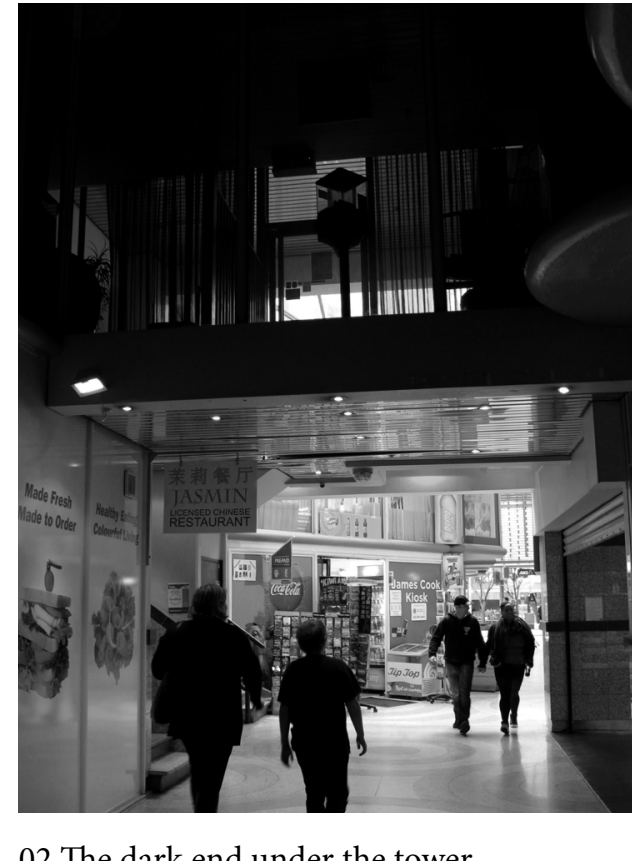

02 The dark end under the tower.

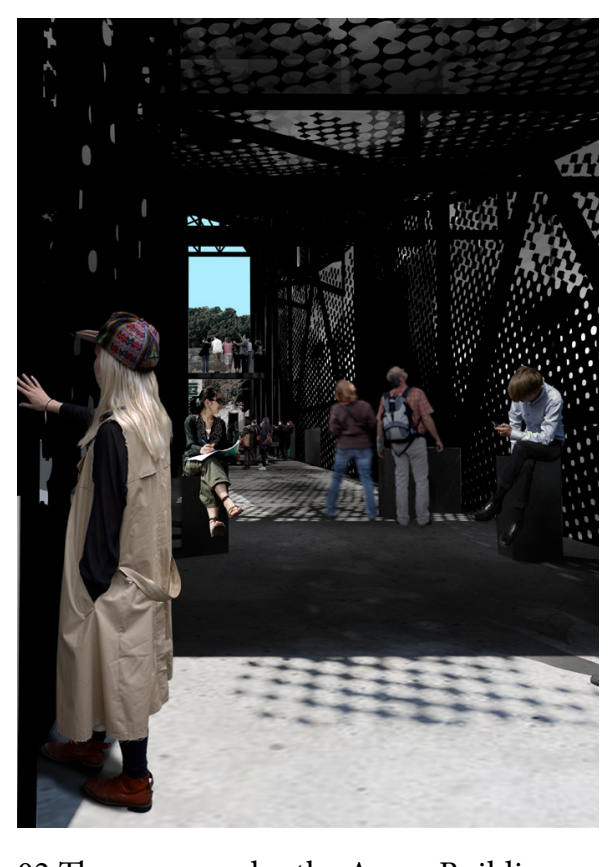

02 The curve under the Aspro Building.

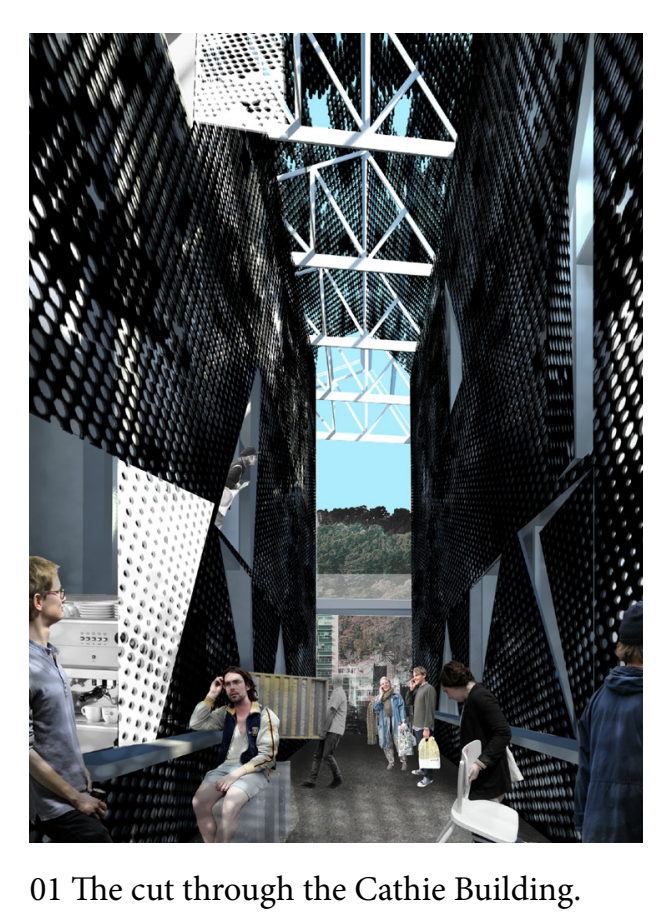

Figure 250 (Top) Diagram of the longitudinal section of The Design, showing how the change in height and transition between the two buildings alters the pedestrian experience. Because the western end of the void curves under the Aspro Building the space is far darker at one end than the other

Figure 2.51 (Bottom) This change in lighting is illustrated in two renders from either end of the interio. 

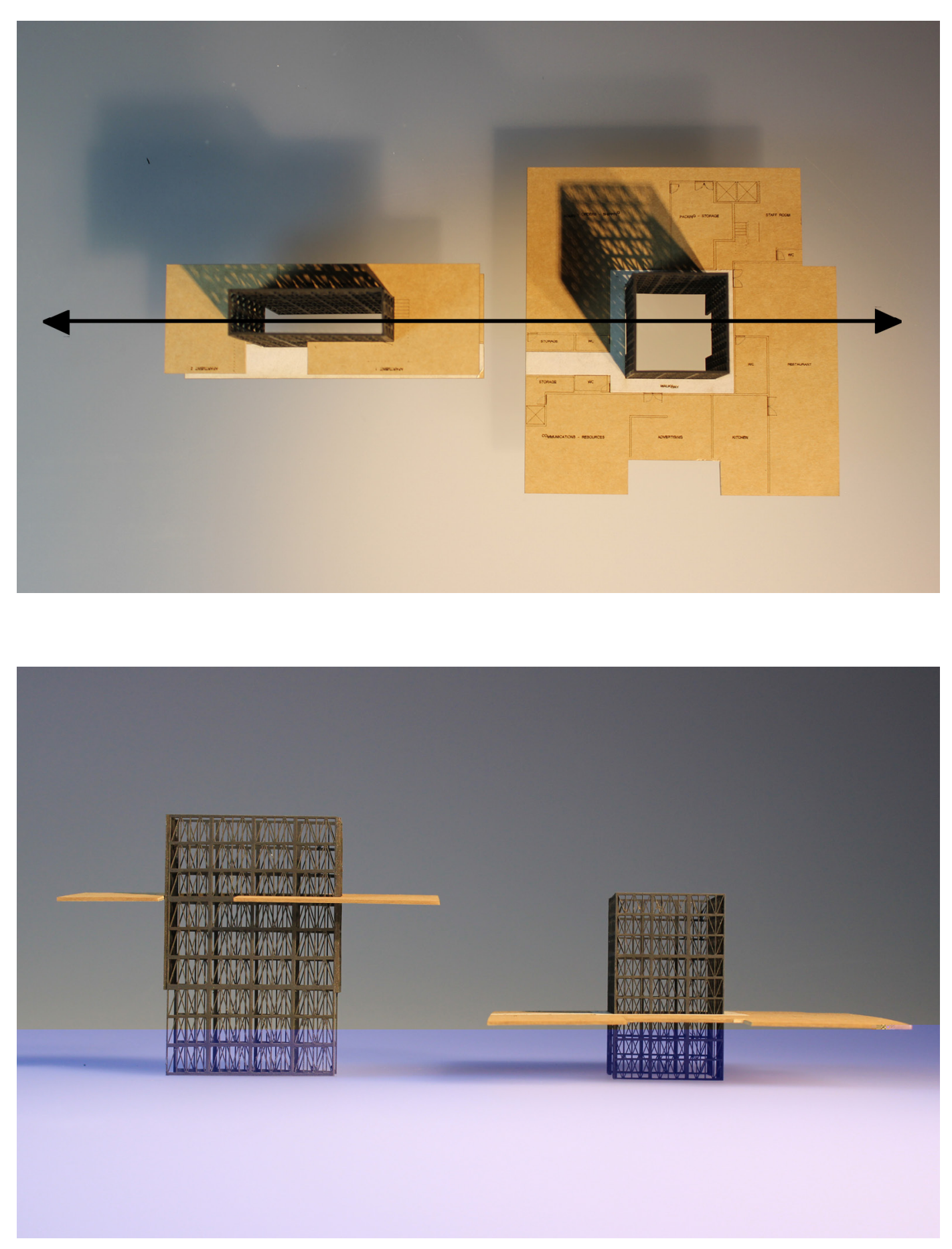

Figure 2.52 Photographs of black cardboard laser cut structural voids cutting through the floorplates of the existing two buildings (brown cardboard). These are shown in plan at the top and in elevation at the bottom.

Along the line

Cardboard models were used to test cutting a large atrium out of each building (figure 2.52). These $\square$ full height cuts would act as light wells and provide strengthening for the prone buildings. Refer to structure section on page 50 for more on these experiments. 
link

Verb. To make, form, or suggest a connection with or between.

The Design is all about links through the city, through the block and within the site.

"The porous city concerns itself with how the interior can reach out and connect to its urban context, and conversely how such urban interiors activate the city; generating a rich dialogue between interior and exterior atmospheric phenomena, and how these contribute to our experience of "urbanity."

(Di Palma, 148)

Inserting the void through the existing building envelope creates an arcade with a controlled internal environment. This eliminates the need for awnings, reconnecting the pedestrian with the upper levels of the building. This shelter has particular value in Wellington where street conditions can be unpleasant due to wind and rain.

The Design encourages interactions between users on different storeys through the porous pattern of the screens. The patterned panels pivot, allowing the private spaces to open out and become a part of the screens. The patterned panels pivot, allowing the private spaces to open out and become a part
of the offices and restaurant operate from the first floor, pedestrian access is largely at the ground level. The staircases provide the perpendicular connectivity (figure 2.57 ). This integration mean the boundaries between public and private spaces are blurred and flexible. As a result pedestrians are more connected with the upper levels of the building, in contrast to the usual disconnection in streets. This design outcome also accentuates the pattern in the screen and the verticality of the space.
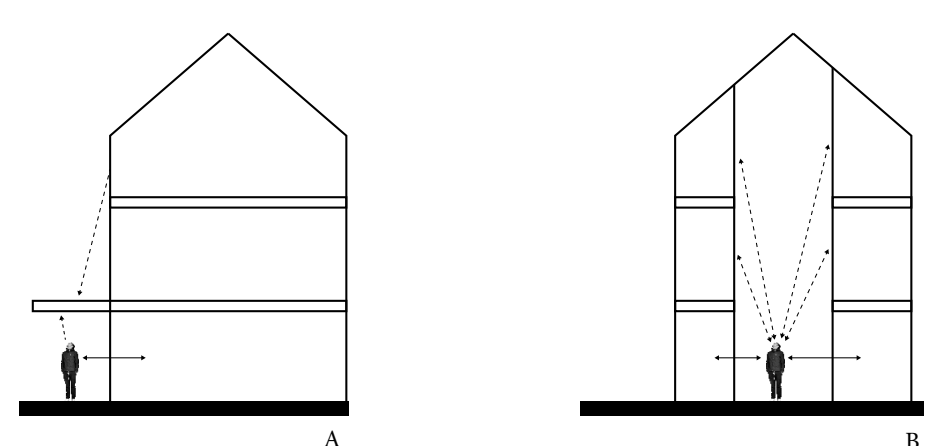

Figure 2.53 (Above) Diagram showing how existing building envelope can be used to eliminate the need for awnings.

Figure 2.54 (Opposite) Photograph of clear perspex model of the cut out, representing the transparenc) and vertical connections created through The Design.

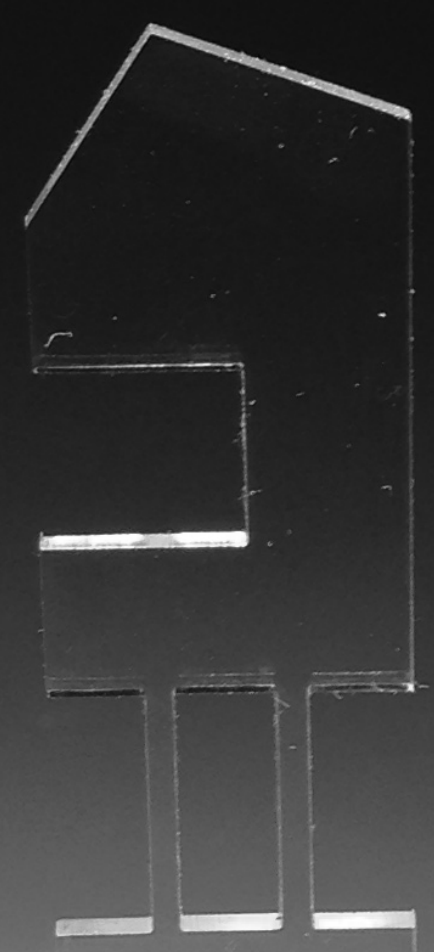




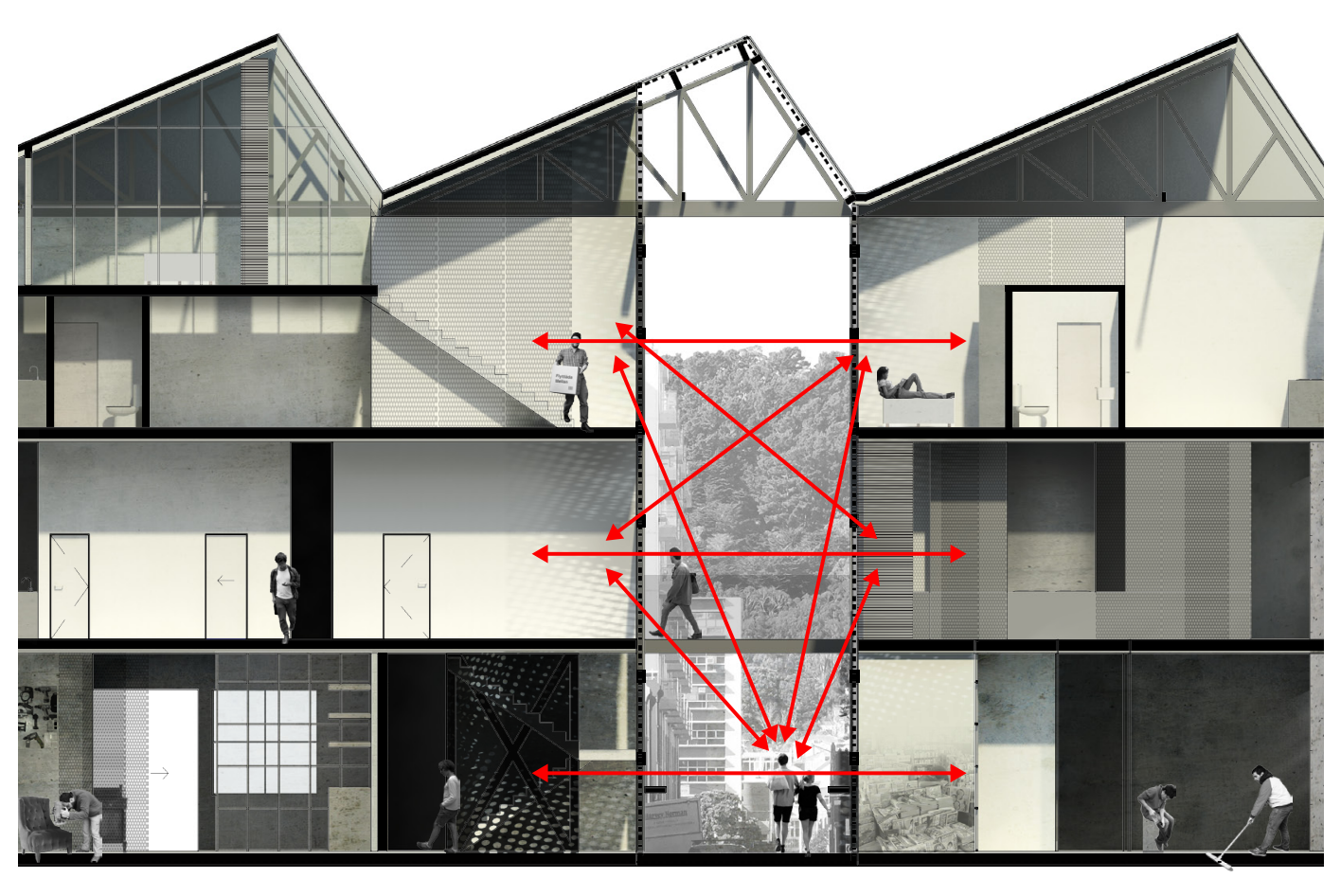

Figure 2.55 Transverse section through the Cathie Building showing connection across the void and between various levels due to the porosity of the patterned screen and the lack of awnings or setbacks Note the horizontal element passing through the void is the bridge and therefore not inhibiting vertical connection along the length of the space.

\section{IIUML}

Figure 2.56 Transverse section diagrams through four standard arcade types (chosen from Geist's stud) of 500 arcades).

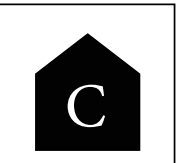

Thats done?

These case studies show how connection within the arcade is inhibited through the use of setbacks and balconies. The largely solid vertical structure between the arcades and surrounding spaces limits visual permeability.
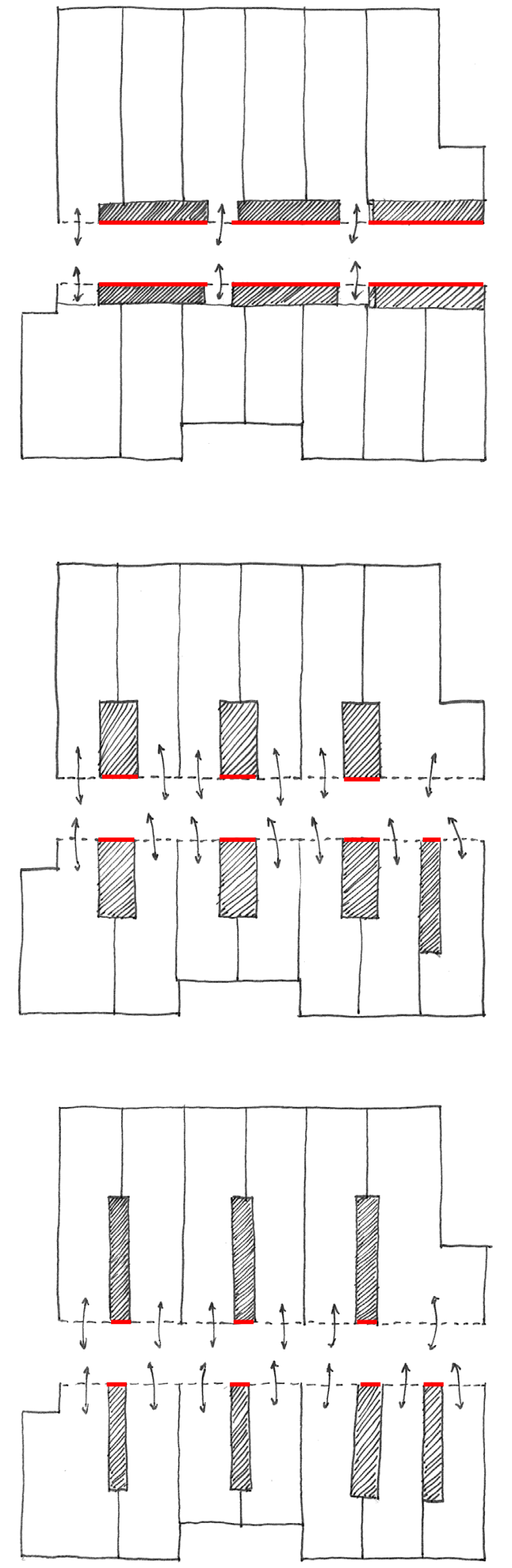

Along the line

Figure 2.57 Flootplan diagrams showing various staircase lavouts to access the apartments on the second floor. The top diagram shows how vertical circulation could cut off the connection between the apartments and the public space below. The second diagram shows the implications of running the circulation perpendicular to the main axis. The bottom diagram maintains this perpendicular orientation, however uses narrow single staircases. The third options provides the most connection between pedestrians and the apartments. It also allows for a variation of activity and use to occur along the the edges of the void. 


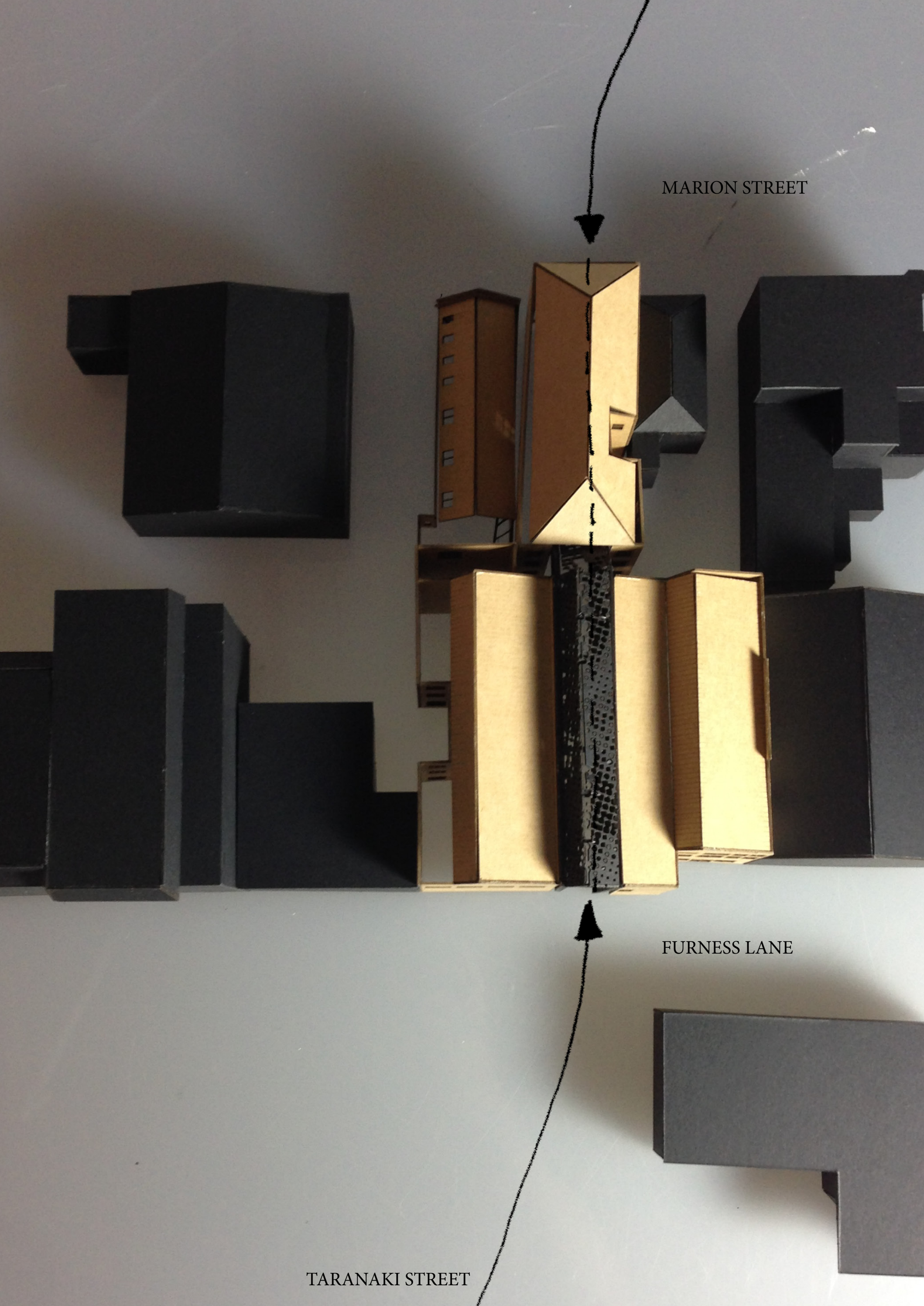

Horizontal connection

I

Laneways and arcades restructure a city grid and create connections. Dead end laneways and large impenetrable blocks mean the pedestrian network in Wellington is disconnected. As previously mentioned in the introduction, The Design links a city block with the regularly used pedestrian routes. The Marion Street end of the void connects with Swan Lane arcade, which runs through to Cuba Street. The Taranaki Street end of the void connects to Furness Lane, which is currently a no-exit service lane (figure 2.58). At a wider scale the void connects across Taranaki Street to Jesse Street and a network of smaller streets and lanes. The scheme completes a connection across the city from east to west, providing a route from Kelburn to Mount Victoria. Reconnecting the existing street system and adding new public spaces to the grid has the potential to enhance the Wellington pedestrian experience.

\section{Who said}

The concept of an 'interior city' has been achieved in Melbourne where you can walk under cover from one side of the city to the other (Di Palma 21) In Melboune the blocks are $200 \mathrm{~m}$ by $200 \mathrm{~T}$ intersected by a secondary street system running east-west. A third street network of laneways and internal arcades cut through the city in a north-south direction. "The many small back lanes and covered arcades provide rhythm, and variation to the otherwise rather rigid street pattern" (Gehl 2003, 80). This layered street network is an interesting city for pedestrians to explore. These arcades and laneways are used as both destinations and thoroughfares depending on what activities are offered within the spaces.

A typological study showed that arcades may vary in size, length, form and style, but the fundamental principle that determines the success of an arcade is reconnecting the city's pedestrian network.

Johan Geist describes in 'Arcades: The History of a Building Type':

It offers public space on private property as well as an easing of traffic congestion, a shor

cut, protection from the weather and an area accessible only to pedestrians. However,

can thrive only if it lies in the main commercial district and connects two streets which are

equally heavily frequented (4)

Figure 2.58 (Opposite) Photograph of the existing site (brown cardboard) showing the void from above and illustrating the horizontal connection throuth the block. The context is modeled in black cerdboant. 


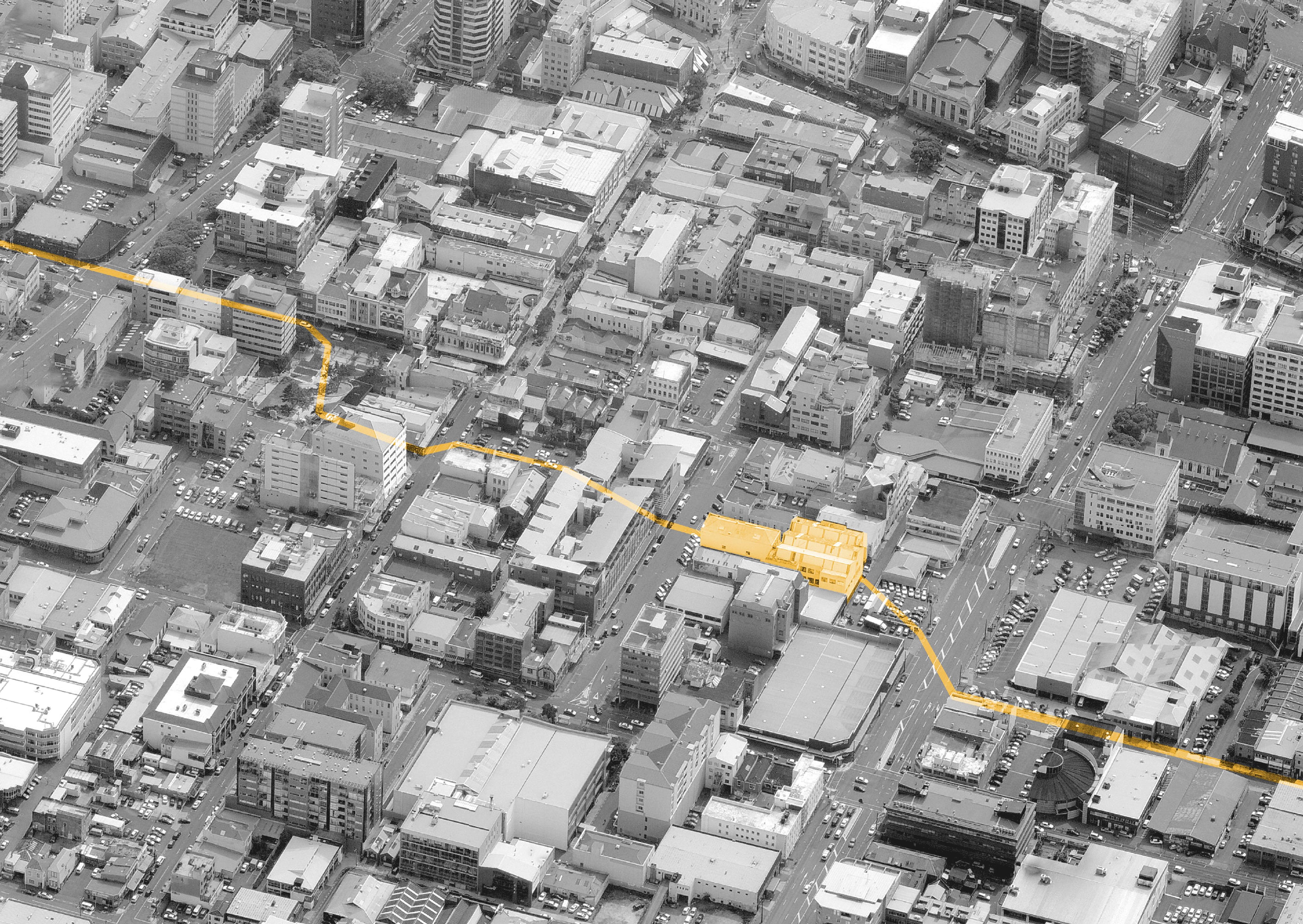


Mapping these connections within and beyond the site was an important phase in the design process. Straight lines were traced between various landmarks and pedestrian routes in the city. Connection between other earthquake prone buildings were also considered in this process, with the potential to create a web of safe and sheltered pedestrian routes through Wellington (figure 2.60). Although a number of routes through the site were considered, these experiments were discarded for a simple cut through the buildings. This bold approach worked well with the structure and aesthetic features of the existing buildings and connected directly with the surrounding lane system.

This webbing experiment had obvious limitations. Although it drew connections between the earthquake prone buildings in the city, it ignores the existing street grid. This was a reasonably severe limitation to this method as the lines of connection would be significantly skewed when imposed over the street network

Petra Blaisse talks about implicating this mapping method in her design of urban park Giardini di Porta Nuova in Milan, Italy. “A web of paths now covered the site, with irregularly shaped plots left between the lines. The graphic strength of the connective web was evident" (132). She also comments that straight lines create connections and orchestrate efficient movement (132).

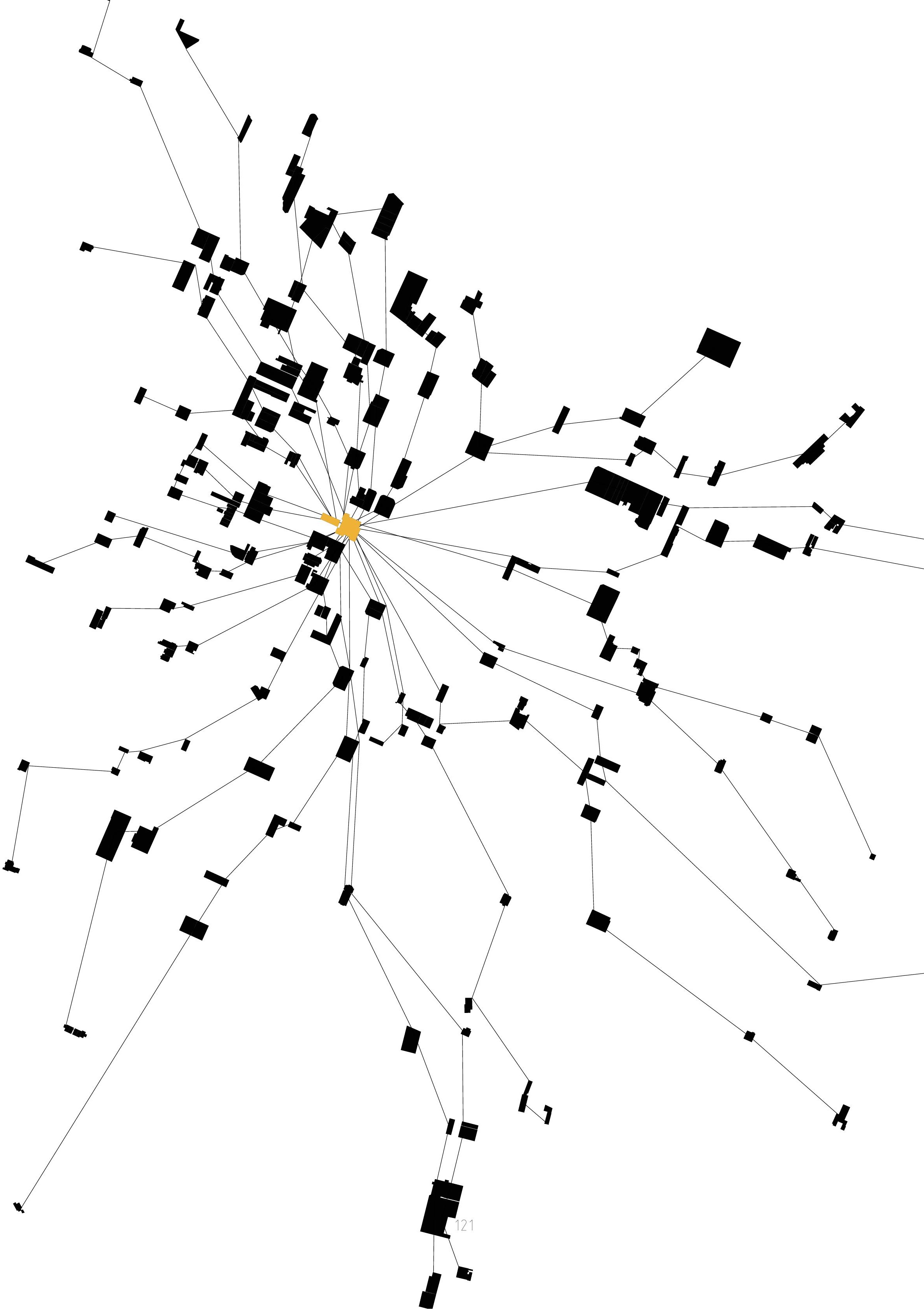



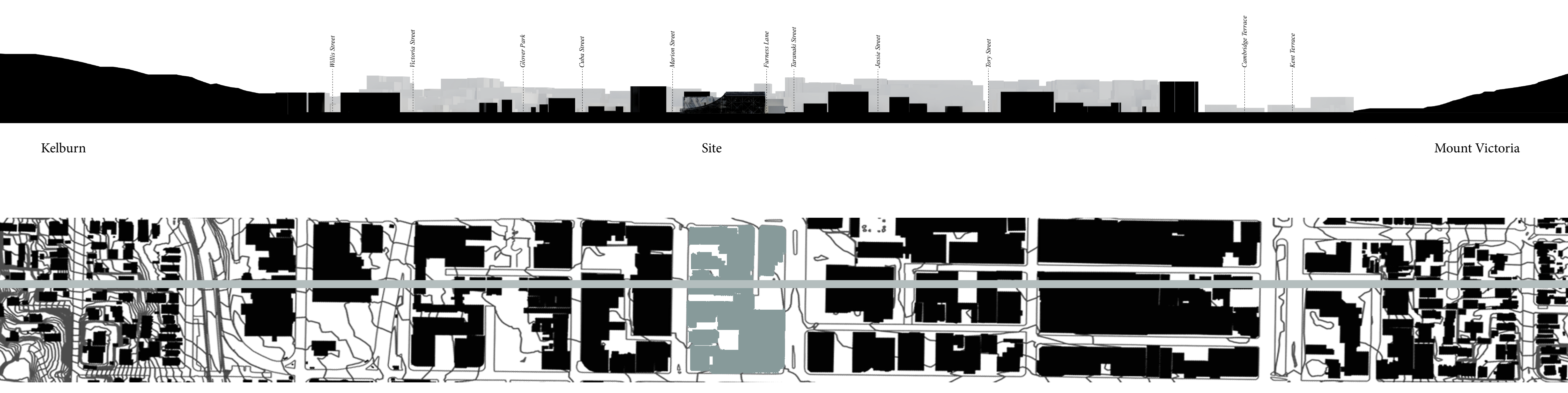


$$
05
$$

BIZARRE BAZAAR

\section{$\mathbf{I}$}

baz•aar

Noun. A market in a Middle Eastern country

In The Design the void is an extension and intensification of the vibrancy of Wellington, rather than

a retreat away from it. The void is the main public space, a backbone of activity, that cuts through the block.

The void is lined with small booths for people to either set up temporary or more permanent stalls. These bazaar-style vendors activate the edges. At the Marion Street entrance a bar opens into the void, with benches running along the length of the passage. These provide a ledge for people to lean or sit, to socialise or observe. Interaction between vendors and pedestrians is encouraged by the permeable and adjustable screens separating the spaces. The vendor's stalls are either partially enclosed or can be opened out to become part of the void.
A diverse mix of uses has been integrated into the buildings.

The primary use of the ground floor of the Cathie Building is an upcycled furniture factory. This relates to other industrial uses on the block: various second hand furniture shops, interior design firms, paint and fabric factories and suppliers (figure 2.62). The process of upcycling the furniture is carried out in a circular movement around the outside of the floor plan, crossing over the void at two points. This allows pedestrians to engage with the upcycling process in two ways: directly in the void and indirectly through the perforated screens.

The first floor of the Cathie Building has a mix of use - office space for the furniture factory, a restaurant and three small apartments. The latter have views into the void, into spaces between the buildings or to Mt Victoria. A pedestrian bridge connects the offices on either side of the void.

The second floors of both buildings have single use: thirteen apartments in the Cathie Building and a kindergarten in the Aspro Building. The type of apartments range from one bedroom studio to larger two bedroom apartments. Four of the apartments have access to outdoor roof space created by peeling back the existing sawtooth roof line of the Cathie Building. The kindergarten has a larger play area that sinks into the existing roofspace of the Aspro Building. These areas give residents and users the opportunity for outdoor activities. They also create light wells into the apartments and kindergarten. 
? In his analysis of the arcade, philosopher Walter Benjamin describes the metaphorical figure of the 'flâneur', an urban explorer who wanders through the city in order to experience it (Benjamin, 895), In the described experience of the flanneur, there is a slowed sense of movement within the chaos of the city. The arcade is portrayed as a retreat from the city; a known and idle interior. The Design proposal challenges this purposeful segregation between the street and the arcade.

The eastern bazaar is a typology which is less subdued than an arcade. The distinctive feature of a bazaar is the open vending stand, a feature that differs considerably from the closed glass store front of the arcade (Geist, 5). In his book 'A Pattern Language', Christopher Alexander describes the edge effect and edge zones in public spaces: 'If the edge fails, then the space never becomes lively' (Gehl, 150). Alexander emphasises the importance of giving the edge volume rather than an interface with no thickness. The edges of a space should be able to be inhabited (Alexander, 755).

Urban sociologist Jane Jacobs advocates for high density mixed use communities with eyes on the street at all times (213). This creates safe places for social interactions. In The Design, the semitransparent and adjustable screens between the surrounding spaces and the void provide many opportunities for surveillance and activation along the edges.
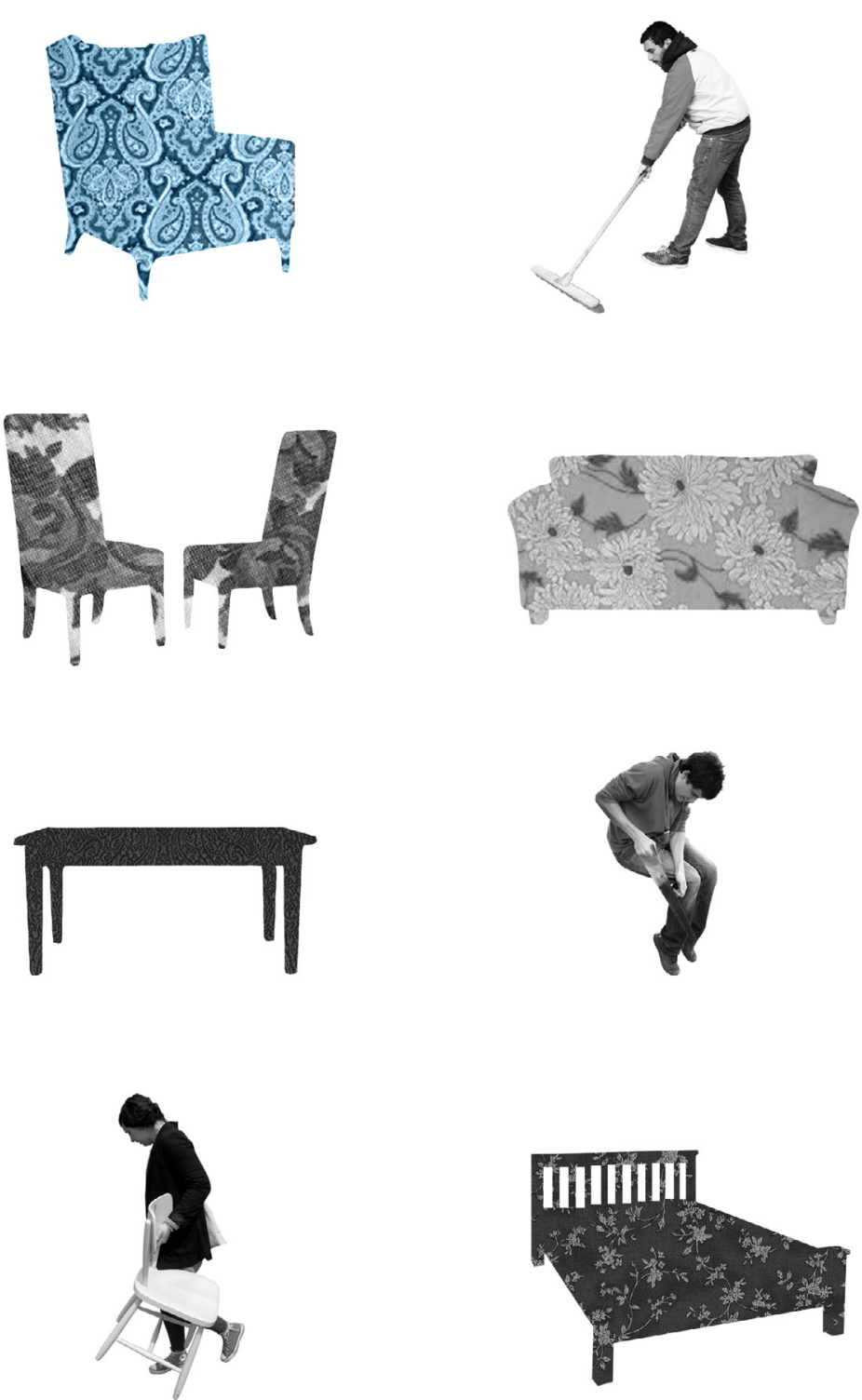
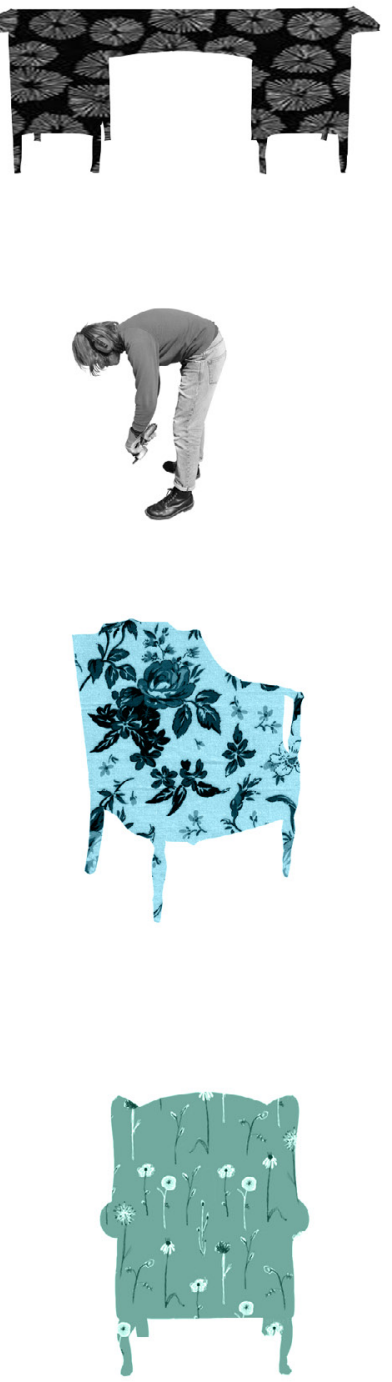


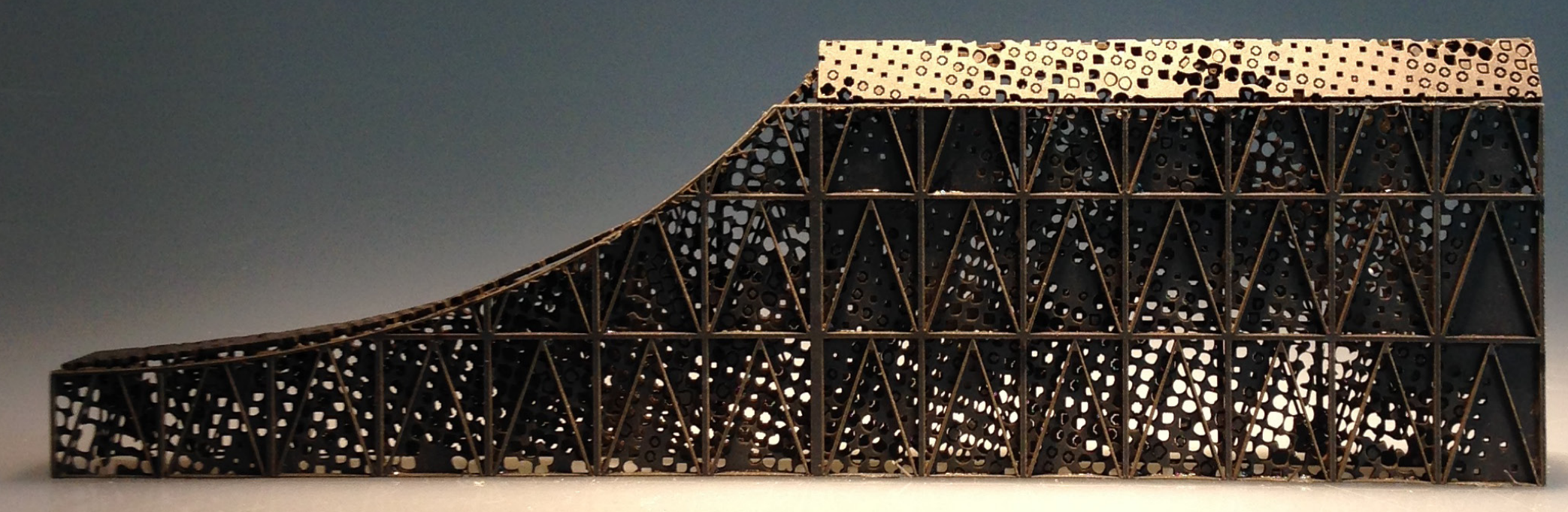

\section{CURVE}

The central section of the void is draped in a swooping curve from three storeys at Taranaki Street to one storey at Marion Street. 


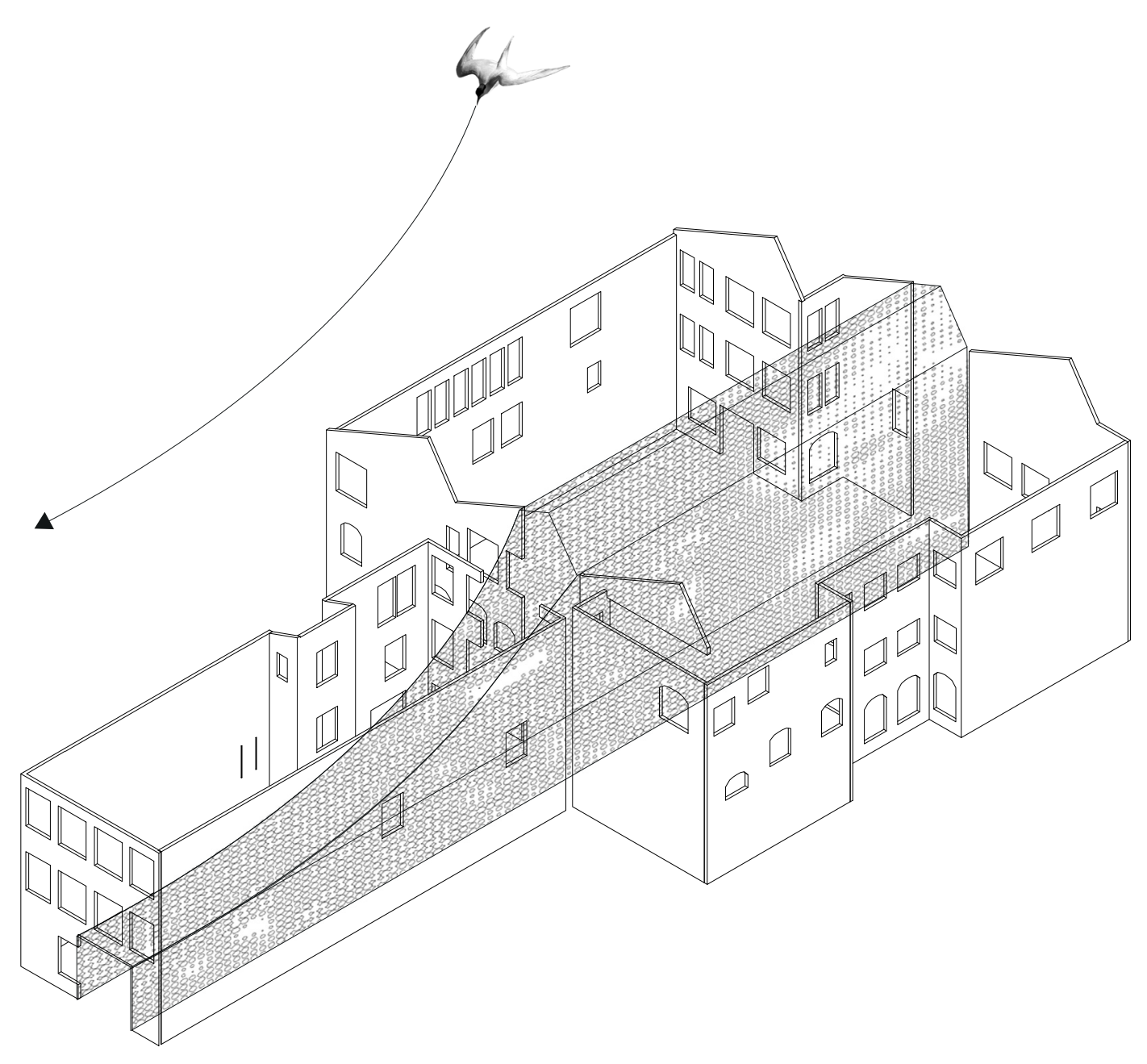

CURVE

01
The Swoop

Exhilaration \& Awe

Alice in Wonderland

Commercial Cathedral

Figure 3.1 (Previous) Photograph of the elevation of the black cardboard model of the void showing the

Figure 3.2 (Above) Axonometric diagram of the Aspro and Cathie Buildings with the curve situated inside. There is a bird moving in a swooping dive above the curve. 

swoops downwards through the Aspro Building to the Marion Street entrance (figure 3.2). The structure and screens around this curve both strengthen the existing buildings and create a unique public space. The shape was determined through experimentation with; floor area requirements within the buildings, the visual impact from within the void and the relationship to the new programmes and surrounding streets.

The outcome differs from both the standard approach to seismic strengthening and the usual form of an arcade. A single height cut through the block, typical of a usual arcade, would provide a monotonous journey for pedestrians. Experiments of different ceiling heights and ground planes were carried out to allow for a varying experience for the pedestrian. 
Whats done?

From Antoni Gaudi to Zaha Hadid, swooped or curved building forms have been prevalent in

architecture. One of the most striking and relevant examples is the work of Oscar Niemeyer, who

combines curves with hard lined geometries and modernist simplicity.

It is not the right angle that attracts me. Nor the straight line, tough, inflexible, created

by man. What attracts me is the free, sensual curve. The curve I find in the mountains of

my country, in the sinuous course of its rivers, in the waves of the sea, in the clouds of the

sky, in the body of the favourite woman. Of curves is made all the universe.

(Niemeyer, 3$)$

The following ase strdes andyse the curve in two of Niemeyer's projects:

Cathedral of Brasilia, 1960-1970

Palácio do Planalto, Brasilia, 1966

More recently, S.A.M.O.O Architects have designed a national library in Senjing City, Korea. Unlike

entirety. Although the subtle gradient of the arc is similar to The Design, it is very much an isolated

piece of architecture and has a lack of integration with other geometries. Due to the existing buildings

in The Design, more of a dialogue between curves and the rectilinear forms on site is necessary.

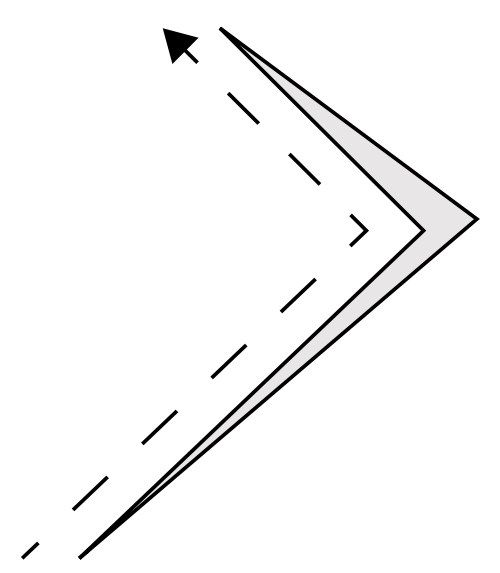

vs.
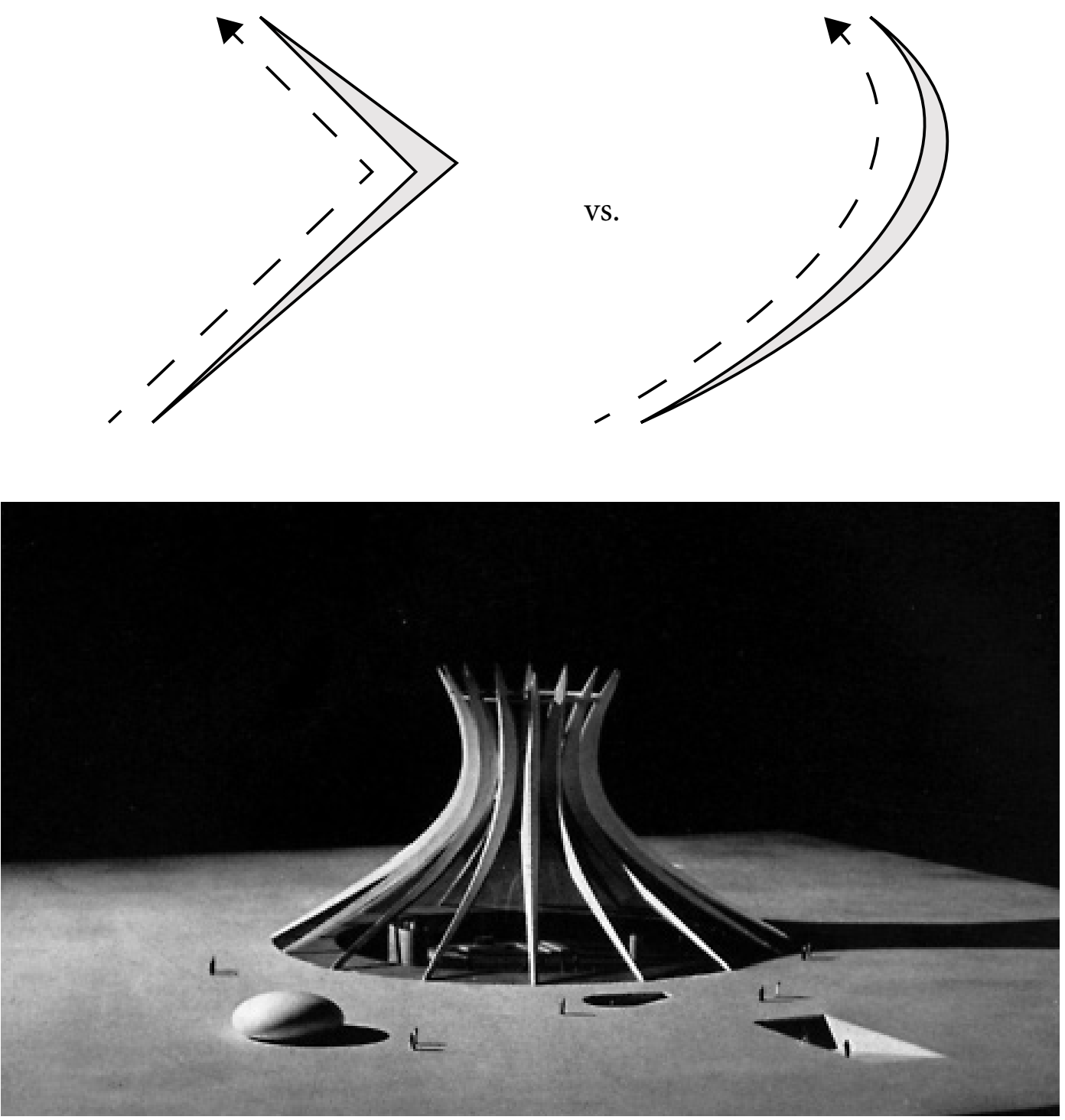

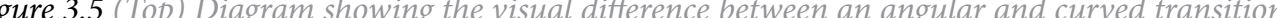
surved image on the right draws the eye upwards in a smooth movement.

Figure 3.6 (Bottom) Photograph of the final model of Cathedral of Brasilia by Oscar Niemeye.

Circular in plan with sixteen curved spires that meet in the centre, the Cathedral of Brasilia is a striking example of elegant curved architecture. The curves encourage the eve to follow a smooth transition from earth to sky, creating an extraordinary underbelly for the users (figures 3.5 and 3.6). 
CASE STUDY

Palácio do Planalto, 1966. Brasilia, Brasil. Architect: Oscar Niemeyer.
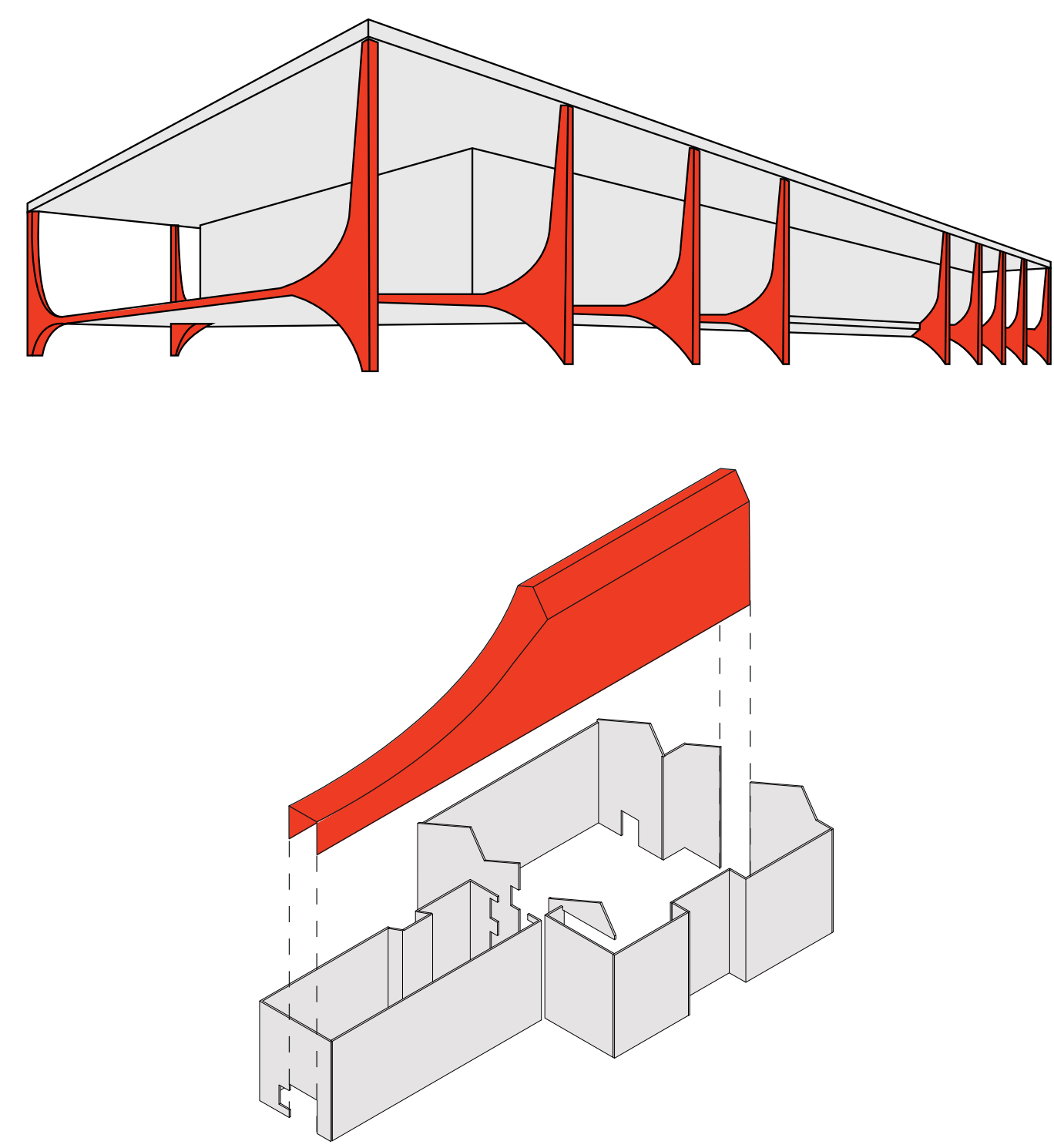

Figure 3.7 (Top) Diagram of Palácio do Planalto highlighting the two opposing aesthetics of curves and rectilinear forms. Although completely different, they work together producing a cohesive outcome. Figure 3.8 (Bottom) Exploded axonometric diagram of The Design showing how the curved insertion juxtaposes the geometry of the surrounding context.

Whats done?

Palácio do Planalto exhibits an impressive unison between curves and rectilinear forms (figure 3.7).
CASE STUDY

National Library of Sejong City, 2013. Sejong City, Korea. Architect: S.A.M.O.O Architects.
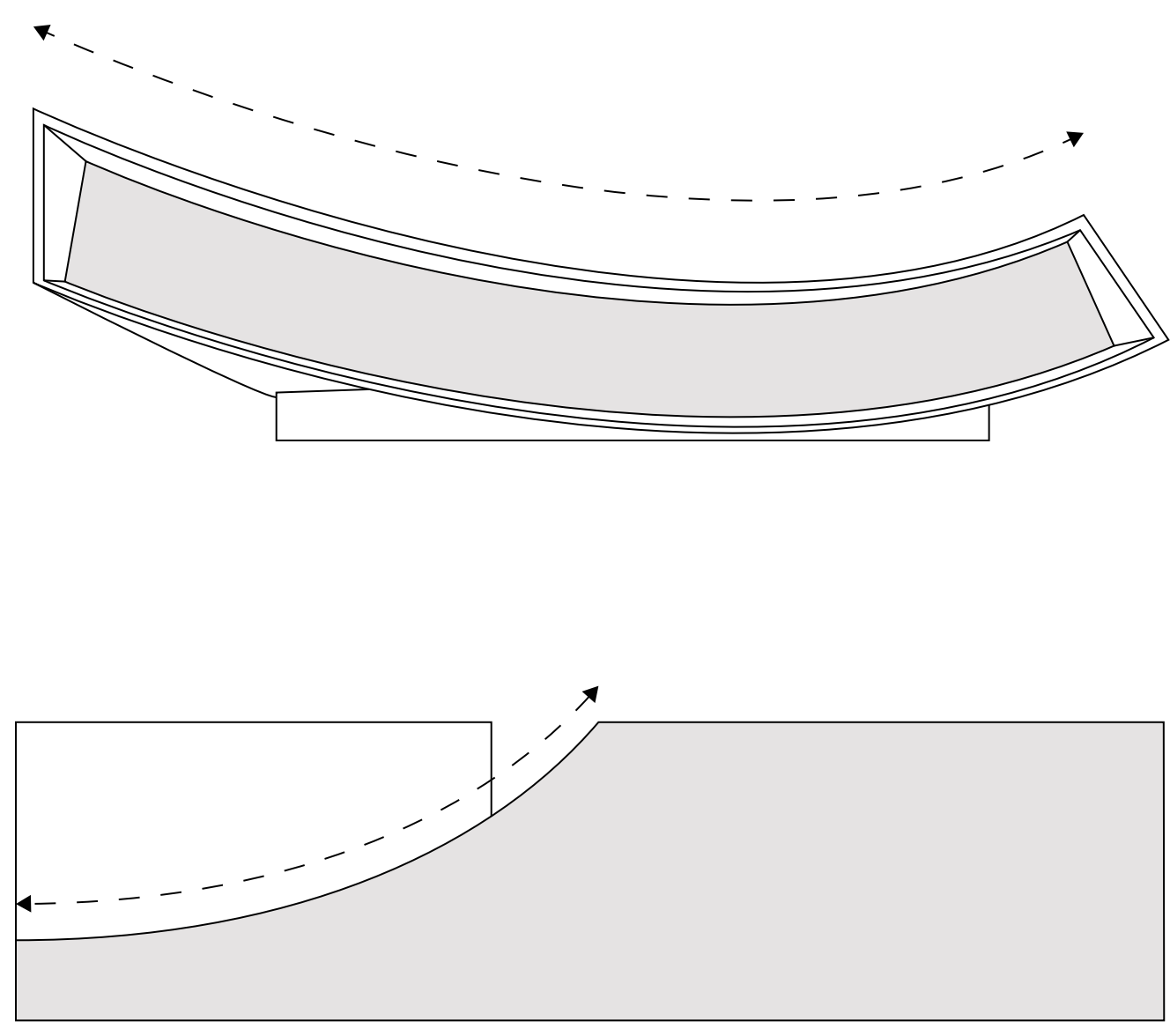

Figure 3.9 (Top) Diagram of the National Library of Seiong City outlining the subtle curve of the building The curve is one dimensional rather than multi-dimensional.

Figure 3.10 (Bottom) Longitudinal section diagram of The Design highlighting the similar degree of an used in the curve.

What's done?

In 2013 S.A.M.O.O Architects built the National Library of Sejong City in Korea. The overall form of the building swoops towards the ground in the centre of the site, and peels up towards the sky at either end (figure 3.9). Although massive, the overall form of the building seems light because from the main entrances it is cantilevered and floating in the air. The subtle arc of the building is a similar aesthetic to the simple curve in The Design (figure 3.10). 
The curve nestled within the rectangular geometries of the building encourages pedestrians to consider the unexpected space (figure 3.11). The patterned curved structure is not the usul engineering seismic strengthening response. The Design becomes a powerful moment of pedestrian discovery and a link connecting the existing, rigid geometries of the city. The Design could become a catalyst for a laneway network in Wellington that links buildings with unexpected revelations along the way.
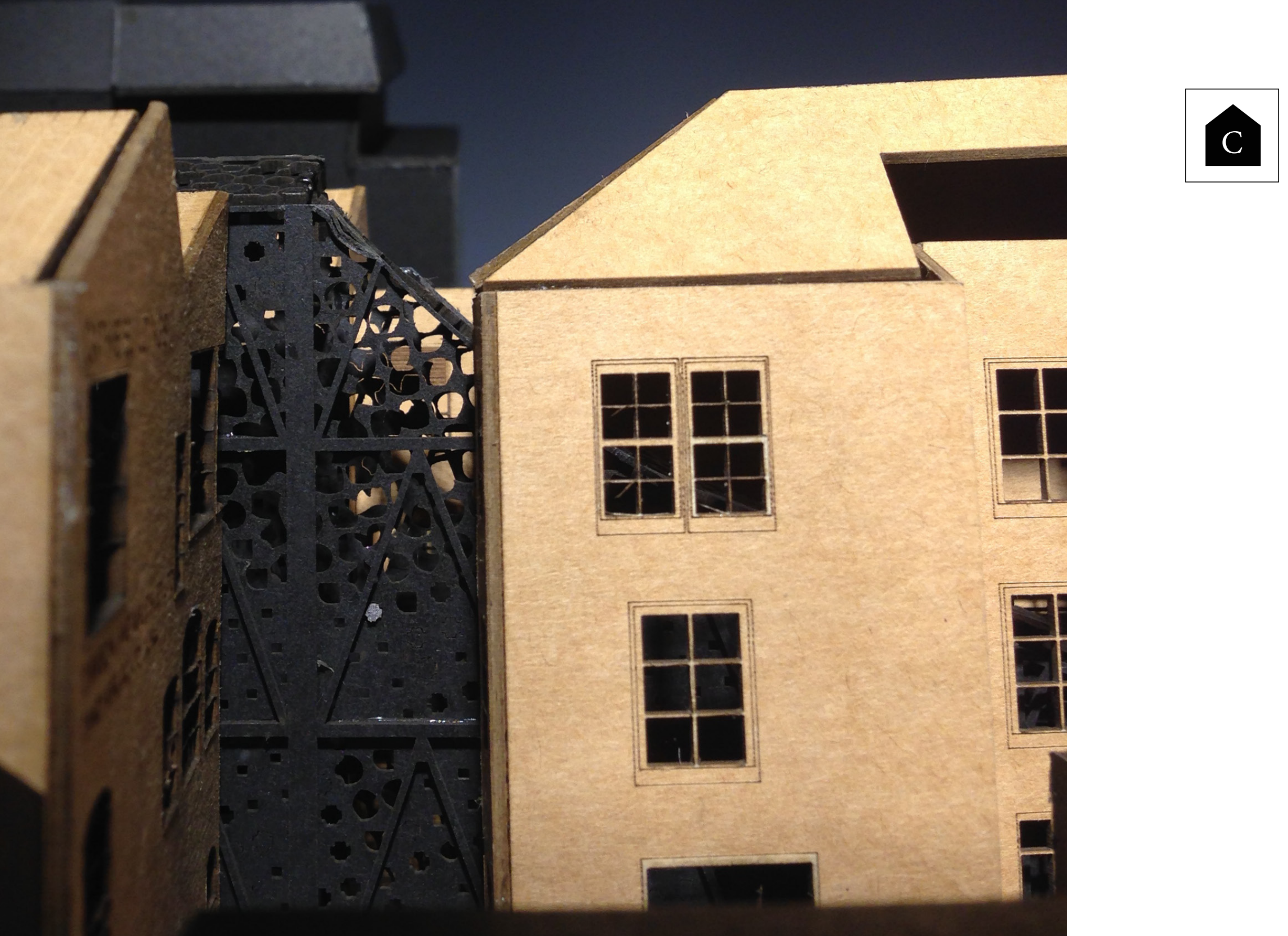

CASE STUDY

Auditório Ibirapuera Park, 2002-2005. São Paulo, Brazil. Architect: Oscar Niemeyer.

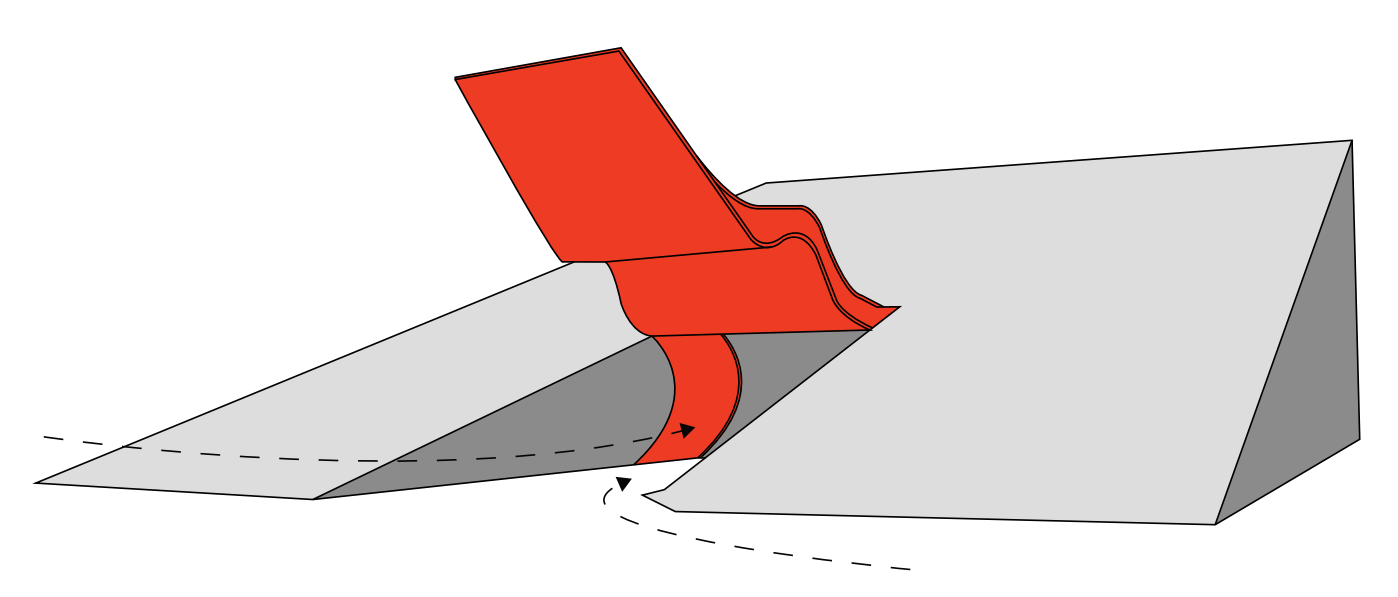

What's done?

Marking the entrance of the Ibirapuera Park Auditorium, a striking and unusual curved form emerges from the simple geometries of the main building (figure 3.12). This entrance creates intrigue in the users, drawing them into the space in a similar manner to the curve pulling people into the Marion Street entrance in The Design.

Figure 3.11 (Opposite) Photograph of the cardboard model showing the connection the curve makes between the Cathie Building (left) and the Aspro Building (rright).

Figure 3.12 (Above) Diagram of the Ibirapuera Park Auditorium showing how the unusual curved tongue draws people inside the rectilinear building. 
$0\}$

ALICE IN WONDERLAND

II

The curve responds to two very different scales of movement and activity. Taranaki Street is a main arterial route for vehicles through the city from north to south. With four lanes of high-speed traffic and large empty lots lining the edges of the street, it is disconnected from a human scale. In contrast, Marion Street has a finer grain of buildings and more pedestrians due to its proximity to Cuba Street (figures 3.16-3.18).

The Marion Street entrance into The Design is one storey (4 metres) high, allowing it to fit discretely into the existing scale of the street and façade of the Aspro Building. The Taranaki Street entrance is three storeys (12 metres) high, a larger cut that is appropriate to the building and the context (figure 3.19). It creates a distinctive entrance for pedestrians approaching from Mount Victoria. The curve connects these two heights in a smooth transition (figure 3.4).

Within the interior, an emphasis on symmetry and rhythm allows the curve to act as a proportioning system for the existing buildings. The pattern and structure create a changing interface along the length of the void, from which a sense of scale of the existing buildings is established.

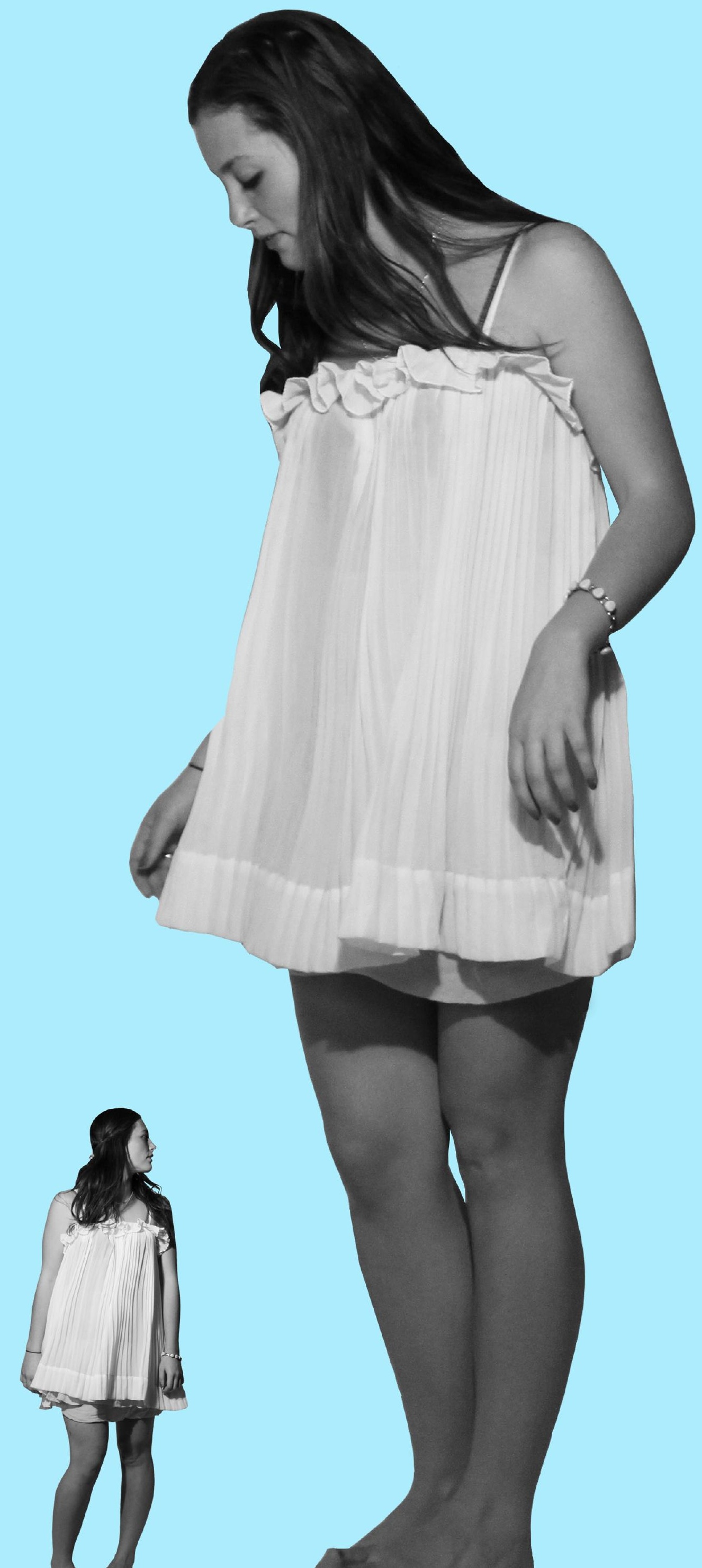



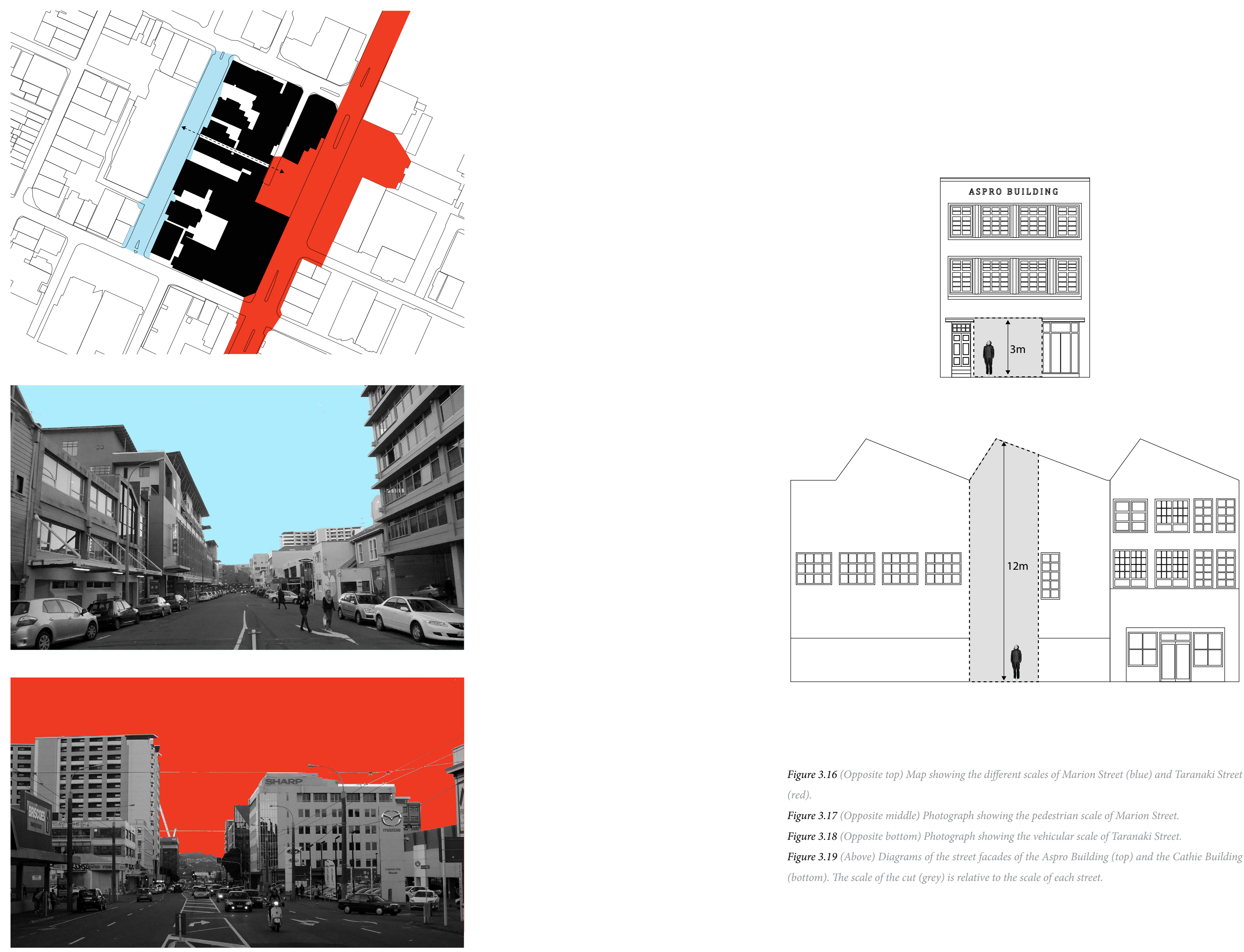

Figure 3.16 (Opposite top) Map showing the different scales of Marion Street (blue) and Taranaki Streed (red).

Figure 3.17 (Opposite middle) Photograph showing the pedestrian scale of Marion Street

Figure 3.18 (Opposite bottom) Photograph showing the vehicular scale of Taranaki Street.

Figure 3.19 (Above) Diagrams of the street facades of the Aspro Building (top) and the Cathie Building (bottom). The scale of the cut (grey) is relative to the scale of each street. 


$$
04
$$

COMMERCIAL CATHEDRAL

II

The Cathie Building can structurally and programmatically function with a 4 metre wide cut out of the interior. However, the smaller footprint of the Aspro Building requires more consideration.

Although the cut reduces the lettable floor area, it provides increased retail frontage on a pedestrian route. The two narrow spaces on either side of the void at ground level are divided into small vendor stalls. These provide maximum variety of interface between retailers and pedestrians. This is beneficial on the ground floor, but the building would be rendered useless if the cut extended the entire height of the Aspro Building. The curve enables the upper storeys to remain intact for the functional needs of offices and a kindergarten. From within these spaces, there are views through the curved screens and into the void below. Where the curve meets the Cathie Building pedestrians find themselves in a cathedral-like space filled with dappled light and shadows, through fenestrated, full height, adjustable screens.

Arcades have several economic opportunities for the city. They provide access to the interior of the block and to otherwise inaccessible buildings (Geist, 12). The arcade is an 'ingenious method' of opening up the city, enabling retail and public amenity within a private building (Geist, 16). The success of an arcade resulted form the combination of two factors: a supply of a boutique range of shops and a supply of public space for undisturbed promenading, window shopping, and display of merchandise (Geist, 35)
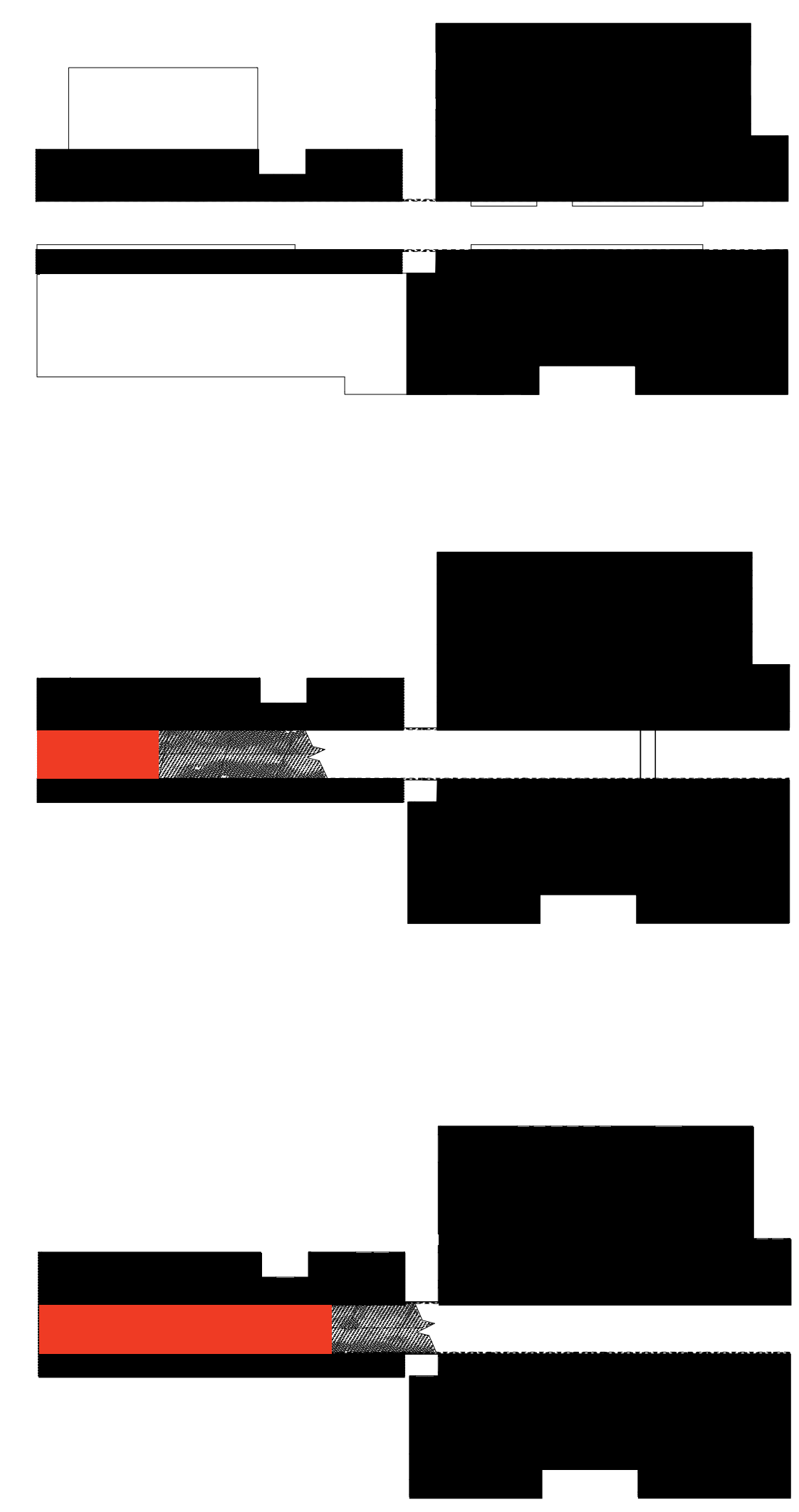

$\mathbf{m}$

The total lettable floor area in the existing Aspro Building is 798m2. The public space of the void cutting through the ground floor is $115 \mathrm{~m} 2$. The curve allows less floor area to be compromised above the ground floor. A total of $88 \mathrm{~m} 2$ is consumed between the two upper floors allowing the kindergarten and offices to function around the curve. The increasing lettable floor area is illustrated in red in the above diagrams (figure 3.20). 


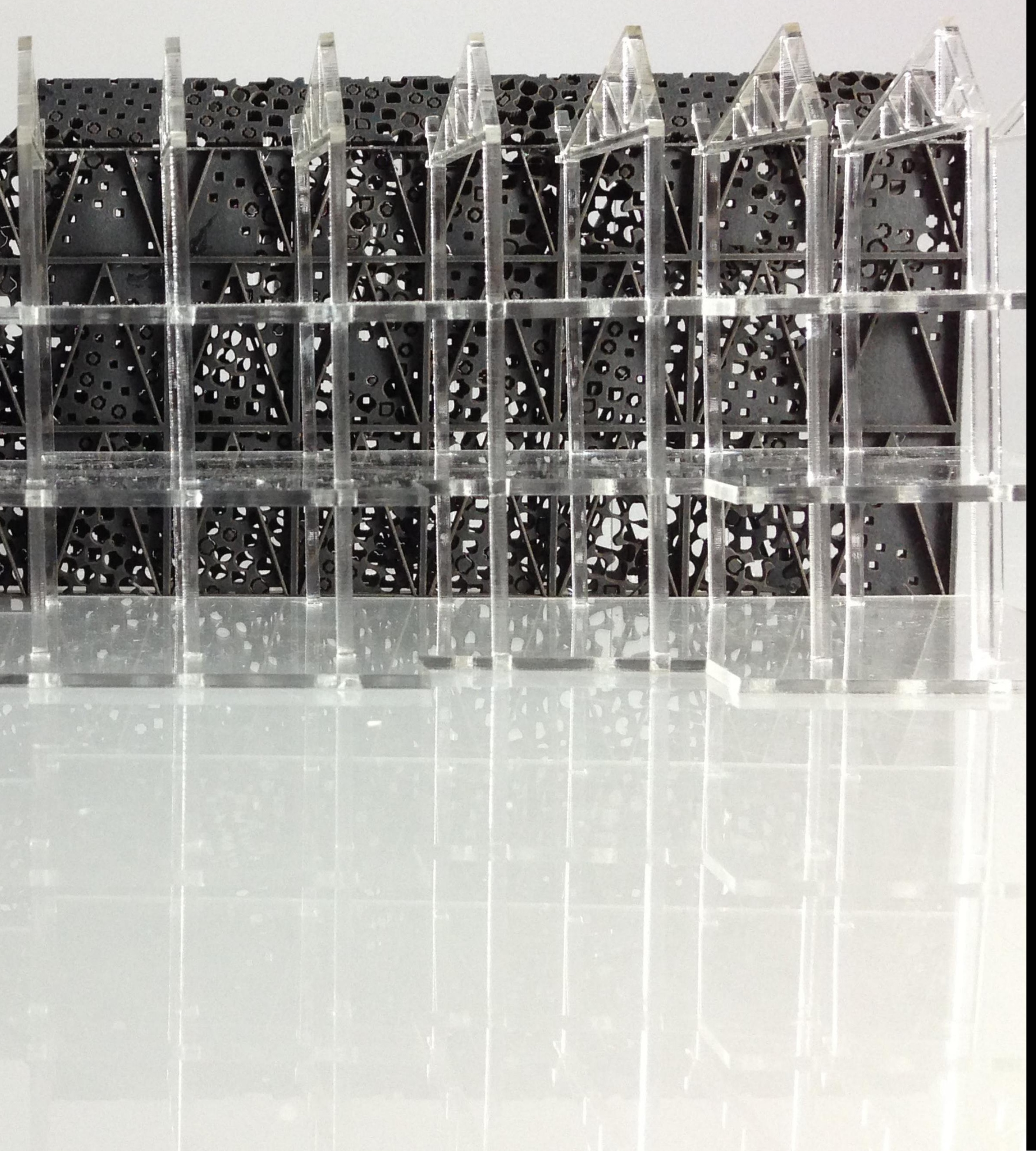

\section{STRUCTURE AND PATTERN}

A combination of perforated steel screens and steel cross bracing strengthens the Cathie Building and Aspro Building from the interior. 
STRUCTURE

PATTERN

A Standard Approach

$$
\text { Skin Deep }
$$

Prosthetic Spine

The Grid

05

Carbon Copy

06

Screening

Figure 4.1 (Previous) Partial elevation of the black cardboard curve model, positioned within a clear

persspex model of the existing structure of the Cathie Building. This shows how the existing structure and

the structure of the intervention align

Figure 4.2 (Following) Aerial map of part of Wellington city highlighting the earthquake prone buildings in yellow. 


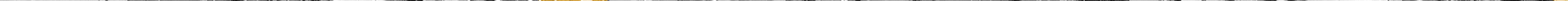




\section{1}

A STANDARD APPROACH

standoard

Adjective. Used or accepted as normal or average

$\mathbf{I}$

An architectural approach that is specific to the particular building being strengthened can reduce the intrusiveness of strengthening. The structural principles of the standard methods diagrammed in figure 4.3 have been translated into a system which responds to the existing and creates a new city space, encouraging movement and circulation through the buildings rather than limiting it.

Who said?

Many strengthening methods (figure 4.4) are relatively superficial additions to the existing structure, usually additions which are able to be removed or altered when technology improves. In 2000, the NZHPT's Guidelines for Earthquake Strengthening state that' strengthening work should be reversible and aim to achieve structural effectiveness at reasonable cost' (Robinson, 4). Unfortunately, a large number of historic buildings have been strengthened using exterior steel cross braces or K-braces on the basis that the work is 'reversible'. In some cases, this work has obstructed the proportions and functionality of the existing building. This approach is unacceptable and should not be argued on the basis of reversibility (McClean, 10).

There has been increasing public concern about this visual impact of earthquake strengthening structure. David Dorwick is a structural engineer who recognised the urgency for earthquake strengthening of heritage buildings, and consequently the need to accept the visually intrusive result

Strengthening elements may have to be visible, and in some cases quite intrusively, because they are in unconventional phaces This is exemplified by the insertion of ding be members within masonry or concrete buildings. Fortunately their apparent intrusiveness can be temporary, once the users of a building become accustomed to them. The visual statement of diagonal braces is known also to be reassuring to earthquake conscious citizens.

(Dorwick, 3)
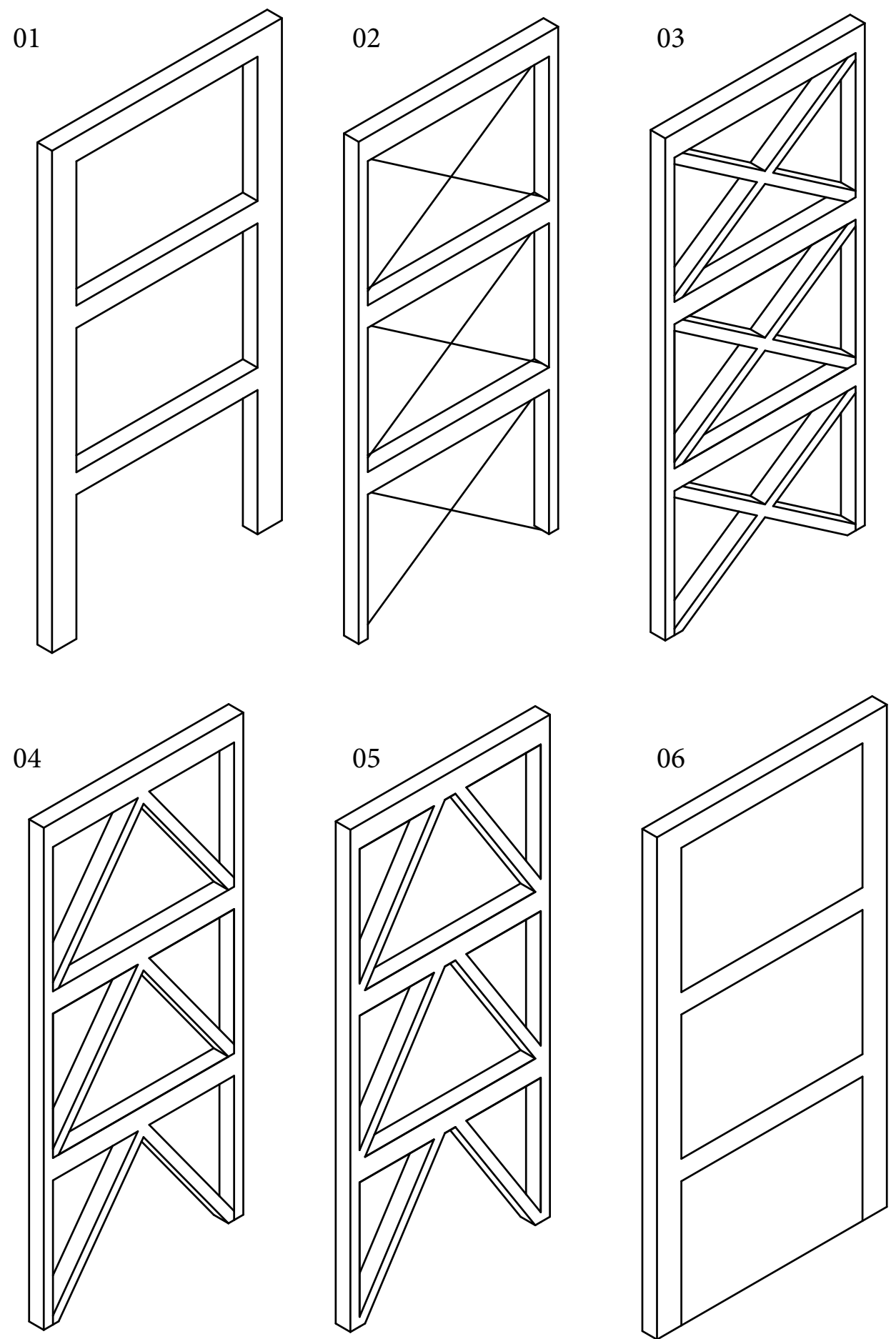

Figure 4.3 Diagrams of standard strengthening methods. 01. moment frame. 02. Steel tension only bracing 03. Steel cross-braced frame 04: Steel K-braced frame 05. Steel eccentric braced frame. 06 Shear wall.

Figure 4.4 (Following) Two photographs of poor earthquake strengthening examples in Wellington. Left: The Cube Student Accomodation on Webb Street with lime green external cross-bracing. Right: UStay Student Accomodation on Willis Street with black external cross bracing. Both projects are visually abrasive and prevent the windows from being openable. 


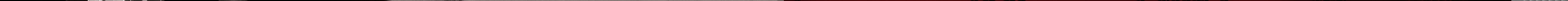




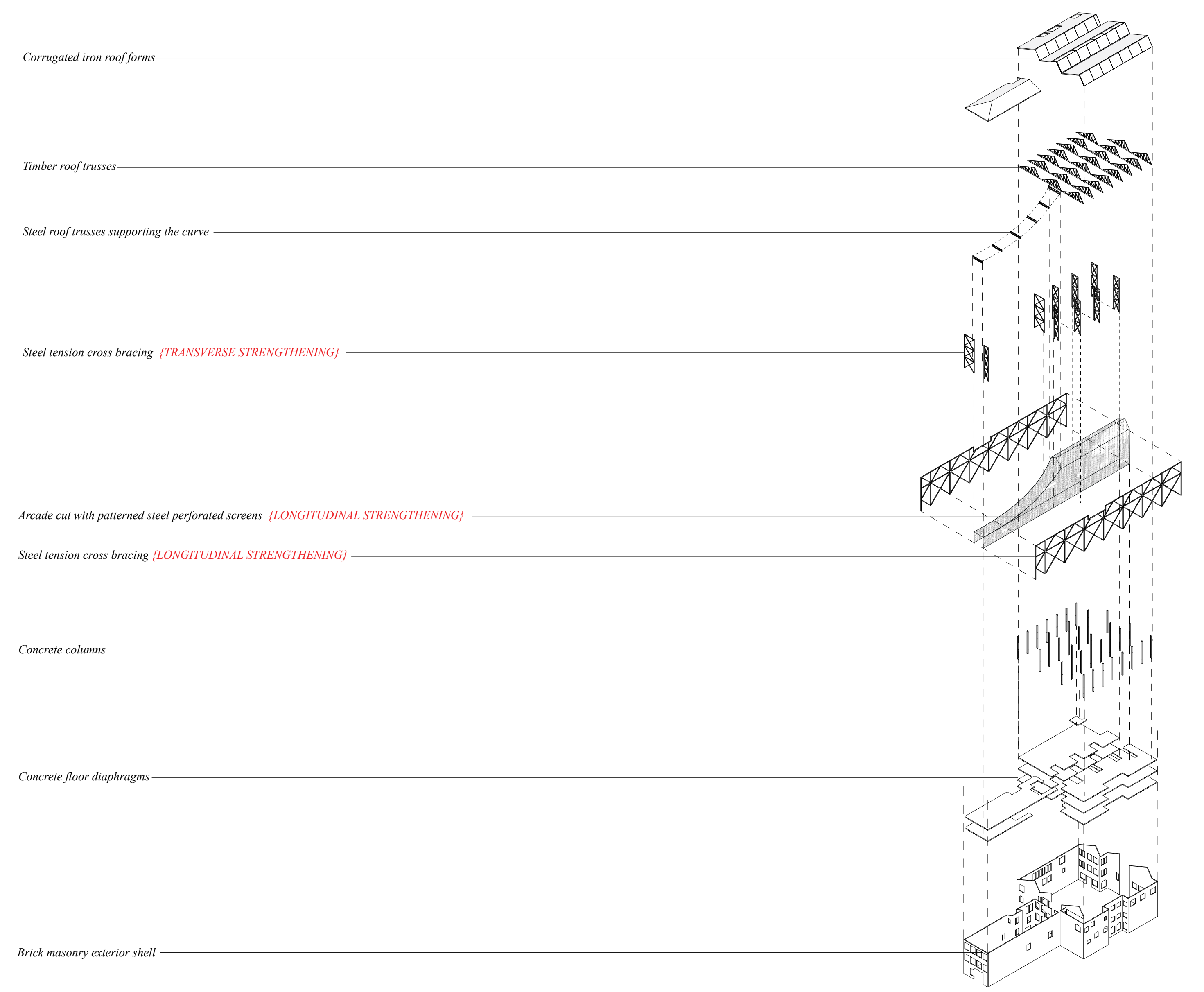


02

SKIN DEEP

skin

Noun. An outer layer or covering.

Two patterned steel screens integrated with eccentrically braced frames run the length of the void (figure 4.6). These frames connect to the floor diaphragms and tie together the two earthquake prone (figure 4.6). These frames connect to the floor diaphragms and tie together the two earthquake prone
buildings. The $15 \mathrm{~mm}$ perforated steel screens act as shear walls. Combined with eccentrically braced frames these screens can be relatively thin despite their overall size. The size of the perforations varies according to structural load paths, with less porosity where more strength is required. The combination of structural systems provides a thin membrane of structure and pattern between the arcade space and the interior of the buildings.

Perpendicular to the cut there are six staircases that strengthen the Cathie Building in the transverse direction (figure 4.7). Utilising the same system of patterned screens and eccentrically braced frames, the structure allows for natural light to filter down the stairwells (figure 4.9). These transparent structural cuts into the existing building allow light to penetrate the interior of the deep footprint of the building. Consequently, the structure enhances the architectural experience of the space (Charleson, 2).

The most recent structural report on the Aspro Building states that it has weak masonry facades on the east and west. This provides a threat for pedestrians on Marion Street and for the preservation of the heritage listed Theosophical Society. For this reason, transverse strengthening for the Aspro Building has been incorporated into the strengthening of the facades (figure 4.10). Steel braced frames on the interior of the facades and a perforated screen on the exterior sandwich the existing weak masonry (figure 4.10). The pattern of these screens aligns with the existing grid of the facades, allowing for greater porosity and the ability to open the screens adjacent to the windows.
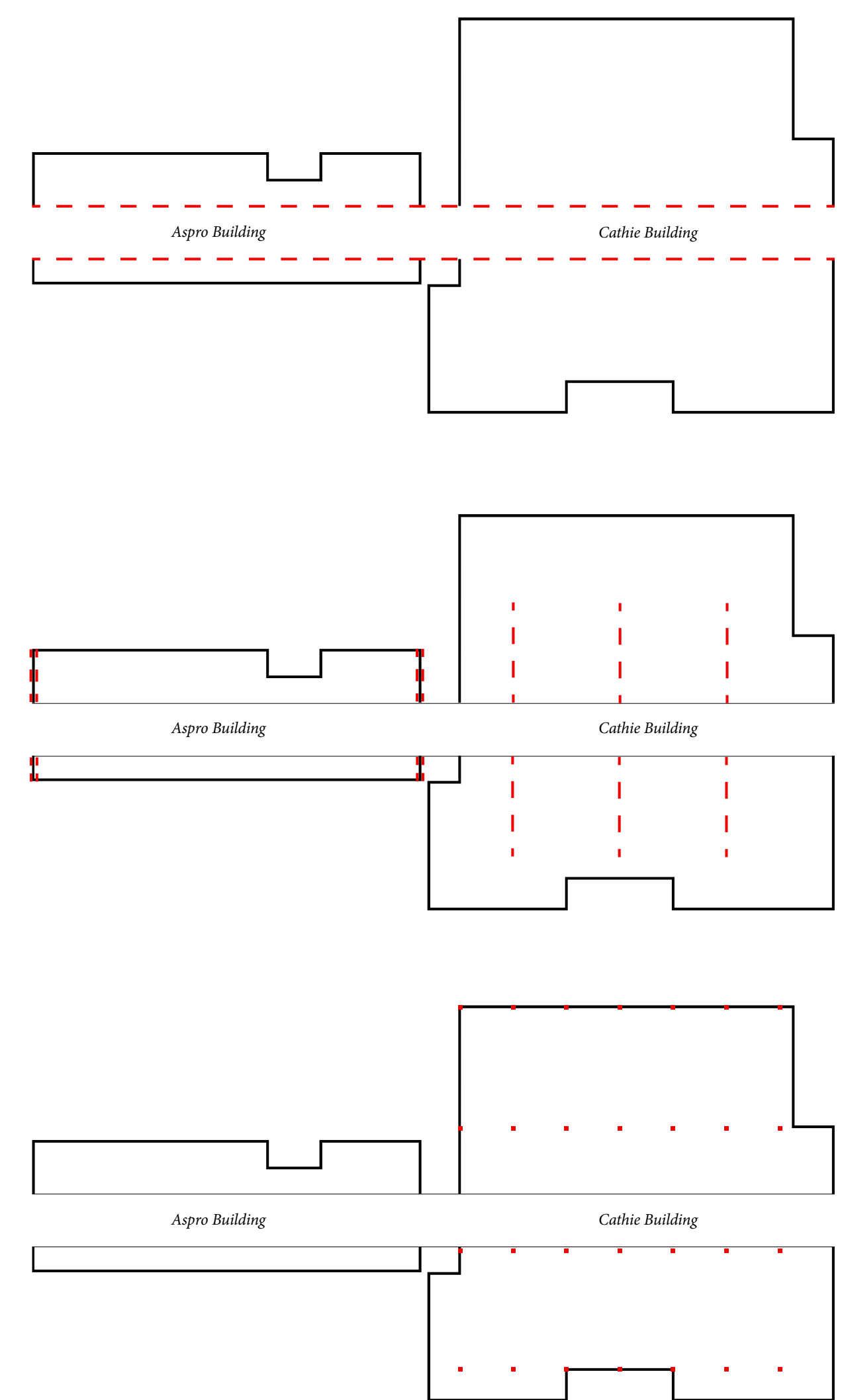

Figure 4.6 (Top) Floorplan diagram showing longitudinal structure tying two buildings togethen Figure 4.7 (Middle) Floorplan diagram showing transverse structure strengthening the facades of the Aspro Building and utilising the stairwells in the Cathie Building.

Figure 4.8 (Bottom) Floorplan diagram showing existing concrete column grid in the Cathie Building that the new structure and apartments are proportioned to. 


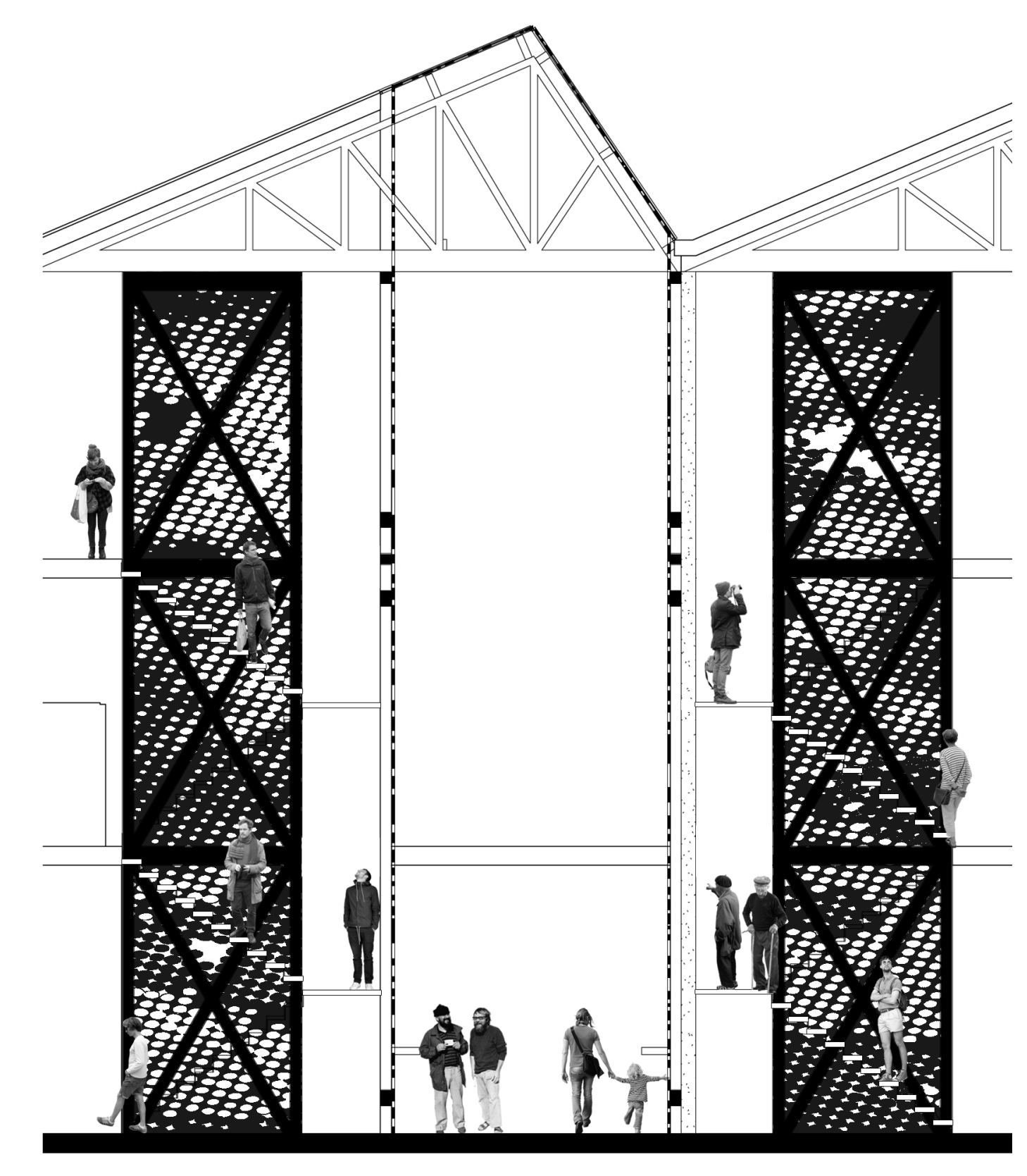

II

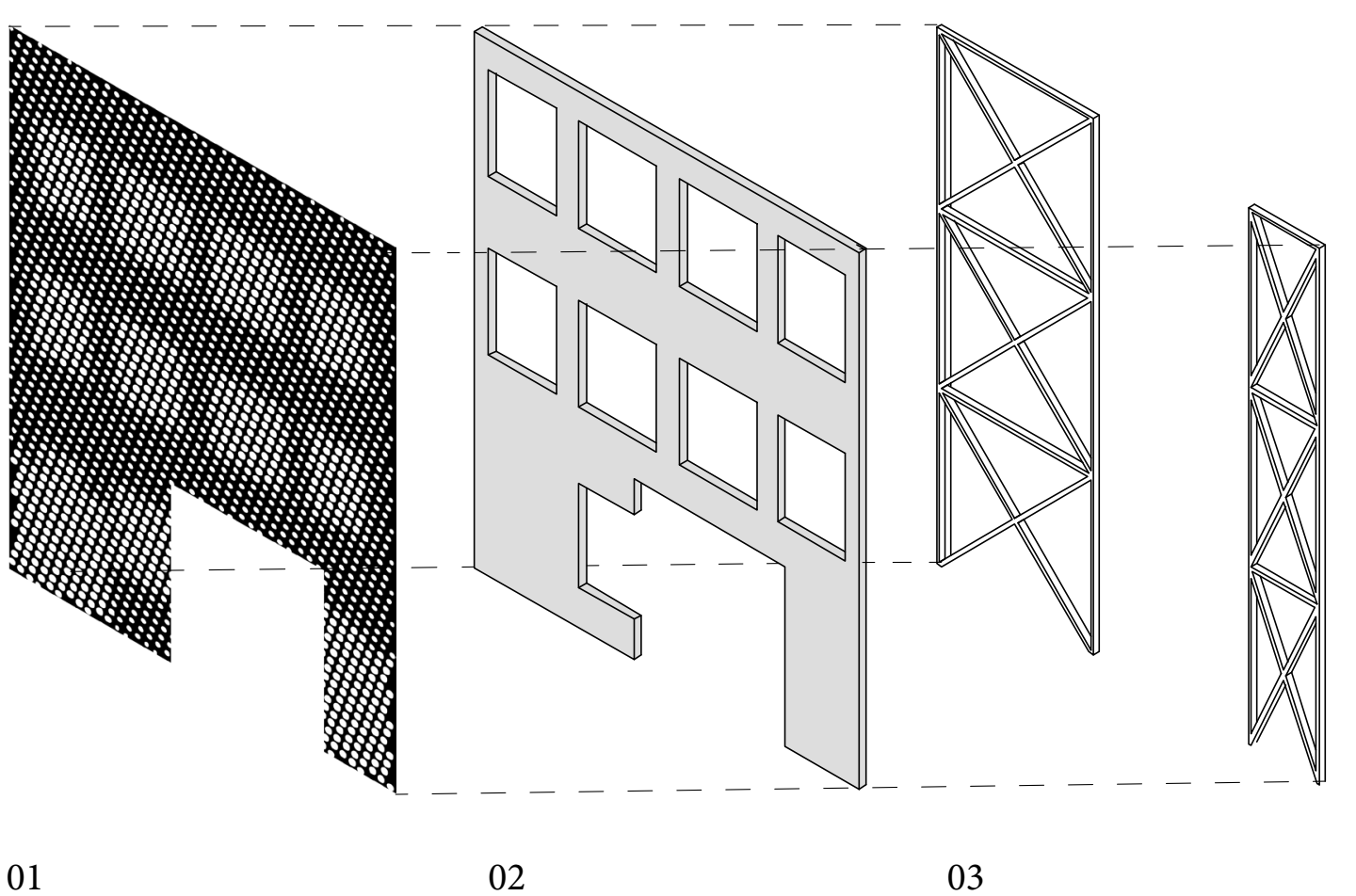




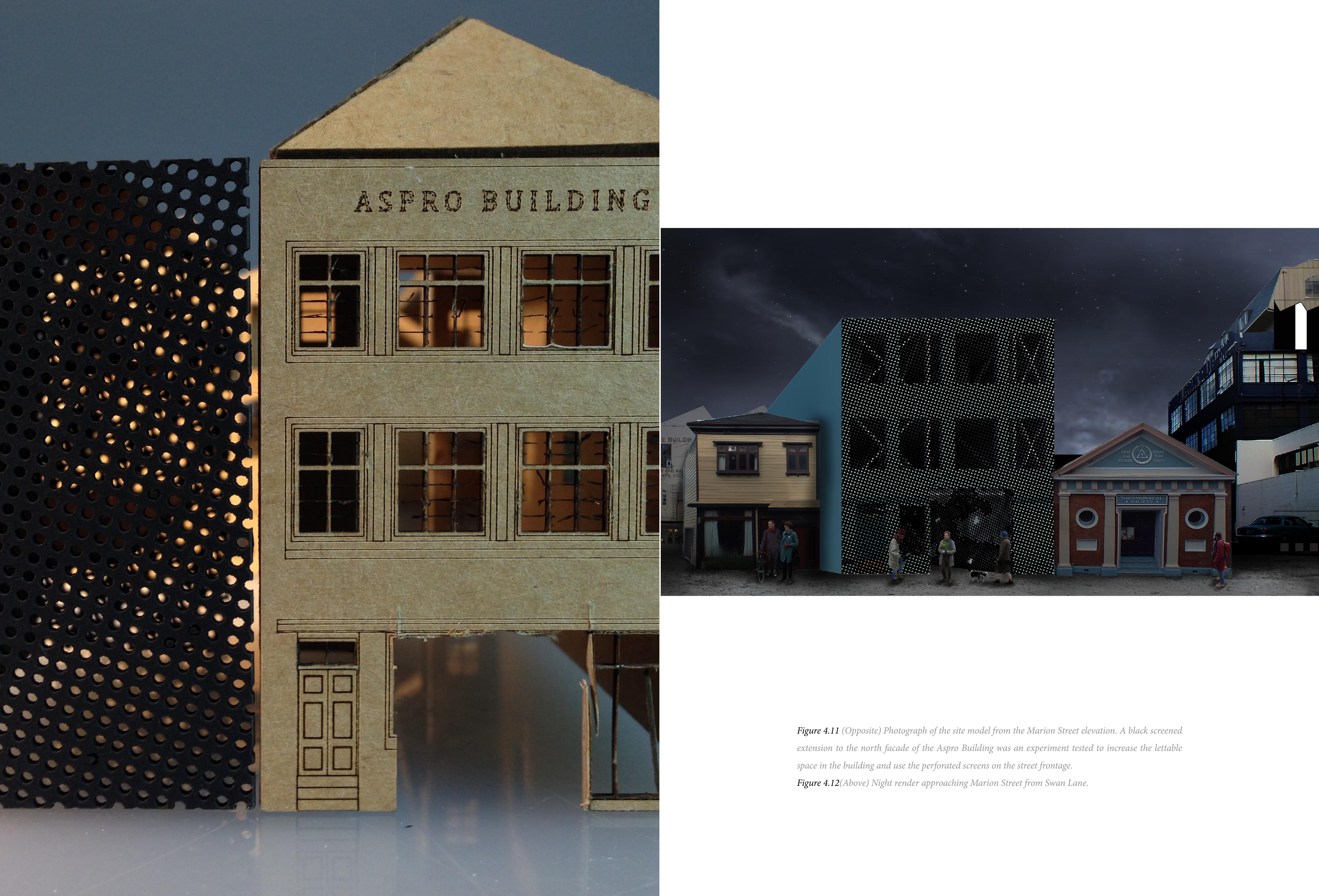




\section{$0\}$ \\ A PROSTHETIC SPINE}

prosotheosis

Noun. A structural addition that props up or extends its host

The insertion of a structural void strengthens the existing buildings from the interior. Similar to a prostheses and a body, the new intervention transforms the otherwise defective building through one move. 'Grafted on to repair some kind of structural flaw, it is a foreign element that reconstructs that which cannot stand up on its own, at once propping up and extending its host. The prosthesis is always structural, establishing the place it appears to be added to (Wigley, 9). The traditional arcade is, as Geist describes 'structurally dependent upon its surrounding buildings for support' (12). The Design reverses this, and the buildings become structurally dependent on the prosthetic insertion. Unlike standard strengthening methods, the void cut through the building creates new public space. This additional space allows earthquake strengthening to be able to contribute to the atmosphere and connect the pedestrian experience in Wellingto

Along the line

This notion of an inserted void providing structural strength was experimented with throughout the year. Some of these void experiments were previously discussed in the 'light section'. on page 110 Various forms of vertical atriums penetrating the existing buildings and strengthening the of the floor diaphragms were tested (figure 4.13). Hexagonal and square voids were inserted into the buildings. These created light central atriums for pedestrians to gather inside the buildings. The hexagonal experiment was incorporated with an overarching structure that spread over the entire site, providing a framework for the existing buildings to be tied to (figures 4.14 and 4.28 ). Resembling the aesthetic of the statement mega-structure period, this was discarded for a more subtle intervention.

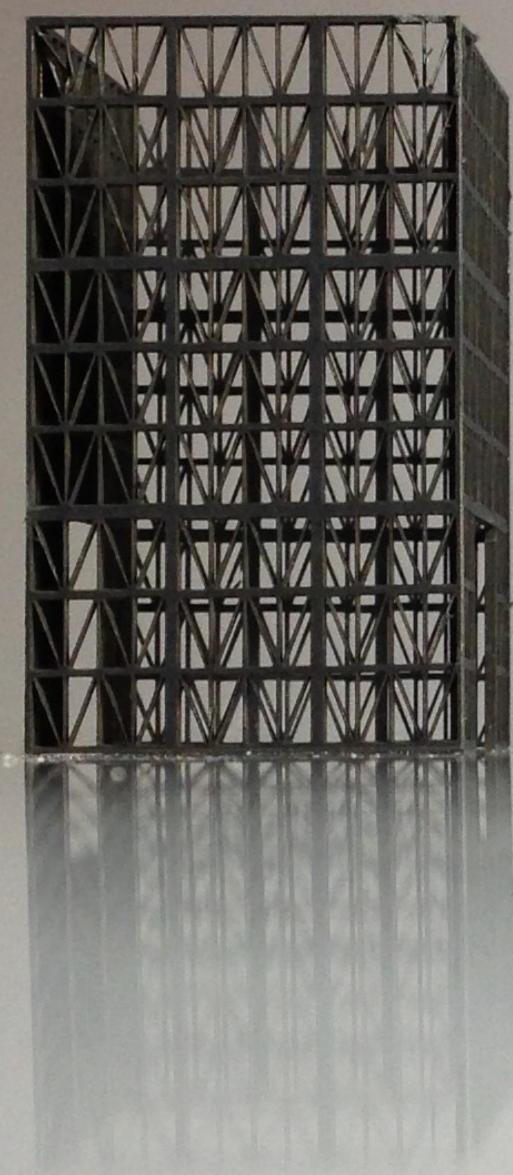

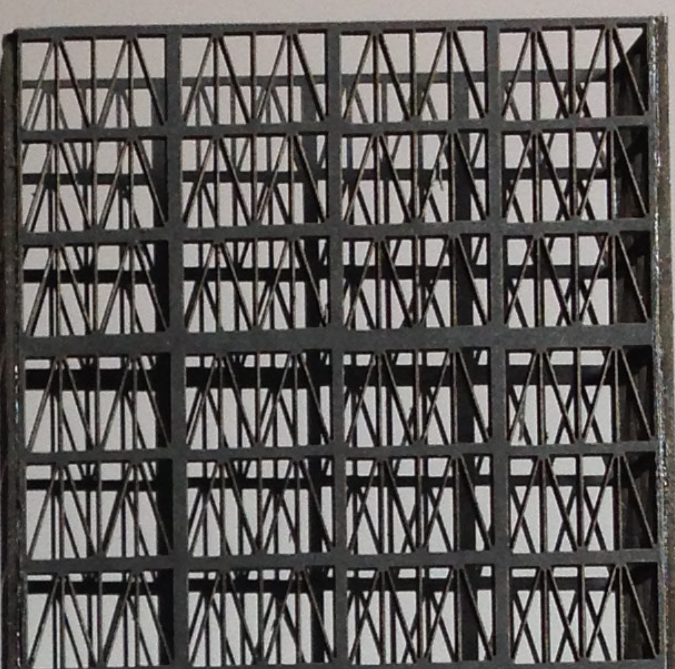

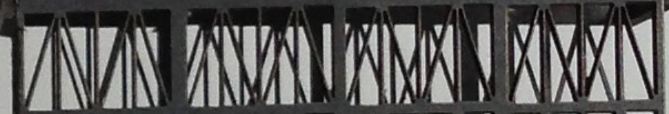

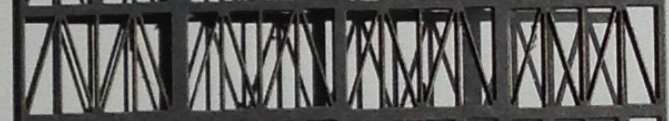

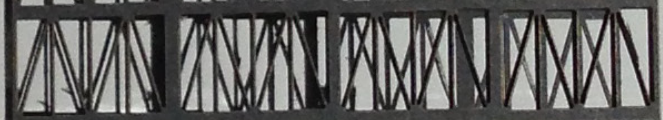
190. 


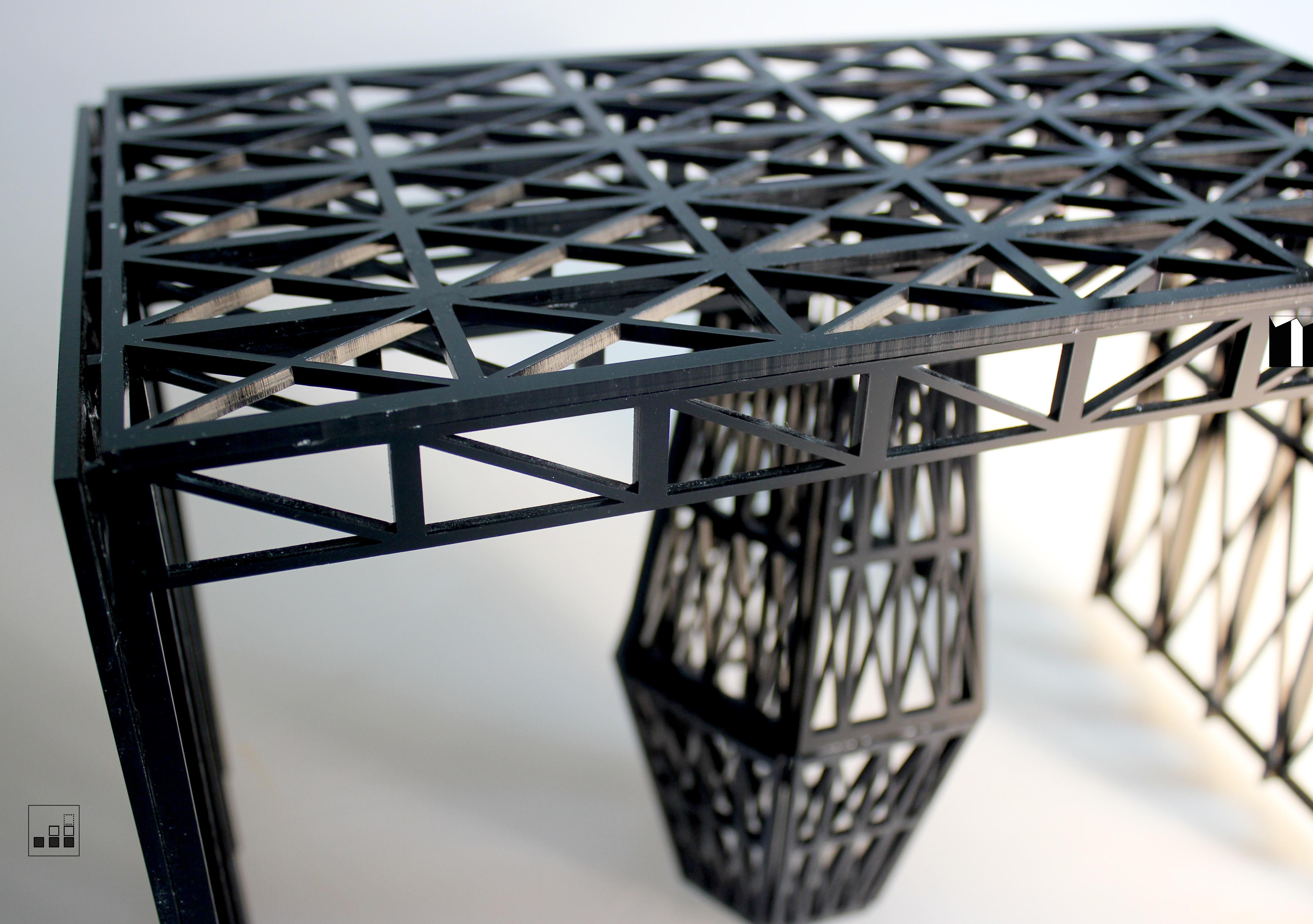




\begin{abstract}
04
THE GRID

grid

Noun. A network of lines that cross each other to form a series of squares or rectangles

The new structure has been integrated with the existing grid of the timber trusses and concrete columns in the Cathie Building (figure 4.15). Clark and Pause discuss in their book 'Precedents in Architecture' how structure can be used to 'define space, articulate circulation, suggest movement or develop composition and modulations' (3). The existing structure defines the dimensions of the surrounding spaces, developing a proportioning system along the length of the void. The bay length of the braced frames is four metres, allocating the width of each apartment to four metres (figure 4.16). Intrusion of structure within the apartments is therefore eliminated. At ground level there are two street vendors per bay. Due to the diagonal cross bracing, ease of movement and circulation through the screen was a consideration (figure 4.15). The perforated screens have been cut to panels which fit into the braced frames. These panels rotate to allow the vendors to open into the void and for people to pass through the structure (figure 4.17).
\end{abstract}

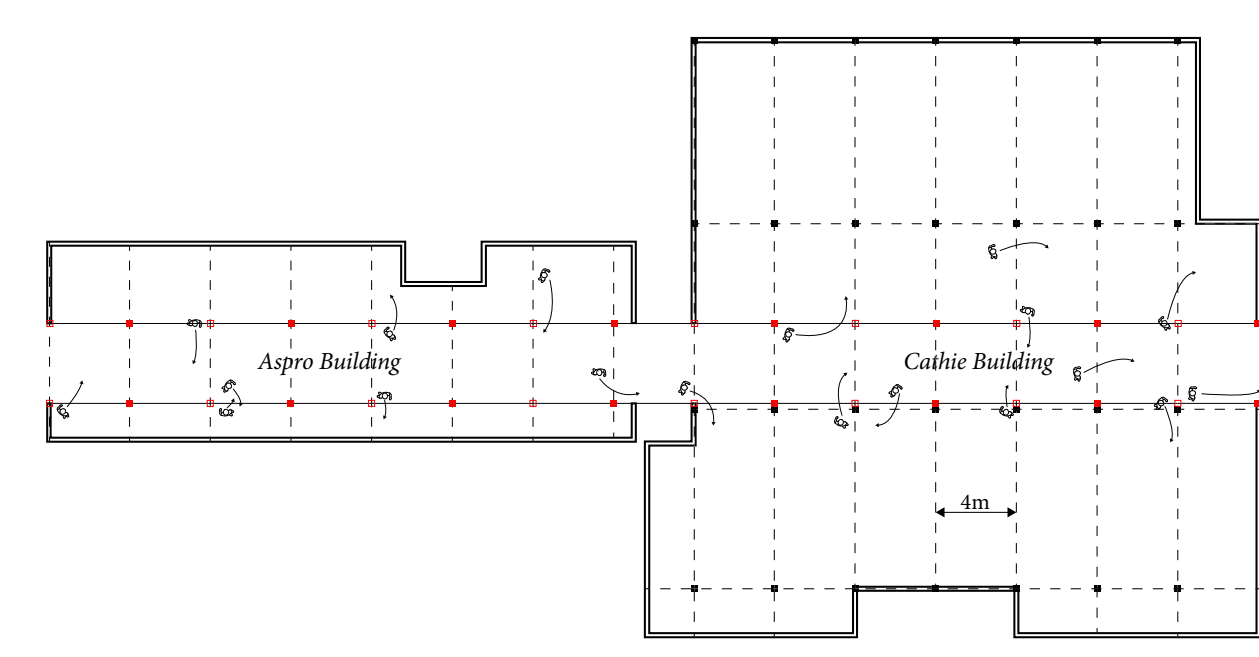

Figure 4.15 Floorplan diagram showing the existing structural grid from the Cathie Building has been replicated along the length of the arcade. Due to diagonal cross-bracing, circulation through the screen is dictated by the structure.

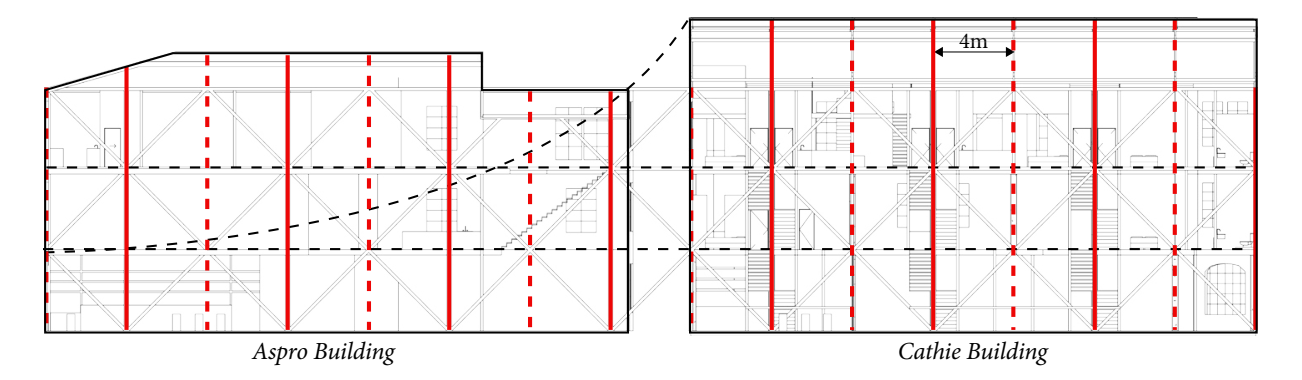

Figure 4.16 Sectional diagram along the length of the void. This illustrates how the structural grid defines the width of the various spaces on each level.

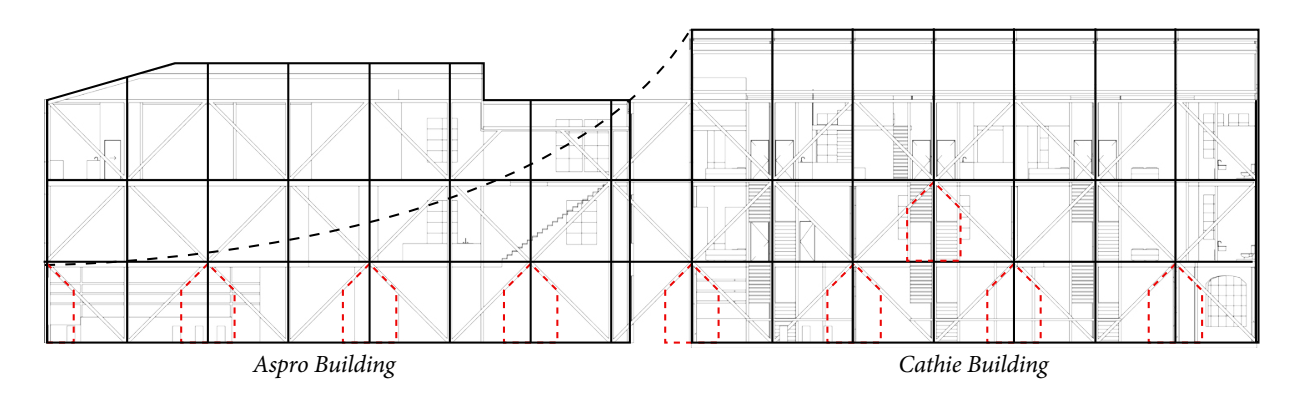

Figure 4.17 Sectional diagram along the length of the void showing how the screens are cut to be able to rotate within the cross-bracing. 
CASE STUDY

Crystal Palace, 1851-1936. Hyde Park, London. Architects: Joseph Paxton and Owen Jones.
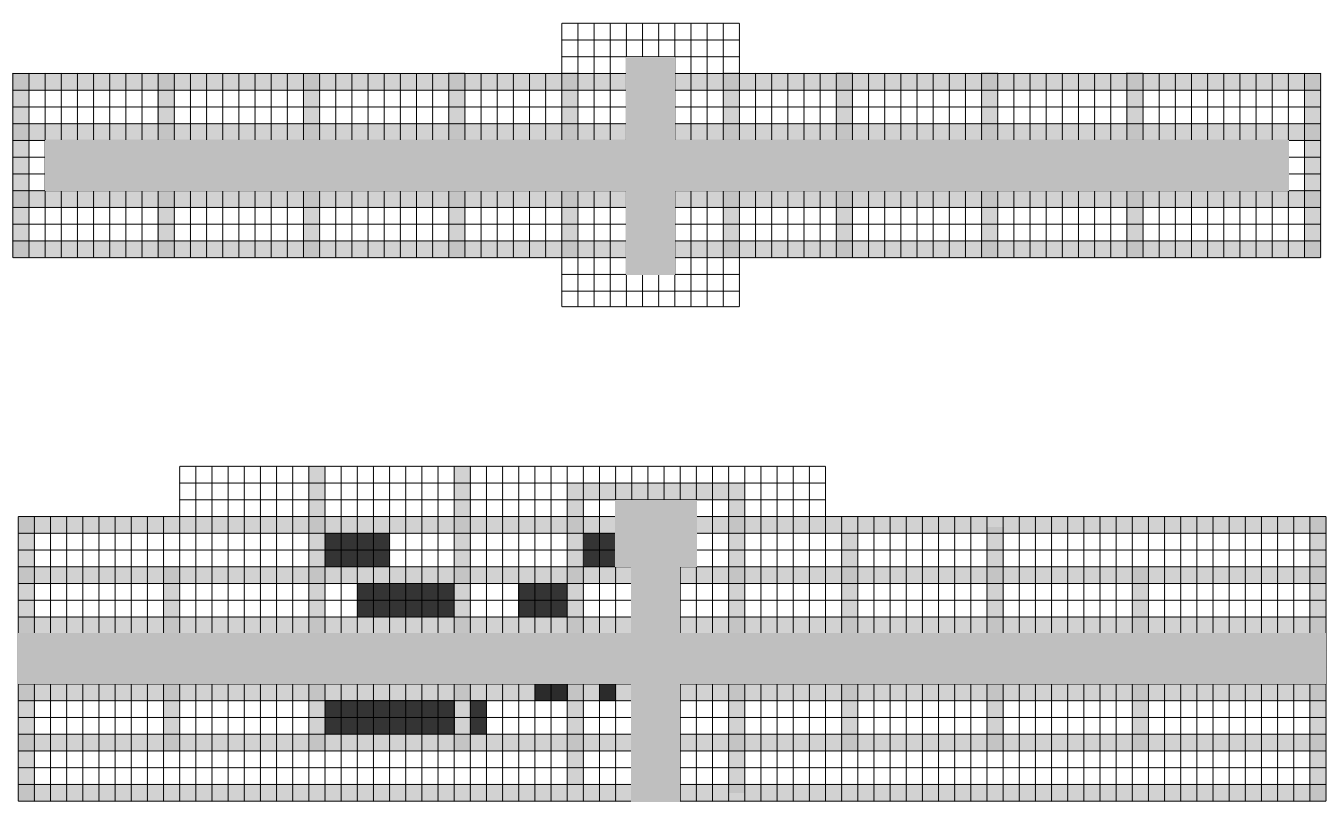

\section{1.}

Figure 4.18 (Top) First floor plan showing how primary and secondary circulation (grey) fit into the structural grid.

Figure 4.19 (Middle) Ground floor plan showing how primary and secondary circulation (pale grey) and the vendor stalls (dark grey) fit into the structural grid.

Figure 4.20 (Bottom) Grid showing various sized vendor stalls, able to increase to a depth of two structural modules and exponentially along the length of the palace.

What's done? The concept of a structural grid has been used as a spatial allocation and articulation device throughou
architectural history. Joseph Paxton's Crystal Palace is an example of a regulated structural grid dividing an expansive space into various sized vendor stalls. Each stall can only increase to a measure of two structural units in depth. However the stall can expand more freely along the length of the palace (figures 4.19 and 4.20 ).

A basic structural module was formed through using the standard dimensions of glass panes, cast ron beams and pillars. These modules were multiplied into a grid, allowing the structure to be extended virtually infinitely. The ground floor of the Crystal Palace equates to a grid 77 modules long by 19 modules wide. Because each module was self-supporting, Paxton was able to eliminate structure in some areas to create larger exhibition spaces.
CASE STUDY

Ville Spatiale (The Spatial City) 1959-1962. Paper architecture, Paris, France. Architect: Yona Friedman and Geam.
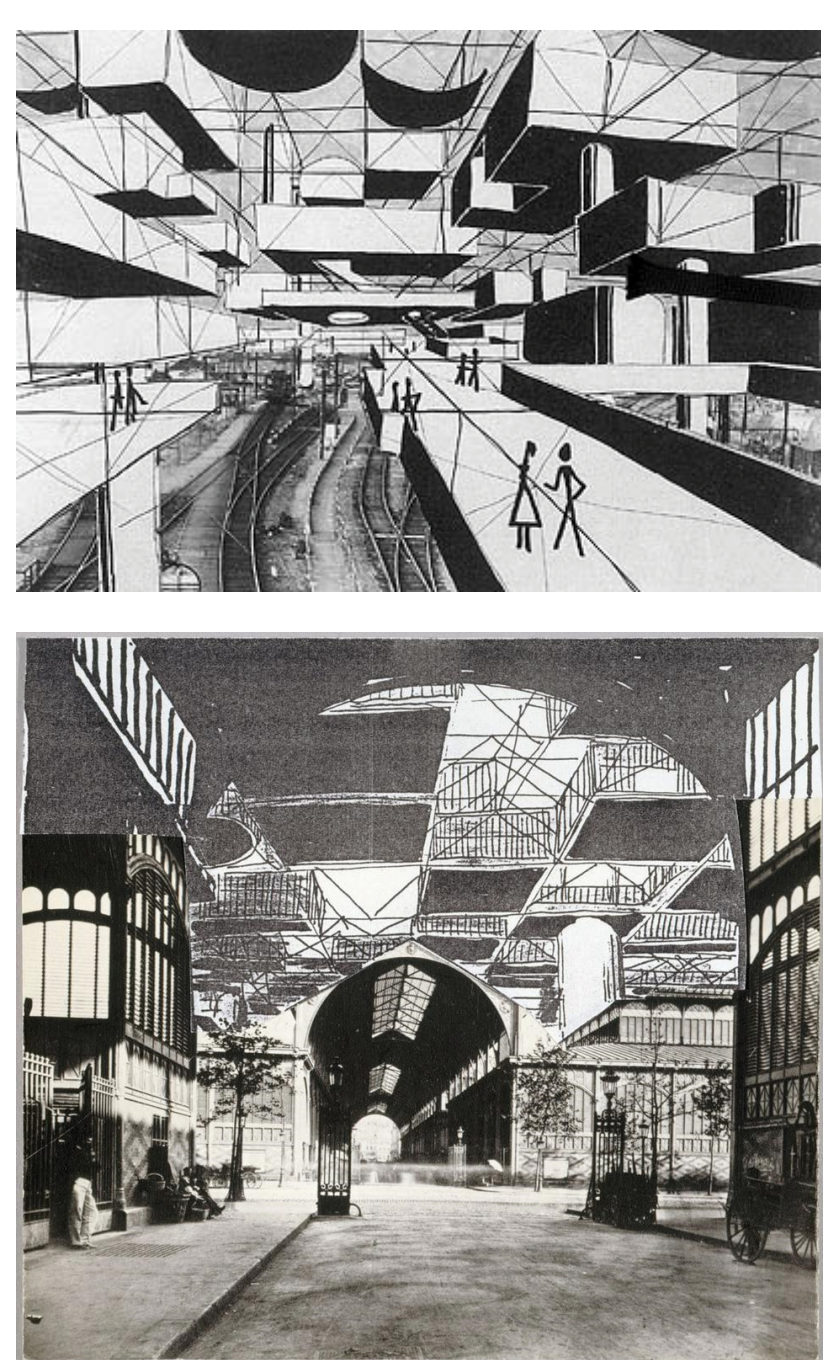

Figure 4.21 Two collage images from Yona Friedman and Geam's proposal for Ville Spatiale.

What's done?

An emphasis on a structural aesthetic was prevalent in the $1960 \mathrm{~s}$ in the mega structure movement. Architect Yona Friedman contributed to this in his project 'The Spatial City?. He proposed a large super-structure which spread over the city in three-dimensional grid. Within this framework people could set up new residences, bringing the life of the city above the existing buildings. Although the scheme is impressive and the drawings provoke a sense of awe in those that view them, the practicality of abandoning entire existing cities was far-fetched. The quality of creating spaces within structure was the primary reason Yona Friedman was included in the case studies (figure 4.21). 
CASE STUDY

House NA, 2010. Tokyo, Japan. Architect: Sou Fujimoto Architects.

c
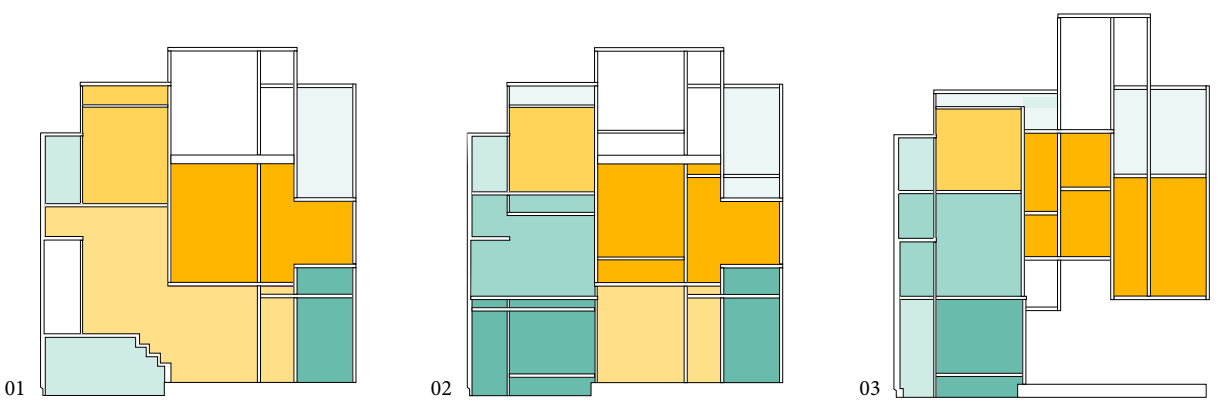

\begin{tabular}{l|l|l|l|l|l|l|l}
\hline LIVE & Bed & HALL & Bath & STORE & EAT & оTHER \\
\hline
\end{tabular}

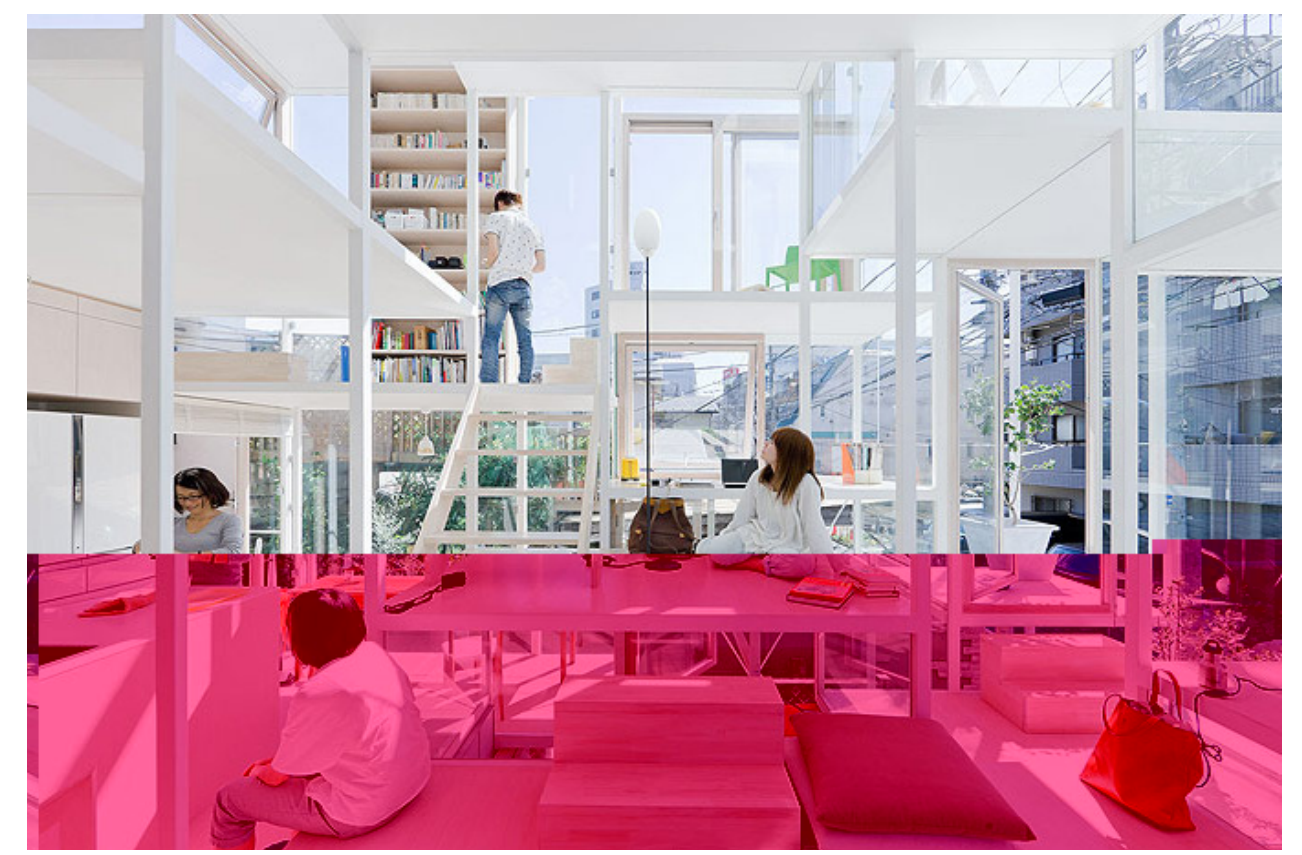

Figure 4.22 (Top) Sectional diagrams showing how the programme of each space in the NA House is defined by the structural module. The section cuts are marked on the plan of the house in this same image.

Figure 4.23 (Bottom) Photograph of the interior of the NA House showing the living room, kitchen and studv. The combination of structure and glass provides a surprisinglv open plan interior considering the changing of levels and apparent segregation of spaces in section.

What's done?

The NA House by Fujimoto Architects is a spatial grid. Vertical structure (predominantly columns) and horizontal floor plates are exposed to the surroundings with everything else being completely glazed. The structural composition breaks the house down into a series of compartments (figure 4.22). Each structural module is inhabited with a different programme (figure 4.22). The use of the house is consequently divided through the implementation of a structural grid.
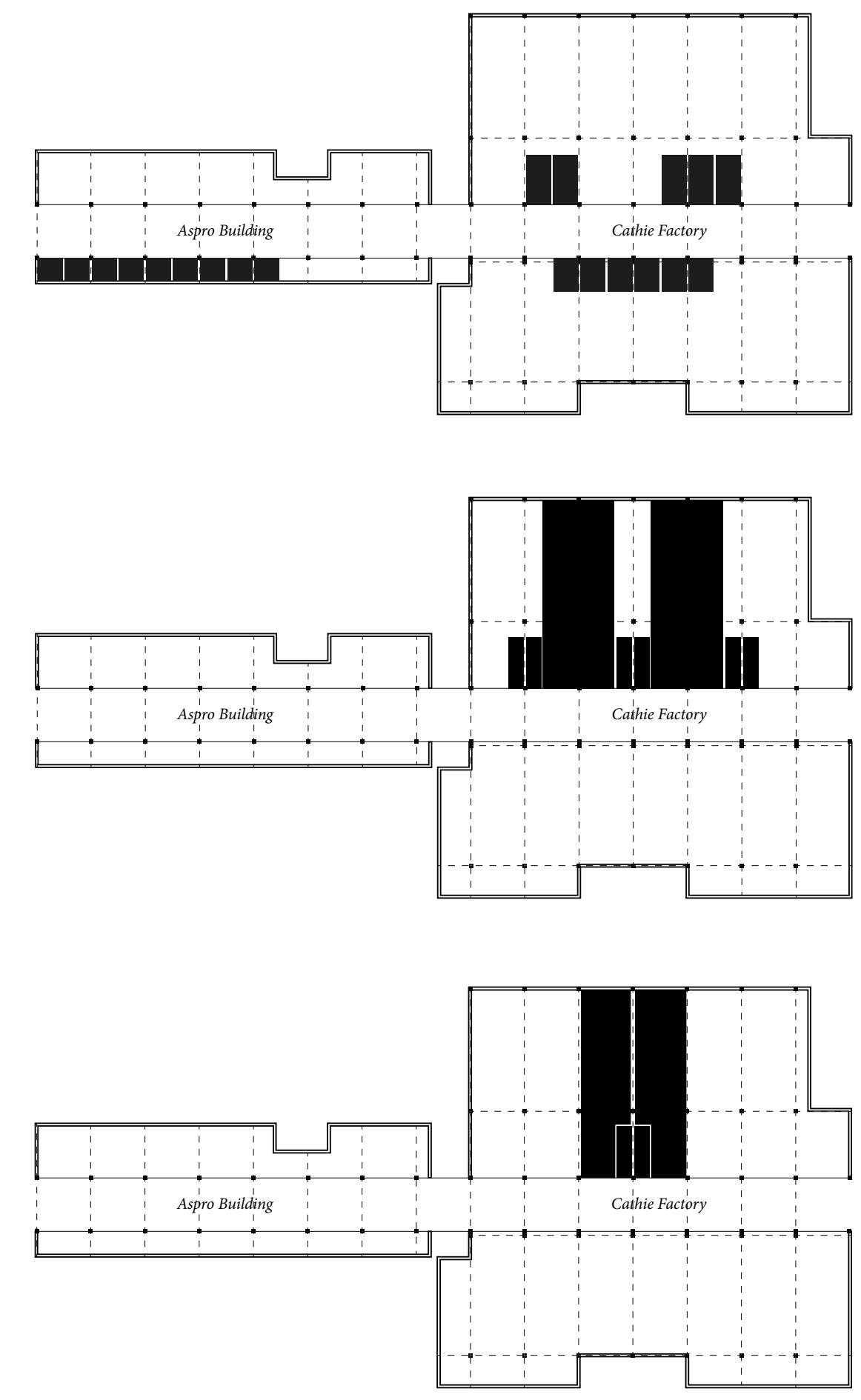

II

This segregation of programme through structure was translated in the design scheme, guiding how the various mixed use is programmed around the arcade (figure 4.24).

Figure 4.24 (Above) Diagrams of three floorplans showing programme fitting within the existing structural grid. Top: Two street vendors fit within each structural module. Middle: Stairwells and offices sppread across two structural modules. Bottom: Each apartment fits into one structural module. 

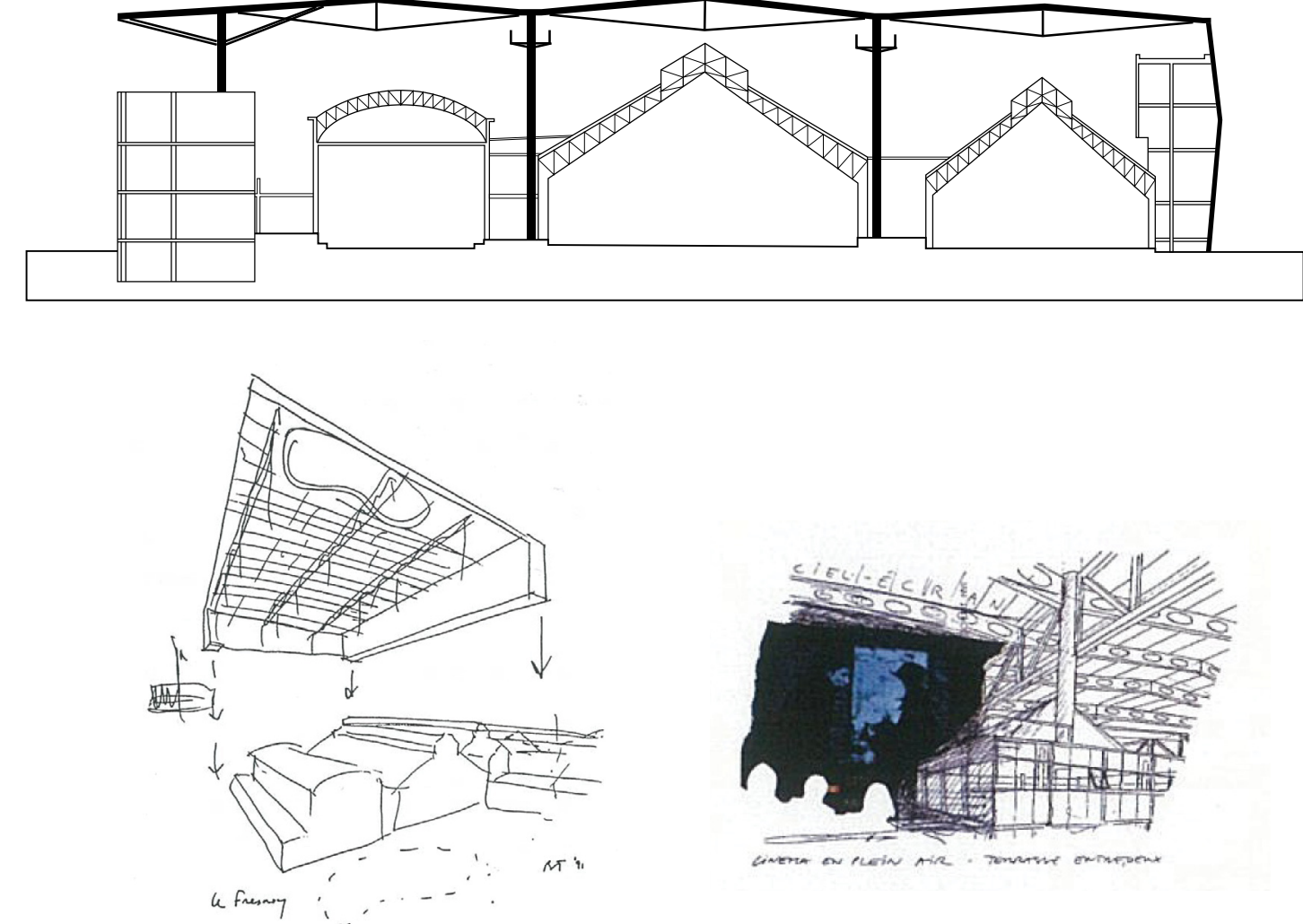

Figure 4.25 (Top) Sectional diagram through Le Fresnoy, showing the relationship between the existing buildings below and the prevareching structure abore.

Figure 4.26 (Bottom) Two of Bernard Tschumis sketches of Le Fresnoy showing the original design strategy of the in-between?

What's done?

The site was originally a leisure park in its peak of popularity in the 1920s and 1930s. By the early 1990s, however, it was completely derelict having been abandoned for over twenty years. Although the buildings were unstable and leaking an artist community had taken over the buildings, using them for exhibitions and installations (Tschumi, 260).

The grand scale of the existing spaces was not allowed for in the allocated budget for reconstruction, and demolition of these buildings would destabilise the community which had formed around them. The proposal consequently kept the existing buildings and placed a technologically new roof over the existing to protect and upgrade the old buildings (Tschumi, 261) (figure 4.25).

The superposed roof generated a new in-between space for inhabitants, and although it was totally utilitarian in its design (composed of structure, ducts, lights etc), it also provided new social and spatial opportunities (figure 4.26). The in-between region was activated through ramps and walkways that weave through the existing rooftops, and connect the facilities housed in the original buildings (Tschumi, 265).
Along the line

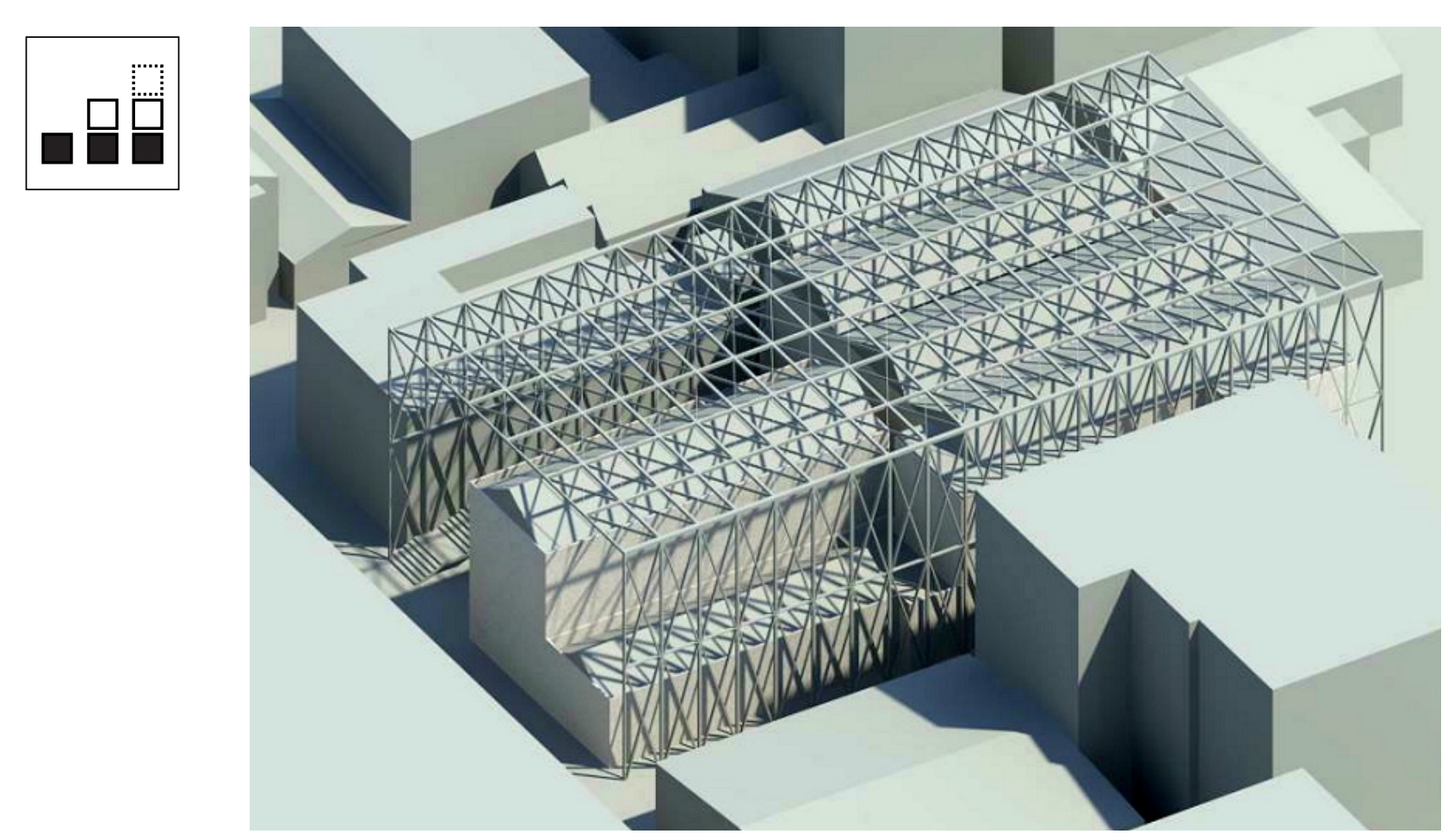

Figure 4.27 Render of the design experiment of a structure that enveloped the entire site.

Along the line

In May, a three-dimensional truss structure was placed over the entire site, wrapping around the Cathie Building, Aspro Building, neighbouring timber villa and the Theosophical Society (figure $4.27)$

The spatial conditions between the structure and the buildings provide opportunities for a new form of inhabitation in the city. The earthquake prone buildings were tied back to this overarching structure with steel tension cables. This secured the facades and overall building envelope. Two voids pierced through the centre of the two buildings, tying the floor diaphragms back to the overarching structure (figure 2.28).

This bold approach implied an aesthetic similar to Superstudio’s mega-structures, however was discarded due to the dominating visual impact it would have on the existing buildings and from a pedestrian perspective. 


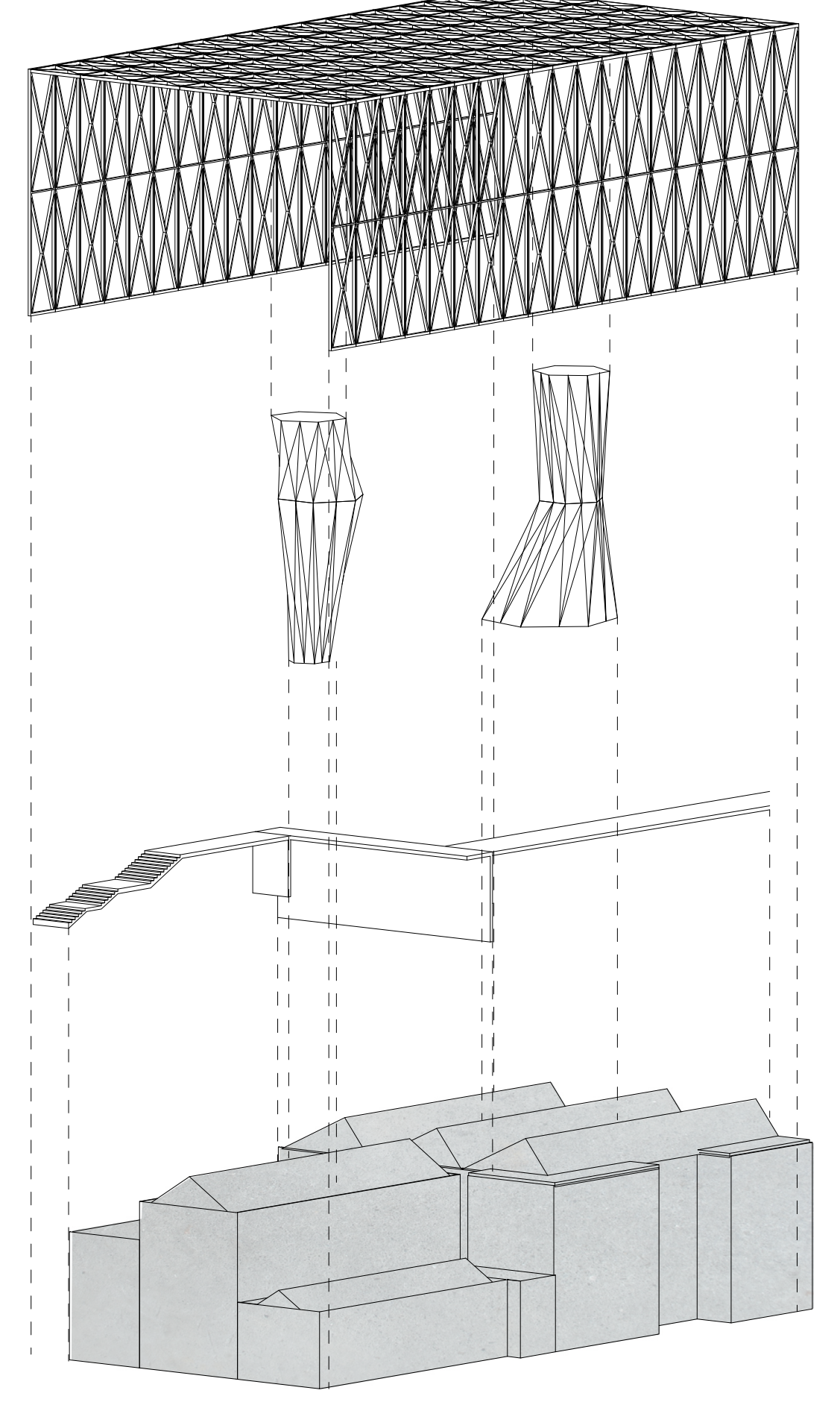

Figure 4.28 (Above) Exploded axonometric of May proposal with overarching structure and structural

voids which tie into the existing buildings

Figure 4.29 (Opposite) Clear perspex model of the existing structure of the Cathie Building with the void and roof trusses would function with the void removed, and how transverse strengthening could be integrated into the existing.

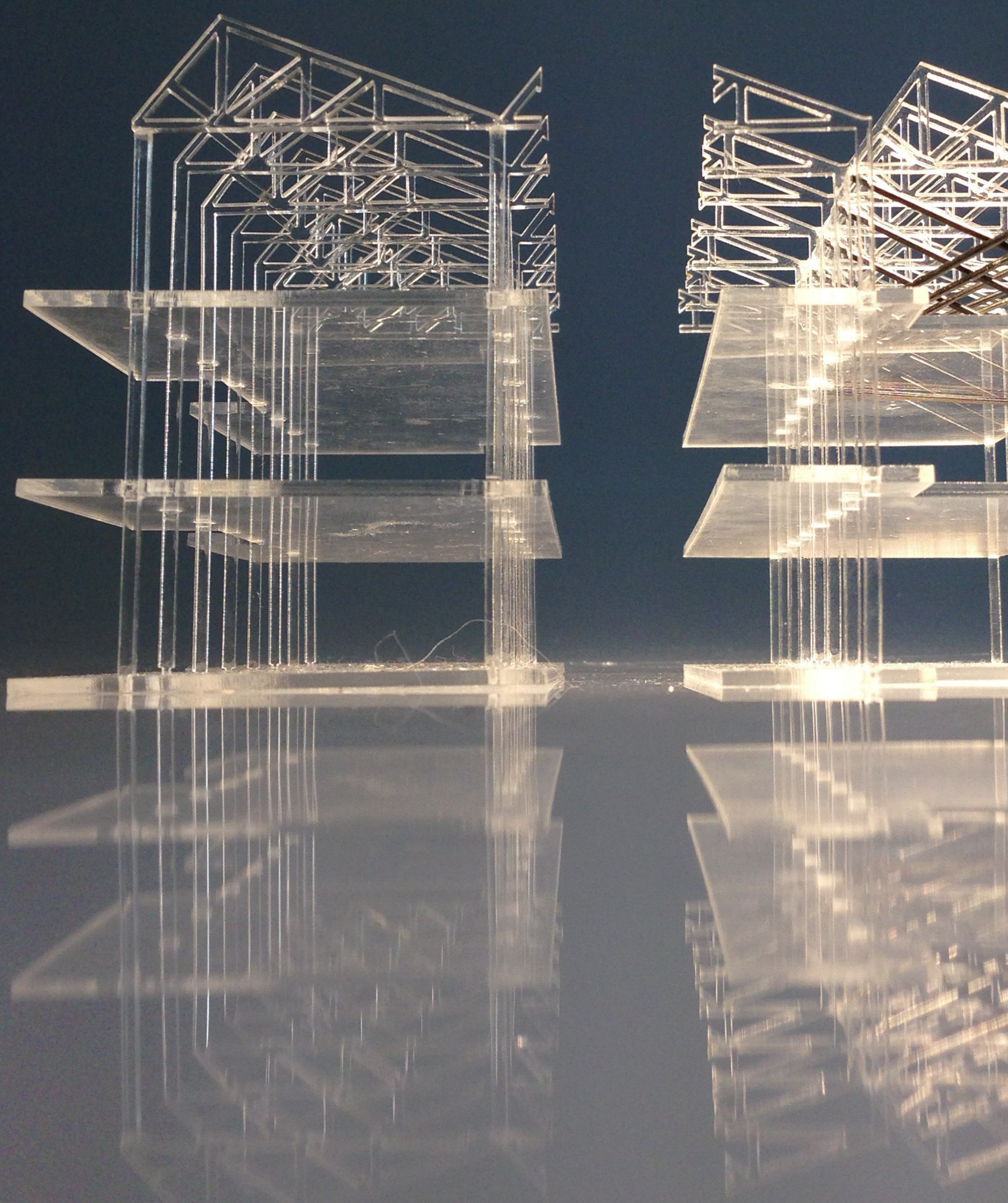




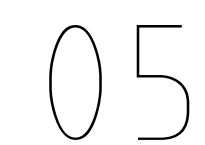

CARBON COPY

car.bon co.py

The pattern cut into the steel screens was derived from existing conditions on site. Materials and textures were overlaid and simplified to create a rasterised image. This was altered to satisfy programmatic and lighting requirements of the interior spaces. The pattern was then redistributed in order to transfer lateral and gravity loads through the screen itself. The fusion with the structure assisted in providing strength in these paths. The rhythm of common structural systems was used as a fundamental generator of pattern (figure 4.30). Through this iterative process the patterned screen, and consequently the lighting and atmosphere within the arcade, is directly related to the pragmatic requirements of the project. Performing as effectively as standard strengthening techniques, the patterned steelwork allows pedestrians to appreciate the specificity to site and an architectural alternative to an engineering problem

"But this mechanised ornament is structural. Indeed, it restructures the body that wears it." (Wigley, 8)

\section{Who said?}

The role of the pattern becomes a form of enrichment for architecture, expressing function and emphasising structure (Gleiniger, 21). Patterns can form unexpected connections between various project requirements through a graphically consistent solution (Andersen, 25). They also have the possibility to reshape mundane building systems, providing a balance between practicality and visual ornament (Andersen, 32).

\section{What's done?}

The following two cases studies, the 0-14 Tower by Reiser + Umemoto and the Prada Aoyama Store by Herzog and De Meuron, illustrate how pattern and structure can be merged into an interesting visual outcome.

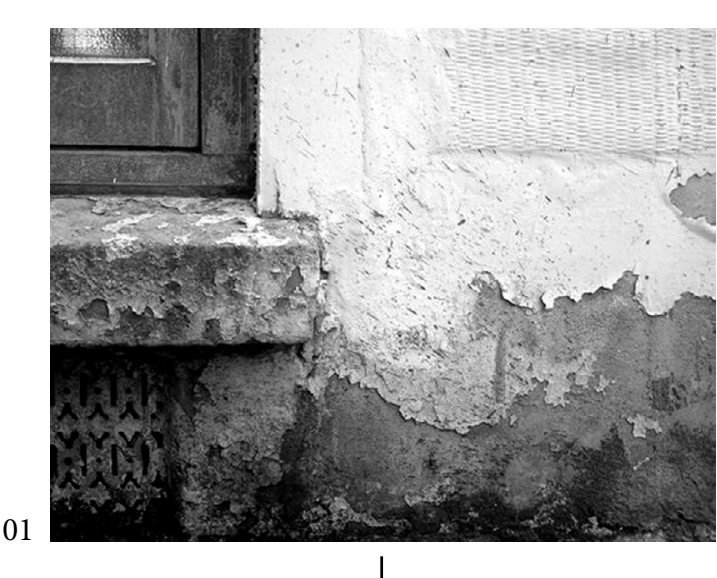

$\downarrow$

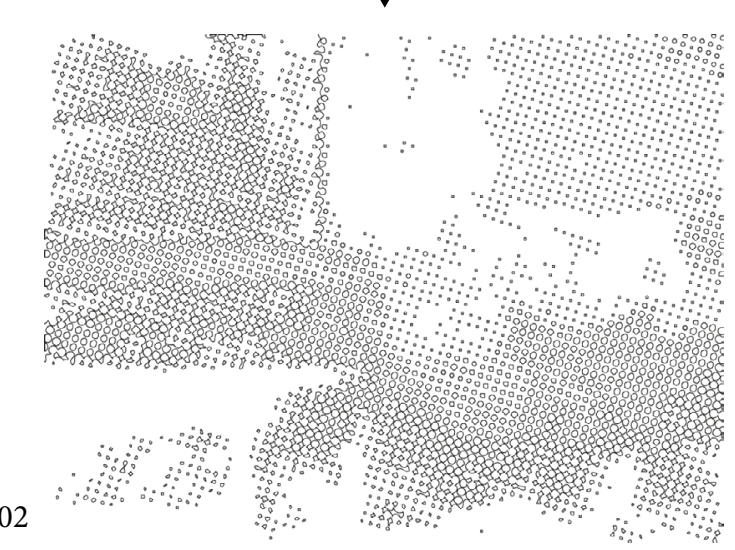

$+$

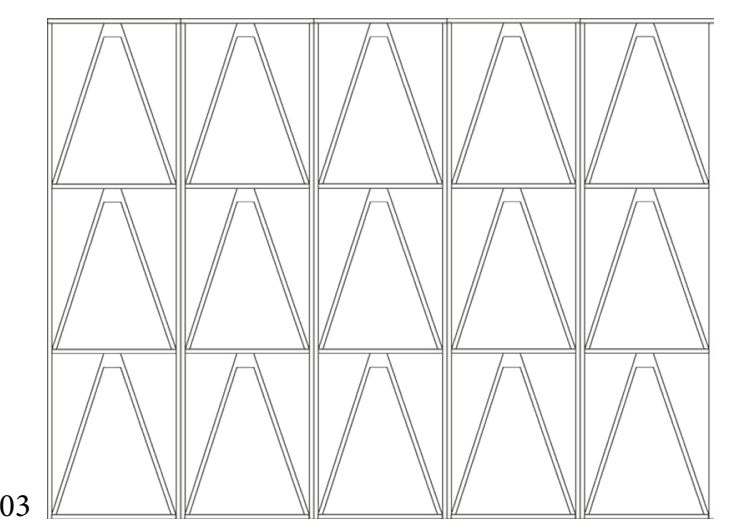

$=$

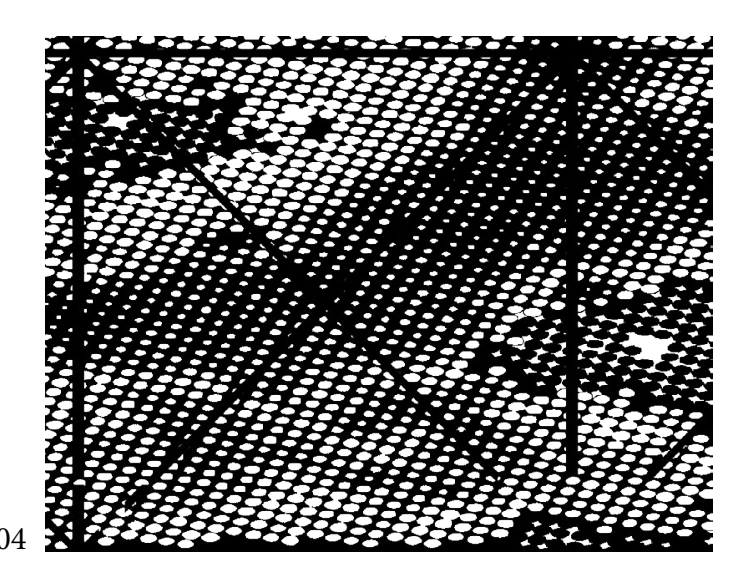


CASE STUDY

0-14 Tower, 2007-2010. Dubai, United Arab Emirates. Architect: Reiser + Umemoto.

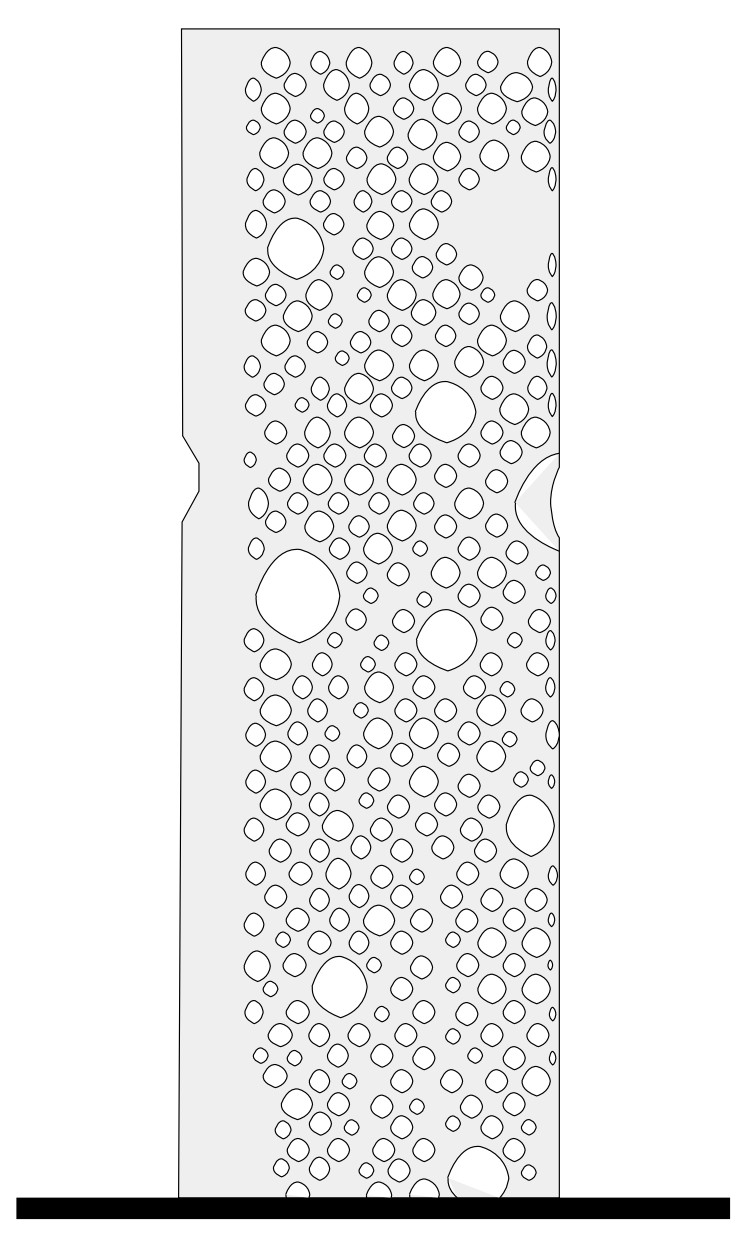

Figure 4.31 Elevation of the 0-14 tower. The concrete exoskeleton has been cut to meet structural, lighting and programmatic requirements.

The $0-14$ Building by Reiser and Umemoto is a large tower project built in Dubai in 2007. The external concrete shell of the building provides a structural exoskeleton that frees the core of the building from lateral forces, creating a column-free open space in the building's interior. A patterned diagrid was imposed upon their building, establishing relationships between material, structure, environmental, and optical effects (Andersen, 26). I was particularly interested in the relationship between the pattern and its structural competencies, a relationship Steele describes in his book '014 Projection and Reception' as follows: "If we introduced a larger opening, the openings immediately below had to become more solid. The variation on the facade was therefore part of an active exchange with the structural engineers. Over the course of the facade's design, load paths were elaborated relative to the simple diagrid. A centreline for the diagrid was drawn up and the openings could drift around the grid lines for a maximum distance, allowing flow lines to move through the field of holes in a fluid way"(113).
CASE STUDY

Prada Aoyama, 2000-2003. Tokyo, Japan. Architect: Herzog \& De Meuron
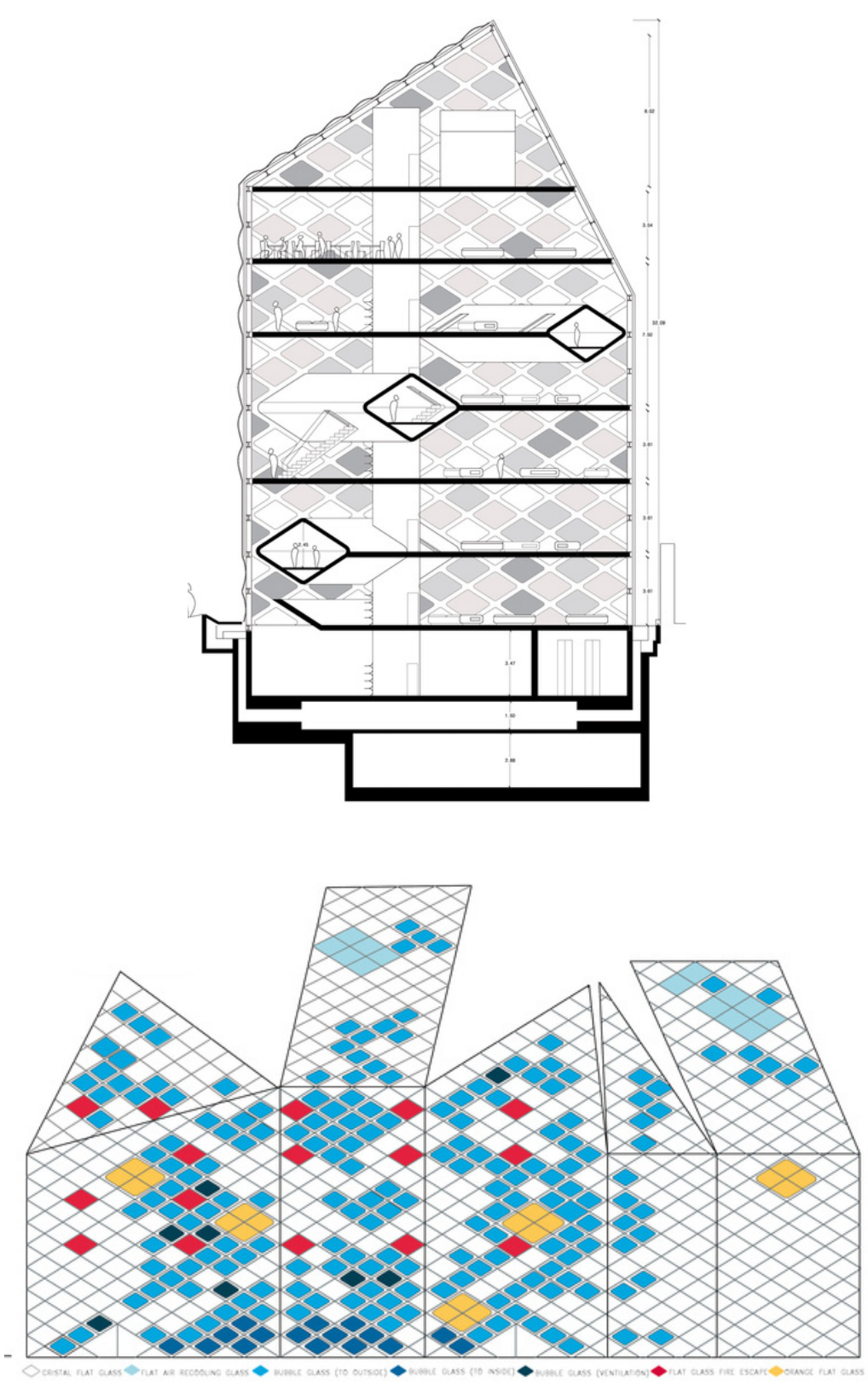

-

This use of an underlying diagrid envelope is an interesting technique also used by Herzog and De Meuron in their Prada Store façade design in Aoyama. Due to the diagrid's uniform diamond pattern it acts as structural solution for earthquake strengthening. Each diamond module is capable of containing a variety of materials, building systems and effects (Andersen, 25).

Figure 4.32 (Top) A cross-section through the building reveals how the modules on the patterned facade extend to function with the interior programmes.

Figure 4.33 (Bottom) The unfolded elevation of the project illustrates how the pattern is able to meet various demands (various treatments of glass are highlighted above) with a graphically consistent solution (Andersen, 32). 

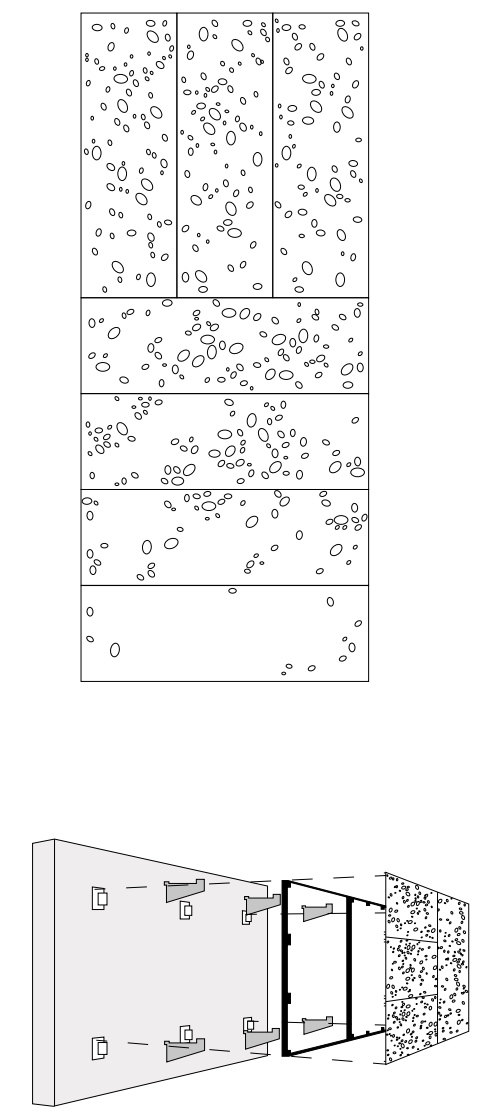

Patterned screens were experimented with on the facades of the existing in order to support the

$\square \square$ existing masonry (figure 4.38). A uniform pattern was cut within the profile of the existing facades, and this was adjusted so that the perforations are slightly bigger where the windows are. This ghosting of the existing window layout was discarded in the Cathie Building due to the dim lighting in the interior spaces. However, it was implemented on the east and west facades of the Aspro Building along with cross bracing to strengthen the weak masonry.
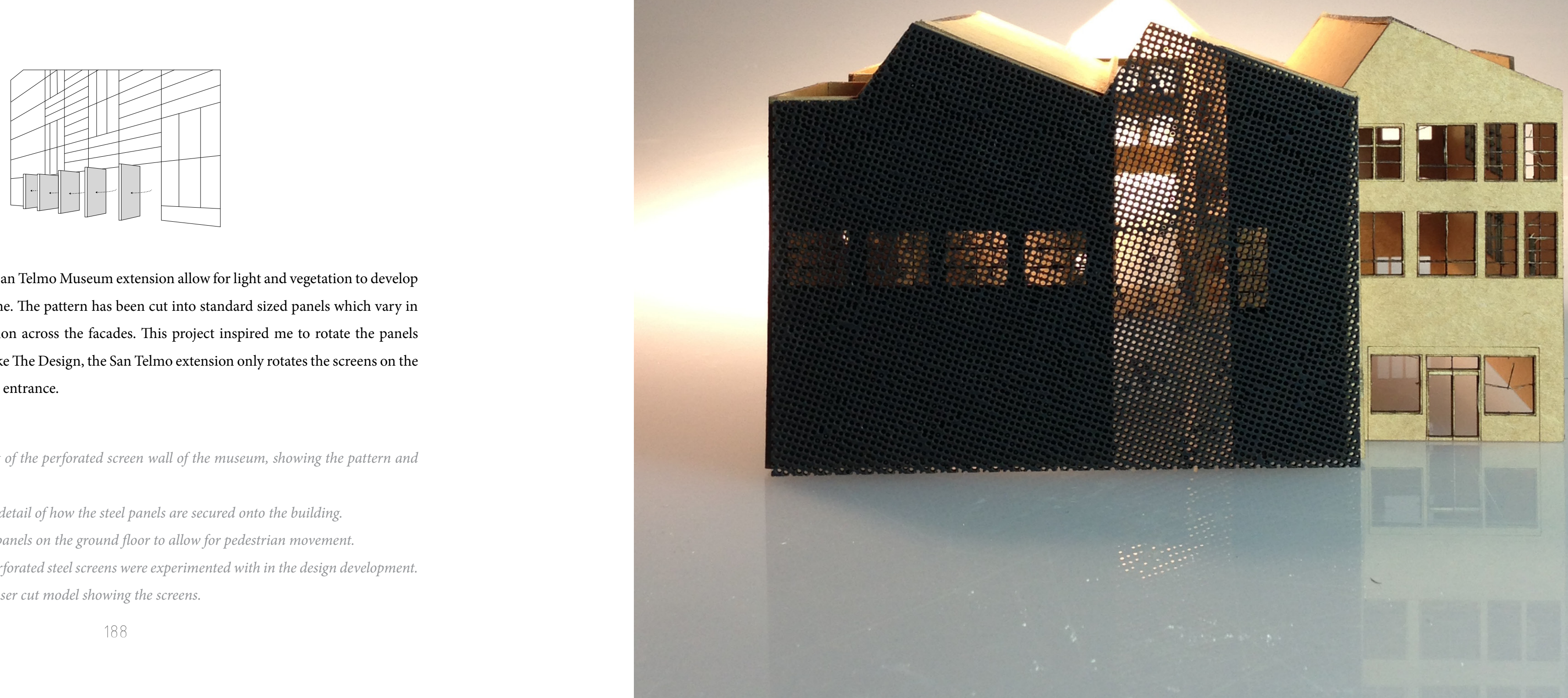

The perforated screens on the San Telmo Museum extension allow for light and vegetation to develop and change the facade over time. The pattern has been cut into standard sized panels which vary in vertical or horizontal orientation across the facades. This project inspired me to rotate the panels within the void. However, unlike The Design, the San Telmo extension only rotates the screens on the ground floor to mark the main entrance.

Figure 4.35 (Top) Detail of part of the perforated screen wall of the museum, showing the pattern and the orientation of the panels.

Figure 4.36 (Middle) Exploded detail of how the steel panels are secured onto the building

Figure 4.37 (Bottom) Rotating panels on the ground floor to allow for pedestrian movement.

Figure 4.38 (Opposite) Black perforated steel screens were experimented with in the design development. This image is a photographed laser cut model showing the screens. 

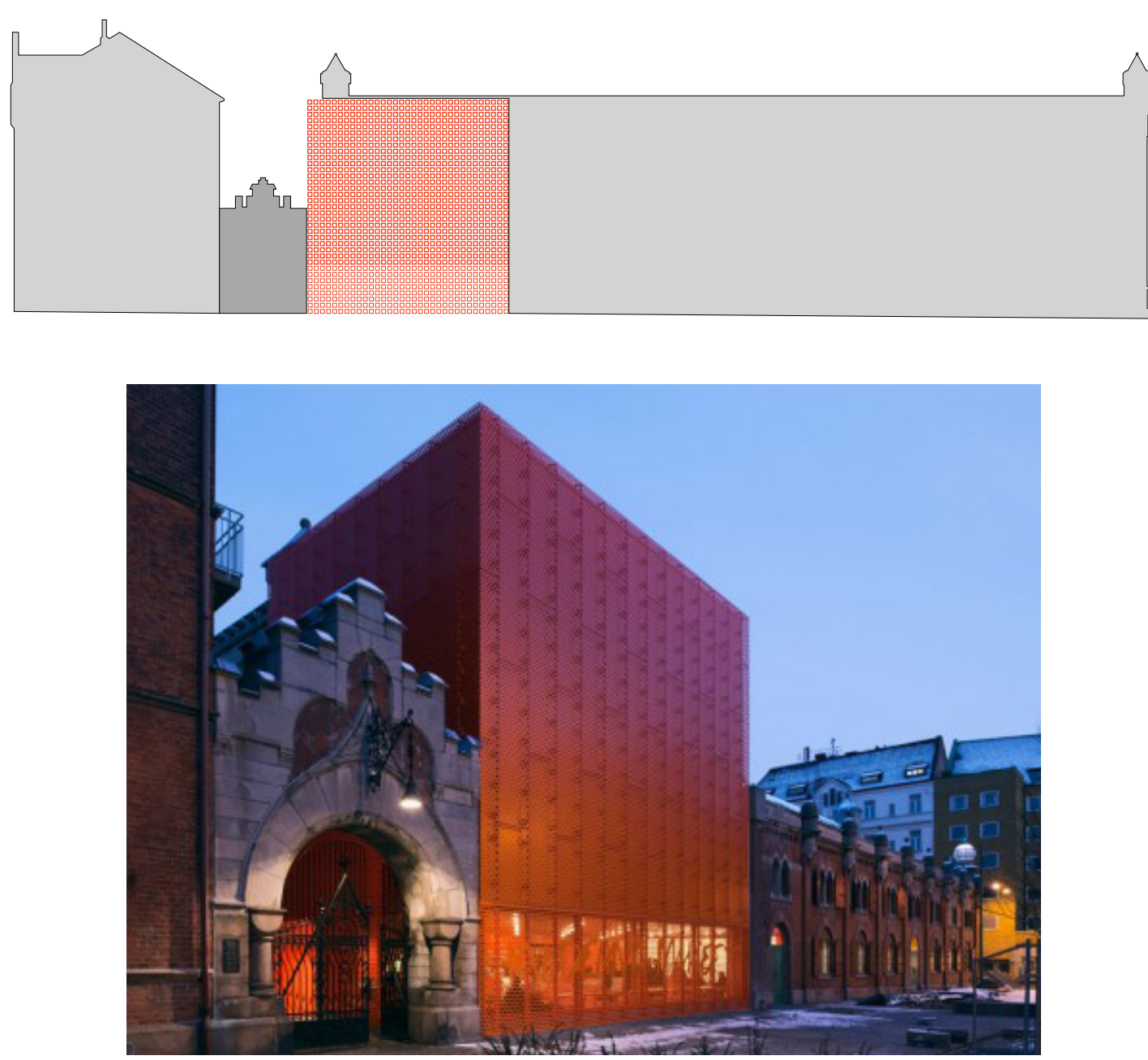

What's done? The extension to the Moderna Museet Malmö is an extreme contrast to the surrounding context
and the existing buildings. The simplicity of the cube form with its minimal detailing contrasts with the classical details of the neighbouring facades. However, the proportions of the intervention are cohesive with the scale of the existing building, allowing the profile to be continued and extended out beyond the end of the building. Light passes through the perforated steel screens from the interior, a striking contrast to the solidity of the surrounding stonework (figure 4.39). These aspects aside, the most notable feature of this project is the fact that it is bright orange. Although completely contrasting to the colour scheme of the city, the burst of colour is bold and refreshing.

Figure 4.39 (Top) Simplifed diagram of the material and colour treatment of the elevation of the Moderna Museet Malmo

Figure 4.40 (Bottom) Photograph showing how explicitly the orange cube juxtaposes its surroundings.
CASE STUDY

The Orange Cube, 2005-2011. Quai Rambaud, Lyon, France. Architect: Jakob + Macfarlane Architects.
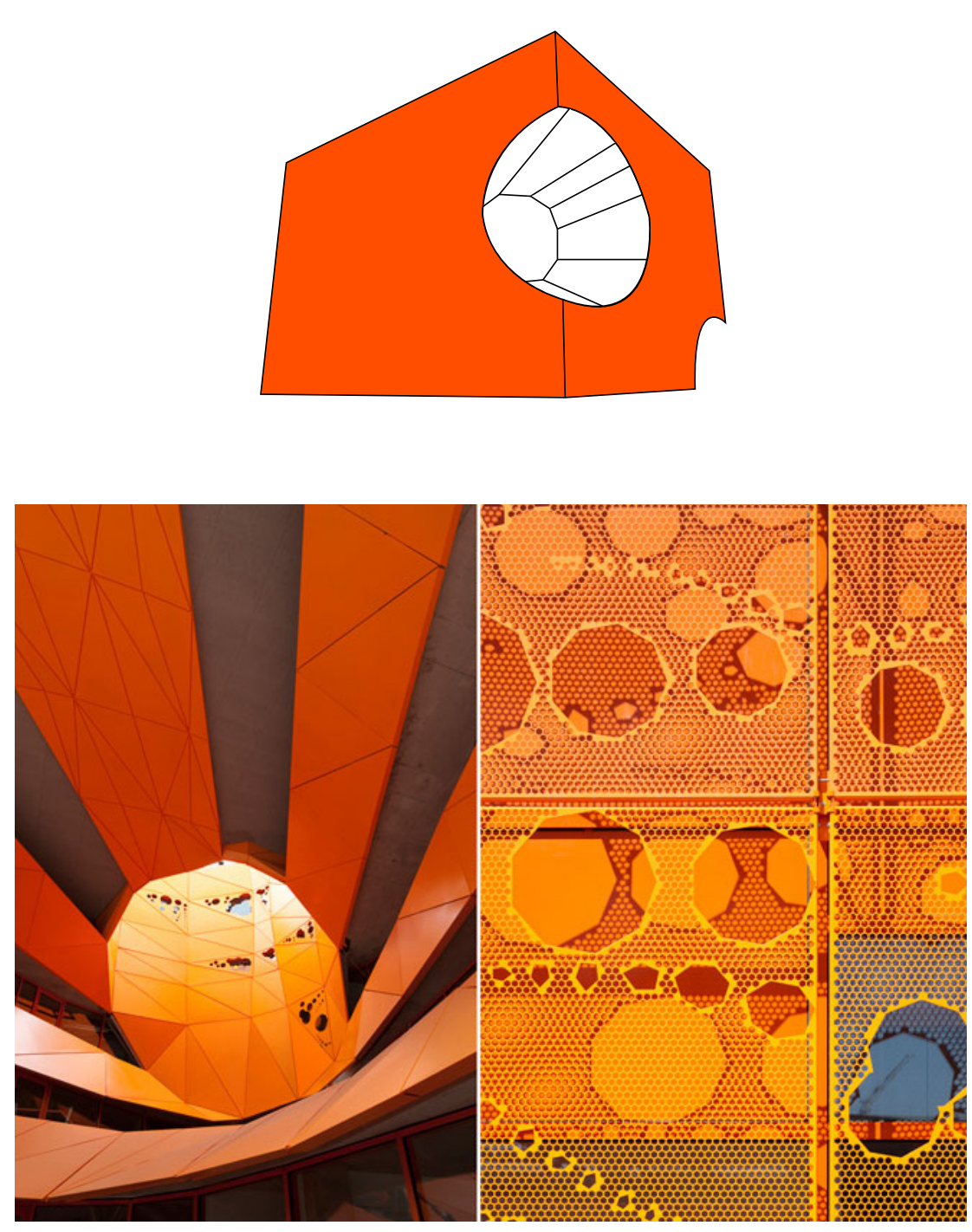

(1)

This use of coloured perforated screens was also prevalent in 'The Orange Cube' project by Jakob + Macfarlane Architects. A conical scoop has been carved out of the simple cube form, allowing both form and colour to make a bold statement to people passing by. The curved form within a rectangular form draws parallels with integrating the curve in The Design. These two projects encouraged me to consider introducing coloured steel in The Design. The following pages show varoius colour tests that were undertaken, and eventually discarded for a black and white scheme.

Figure 4.41 (Top) Diagram of 'The Orange Cube' emphasising the simplicity of form and the boldnes. of coloun

Figure 4.42 (Bottom) Photographs of 'The Orange Cube' from within the conical form and a close up of the orange perforated screens. 


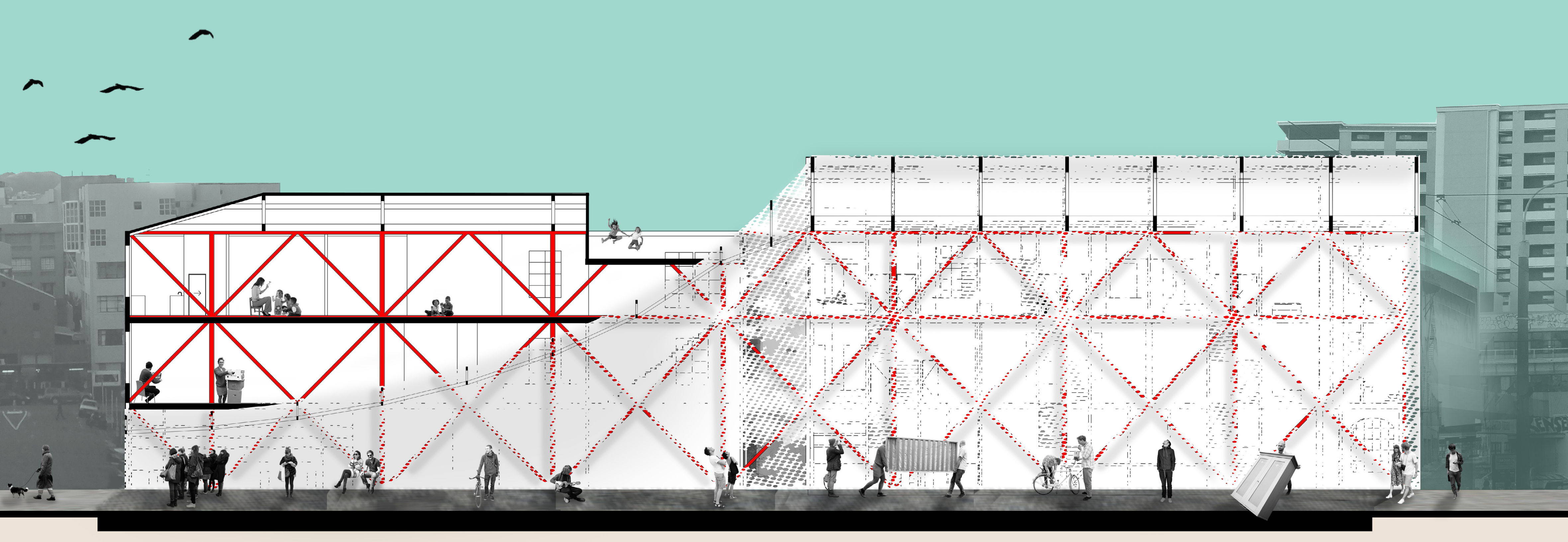

므뭄 


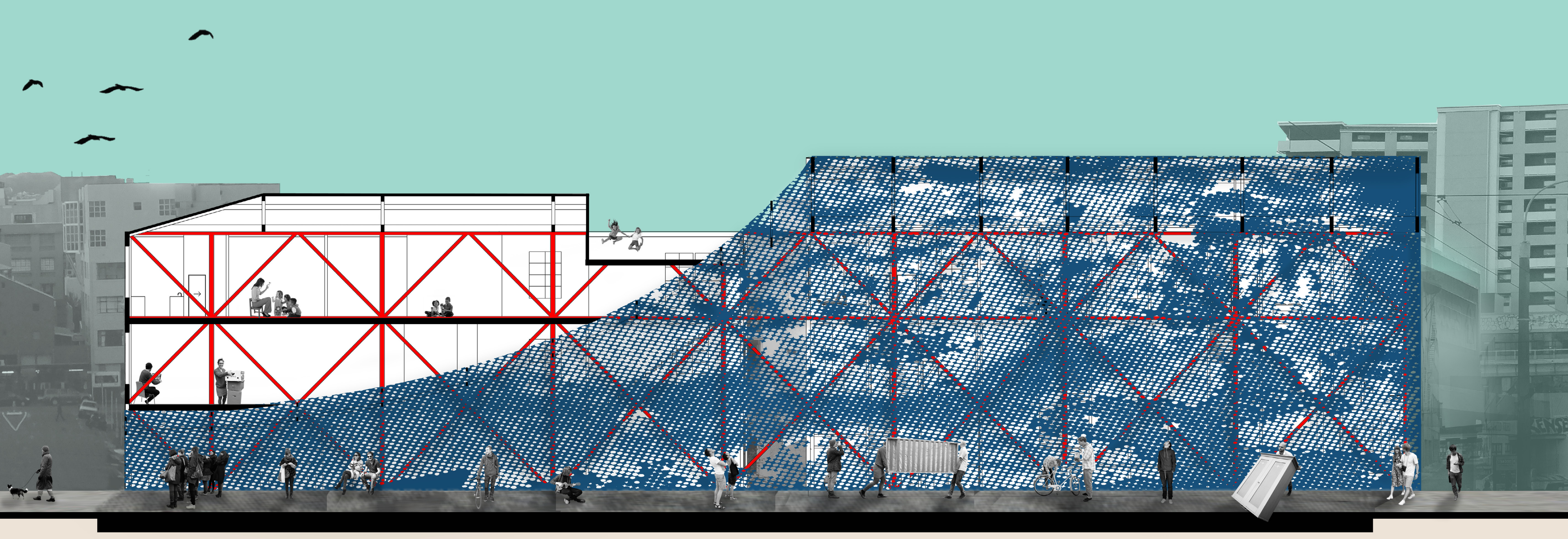

므묘 


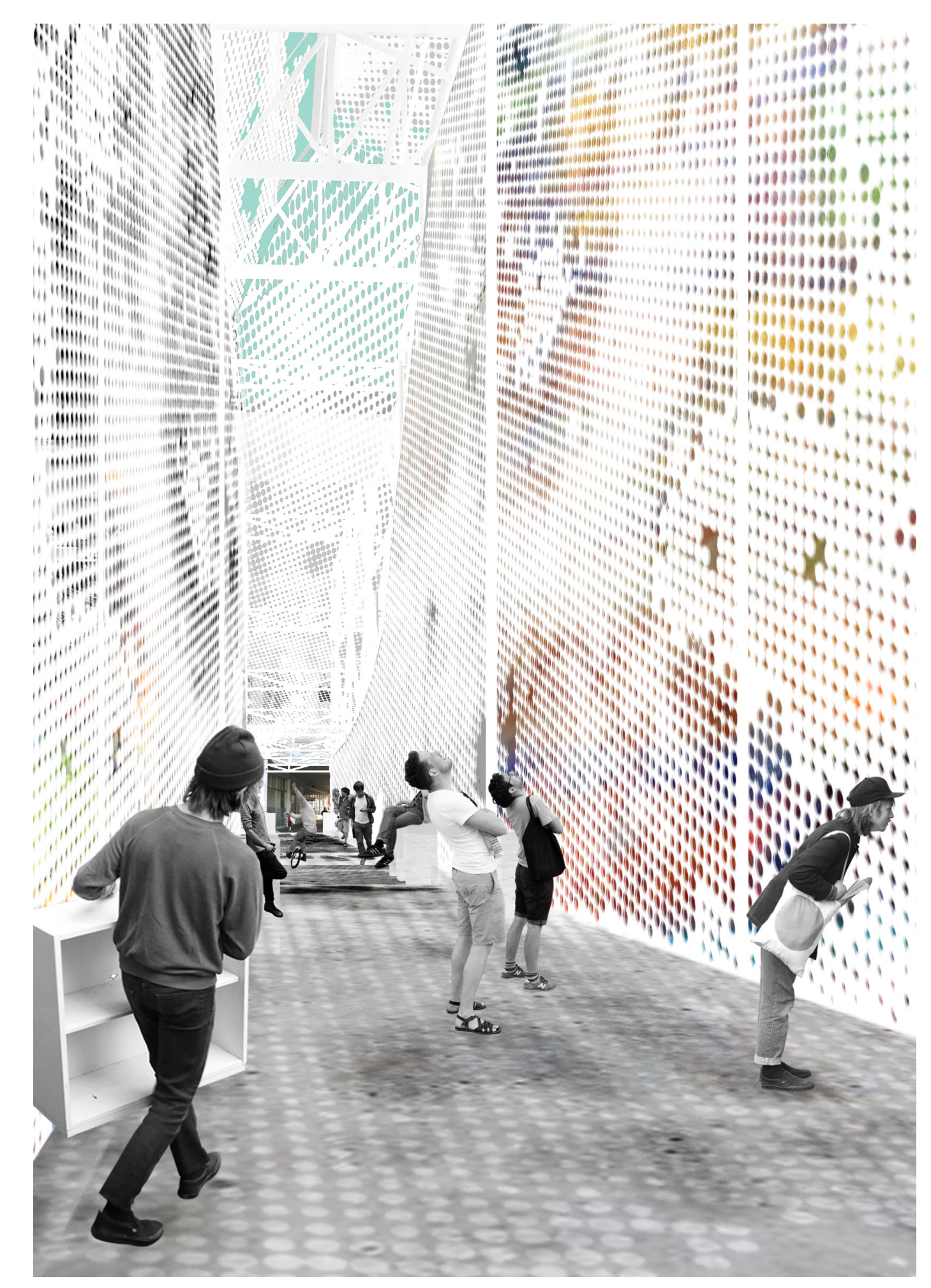

Figure 4.47 Interior perspective colour test: white pattern, white structure. 


\section{THE END}

ex*eogeosis

Noun. Critical explanation or interpretation of a text (and, in this case, of a design)

This thesis developed from two problems: 626 buildings in Wellington are condemned as earthquake prone, and many pedestrian routes through the city are disconnected and lack vibrancy. The extent of earthquake strengthening that has to occur in Wellington provides an exciting opportunity for architecture. The Design was an architectural response to strengthening and revitalising underutilised older buildings, whilst also improving the pedestrian network.

The annotated approach to research meant that the focus was primarily on the design process and outcome, and review of previous work was evaluated through the design itself. Case studies and literature reviews, along with various process experiments, have provided a thorough understanding of the project in terms of pattern and structure, void and curve. This research discovered the following:

The importance of connection

The Design revealed the need for both horizontal and vertical connection in our cities. The Design linked the two buildings to the surrounding street network and provided a space wide enough for movement and interaction between users. The vertical cut allowed visual connection between pedestrians at ground level and the upper floors of the Cathie Building, enhanced through the perforations and pivoting of the steel screens.

Providing strength

Provision of public space through strengthening was an important development in this project, allowing a single intervention to not only strengthen two earthquake prone buildings, but also to provide a strong sense of place in the city.

Old + new

It was a challenge integrating a new intervention into existing building fabric without compromising the character of the old buildings. This was negotiated through experimentation with scale, materiality, geometry and pattern. The Design provided a new use for the existing site, upcycling the block aesthetically, structurally and programmatically.

The unexpected

Engagement between pedestrians and their urban surroundings was another important outcome of The Design. The form of the swoop provides an unusual discovery within the city's pedestrian network. 


\section{Opportunities and limitations}

The economic and sustainable benefits of upcycling existing building fabric are considerable. The cost, resources and time for rebuilding over six hundred buildings is enormous and there would be significant loss of heritage character.

The thesis focused on the architectural qualities of earthquake strengthening for a single site. Implementing strengthening for an entire city has many additional challenges. Practical realities, such as cost and construction times, would be crucial to establish whether The Design is feasible in other settings. Structural issues, such as tolerance and strength, resulting from cutting into different buildings would also require detailed analysis

The swoop challenges the geometries and scale of the existing buildings. Although it offers an interesting juxtaposition with the surroundings and creates a unique internal space, there is scope for further refinement in terms of its structural integrity and influence on surrounding programmes. The form of the curve, with its patterned screens and structural composition, could also be altered to respond to different buildings in the city.

\section{The future city}

With time, the city grows upon itself; it acquires a consciousness and memory. In the course of its construction, its original themes persist, but at the same time it modifies and render these themes of its own development more specific.

(Rossi, 21)

The principles of The Design could be replicated for other earthquake prone buildings at varying scale and form. The context of other sites could inform different shapes, patterns and colous responding to particular qualities of the buildings. In addition to providing a new network of public space within the city, pedestrians would be encouraged to interact with and acknowledge change in the built environment on their journey across Wellington.

This architectural approach to seismic strengthening could also be applied to new construction throughout New Zealand, for example new buildings in Christchurch. There is an opportunity to strengthen buildings in a way that increases permeability and connectivity.

The Design offers a solution that partially preserves existing buildings, creates a unique and contemporary addition to the city, revitalises poorly utilised areas and enhances connections between urban spaces. 
List of case studies [in order of appearance]

\section{VOID}

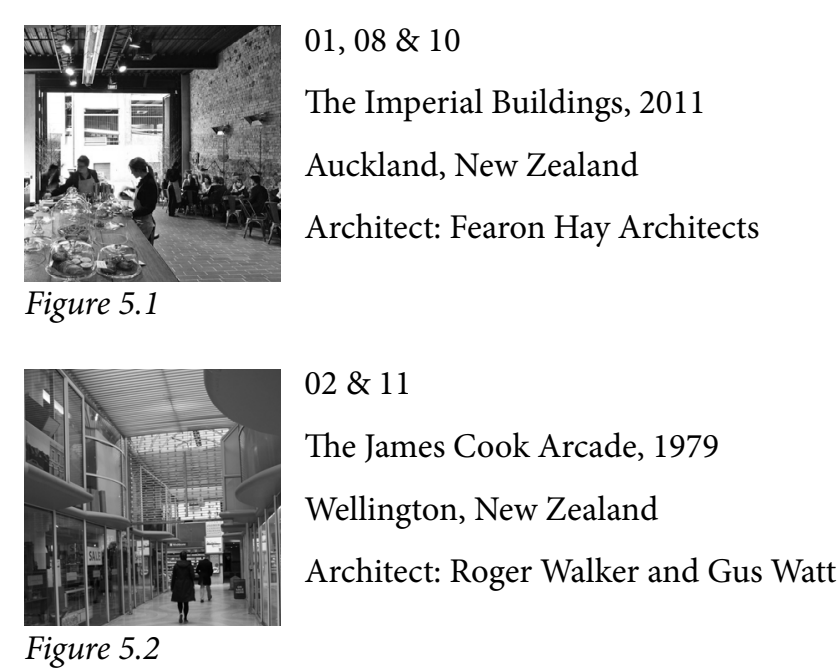

Spew Jersey, United States
Artist: Gordon Matta-Clark




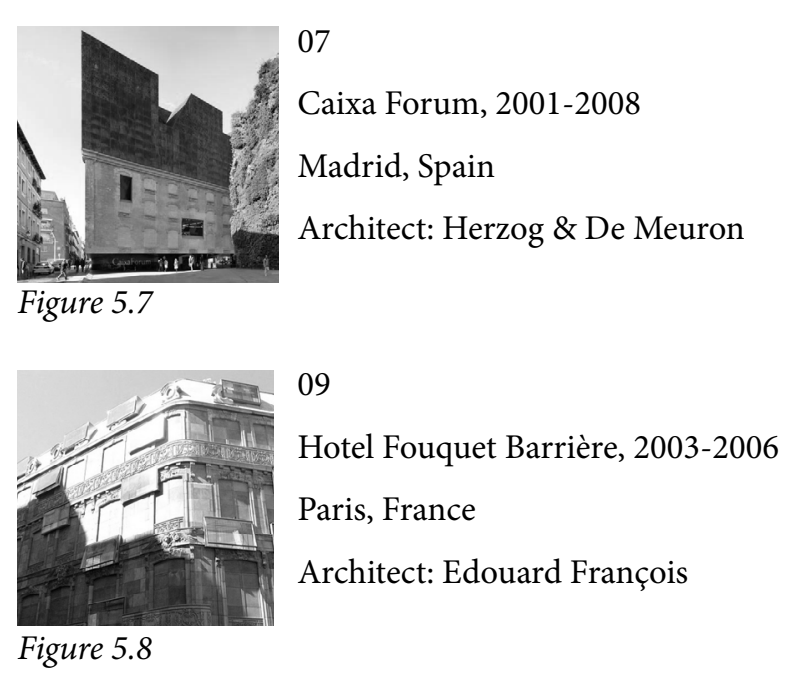

CURVE

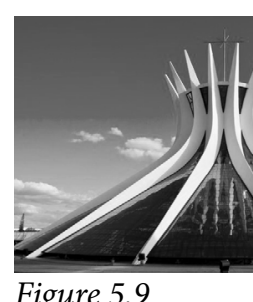

12

Cathedral of Brasilia, 1960-1970

Brasília, Brasil

Architect: Oscar Niemeyer

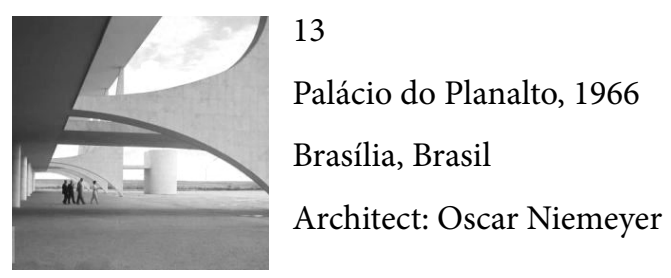

Figure 5.10

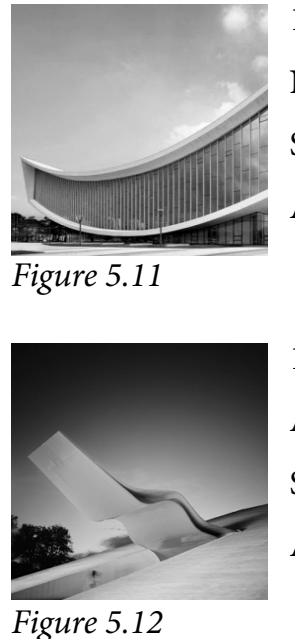

(1) 2013

Sejong City, Korea

Artist: S.A.M.O.O Architects

2002-2005

Sao Paulo, Brasil

Architect: Oscar Neimeyer

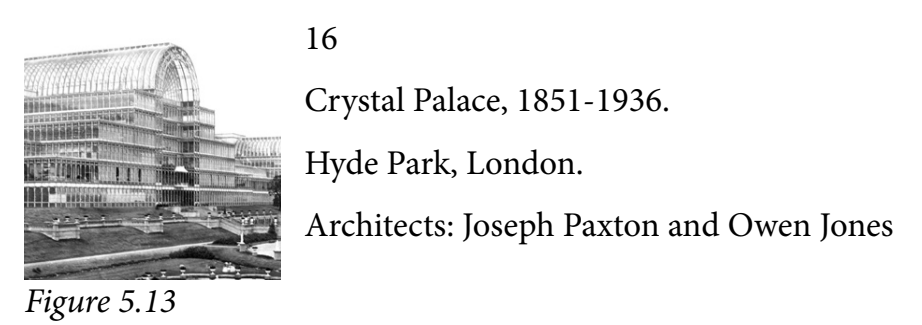

17

Ville Spatiale (The Spatial City) 1959-1962

Paper architecture, Paris, France.

Architect: Yona Friedman and Geam

Figure 5.14

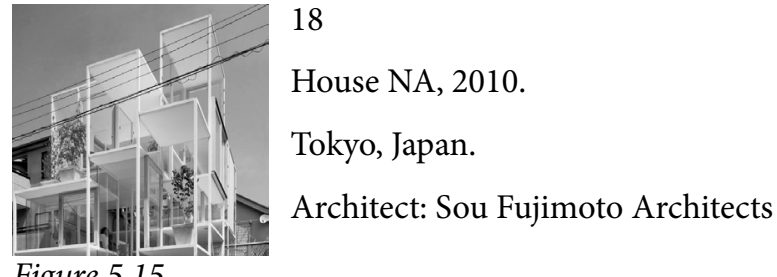

150

Le Fresnoy National Studio for Contemporary Arts, 1991-1997. Tourcoing, Nord-Pas-de-Calais, France. Architect: Bernard Tschum

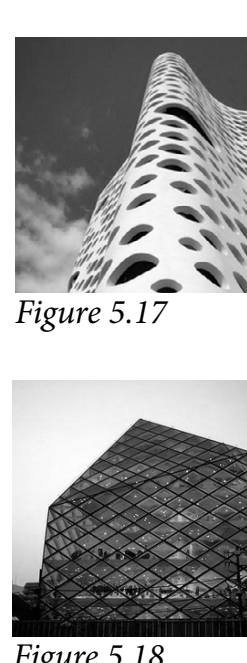

20

0-14 Tower, 2007-2010

Dubai, United Arab Emirates.

Prada Aoyama, 2000-2003.

Tokyo, Japan.

Architect: Herzog \& De Meuron 


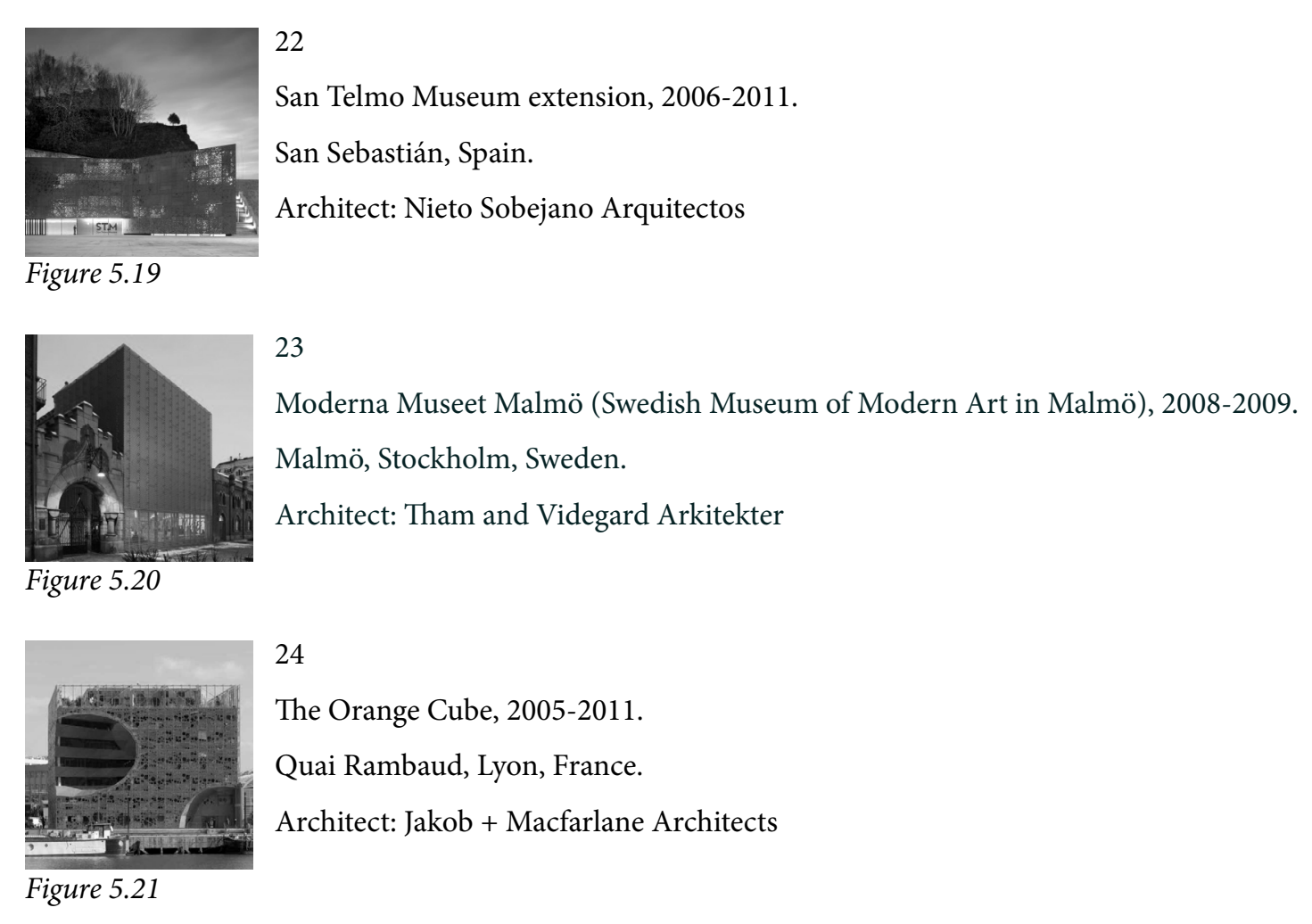


Adams, William Lee. "Do These Buildings Turn You On? The Strange Psychology of Curvy Architecture." CNN. Cable News Network, 26 Nov. 2013. Web. 07 Jan. 2014. <http://edition.cnn. com/2013/11/26/world/do-these-buildings-turn-you-on/s.

Alexander, Christopher, Sara Ishikawa, and Murray Silverstein. A Pattern Language: Towns, Buildings, Construction. New York: Oxford UP, 1977. Print.

Andersen, Paul, and David L. Salomon. The Architecture of Patterns. New York: W.W. Norton \&, 2010. Print.

Attlee, James, Lisa Le Feuvre, and Gordon Matta-Clark. Gordon Matta-Clark: The Space Between. Tucson, AZ: Nazraeli, 2003. Print.

Benjamin, Walter, and Rolf Tiedemann. The Arcades Project. Cambridge, MA: Belknap, 1999. Print.

Benjamin, Walter, Edmund Jephcott, Howard Eiland, and Michael W. Jennings. Walter Benjamin: Selected Writings. Vol. 4, 1938-1940. Cambridge, Massachusetts: Harvard UP, 2003. Print.

Blaisse, Petra. Inside Outside. New York: Monacelli, 2009. Print.

Charleson, Andrew. Seismic Design for Architects: Outwitting the Quake. Amsterdam: Elsevier/ Architectural, 2008. Print.

Charleson, Andrew. Structure as Architecture: A Source Book for Architects and Structural Engineers Oxford: Elsevier/Architectural, 2005. Print.

Clark, Roger H., and Michael Pause. Precedents in Architecture: Analytic Diagrams, Formative Ideas, and Partis. Hoboken, NJ: John Wiley \& Sons, 2012. Print.

Conroy, B. The Arcade: A study of the traditional concept of an arcade, and its implications to contemporary Wellington. Thesis. Victoria University of Wellington, 1984. Print.

Dorwick, David. Earthquake Resistant Design and Risk Reduction. Second Edition. United States: John Wiley \& Sons, 2009. PDF.

"Earthquake Prone Buildings Policy." Wellington City Council. Wellington City Council (WCC), n.d. Web. 18 Mar. 2013. < http://wellington.govt.nz/services/rates-and-property/earthquake-pronebuildings/earthquake-prone-buildings-policy >
Geist, Johann Friedrich. Arcades: The History of a Building Type. Cambridge, MA: MIT, 1983. Print.

Gleiniger, Andrea, Georg Vrachliotis. Pattern: ornament, structure, and behavior. Boston: Birkhäuser 2009. Print.

Jacobs, Jane. The Death and Life of Great American Cities. New York: Random House, 1961. Print.

McClean, Robert. Earthquake Strengthening - Improving the Structural Performance of Heritage Buildings. Update of Guidelines for Earthquake Strengthening. Wellington: New Zealand Heritage Places Trust (NZHPT), 2010.

“New Zealand Building Act." Public Act 2004, No.72. Reprint as at 1 January 2014.

Niemeyer, Oscar. The Curves of Time: The Memoirs of Oscar Niemeyer. London: Phaidon, 2000. Print.

Palma, Vittoria Di, Diana Periton, and Marina Lathouri. Intimate Metropolis: Constructing Public and Private in the Modern City. London: Routledge, 2008. Print.

Pound, Christopher. Arcade spaces in Wellington: A study of the functions that arcade spaces perform in Wellington's central business district. Thesis. Victoria University of Wellington, 1988. Print.

Rajagopal, Avinash. "The Creative Process: Spatial Conversations with Petra Blaisse." Metropolis Magazine. N.p., Mar. 2013. Web. 12 Dec. 2013. <http://www.metropolismag.com/March-2013/TheCreative-Process-Spatial-Conversations-Petra-Blaisse/>.

Robinson, Lou, Ian Bowman. Guidelines for Earthquake Strengthening. Wellington: NZHPT, 2000

Rossi, Aldo. The Architecture of the City. Cambridge, Massachusetts: MIT Press, 1982.

"Splitting: Gordon Matta-Clark." The Metropolitan Museum of Art. Met Publications, 2002. Web. 25 July 2013. <http://www.metmuseum.org/Collections/search-the-collections/266709>.

Steele, Brett D., Jesse Reiser, and Nanako Umemoto. 0-14: Projection and Reception: Reiser Umemoto. London: Architectural Association, 2011. Print.

Tschumi, Bernard. Architecture Concepts: Red Is Not a Color. New York: Rizzoli, 2012. Print.

Wigley, Mark. "Prosthetic Theory: The Disciplining of Architecture." Assemblage 15 (1991): 6-29. JSTOR. Web. 04 Nov, 2013, <http://wwwjstor.org/stable/3171122>. 
Introduction

Figure 1.1 Aerial photo of Wellington with site and pedestrian connection highlighted. Source: AuthorFigure 1.2 People along the line. Source: Author

Figure 1.3 Pattern cut into steel perforated screens in the project. Source: Author.

Figure 1.4 Photograph within black cardboard model of The Design. Source: Author.

Figure 1.5 Four diagrams illustrating the categories within each section. Source: Author.

Figure 1.6 Research diagram showing how The Design responds to the problems. Source: Author.

Figure 1.7 The gap between the Cathie Building and Aspro building. Source: Author.

Figure 1.8 Longitudinal section through The Design. Source: Author.

Figure 1.9 Inside the Cathie Building part of the void during the day. Source: Author

Figure 1.10 Exploded axonometric showing the various components in The Design. Source: Author

Figure 1.11 Perspective inside the Cathie Building part of the void during the night. Source: Author

Figure 1.12 Ground floor plan of The Design. Source: Author.

Figure 1.13 First floor plan of The Design. Source: Author.

Figure 1.14 Second floor plan of The Design Source: Author.

Figure 1.15 Roof plan of The Design. Source: Author.

Figure 1.16 Interior render looking into the low part of the curve from Marion Street. Source: Author.

Figure 1.17 Night render approaching Marion Street from the post office arcade. Source: Author

Figure 1.18 Transverse section through Cathie Building. Source: Author.

Figure 1.19 View from Taranaki Street showing the void cut out of the east facade. Source: Author. Figure 1.20 Photo of the cardboard model of the Cathie Building. Source: Author

Figure 1.21 Rubble on the street post Wairarapa earthquake. Source:

<http://info.geonet.org.nz/display/quake/M+7.2,+Wairarapa+I,+24+June+1942>

Figure 1.22 Timeline for strengthening of these listed buildings. Source: Author.

Figure 1.23 Construction dates of earthquake prone buildings in Wellington. Source: Autho

Figure 1.24 Heritage listed buildings on the earthquake prone building list. Source: Author

Figure 1.25 Map of central Wellington highlighting earthquake prone buildings. Source: Author

Figure 1.26 Demolition of earthquake prone buildings. Source: Author.

Figure 1.27 Retaining facade/parts of the building and rebuilding. Source: Autho

Figure 1.28 Plan diagram showing structure segregating public and private. Source: Author

Figure 1.29 Contradicting aesthetic between structure and the existing. Source: Author.

Figure 1.30 The exterior of the UStay Apartments on Willis Street, Wellington. Source: Author.
Figure 1.31 Breaking up the block and large building footprints. Source: Author.

Figure 1.32 Pedestrian experience in Wellington due to weather awnings. Source: Author Figure 1.33 Photos of Cuba Street and Furness Lane. Source: Author.

Figure 1.34 People along the line. Source: Author.

Figure 1.35 Aerial view of Wellington City (stitched together from Bing Maps). Source: Author. Figure 1.36 Closer aerial view of the block and the surrounding streets. Source: Author.

Figure 1.37 Contextual section and corresponding plan across the city from west to east. Source: Author. Figure 1.38 Diagram of the earthquake prone building and their construction dates. Source: Author Figure 1.39 Cut out elevation of the eleven earthquake prone buildings on the block. Source: Autho Figure 1.40 Diagram of the block highlighting the site in red. Source: Author.

Figure 1.41 Site plan. Source: Author.

Figure 1.42 Aerial photo of the block with the building footprints overlaid. Source: Author Figure 1.43 Matrix of photos from the site. Source: Author.

Figure 1.44 Facades of the two buildings in The Design. Source: Author.

Figure 1.45 Photo looking up at the Cathie Building east facade. Source: Author.

Figure 1.46 Analysis of the Aspro Building. Source: Author.

Figure 1.47 Analysis of the Cathie Building Source: Author.

Void

Figure 2.1 Line drawing of the east elevation of the Cathie Building. Source: Author. Figure 2.2 Plan, four transverse sections, and a longitudinal section of The Design. Source: Author. Figure 2.3 Figure ground floorplan diagrams of case studies. Source: Author. Figure 2.4 Figure ground transverse section diagrams of case studies. Source: Author. Figure 2.5 Figure ground longitudinal section diagrams of case studies. Source: Author. Figure 2.6 Brown cardboard model of the Cathie Building. Source: Author.

Figure 2.7 The form of the void standing alone. Source: Author.

Figure 2.8 View from Taranaki Street showing the void cut out of the east facade. Source: Author Figure 2.9 The relationship between distance and intensity of contact. Source: (Gehl, 68).

Figure 2.10 Exploded axonometric diagram showing the cut in the two buildings. Source: Author 
Figure 2.11 The cut in the east and west elevations of the two buildings. Source: Author. Figure 2.12 Comparison between The Design and two arcade case studies. Source: Author. Figure 2.13 Three of Gordon Matta-Clark's cutting projects in Barcelona, Spain. Source: <openhousebarcelona-macba-shop-gallery-installations-deeper-cut-art-architecture-gordon-matta-clark $>$. Figure 2.14 Diagram of Gordon Matta-Clark's splitting project before and affer. Source: Author Figure 2.15 Close up photograph from the split in Gordon Matta-Clark's splitting project. Source, <http://artoffheday.files.wordpress.com/2011/04/image049.jpg >

Figure 2.16 Three process cardboard models experimenting with cutting. Source: Author Figure 2.17 The gap in The Design. Source: Author.

Figure 2.18 The straight cut allows for visual permeability along the void. Source: Autho

Figure 2.19 A cut through the buildings connects with existing pedestrian routes. Source: Author.

Figure 2.20 The void removed but no structural form inserted. Source: Author

Figure 2.21 The leftovers from the cut. Source: Author.

Figure 2.22 Photo showing the east facade of the Aspro Building. Source: Author.

Figure 2.23 North elevation of cardboard model. Source: Autho

Figure 2.24 Exploded axonometric showing the various components in The Design. Source: Author

Figure 2.25 Massing experiments to increase the lettable floor area. Source: Author.

Figure 2.26 Experiments of making a horizontal cut. Source: Author.

Figure 2.27 The linear form of the San Telmo Museum extension. Source: Author-

Figure 2.28 Building profiles: old and new. Source: Author.

Figure 2.29 Diagram of the existing ruins and the new intervention. Source: Author

Figure 2.30 Diagram of the Cathie Building east facade. Source: Autho

Figure 2.31 Photograph showing the join between the new mass and the existing ruins. Source: Author.

Figure 2.32 Diagram of the Kolumba Museum showing the weight of the new mass. Source: Author-

Figure 2.33 The Caixa Forum showing how the new mass sits on top. Source: Author.

Figure 2.34 Process diagram showing experimentation of mass on top of the existing site. Source: Author.

Figure 2.35 Foam board and photographic model of the Cathie Building. Source: Author.

Figure 2.36 Process model experimenting with black cardboard laser cut screens. Source: Author Figure 2.37 The entrance to Imperial Lane is cut to echo the profile of the old. Source: Author.

Figure 2.38 Hotel Fouquet Barriere is an interesting interpretation of old and new. Source: Author.

Figure 2.39 Photograph of brown cardboard model of the Cathie Building. Source: Autho

Figure 2.40 Photograph of brown cardboard model showing the void. Source: Author

Figure 2.41 The cuts into the sawtooth roof allowings light into the apartments. Source: Author.

Figure 2.42 Daytime perspective from within the void illustrating how light filters. Source: Author. Figure 2.43 Photograph exploiting the standard feature of a fully glazed roof in an arcade. Source:
Figure 2.44 Widening of the central light well to allow for vertical circulation. Source: Author. Figure 2.45 People gathering in Imperial Lane where there is more natural light. Source: $<$ http://www. wanz.co.nz/Awards2012/awards2012_Comm100KPlus_Rylock>.

Figure 2.46 The gap letting natural light into the central space, drawing pedestrians in. Source: Author Figure 2.47 Perspective render of the courtyard that is located in this central light point. Source: Author Figure 2.48 Diagram of the longitudinal section of the James Cook Arcade. Source: Author. Figure 2.49 Lighting changing the atmosphere and pedestrian experience. Source: Author. Figure 2.50 Diagram of the longitudinal section of The Design. Source: Author. Figure 2.51 Two renders showing the change in lighting. Source: Author

Figure 2.52 Photographs of black cardboard laser cut structural voids. Source: Author. Figure 2.53 How existing building envelope can eliminate the need for awnings. Source: Author. Figure 2.54 Photograph of clear perspex model of the cut out. Source: Author. Figure 2.55 Transverse section showing connection across the void. Source: Author. Figure 2.56 Transverse section diagrams through four standard arcade types. Source: Autho Figure 2.57 Floorplan diagrams showing various staircase layouts. Source: Autho Figure 2.58 Photograph of cardboard models showing the horizontal connection. Source: Autho Figure 2.59 Aerial photograph of Wellington with the existing pedestrian route. Source: Author. Figure 2.60 Earthquake prone building in Wellington mapped in relation to each other. Source: Author. Figure 2.61 Contextual section and corresponding plan across the city from west to east. Source: Author Figure 2.62 Cut of figure of furniture and people. Source: Author.

Curve

Figure 3.1 Photograph of the elevation of the black cardboard model showing the curve. Source: Author Figure 3.2 There is a bird moving in a swooping dive above the curve. Source: Author. Figure 3.3 Looking towards the roof curving under the Aspro Building. Source: Author. Figure 3.4 Longitudinal section through The Design showing the curve. Source: Author. Figure 3.5 The visual difference between an angular and curved transition. Source: Author. Figure 3.6 Photograph of the final model of Cathedral of Brasilia by Oscar Niemeyer. Source: <http:// archiveofaffinities.tumblr.com/post/40165436678/oscar-niemeyer-cathedral-brasilia-brazil-1959> Figure 3.7 Palácio do Planalto with the two aesthetics of curves and rectilinear forms. Source: Author. Figure 3.8 The curved insertion juxtaposes the geometry of the surrounding context. Source: Author. Figure 3.9 Diagram of the curve in National Library of Sejong City. Source: Author. Figure 3.10 Longitudinal section diagram of the arc in The Design. Source: Author. Figure 3.11 Photograph of the cardboard model showing the connection of the curve. Source: Autho 
Figure 3.12 Ibirapuera Park Auditorium: the curved tongue draws people inside. Source: Author. Figure 3.13 Two faces of a pedestrian: the oblivious and the surprised. Source: Author. Figure 3.14 Dental floss. Source:

<http://www.fastcodesign.com/3020075/why-our-brains-love-curvy-architecture> Figure 3.15 Small girl and large girl, a transitioning scale. Source: Author Figure 3.16 Map showing the different scales of Marion Street and Taranaki Street. Source: Author. Figure 3.17 Photograph showing the pedestrian scale of Marion Street. Source: Author. Figure 3.18 Photograph showing the vehicular scale of Taranaki Street. Source: Author. Figure 3.19 Facades with cuts. Source: Author.

Figure 3.20 The curve allows the total lettable floor area to increase. Source: Author.

\section{Pattern and Structure}

Figure 4.1 Partial elevation of the black cardboard curve model within clear perspex. Source: Author. Figure 4.2 Aerial map of part of Wellington city with the earthquake prone buildings. Source: Author. Figure 4.3 Diagrams of standard strengthening methods. Source: Author.

Figure 4.4 Two photographs of poor earthquake strengthening examples in Wellington. Source: Author Figure 4.5 Exploded axonometric showing the various structural components. Source: Author. Figure 4.6 Floorplan diagram showing longitudinal structure tying buildings together. Source: Author. Figure 4.7 Floorplan diagram showing transverse structure on the Aspro Building. Source: Author. Figure 4.8 Floorplan diagram showing existing column grid in the Cathie Building. Source: Author. Figure 4.9 Staircases running perpendicular to the void. Source: Author

Figure 4.10 Perforated screens and structure sandwiching the existing weak masonry. Source: Author. Figure 4.11 Photograph of the site model from the Marion Street elevation. Source: Author. Figure 4.12 Night render approaching Marion Street from Swan Lane. Source: Author Figure 4.13 Photograph of black laser cut models of structural void experiments. Source: Author. Figure 4.14 Photograph of a structural experiment from the May Review. Source: Author. Figure 4.15 Floorplan showing the existing structural grid from the Cathie Building. Source: Author Figure 4.16 Sectional diagram along the length of the void. Source: Author

Figure 4.17 How the screens are cut to be able to rotate within the cross-bracing. Source: Autho Figure 4.18 How primary and secondary circulation fit into the structural grid. Source: Author. Figure 4.19 How circulation and programme fit into the structural grid. Source: Author. Figure 4.20 Various sized vendor stalls along the length of the palace. Source: Author.
Figure 4.21 Two collage images from Yona Friedman and Geam's proposal for Ville Spatiale. So u rce <http://www.classic.archined.nl/news/9806/friedman.html>

Figure 4.22 The programme of each space in the NA House is defined by the structure. Source: Author. Figure 4.23 Photograph of the interior of the NA House. Source: <http://www.domusweb.it/en/ architecture/2011/12/20/tokyo-s-vertical-thresholds-3-sou-fujimoto.html>

Figure 4.24 Programme fitting within the existing structural grid. Source: Author

Figure 4.25 Sectional diagram through Le Fresnoy. Source: Author.

Figure 4.26 Two of Bernard Tschumis sketches of Le Fresnoy. Source: Tschumi, 261.

Figure 4.27 Render of the design experiment of a structure that enveloped the entire site. Source: Author.

Figure 4.28 Exploded axonometric of May proposal. Source: Author.

Figure 4.29 Clear perspex model of the existing structure of the Cathie Building. Source: Author.

Figure 4.30 The process taken to formulate the patterned screens. Source: Author

Figure 4.31 Elevation of the 0-14 tower. Source: Author.

Figure 4.32 A cross-section through Prada Aoyama reveals how pattern relates to function. Source

<http://www.behance.net/gallery/Prada-Aoyama-Flagship-store-by-Herzog-de-Meuron/5026655 Figure 4.33 The unfolded elevation of the Prada Aoyama. Source: <http://www.behance.net/gallery/ Prada-Aoyama-Flagship-store-by-Herzog-de-Meuron/5026655>

Figure 4.34 Perspective inside the Cathie Building part of the void during the night. Source: Author Figure 4.35 Detail of part of the perforated screen wall of the San Telmo Museum. Source: Author. Figure 4.36 Exploded detail of how the steel panels are secured onto the building. Source: Author. Figure 4.37 Rotating panels on the ground floor to allow for pedestrian movement. Source: Author. Figure 4.38 Black perforated steel screens were experimented with in process. Source: Author Figure 4.39 Material and colour of the Moderna Museet Malmö. Source: Autho

Figure 4.40 Photograph showing how explicitly the orange cube juxtaposes its surroundings. Source $<$ http://www.tvark.se/moderna-museet-malmo/>

Figure 4.41 'The Orange Cube' emphasising the simplicity of form and the colour. Source: Author.

Figure 4.42 Within the conical form and a close up of the orange perforated screens. Source: <http:// www.yatzer.com/The-Orange-Cube-by-Jakob-and-Macfarlane-Architects>

Figure 4.43 Longitudinal section colour test 1: red pattern, red structure. Source: Author

Figure 4.44 Longitudinal section colour test 2: white pattern, red structure. Source: AuthorFigure 4.45 Longitudinal section colour test 3: blue pattern, red structure. Source: AuthorFigure 4.46 Longitudinal section colour test 4: grey pattern, grey structure. Source: Author. Figure 4.47 Interior perspective colour test: white pattern, white structure. Source: Author. 


\section{The End}

Figure 5.1 Imperial Buildings by Fearon Hay. Source: <http://architecturenow.co.nz//articles/themperial-buildings/>

Figure 5.2 James Cook Arcade by Roger Walker. Source: Author.

Figure 5.3 Splitting by Gordon Matta-Clark. Source: <http://camilayelarte.blogspot.co.nz/2011/06/ gordon-matta-clark-el-alquimista-urbano.html>

Figure 5.4 San Telmo Museum by Nietos Sobejano. Source: <http://www.archdaily.com/category/ architecture-schools-events/html

Figure 5.5 The Dovecote Studio by Haworth Tompkins. Source: <http://www.archdaily.com/89980/ dovecote-studio-haworth-tompkins/

Figure 5.6 Kolumba Museum by Peter Zumthor. Source: <http://architecturalmoleskine.blogspot. co.nz/2012/04/peter-zumthor-kolumba-museum-cologne.html>

Figure 5.7 Caixa Forum by Herzog and De Meuron. Source: <http://www.e-architect.co.uk/madrid/ caixa-forumhtml>

Figure 5.8 Hotel Fouquet Barrière by Edouard François. Source: <http://famouswonders.com/parisluxury-hotels/>

Figure 5.9 Cathedral of Brasilia by Oscar Neimeyer. Source: <http://www.cntraveler.com/arts/2012/12/ oscar-niemeyer-architecture-design-photos-120612_slideshow_item2_3>

Figure 5.10 Palácio do Planalto by Oscar Niemeyer. Source: <http://designkultur.wordpress. com/2010/08/27/brasilia-50-anos-life-file-president-kubitschek-outside-the-palacio-do-planaltoby-dmitri-kessel/>

Figure 5.11 National Library ofSejong City by S.A.M.O.O Architects.Source:<http.//www arch2o.com/ knowledge-is-power-national-library-of-sejong-city-s-a-m-o-o-architects/outside-the-palacio-doplanalto-by-dmitri-kessel/>

Figure 5.12 Auditório Ibirapuera Park by Oscar Neimeyer. Source: <http://www.archdaily.com.br/ br/01-46146/fotografia-e-arquitetura-pedro-kok/auditorio-ibirapuera-oscar-niemeyer/outside-thepalacio-do-planalto-by-dmitri-kessel/>

Figure 5.13 Crystal Palace by Joseph Paxton. Source: <http://redicecreations.com/article. php?id=27155>

Figure 5.14 Villa Spatiale by Yona Friedman. Source: <http://raccordi.blogspot.co.nz/2012/07/utopiacome-sintesi-tra-ricerca.html>

Figure 5.15 NA House by Sou Fujimoto. Source: <https://www.japlusu.com/news/10-extraordinaryjapanese-houses>
Figure 5.16 Le Fresnoy by Bernard Tschumi Source: <http.//wwwtschumi.com/projects/14/>

Figure 5.17 0-14 Building by Reiser and Umumoto. Source: <http://prafulla.net/graphics/amazing/ amazing-o-14-tower-in-dubai/

Figure 5.18 Prada Aoyama by Herzog and De Meuron. Source: <http://aalonadesign.blogspot. co.nz/2009/03/prada-a $/$ hatokyo-herzog-de-meuron.html

Figure 5.19 San Telmo Museum by Nietos Sobejano. Source: <http://www.archdaily.com/category/ architecture-schools-events/html

Figure 5.20 Moderna Museet Malmö by Tham and Videgard Arkitekter. Source: <http://aalonadesign. blogspot.co.nz/2009/03/prada-aoyamatokyo-herzog-de-meuron.html>

Figure 5.21 The Orange Cube by Jakob + Macfarlane Architects. Source: <http://architecturelinked. com/profiles/blogs/the-orange-cube> 